UNIVERSIDADE DE SÃO PAULO

INSTITUTO DE PSICOLOGIA

SIMONE CAGNIN

AFETO E COGNIÇÃO: EFEITOS DE SIMILARIDADES

AFETIVAS NA TRANSFERÊNCIA ANALÓGICA

EM RESOLUÇÃO DE PROBLEMAS

São Paulo 
SIMONE CAGNIN

\section{AFETO E COGNIÇÃO: EFEITOS DE SIMILARIDADES AFETIVAS NA TRANSFERÊNCIA ANALÓGICA EM RESOLUÇÃO DE PROBLEMAS}

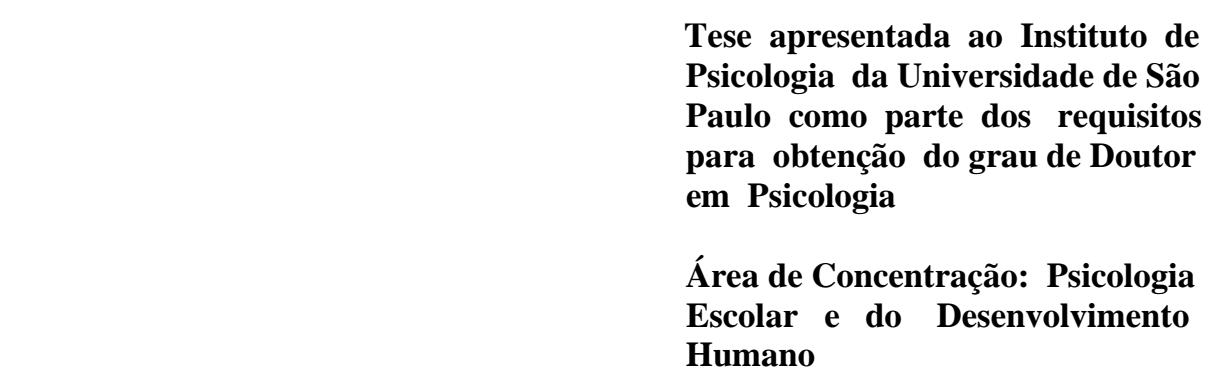

Orientadora: Dra. MARIA ISABEL DA SILVA LEME

São Paulo

2008 
AUTORIZO A REPRODUÇÃO E DIVULGAÇÃO TOTAL OU PARCIAL DESTE TRABALHO, POR QUALQUER MEIO CONVENCIONAL OU ELETRÔNICO, PARA FINS DE ESTUDO E PESQUISA, DESDE QUE CITADA A FONTE.

Catalogação na publicação

Serviço de Biblioteca e Documentação

Instituto de Psicologia da Universidade de São Paulo

Cagnin, Simone.

Afeto e cognição: efeitos de similaridades afetivas na transferência analógica em resolução de problemas / Simone Cagnin; orientadora Maria Isabel da Silva Leme. -- São Paulo, 2008.

$346 \mathrm{p}$.

Tese (Doutorado - Programa de Pós-Graduação em Psicologia. Área de Concentração: Psicologia Escolar e do Desenvolvimento Humano) - Instituto de Psicologia da Universidade de São Paulo.

1. Afeição 2. Cognição 3. Analogia 4. Transferência (aprendizagem) 5. Solução de problemas I. Título.

BF511 
SIMONE CAGNIN

AFETO E COGNIÇÃO: EFEITOS DE SIMILARIDADES AFETIVAS NA TRANSFERÊNCIA ANALÓGICA EM RESOLUÇÃO DE PROBLEMAS

Banca Examinadora

Nome do Examinador

Assinatura

Nome do Examinador

Assinatura

Nome do Examinador

Assinatura

Nome do Examinador

Assinatura

Nome do Examinador

Assinatura

Tese defendida e aprovada em

São Paulo

2008 


\section{DEDICATÓRIA}

Aos meus queridos pais

Athayr

e

Diva 


\section{AGRADECIMENTOS}

. À minha orientadora Profa. Dra. Maria Isabel da Silva Leme, por sua lúcida orientação, compreensão e constante incentivo em todos os momentos da presente tese.

. A meus pais, Athayr Cagnin e Diva Rosea Madureira Cagnin, pelo apoio incondicional e pela ajuda financeira que muito contribuiu para os gastos relacionados ao doutorado e à realização da pesquisa.

- À Profa. Dra. Maniusia Mota de Oliveira, pela inestimável contribuição na parte metodológica e estatística da tese.

. À minha amiga Mariana de Oliveira, pela ajuda na revisão ortográfica do presente trabalho.

. À Profa. Dra. Marise Bezerra Jurberg, por sua gentileza de sempre.

. Às professoras Dra. Maria Lúcia Seidl de Moura e Dra. Emma Otta, pelas boas sugestões feitas no exame de qualificação que muito contribuíram para o aprimoramento do estudo aqui desenvolvido.

. Ao Altay Alves Lino de Souza, pelas boas dicas estatísticas e pela disponibilidade em ajudar.

- Aos meus colegas do Departamento de Fundamentos de Psicologia e à Direção do Instituto de Psicologia que me apoiaram no meu pedido de licença PROCAD.

- Às professoras Marly Imperial e Glória Ambrósio, respectivas coordenadoras da Universidade de Vila Velha e da Faculdade de Direito de Cachoeiro de Itapemirim, pela colaboração na intermediação no contato com os professores e alunos dessas respectivas instituições de ensino.

- Aos professores dos cursos de Psicologia, de Direito e de Comunicação Social, da Universidade do Estado do Rio de Janeiro, da Universidade Federal do Espírito Santo, da Universidade de Vila Velha, do Centro Universitário São Camilo e da Faculdade de Direito de Cachoeiro de Itapemirim, por permitirem que suas turmas participassem da pesquisa e dos estudos pilotos realizados.

. Aos parentes e amigos que demonstraram compreensão e aceitação da minha ausência nos momentos em que estive totalmente envolvida na elaboração da tese.

. Por fim, meu agradecimento, mais que especial, a todos os estudantes universitários que participaram da pesquisa e dos estudos pilotos realizados.

A todos vocês, muito obrigada. 
A relação entre o afeto e a cognição poderia ser vista como semelhante àquela entre a flor e a borboleta.

A borboleta é a metamorfose da flor, É a pétala solta transmutada pelas eras, Síntese dos insetos que camuflam sua cor, No tempo das espécies, abre a primavera.

A borboleta é da flor o complemento, Pólen que no ventre fecunda seu odor, Alvo e seta que se cruzam em movimento, Híbrida em seu vôo grávido de flor.

(Simone Cagnin) 


\section{RESUMO}

CAGNIN, S. Afeto e cognição: efeitos de similaridades afetivas na transferência analógica em resolução de problemas. Tese de doutorado, 346 pp., Instituto de Psicologia da Universidade de São Paulo, São Paulo, 2008.

Esse trabalho tem como principal objetivo estudar a influência das similaridades afetivas de problemas mal-definidos no processo de transferência analógica. Procura estudar, de modo mais específico, o efeito sobre a transferência analógica da similaridade entre as tonalidades afetivas agradáveis/alegres e desagradáveis/ tristes de histórias, que apresentam problemas análogos ao problema da radiação de Duncker. Esses efeitos são, por sua vez, investigados a partir da preferência, na situação-problema “alvo”, por um modo de solução aprendido na situação-problema “fonte”, quando vários modos de solução são apresentados aos participantes da pesquisa. Objetiva-se investigar esse tipo de influência em dois intervalos de tempo distintos: em sessões consecutivas e em sessões com intervalo de uma semana. Os resultados encontrados apontam para a existência de efeitos positivos dessas similaridades nos dois intervalos de tempo pesquisados, com maior freqüência relativa nas sessões consecutivas. Desse modo, pode-se concluir que, quando há mais de uma solução disponível e funcionalmente adequada para um determinado problema, similaridades de superfície, como as tonalidades afetivas de histórias de problemas, influenciam a preferência por um modo de solução. Verificou-se ainda que esse tipo de influência das similaridades afetivas não depende de uma alteração do estado de humor dos indivíduos. O papel do afeto na cognição poderia ser assim visto como mais abrangente do que o pressuposto na literatura da área, pois mesmo quando os indivíduos não se consideram afetados em seu humor pela leitura de histórias tristes e alegres, eles demonstram sofrer a influência das tonalidades afetivas dessas histórias.

Palavras-chave: Afeto. Cognição. Analogia. Transferência de Aprendizagem. Resolução de Problemas. 


\begin{abstract}
CAGNIN, S. Affect and cognition: effects of affective similarity in analogical transfer in problem solving. Doctoral Dissertation, 346 pp., Instituto de Psicologia da Universidade de São Paulo, São Paulo, 2008.

The objective of this work is to study the influence of affective similarities of illdefined problems in analogical transfer. In a specific way, it seeks to study the effect of the similarities of happy/ pleasant and sad/ unpleasant affective tonalities of stories presented in problems analogs to the Duncker's radiation problem. These effects are investigated through the preference, in the target problem, for one kind of solution learned in the source problems, when more than one solution is presented. This research also focuses on such an influence in two different times: consecutive sessions and sessions with one week delay. The results point out to the existence of positive effects of these similarities in both intervals of time, with higher relative frequency in the consecutive sessions. The conclusion is that surface similarities, like the affective similarities of problems, influence the preference for one kind of solution, when there is more than one appropriate solution to the problem. It is showed that such an influence doesn't require a change in the individual's mood. It also suggests that the influence of the affect in cognition is broader than it is assumed in the literature, because even when the individuals don't report a change in their mood, they are influenced by the affective similarities of the problem's stories.
\end{abstract}

Keywords: Affect. Cognition. Analogy. Transfer of Learning. Problem Solving. 


\section{SUMÁRIO}

Página

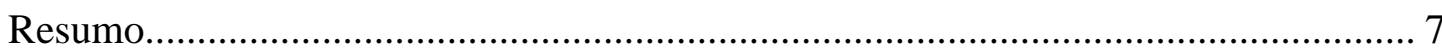

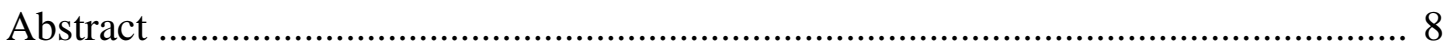

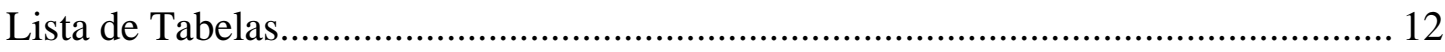

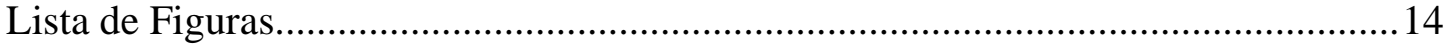

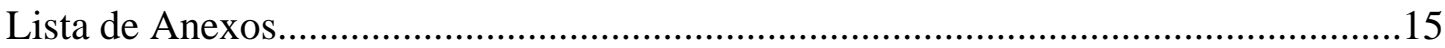

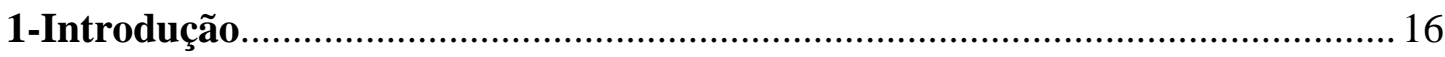

2-Capítulo I: Resolução de Problemas e Transferência Analógica...................... 23

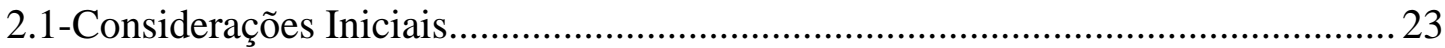

2.2-Definições Iniciais e Características do Pensamento Analógico............................22

2.3-Modelos Simbólicos/ Seriais, Modelos Conexionistas e Modelos Híbridos:

Algumas Contribuições para o Estudo da Memória e do Pensamento Analógico........35

2.4-Facilitação da Transferência Analógica: Fatores que Intervém

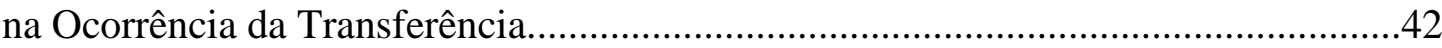

2.4.1-Ordem de Apresentação dos Problemas “Fonte” e “Alvo”................................. 43

2.4.2-Similaridades de Superfície, Estruturais e Pragmáticas e a

Facilitação da Transferência Analógica....................................................................48

2.4.3-Construção de um Esquema de Aprendizagem Apropriado................................55

2.4.4-Transferência Analógica e Similaridade de Contexto:

A Facilitação da Transferência pela Semelhança de Contextos..................................71

2.4.5-Intervalo de Tempo entre as Sessões................................................................79

3-Capítulo II: Papel dos Conteúdos dos Enunciados de Problemas na Resolução de Problemas e na Transferência Analógica................................. 89

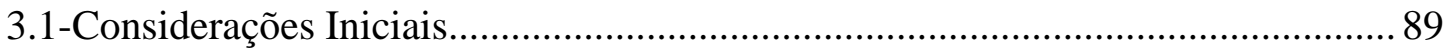

3.2-Papel dos Conteúdos dos Enunciados de Problemas na Resolução de Problemas Bem-definidos e na Transferência Analógica.............................................................90

3.2.1-Papel dos Conteúdos dos Enunciados de Problemas na Resolução de Problemas Bem-definidos Dependentes de Domínio. 
3.2.2-Papel dos Conteúdos dos Enunciados de Problemas na Resolução de Problemas Bem-definidos Independentes de Domínio.

3.2.3-Papel dos Conteúdos dos Enunciados de Problemas no Raciocínio Humano.

3.2.4-Papel dos Conteúdos dos Enunciados de Problemas na Resolução

de Problemas Mal-definidos e na Transferência Analógica. 105

4-Capítulo III: Afeto, Memória, Resolução de Problemas e Transferência Analógica.

4.1-Definições Iniciais.

4.2-Considerações Iniciais sobre o Papel do Afeto na Cognição.

4.3-Influência dos Estados Afetivos na Memória. .125

4.4-Influência dos Estados Afetivos na Resolução de Diferentes

Situações-problema e na Transferência Analógica.

4.5-Influência das Tonalidades Afetivas dos Conteúdos dos Enunciados

dos Problemas na Resolução de Problemas e na Transferência Analógica. 162

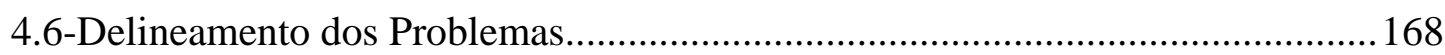

5-Hipóteses Experimentais e Plano Experimental...............................................170

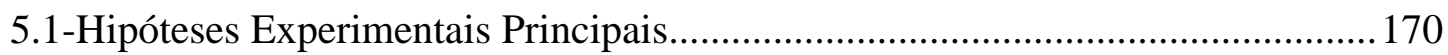

5.2-Hipóteses Experimentais Secundárias.............................................................170

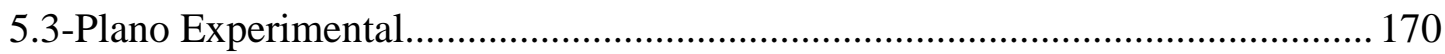

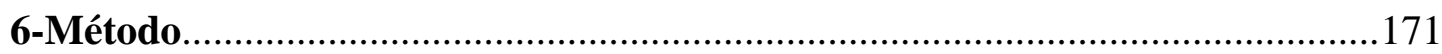

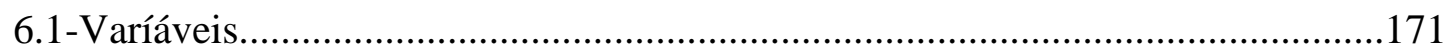

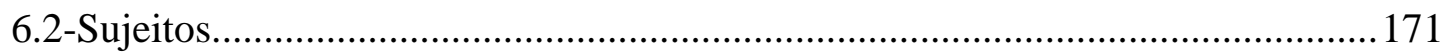

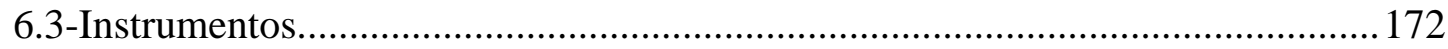

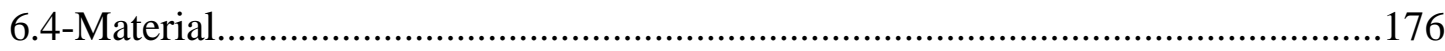

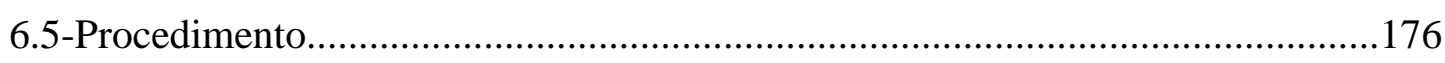

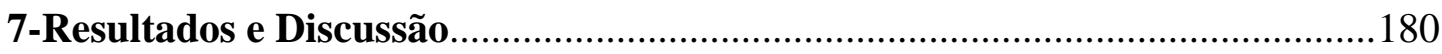

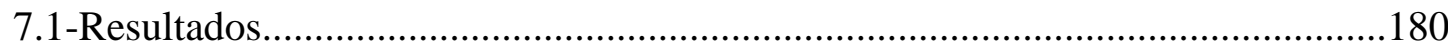


7.1.1- Resultados para as Sessões Consecutivas.

180

7.1.2-Resultados para o Intervalo de Tempo de Uma Semana entre as Sessões....... 188

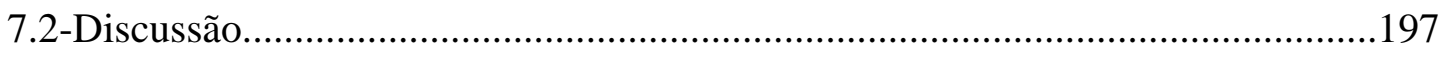

8-Justificativas Encontradas para as Respostas Dadas....................................207

8.1-Resultados Relativos às Justificativas Encontradas para as Respostas nas Sessões Consecutivas e nas Sessões com Intervalo de uma Semana...................207

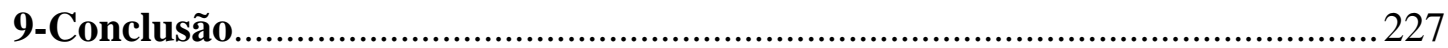

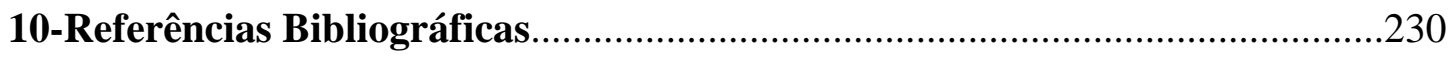

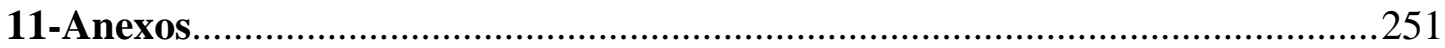




\section{LISTA DE TABELAS}

Página

\section{LISTA DE TABELAS DAS SESSÕES CONSECUTIVAS}

Tabela 1: Freqüência de sujeitos que transferiram para o problema alvo os modos de solução dos problemas fonte.

Tabela 2: Freqüência de transferências nas condições de problema alvo triste e alegre

Tabela 3: Freqüência de sujeitos que resolveram o problema alvo utilizando modos de solução serial, convergente ou outro modo, nas condições de problema alvo triste e alegre.

Tabela 4: Preferência por modos de solução do problema alvo em função das tonalidades afetivas dos problemas alvo e fonte.

Tabela 5: Freqüência de sujeitos que exibiram variação de humor positiva, negativa ou não exibiram, nas condições de problema alvo triste e alegre 185

\section{LISTA DE TABELAS DAS SESSÕES COM INTERVALO DE UMA SEMANA}

Tabela 6: Freqüência de sujeitos que transferiram para o problema alvo os modos de solução dos problemas fonte. 188

Tabela 7: Freqüência de transferências nas condições de problema alvo triste e alegre 189

Tabela 8: Freqüência de sujeitos que resolveram o problema alvo utilizando modos de solução serial, convergente ou outro modo, nas condições de problema alvo triste e alegre. 
Tabela 9: Preferência por modos de solução do problema alvo em função das tonalidades afetivas dos problemas fonte e alvo. 190

Tabela 10: Freqüência de sujeitos que exibiram variação de humor positiva, negativa ou não exibiram, nas condições de problema alvo triste e alegre.

\section{LISTA DE TABELAS COMPARATIVAS DOS DOIS INTERVALOS DE TEMPO}

Tabela 11: Freqüência de transferência nas sessões consecutivas e nas sessões com intervalo de uma semana

Tabela 12: Freqüência de sujeitos que realizaram transferência de acordo com as similaridades entre as tonalidades afetivas dos problemas fonte e alvo nas sessões consecutivas e nas sessões com intervalo de uma semana.

Tabela 13: Freqüência dos tipos de justificativas das soluções dadas ao problema “alvo” nas sessões consecutivas e nas sessões com intervalo de uma semana. 208

\section{LISTA DE TABELAS DO ESTUDO PILOTO 1 (ANEXO 2)}

Tabela 14: Escalas de avaliação das histórias vinculadas aos problemas alvo .275

Tabela 15: Escalas de avaliação das histórias vinculadas aos problemas fonte e distrativos

Tabela 16: Dimensões de avaliação das escalas vinculadas aos problemas alvo..... 277

Tabela 17: Dimensões de avaliação das escalas vinculadas aos problemas fonte e distrativos. 


\section{LISTA DE TABELAS RELATIVAS À ORDEM DE APRESENTAÇÃO DOS PROBLEMAS “FONTE” E AO MODO DE VINCULAÇÃO DAS SOLUÇÕES AOS PROBLEMAS “FONTE” (ANEXO 6)}

\section{LISTA DE TABELAS DAS SESSÕES CONSECUTIVAS}

Tabela 18: Freqüência de sujeitos que exibiram transferência e a ordem de apresentação dos problemas fonte.

Tabela 19: Freqüência de escolha dos problemas fonte e a ordem em que foram apresentados.

Tabela 20: Variações do humor e ordem de apresentação dos problemas fonte. 328

LISTA DE TABELAS DAS SESSÕES COM INTERVALO DE UMA SEMANA

Tabela 21: Freqüência de sujeitos que exibiram transferência e a ordem de apresentação dos problemas fonte.

Tabela 22: Freqüência de escolha dos problemas fonte e a ordem em que foram apresentados

Tabela 23: Variações do humor e ordem de apresentação dos problemas fonte. 330

\section{LISTA DE FIGURAS}

\section{LISTA DE FIGURAS DAS SESSÕES CONSECUTIVAS}

Figura 1: Preferência por modos de solução do problema alvo em função das tonalidades afetivas dos problemas fonte e alvo..... 184

Figura 2: Variação do humor exibida pelos sujeitos nas condições de problema alvo triste e alegre. 
Figura 3: Associações entre as variáveis problema alvo, problema fonte vinculado ao modo de solução e variação de humor: mapa gerado por análise de correspondência múltipla.....

\section{LISTA DE FIGURAS DAS SESSÕES COM INTERVALO DE UMA SEMANA}

Figura 4: Preferência por modos de solução do problema alvo em função das tonalidades afetivas dos problemas fonte e alvo.

Figura 5: Variação do humor exibida pelos sujeitos nas condições de problema alvo triste e alegre.

Figura 6: Associações entre as variáveis problema alvo, problema fonte vinculado ao modo de solução e variação de humor: mapa gerado por análise de correspondência múltipla....

\section{LISTA DE ANEXOS}

Anexo 1: Histórias dos problemas.

Anexo 2: Estudo Piloto 1 .272

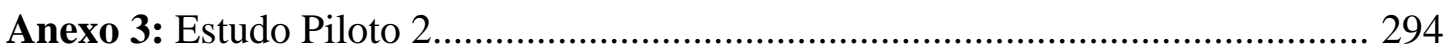

Anexo 4: Controle de equivalência de palavras......................................................... 309

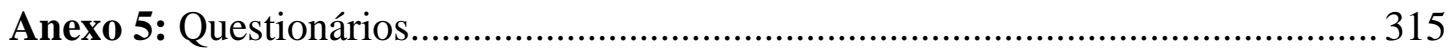

Anexo 6: Avaliação dos controles utilizados: Ordem de apresentação dos problemas "fonte" e modo de vinculação das soluções aos problemas "fonte"

Anexo 7: Folhas de instrução/ respostas.

Anexo 8: Termo de consentimento livre e esclarecido. 


\section{1-Introdução}

Nas últimas duas décadas tem havido um aumento no número de estudos que focalizam a influência do afeto nos processos cognitivos. Entretanto, parte significativa desses estudos é dirigida para a investigação da influência dos estados de humor ou de emoções mais específicas no processamento da informação. E, nesse contexto, observase um número expressivo de investigações que focalizam a influência do afeto na memória ou em situações-problema que envolvem tarefas complexas, muitas delas ocorrendo em um contexto de interação social. De modo complementar, verifica-se também menor número de estudos mais direcionados à influência do afeto na resolução de problemas bem e mal-definidos e, especialmente no âmbito da transferência analógica, há ainda relativamente poucos estudos preocupados com esse tipo de influência.

Para fundamentar nossa proposta de pesquisa, partimos de duas vertentes principais de estudos: por um lado, estudos cognitivistas com a tradicional ênfase no processamento da informação e, por outro, estudos que abordam mais diretamente a influência do afeto na cognição.

No âmbito da resolução de problemas e, em especial, da transferência analógica, muitos estudos contemporâneos poderiam ser vistos como seguidores da tradição cognitivista ao enfatizar o processamento da informação e os modelos de processamento aí implicados. Ainda que não abordem diretamente a influência do afeto na cognição, estudos como os de Gick e Holyoak (1980; 1983), Holyoak e Koh (1987), Bassok e Holyoak (1989), Blessing e Ross (1996), Gentner e Markman (1997), Catrambone (2002), Novick e Bassok (2005), Helfenstein e Saariluoma (2006), dentre outros, mostram-se de fundamental importância para a apresentação do referencial conceitual do qual partimos, pois nos permitem um melhor entendimento dos mecanismos cognitivos envolvidos nos processos de resolução de problemas e de transferência analógica. Essas pesquisas também trazem importantes evidências empíricas que apontam para fatores facilitadores da transferência analógica em situações-problema diversificadas.

Estudos realizados no âmbito da transferência analógica vêm trazendo evidências de que similaridades de superfície de diferentes naturezas teriam um importante papel na resolução de problemas análogos (Holyoak \& Koh, 1987; Ross, 1989; Bassok, Wu \& Olseth, 1995; Heydenbluth \& Hesse, 1996; Bassok, Chase \& Martin, 1998; 
Catrambone, 2002, só para citar alguns). Assim, não só as similaridades estruturais entre problemas, ou seja, as similaridades de suas estruturas profundas, seriam facilitadoras da transferência analógica, pois as similaridades de superfície poderiam facilitar a resolução de problemas e a transferência analógica, mesmo frente a problemas bem-definidos que requisitam perícia.

As chamadas "características de superfície” de um problema referem-se àquelas características mais periféricas (por exemplo, características perceptuais, conteúdos dos enunciados, etc.) que costumam ser vistas como tendo menor influência no processo de resolução de problemas, bem como no processo de transferência analógica. Essas características são tradicionalmente vistas como estando em contraposição às chamadas “estruturas profundas” do problema (por exemplo, relações, princípios, equações, regras lógicas, etc.) as quais, por sua vez, são consideradas como tendo uma influência direta na solução do mesmo. Entretanto, apesar de uma tradicional ênfase, dos estudos da área, nos aspectos mais estruturais e profundos dos problemas, hoje em dia a importância das características de superfície tem sido focalizada, em especial, o seu papel nos processos iniciais - representação e acesso - de resolução de problema e de transferência analógica.

Nesse sentido, as similaridades de superfície e, incluímos aqui as tonalidades afetivas dos conteúdos das histórias dos problemas, parecem ter um papel importante na facilitação da representação mental inicial dos problemas e, conseqüentemente, na compreensão dos seus argumentos e objetivos, bem como também parecem influenciar o processo de transferência analógica como um todo.

Os estudos que apontam para a importância das similaridades de superfície na transferência analógica costumam focalizar aspectos cognitivos destas similaridades, em especial, a semelhança entre os conteúdos semânticos dos enunciados de problemas análogos que evocam um contexto temático similar (p.e. Holyoak \& Koh, 1987; Catrambone, 2002).

Porém, as tonalidades afetivas das histórias dos problemas poderiam ser consideradas, a nosso ver, como um tipo de característica de superfície especial, pois se, por um lado, poderiam ser consideradas como característica periférica, ou seja, sem vinculação direta com as estruturas profundas, por outro lado, o cunho afetivo dessas características parece torná-las diferenciadas de outras características de superfície neutras. 
Trabalhos realizados no âmbito da memória têm apontado para o fato de que o acesso aos conteúdos da memória depende não só do caráter semântico destes conteúdos, mas especialmente do valor afetivo dos mesmos (Bower, 1981; 1992; Bower \& Forgas, 2001; Innes-Ker \& Niedenthal, 2002; Curran, 2007). Porém, no âmbito da transferência analógica, poucos estudos têm investigado o papel da valência afetiva desses conteúdos no processo de transferência, ou seja, o papel da semelhança da conotação afetiva (positiva ou negativa) de conteúdos presentes em contextos temáticos/ histórias semanticamente diferentes. Uma pesquisa que se proponha a investigar, mais diretamente, a influência da valência afetiva destes conteúdos no processo de transferência analógica pode ajudar a esclarecer questões ainda não respondidas a respeito da importância deste tipo de similaridade nesse processo.

O uso recorrente de analogias nas ciências, nas artes, na política, na literatura e, especialmente, nas situações informais do dia a dia, também reforça a importância de estudos sobre a transferência analógica, pois o pensamento analógico parece fazer-se presente em inúmeras situações-problema do cotidiano. E, na medida em que o uso de analogias pode sofrer a influência do afeto, mostra-se relevante a proposta de um estudo que focalize mais diretamente o papel das similaridades afetivas de histórias de problemas na transferência analógica.

Entretanto, no âmbito da resolução de problemas e, mais ainda, no âmbito da transferência analógica, o número de pesquisas direcionadas para a investigação desta influência ainda se mostra bastante reduzido. Inclusive, no que se refere à transferência analógica, foi encontrado apenas um estudo (Hesse, Kauer \& Spies, 1997) que aborda diretamente essa questão, mas esse estudo configurou-se em moldes diferentes daqueles da pesquisa aqui proposta.

De fato, não foram observados, na literatura consultada, estudos que abordassem, diretamente, por um lado, a influência das tonalidades afetivas de histórias de problemas análogos mal-definidos na transferência analógica e, por outro lado, não foram encontrados estudos que abordassem o efeito do decurso do tempo na manutenção do vínculo entre as tonalidades afetivas dos problemas. A relevância do estudo do papel da similaridade das tonalidades afetivas dos conteúdos de histórias de problemas maldefinidos, semelhantes a problemas cotidianos, como aqueles propostos em nossa pesquisa, fica, então, evidenciada.

Observamos, assim, na área, espaços de pesquisa ainda não explorados de modo sistemático, quais sejam, por um lado, a investigação do papel das similaridades afetivas 
de histórias de problemas mal-definidos no processo de transferência analógica e, nesse contexto, a influência do estado de humor dos indivíduos, tal como relatados pelos mesmos e, por outro lado, o efeito do decurso do tempo nesse tipo de transferência analógica; objetos do trabalho aqui proposto.

Já nos estudos mais diretamente voltados para a influência do afeto na cognição, encontramos uma prevalência de investigações que focalizam a influência dos estados de humor ou das emoções em diferentes processos cognitivos. Nesses estudos, de modo correlato aos estudos cognitivistas sobre a resolução de problemas análogos, as similaridades das tonalidades afetivas dos estímulos apresentados não têm merecido o devido destaque, pois a ênfase costuma se dar na influência dos estados de humor ou das emoções mais específicas no processamento cognitivo (p.e. Isen, Daubman \& Novicki, 1987; Tiedens \& Linton, 2001; Forgas, 2001a; Bower \& Forgas, 2001, dentre outros).

Não obstante, muitos desses estudos têm aqui especial importância, especialmente aqueles que investigam os efeitos do estado de humor no processamento da informação como os de Bower (1981;1992), Isen e Daubman (1984), Isen, Daubman e Nowicki (1987), Forgas (1995; 1998; 2001a; 2001b), Bower e Forgas (2001), Bless (2001), dentre outros, não só por trazer à tona importantes discussões teóricas, mas especialmente, por apresentar evidências empíricas que cada vez mais explicitam a influência do afeto na cognição.

A interface entre cognição e afeto tem-se revelado multifacetada abrangendo diferentes áreas do conhecimento e diversificadas linhas de pesquisas. Estão aí incluídos, desde estudos mais voltados para o “hardware” cerebral envolvido nessa interseção e/ou para a relação cérebro-mente aí implicada (p. e. Damásio, 1994; 1996; 2000; 2004; Adolphs \& Damásio, 2001) , até estudos mais focalizados na construção de modelos teóricos psicológicos que procuram integrar as dimensões afetiva e cognitiva (p.e. Bower, 1981; Bower \& Forgas, 2001; Forgas, 2001a; 2001b) Alguns desses modelos, apesar da influência da metáfora computacional típica do cognitivismo tradicional, poderiam ser, talvez, considerados "híbridos", na medida em que se preocupam em entender o impacto dos estados afetivos no processamento da informação. Com ênfase funcionalista e preocupação mais “molar”, muitas investigações científicas contemporâneas vêm dinamizando o debate sobre as relações entre o afeto e a cognição com novas e interessantes hipóteses e um corpo de dados empíricos que enriquecem e problematizam cada vez mais o papel do afeto na cognição. 
Podemos observar que essas últimas investigações, em sua maioria, vêm se contrapondo à perspectiva cognitivista mais tradicional que costuma colocar entre parênteses o papel dos estados afetivos e das influências sócio-culturais no processamento cognitivo propriamente dito.

Dois principais motivos suscitaram nosso interesse por esse tema de pesquisa: por um lado, estudos realizados no âmbito da resolução de problemas, como docente de disciplinas que focalizam, especialmente, a memória e o pensamento humanos, a par da atividade complementar de orientação de trabalhos de graduação e pós-graduação latosenso e, por outro lado, a insatisfação com a prevalência de estudos que pouco privilegiam a influência do afeto nessas esferas.

O trabalho aqui apresentado, conforme já referido, tem como principal objetivo estudar a influência das similaridades afetivas de problemas no processo de transferência analógica. De modo mais específico, visa a investigar o efeito, sobre a transferência analógica, da similaridade entre as tonalidades afetivas agradáveis/alegres e desagradáveis/ tristes de histórias de problemas “fonte” e “alvo”.

Esse efeito de similaridade entre tonalidades afetivas de histórias de problemas é investigado, por sua vez, a partir da escolha feita pelos indivíduos, na situação-problema “alvo”, de um modo de solução aprendido na situação-problema "fonte”, quando vários modos de solução são apresentados. O modo de solução do problema “alvo” é, a nosso ver, preferencialmente escolhido por estar presente em uma das histórias “fonte” de mesma tonalidade afetiva da história "alvo".

Objetivamos ainda investigar os efeitos do decurso do tempo no processo de transferência analógica. Consideramos que, mesmo com a passagem de tempo, os efeitos positivos das similaridades afetivas das histórias na transferência analógica se manterão, ainda que em menor grau, embora, como esperado, possa haver um declínio natural no processo de transferência como um todo.

Acreditamos que uma investigação que aborde, de modo mais sistemático, os efeitos que as similaridades afetivas das histórias de problemas análogos possam vir a ter na transferência analógica, poderia ser significativa para o processo ensino-aprendizagem. Subsídios para uma melhor compreensão de aspectos facilitadores ou inibidores da aprendizagem e de sua transferência em diferentes situações-problema poderiam daí advir. Nessa perspectiva, essa investigação pode ajudar a aprofundar o debate sobre o uso pedagógico de analogias no contexto escolar, bem como sobre a complexa questão da influência do afeto na transferência entre domínios de conhecimento, ou mesmo 
dentro de um mesmo domínio, o que, a nosso ver, poderia redimensionar, não só aspectos teórico-empíricos mais amplos, mas especialmente aspectos didáticos mais específicos, aspectos estes relacionados à organização dos conteúdos escolares propriamente ditos.

A investigação psicológica do impacto da similaridade afetiva de histórias de problemas no processo da transferência analógica mostra-se, assim, relevante no contexto da Psicologia Escolar e justifica a inserção deste estudo na linha de pesquisa “Desenvolvimento e Aprendizagem” do programa de Psicologia Escolar e do Desenvolvimento Humano da Universidade de São Paulo.

Em síntese, acreditamos que a pesquisa aqui delineada possa trazer significativas contribuições não só para a amplificação de questões teórico-empíricas incipientes ou mesmo não formuladas na área, mas também para o redimensionamento de reflexões a respeito do processo ensino-aprendizagem, especialmente no que se refere à influência do afeto nos processos de resolução de problemas e de transferência analógica no âmbito acadêmico e escolar como um todo.

Apesar da dificuldade de uma demarcação mais nítida das fronteiras entre as disciplinas e as áreas de pesquisa que têm particular interesse pela interface entre o afeto e a cognição, uma organização por capítulos mostrou-se necessária, não só visando clareza maior na apresentação da fundamentação teórica e empírica, mas também como forma de circunscrever questões a seus contextos mais típicos.

Tendo isso em vista, três capítulos com fronteiras não muito nítidas foram esboçados. O primeiro capítulo focaliza especialmente a resolução de problemas e a transferência analógica através da apresentação de conceitos, modelos teóricos e as principais evidências empíricas produzidas na área. Uma ênfase especial aos fatores envolvidos na facilitação da transferência analógica é a tônica desse capítulo. O segundo capítulo, por sua vez, aborda o papel dos conteúdos dos enunciados de problemas de diferentes naturezas nesses processos. O terceiro e último capítulo traz a dimensão do afeto para o âmbito da memória, da resolução de problemas e da transferência analógica. Esse último capítulo complementa os anteriores e pretende trazer subsídios mais específicos para as nossas principais hipóteses de pesquisa. Nesse sentido, todos os capítulos são solidários em suas argumentações.

Em cada um dos capítulos, uma subdivisão em algumas seções mais amplas foi delineada para uma melhor apresentação dos principais conceitos utilizados, das principais teorias e modelos teóricos produzidos na área, das evidências empíricas que 
se mostram pertinentes para a fundamentação do presente trabalho e das questões ainda não respondidas por estudos mais diretamente relacionados à nossa proposta de pesquisa. 


\section{2-Capítulo I: Resolução de Problemas e Transferência Analógica}

\section{1-Considerações Iniciais:}

Inúmeros estudos contemporâneos recobrindo diferentes tendências e ênfases têm sido realizados no âmbito da resolução de problemas e da transferência analógica. Diferentes estudos, desde aqueles que abordam o papel do conhecimento na resolução de problemas e na transferência analógica, como as tradicionais pesquisas que contrapõem o desempenho de peritos e de novatos frente a tarefas cognitivas de diferentes domínios, passando por estudos que enfatizam a resolução de problemas bem-definidos independentes de domínio ou mesmo problemas mal-definidos e cotidianos, até aqueles estudos que priorizam os aspectos instrucionais envolvidos na solução de problemas e na transferência de aprendizagem, só para citar alguns, poderiam ilustrar a multiplicidade de interesses e de enfoques que costumam transitar por tão ampla área do conhecimento.

Apesar da diversidade de linhas de pesquisas encontradas na área, um número significativo destas pesquisas, especialmente as dirigidas ao estudo do pensamento humano adulto, ainda parece compartilhar de uma abordagem cognitivista tradicional, com sua ênfase no processamento da informação, processamento este envolvido no raciocínio dedutivo e indutivo, na resolução de problemas e na transferência analógica.

Inicialmente, na primeira seção desse capítulo, uma definição de termos tais como, “resolução de problemas”, “transferência analógica”, "similaridade”, dentre outros, será apresentada, definição esta seguida de discussão teórica e de evidências empíricas que visam a circunscrever algumas questões importantes na área. Uma caracterização do pensamento analógico será também esboçada com o intuito de trazer subsídios para uma reflexão sobre as principais pesquisas empíricas e estudos teóricos desenvolvidos na área. A seguir, a ênfase será dirigida para os fatores envolvidos na facilitação da transferência analógica, com destaque para a ordem de apresentação dos problemas, a construção de um esquema de aprendizado apropriado, as similaridades das características de superfície, estruturais e pragmáticas, a similaridade de contextos e o intervalo de tempo entre as sessões. Apesar da íntima relação entre muitos desses fatores, uma apresentação individualizada dos mesmos objetivou apenas destacá-los e não os isolar como variáveis estanques ou que concorrem entre si. 
De modo complementar, no segundo capítulo, será focalizado o papel dos conteúdos dos enunciados de problemas nos processos de resolução de problemas e de transferência analógica e no raciocínio humano, objetivando a apresentação de achados empíricos que vêm apontando para os efeitos positivos destes conteúdos nestes processos, o que é de particular interesse para a nossa pesquisa. Abordaremos, nesse capítulo, a influência dos conteúdos dos enunciados de problemas de diferentes naturezas, ou seja, de problemas bem-definidos independentes e dependentes de domínio, alguns deles típicos de contextos acadêmicos; e de problemas mal-definidos, mais típicos do cotidiano e de situações que envolvem algum tipo de interação social. O papel dos conteúdos dos enunciados de problemas em tarefas que envolvem raciocínio também será aqui abordado.

Apesar de nossa preocupação se dirigir mais diretamente para a influência dos conteúdos de enunciados de problemas análogos mal-definidos, as evidências empíricas obtidas em estudos com diferentes tipos de problemas podem vir a corroborar a importância desses conteúdos e de outras características de superfície nos processos de resolução de problemas e de transferência analógica.

Em suma, acreditamos que esse primeiro capítulo, ao buscar esclarecer algumas definições teóricas iniciais, bem como ao apresentar alguns estudos importantes na área, pode vir a fornecer uma base conceitual e empírica inicial que servirá de apoio especialmente para a fundamentação das nossas principais hipóteses e para a análise dos resultados da pesquisa.

\section{2-Definições Iniciais e Características do Pensamento Analógico}

Antes de aprofundarmos nossas considerações, cabe, como esclarecimento inicial, uma definição do termo "problema”, bem como uma definição do termo "transferência analógica”, termos usados de modo recorrente ao longo do nosso trabalho.

No passado, Duncker (1945) já havia observado que um problema sempre surge quando os indivíduos possuem um objetivo, mas não sabem como colocá-lo em prática, ou seja, não sabem como operacionalizá-lo. Entretanto, para esse autor, não seria possível partir de uma dada situação inicial em direção a uma situação desejada apenas através de ações físicas no meio ambiente, pois haveria a necessidade da mediação do pensamento como recurso fundamental para que essas operações fossem planejadas e monitoradas. 
Parte-se aqui de uma concepção de problema similar à definição de Duncker e tida como mais consensual do ponto de vista das investigações cognitivas contemporâneas, como aquela proposta por Newell e Simon (1972), Sternberg (2000) e Pretz, Naples e Sternberg (2003), dentre outros. Para esses autores, um problema poderia ser visto como sendo uma situação que demanda um conjunto de ações dirigidas a um objetivo a ser alcançado, onde nem sempre os meios para operacionalizá-las estão bem definidos. Em outras palavras, parte-se de uma definição de problema como um processo que demanda uma transformação de um estado inicial de conhecimento pela aplicação de operações mentais que visam à superação de obstáculos para se chegar a um estado final de meta ou de resolução. Para resolver um problema, o solucionador precisa assim se referir não apenas à descrição do problema em si, ou seja, a seus enunciados, a seus conteúdos semânticos, a suas restrições, etc., mas também precisa fazer uso de conhecimentos prévios e de estratégias de processamento mais gerais, que costumam ser denominadas "heurísticas”, e/ou de estratégias mais específicas, adequadas ao tipo de problema em questão.

Como propõe a Teoria do Espaço do Problema de Newell e Simon (1972), haveria um “espaço do problema” que seria construído pelo solucionador e que demarcaria, sob termos representacionais explícitos, os vários estados e processos hipotéticos que estariam envolvidos no processamento da informação no âmbito da resolução de problemas. Para explicar (e simular computacionalmente) esses processos, estes autores propuseram um programa computacional denominado "Solucionador Geral de Problemas” (o chamado “GPS”), programa esse que veio substituir o programa anteriormente proposto por eles e por Shaw (Newell, Shaw \& Simon, 1958) denominado L.T. ("Logic Theorist”). A simulação computacional dos "passos" envolvidos na resolução de problemas e a construção de uma teoria geral que enfocasse os diferentes processamentos cognitivos subjacentes ao processo de resolução de problema como um todo foram os dois principais objetivos desses autores. Assim, Simon e colaboradores, investigando os processos responsáveis pela construção das representações mentais iniciais de um problema, enfatizaram as formas através das quais a percepção e a compreensão são usadas para construir estas representações.

Nesse sentido, então, o GPS não seria somente um programa computacional capaz de simular o pensamento lógico envolvido na solução de muitos problemas, mas também seria uma referência teórica para explicar o processamento da informação nos seres humanos. Inclusive, a abordagem do processamento da informação deve parte do seu 
sucesso aos trabalhos inaugurais de Simon e colaboradores nas décadas de 1950, 1960, 1970 e 1980.

Simon e colaboradores (Newell, Shaw \& Simon, 1958; Newell \& Simon, 1972; Simon \& Hayes, 1976; Kotovsky, Hayes \& Simon, 1985), propuseram um pequeno número de heurísticas gerais que seriam utilizadas na resolução de diferentes problemas e enfatizaram a natureza deliberada do pensamento analítico e o caráter serial e simbólico do pensamento, sendo alguns dos principais expoentes da abordagem serialsimbólica do processamento da informação.

Já no que se refere ao termo transferência analógica, cabe observar, conjuntamente com Leme (2001), que há uma grande diversidade de concepções do que seria considerado transferência, transferência analógica, ou mesmo na escolha dos critérios adotados para a definição de dois problemas como análogos. Essa diversidade conceitual, inclusive, extrapola o conceito de transferência analógica e parece estar presente no processo de construção teórica de vários constructos produzidos na área.

Apesar da heterogeneidade de definições, parte-se da definição tradicional de transferência analógica, como a proposta por Holyoak e Koh (1987) que a consideram, em um nível global, como a generalização e a adaptação de conhecimentos de uma situação anterior base (fonte) para uma nova situação posterior (alvo), a partir de similaridades compartilhadas entre as duas situações.

Sendo assim, quando abordamos a resolução de problemas que envolvem uma analogia, devemos nos indagar que tipos de processamento e quais etapas de processamento estariam envolvidos nesse contexto. Nesse sentido, também poderíamos conceituar a resolução de problemas análogos como envolvendo um "espaço do problema”, cujo percurso partiria de um processamento inicial, onde haveria a representação do problema e a recuperação de conhecimentos prévios, incluindo-se as informações sobre o problema “fonte”, seguido por um posterior processamento onde, por sua vez, haveria uma comparação ou um "mapeamento" de características comuns entre o problema "fonte” e o "alvo". Após esses estágios iniciais de processamento, uma adaptação do problema “fonte” ao problema “alvo” seria necessária, pois as duas situações-problema costumam ser de diferentes domínios, o que requer um processo de “adequação" daquilo que é recuperado na memória (problema "fonte”) às condições do problema “alvo”. Mas para que essa “adaptação” ou “aplicação” do conhecimento prévio ocorra, processos de generalização e de inferência costumam também estar 
envolvidos, pois permitem certa abstração e uma “descontextualização” dos domínios dos problemas “fonte” e “alvo".

Os processos de recuperação e de mapeamento destacam-se como processos chaves no pensamento analógico, pois permitem a adequação das informações acessadas na Memória a Longo-Prazo (MLP) para o problema “alvo” em curso. Uma recuperação é considerada bem sucedida quando o problema “alvo” ativa o acesso a informações prévias relativas ao problema “fonte” na MLP, enquanto o mapeamento é considerado bem sucedido quando há um melhor número de correspondências entre o problema "fonte" e o "alvo".

Com ênfase no mapeamento analógico, Gentner e Toupin (1986) consideraram que o processamento de analogias envolve mapear um sistema de relações entre objetos do problema “fonte" (base) e objetos do problema "alvo", com destaque para as similaridades na estrutura relacional dos problemas. Um princípio de sistemacidade, como proposto por esses autores, parece guiar o mapeamento, estabelecendo como parâmetro que uma característica (predicado) que pertença à base e que esteja incluída em um sistema mapeável de relações mutuamente conectadas tem mais chance de ser importada para o “alvo” do que um predicado isolado. Nessa direção, Markmann (1997), ao investigar a transferência analógica em universitários, também focalizou a importância do princípio de sistemacidade como uma “coação” fundamental na inferência analógica, é o que seus achados parecem sugerir.

Não obstante, evidências mais recentes de Day e Gentner (2007) vêm apontando para a possibilidade de muitas inferências analógicas se darem de modo não intencional e sem consciência. Seus achados sugeriram que a compreensão e a interpretação de textos poderiam ser influenciadas pela leitura prévia de passagens análogas com diferentes conteúdos. Na concepção desses autores, mesmo o processo de mapeamento analógico, tradicionalmente visto como um processo deliberado e explícito, poderia ocorrer de modo implícito e rápido, sem o engajamento consciente dos indivíduos.

Estudos de Ripoll, Brude e Coulon (2003) também apresentaram evidências que parecem complementar as de Day e Gentner (2007), pois, para os primeiros autores, antes do processo de mapeamento propriamente dito já haveria analogia, isto é, não haveria a necessidade de uma correspondência “termo a termo" entre os predicados dos problemas análogos para que houvesse a extração das propriedades relevantes do problema "fonte". Foi verificado em seus estudos que quando o problema "fonte" permitia a generalização de um contexto para o processamento do problema "alvo”, o 
recurso da comparação/ mapeamento não se tornava pré-requisito para a transferência, pois os indivíduos foram capazes de usar propriedades globais do problema "fonte” de modo precoce durante o processamento analógico. Os autores também sinalizaram para a falta, em pesquisas na área, de uma melhor discriminação da relação entre as representações iniciais do problema e o processamento analógico propriamente dito, pois, a seu ver, apesar de interdependentes, esses processos envolvem distintos mecanismos cognitivos.

Gick e Holyoak (1983) sinalizaram que a estrutura de uma analogia seria ditada por sua função, ou seja, a função de uma analogia seria derivar uma nova solução, hipótese ou predição a partir de uma situação-problema anterior análoga. Os indivíduos durante o processo de transferência analógica notam as correspondências entre alguns problemas conhecidos e um novo problema ainda não resolvido e, tendo isso como referência, derivam uma solução análoga potencial. Cada análogo poderia assim ser dividido em duas partes: uma que fornece a base inicial para o processo de comparação de correspondências/ mapeamento e outra que constitui a “conclusão”.

Gick \& Holyoak (1983), citando Hesse (1977), destacaram dois tipos de relações distintas envolvidas na analogia, sendo a primeira delas o mapeamento "horizontal" do conjunto de correspondências entre dois ou mais análogos que, acrescentaríamos, poderia ser vista também como uma relação inter-problemas. A outra relação, por sua vez, seria aquilo que Hesse chama de relação “vertical”, isto é, uma relação que se daria entre as duas partes de um mesmo problema particular, mostrando-se assim ser uma relação “intra-problema”. Não obstante, as relações horizontais e verticais estariam intrinsecamente conectadas ao longo do processo de transferência analógica. Em um nível mais geral, as relações verticais seriam relações entre as condições antecedentes relevantes e as suas conseqüências correlatas, sendo que, em muitos casos, as relações verticais correspondem às relações causais que ocorrem em um dado modelo mental de cada situação construído pelo indivíduo. Nessa perspectiva, alguns aspectos iniciais de uma determinada situação-problema poderiam ser suficientes para o resgate de uma solução análoga, sem que fosse necessário um mapeamento exaustivo de todas as correspondências possíveis entre dois ou mais análogos.

No processo de transferência analógica os problemas “fonte” e "alvo" costumam compartilhar similaridades que poderiam ser, basicamente, de três tipos: superficiais, pragmáticas e estruturais. As similaridades superficiais referem-se às similaridades das características de superfície dos problemas, ou seja, à semelhança entre aquelas 
características que revestem perifericamente os problemas, por exemplo, palavras, objetos, representações físicas e/ou espaciais, números, etc., bem como os conteúdos dos enunciados e aquilo que denominamos de tonalidade afetiva dos enunciados e da história como um todo. Já as chamadas similaridades pragmáticas, como o próprio termo indica, dizem respeito à semelhança de objetivos entre problemas, sendo que estes objetivos não são dos problemas em si, mas sim dos indivíduos que estão em processo de sua solução e transferência. Por último, as similaridades estruturais ou também chamadas de "estruturas profundas" são consideradas aquelas similaridades que realmente “definem” dois problemas como verdadeiramente análogos, pois conformariam uma espécie de “esqueleto” lógico que daria sustentáculo a ambos os problemas.

Esses três tipos de similaridade funcionariam como “coações” sintáticas, semânticas e pragmáticas que atuariam no processamento analógico e que, quando satisfeitas, permitiriam um mapeamento bem sucedido. Entretanto, nenhuma dessas coações é absoluta, na verdade podemos concebê-las como tipos de ativação que guiam o processamento de informações, constituindo assim um “somatório de ativações”, como na acepção de Holyoak e Koh (1987), Anderson (1983; 1987a), Rumelhart (1991), que focalizaria as informações mais pertinentes para a transferência analógica. Em outros termos, como observaram Novick e Hmelo (1994), essas múltiplas “coações” seriam aplicadas, em paralelo, durante o processo de transferência e de resolução de problemas, ou seja, elas ativariam uma rede de conexões de conceitos na memória a longo-prazo (MLP). Os padrões de ativação levariam a um número de conceitos ativados/desativados, e quando se chegasse a um nível estável de ativações (somatório de ativações), a rede de conceitos com maior ativação seria mapeada.

Mas, apesar de os três tipos básicos de similaridade terem a sua importância na transferência analógica, para muitos autores é a chamada similaridade estrutural ou também chamada de "estrutura profunda" ou ainda "sintática” que seria aquela que, como vimos, definiria dois problemas como verdadeiramente análogos, em função de seu isomorfismo estrutural.

A abertura de um parêntese para abordar o conceito de similaridade talvez seja oportuna, pois os conceitos de similaridade e de analogia estão parcialmente relacionados. Como observou, no passado, Tversky (1977), a similaridade desempenha um papel importante na organização de princípios através dos quais os indivíduos 
classificam objetos, formam conceitos e fazem generalizações. Entretanto a apreensão de similaridades entre objetos, pessoas, eventos, etc. não se dá em um vácuo, pois a similaridade depende do contexto e de todo um sistema de referências que traz um sentido e um significado a essa apreensão. O mesmo poderia ser dito do conceito de analogia.

Gentner e Markmann (1997), ao fazer uma diferenciação entre o conceito de similaridade e o de analogia, enfatizaram os aspectos perceptuais envolvidos na apreensão da similaridade entre duas situações ou objetos, em contrapartida ao conceito de analogia, que por sua vez, depende de “relações comuns” entre duas situaçõesproblema. Sendo assim, a apreensão de relações comuns entre duas ou mais situações é essencial para o raciocínio analógico, mas a similaridade de elementos/objetos presentes nessas situações não o é. É claro que a similaridade “superficial” pode estar também presente em dois ou mais problemas isomórficos, porém ela não é definidora da analogia entre eles, pois são as suas "relações comuns", ou seja, as suas "estruturas profundas” que irão definir o seu caráter analógico.

Autores como Holyoak e Thagard (1997) e Holyoak (2005), dentre outros, também preferiram utilizar o termo "similaridade" para se referir, em especial, à semelhança dos elementos dos problemas, ou melhor, à semelhança de aspectos mais superficiais compartilhados pelos problemas (objetos, conceitos, etc.). Quando se referiram às estruturas profundas, preferiram utilizar o termo "estrutura”. Observamos assim certa heterogeneidade na utilização do termo "similaridade” na literatura na área, pois alguns autores, por um lado, parecem utilizar uma acepção de similaridade como sinônimo de “semelhança” e que, a seu ver, comporta diferentes dimensões (superficiais, estruturais, pragmáticas) e outros, por outro lado, preferem utilizar este termo apenas quando se referem às semelhanças mais superficiais entre problemas.

Goldstone e Son (2005), ao abordar o conceito de similaridade, também enfatizaram, em especial, as funções perceptuais que a apóiam, o que vem a reforçar uma acepção mais estrito senso de similaridade, como aquela de Holyoak e Thagard (1997). Já em relação à analogia, como vimos, seria a “similaridade” entre as estruturas profundas de dois ou mais problemas que iria definir seu caráter analógico.

A transferência entre problemas análogos de mesma estrutura profunda, mas que se situam em domínios diferentes do conhecimento, é a mais estudada em diferentes pesquisas na área, pois para muitos autores, como Robertson (2001), a transferência inter-domínios poderia ser vista como a verdadeira transferência analógica, sendo a 
transferência intra-domínio vista, nesse contexto, como um aperfeiçoamento de uma área de conhecimento. Na medida em que exige uma maior adaptação das informações adquiridas em uma situação fonte (de um domínio) para uma situação alvo (de outro domínio), a transferência inter-domínios poderia ser considerada, talvez, a mais "típica” ou, em outras palavras, a mais "autêntica” transferência.

Embora possamos observar, na literatura da área, certo predomínio de estudos com ênfase na transferência interdomínios, como os tradicionais estudos de Gick e Holyoak (1980; 1983), Gentner e Gentner (1983), Schunn e Dunbar (1996), só para citar alguns, há também estudos que investigam a transferência intradomínio, como, por exemplo, no domínio da matemática, os estudos de Novick (1988), Novick e Holyoak (1991), Novick e Bassok (2005) e de Bassok, Chase e Martin (1998). Em alguns desses estudos, que serão discriminados na próxima seção, observamos também a investigação da transferência analógica entre domínios mais próximos e mais distantes em uma mesma pesquisa como, por exemplo, entre domínios como física e matemática (Bassok \& Holyoak, 1989) e domínios como finanças e matemática (Bassok, 1990).

Por último vale ainda destacar, no âmbito da resolução de problemas e da transferência analógica, que o grau de definição do problema, bem ou mal-definido costuma ser um dos parâmetros utilizados na categorização de estudos na área. Entretanto, somam-se ao grau de definição dos estados iniciais e de meta e à explicitação das condições e limitações do problema, o grau de dificuldade envolvido em sua resolução, bem como a maior ou menor proximidade desses problemas com as situações-problema cotidianas. Sendo assim, quando se pensa em uma diferenciação entre problemas bem e mal-definidos, não seria apenas, como o nome parece sugerir, o grau de “definição” dos problemas o único critério possível para caracterizá-los.

Alguns destes estudos utilizam situações-problema independentes ou parcialmente independentes de domínio, como, por exemplo, as pesquisas de Reed, Ernst e Banerji (1974), Kotovsky, Hayes e Simon (1985), com problemas bem-definidos. Outros, por sua vez, como as pesquisas de Gick e Holyoak (1980, 1983), Holyoak e Koh (1987), Catrambone e Holyoak (1989), utilizam problemas mal-definidos que envolvem um processo de insight, como o problema da radiação de Duncker (1945) e seus análogos.

Como nossa pesquisa se propõe a utilizar situações-problema mal-definidas, com a apresentação de problemas análogos ao da radiação de Duncker, uma breve apresentação deste tipo de problema é proposta abaixo. Inicialmente recorreremos ao 
próprio Duncker (1945) e ao problema da radiação proposto em seus experimentos para uma caracterização inicial desse tipo de problema.

Duncker (1945), um dos principais expoentes da abordagem gestaltista na psicologia, buscou investigar a estrutura e a dinâmica dos processos de resolução de problemas em diferentes tipos de problemas “práticos” como o problema da radiação por ele proposto. Em sua versão clássica esse problema supõe uma situação médica onde um paciente apresenta um tumor maligno e inoperável no estômago. A necessidade de um tratamento torna-se premente com o intuito de evitar a morte do paciente. O uso de um tipo de radiação é proposto como tratamento, sendo que os raios deveriam ter uma alta intensidade para que o tratamento fosse eficaz. Porém, havia um problema a ser resolvido, pois o uso de uma alta intensidade de radiação, apesar de eficaz para destruir o tumor, seria altamente perniciosa para os tecidos corporais sadios que o envolviam. O uso de dosagens pequenas da radiação, por sua vez preservaria os tecidos corporais, mas, em compensação, não afetaria o tumor. Como então resolver esse problema tendo em mente os dois principais objetivos e "coações” do mesmo: a destruição do tumor e a preservação dos tecidos corporais sadios? Duncker propôs algumas soluções possíveis, sendo a solução mais conhecida a da convergência de raios de baixa intensidade emitidos simultaneamente a partir de várias fontes de emissão.

Duncker (1945), em alguns dos seus experimentos, contrapôs o desempenho dos indivíduos que recebiam um problema análogo antes da apresentação do problema da radiação com o desempenho de indivíduos que não recebiam um análogo. Aqueles que não foram submetidos a uma situação-problema análoga anterior, propuseram três tipos básicos de solução: a primeira propondo a redução da intensidade dos raios quando os mesmos atravessassem os tecidos sadios; a segunda propondo, por sua vez, a evitação do contato entre os raios e os tecidos sadios e a terceira, propondo a redução da sensibilidade dos tecidos à radiação, através de algum tipo de tratamento como uma “imunização” prévia dos tecidos.

Uma das versões análogas ao problema da radiação mais comuns, também proposta inicialmente por Duncker (1945), foi o problema denominado “O General”. Essa versão relata uma história de um general e seu exército que têm o objetivo de capturar um forte dominado por um tirano. De modo análogo ao problema da radiação, a solução desse problema supõe a divisão do exército em pequenos grupos de soldados que convergem simultaneamente, através de diferentes caminhos, para o forte, assim minimizando os 
possíveis danos causados por estradas minadas que poderiam destruir o exército e as vilas vizinhas. Entretanto, nesse caso, não há um isomorfismo perfeito entre esses dois análogos. Por exemplo, ao compararmos o problema da radiação de Duncker com seu análogo o “O General”, observamos que não há uma correspondência/ mapeamento perfeito entre seus elementos. Os raios no problema da radiação são os instrumentos da destruição do tumor e uma alta intensidade dos mesmos poderia destruir os tecidos corporais sadios, enquanto no problema do general, o próprio exército e as vilas vizinhas poderiam ser destruídos pelas minas. Em outras palavras, não haveria uma correspondência semântica dos papéis desempenhados pelos elementos nas duas histórias, pois, em uma delas, os raios seriam o "instrumento" de destruição do tumor e, na outra, o elemento a ser pareado com os raios, no caso o exército, seria o "objeto" da destruição das minas.

Cabe observar também que o próprio Duncker, nesses mesmos estudos, apresentou um outro tipo de solução para o problema da radiação, além do tipo de solução da convergência de raios de baixa intensidade: a solução de evitação do contato entre os raios e os tecidos corporais. Isso poderia se dar de duas maneiras: o envio de uma alta intensidade de raios para o tumor no estômago através de uma rota já “aberta”, no caso, o esôfago (uma rota “alternativa”) ou através de uma incisão na parede do estômago, com a remoção dos tecidos corporais sadios que estivessem no caminho dos raios de alta intensidade a serem aplicados (uma operação). De modo análogo, no problema do general, a evitação do contato do exército com as minas poderia ser feito de dois modos: encontrar uma estrada não minada e enviar todo o exército por ela ("rota alternativa”) ou cavar um túnel embaixo das minas e enviar o exército por ele ( semelhança com a operação na história anterior).

Evidências empíricas do próprio Duncker (1945) demonstraram que os participantes tiveram muita dificuldade em transferir espontaneamente uma solução análoga (apenas dois em 42 participantes), quando eram apresentados primeiro ao problema do general e depois ao problema da radiação. Uma possível explicação seria a de que os indivíduos teriam dificuldade, no problema da radiação, em pensar na “divisibilidade” de raios, como ocorreu na dispersão e divisão do exército. Quando Duncker utilizou termos como “partículas” no lugar de raios, inclusive, houve o favorecimento da solução de divisibilidade das mesmas, de modo análogo à divisão do exército no problema "O General”. 
Porém evidências empíricas complementares de Duncker, nesses estudos, sugeriram que 29\% dos participantes forneceram a solução da abertura de uma passagem alternativa para se chegar ao estômago no problema da radiação, após a apresentação do tipo de solução que propunha o uso de uma rota alternativa não bloqueada por minas no problema “O General”. Já a apresentação, na situação-problema “fonte”, da solução da abertura de um túnel pelo general e seu exército embaixo das estradas minadas, obteve, por sua vez, uma transferência espontânea em 40\% dos participantes no problema da radiação (solução de operação). Porém, nesse último caso, a solução da abertura de um caminho para se chegar ao tumor através de uma cirurgia não levou em conta uma das “coações” do problema que seria a impossibilidade da realização de uma cirurgia. Nesse sentido, essa última solução poderia ser vista como uma falsa analogia, na medida em que a solução proposta não seria apropriada, apesar de ter sido análoga em termos do mapeamento de elementos tais como cavar/ fazer uma incisão, passagem/ túnel, retirar terra/ retirar tecidos corporais, etc.

Cabe ainda observar que o problema da radiação e as suas versões análogas, como a história do general, tornaram-se alguns dos problemas mal-definidos, preferencialmente, investigados por muitos estudos no âmbito da transferência analógica. A pesquisa ora proposta pretende, de certo modo, complementar estudos clássicos, como os de Duncker (1945), bem como estudos posteriores de Gick e Holyoak ( 1980; 1983), Gick (1985; 1990), Holyoak e Koh (1987), Catrambone e Holyoak (1989), Catrambone (2002), Grant e Spivey (2003), Helfenstein e Saariluoma (2006), Kurtz e Loewenstein (2007), dentre outros, que também utilizaram o problema da radiação e/ou seus análogos. Porém, como veremos ao longo do presente trabalho, esses estudos não investigaram os efeitos da tonalidade afetiva das histórias dos problemas na transferência analógica e utilizaram versões “neutras” do problema da radiação. Não obstante, poderíamos aqui questionar a própria “neutralidade” do problema da radiação em sua versão “clássica”, de Duncker, pois a sua história relata uma situação médica e um paciente com um tumor maligno. Não encontramos na literatura da área, estudos que manipulassem a tonalidade afetiva de histórias de problemas análogos ao problema da radiação, como aquele proposto em nossa pesquisa.

O próprio Duncker, apesar de não ter direcionado seus estudos para a investigação dos efeitos da tonalidade afetiva, sinalizou também que a semelhança dos conteúdos dos enunciados dos problemas poderia favorecer o processo de transferência. Nessa perspectiva, a proximidade semântica entre conteúdos de enunciados de problemas 
análogos, ainda que neutros, seria um importante fator a ser considerado quando se pesquisa o processo de transferência analógica, como veremos de modo mais aprofundado nas seções posteriores.

Após a apresentação de alguns conceitos iniciais, das características principais do pensamento analógico e do problema da radiação de Duncker, faremos a seguir uma breve caracterização dos principais tipos de modelos de processamento da informação que vêm servindo de inspiração para a construção de teorias no âmbito da Psicologia Cognitiva e em áreas afins. Alguns desses modelos vêm trazendo pertinentes contribuições para o entendimento do funcionamento da cognição humana, sendo de nosso interesse especialmente aqueles direcionados para o estudo da memória e do pensamento analógico.

2.3-Modelos Simbólicos/ Seriais, Modelos Conexionistas e Modelos Híbridos: Algumas Contribuições para o Estudo da Memória e do Pensamento Analógico

Dois modelos principais costumam servir de referência para o estudo contemporâneo da cognição humana. O primeiro deles, o modelo simbólico/ serial, inspirado pela lógica formal e pelas teorias da computação, enfatiza a manipulação seqüencial de representações simbólicas no processamento cognitivo. O segundo deles, o modelo conexionista, por sua vez inspirado no design das redes neurais do cérebro, enfatiza as interações que ocorrem em redes compostas de componentes simples, sendo os processos cognitivos vistos aqui como derivados de um somatório de ativações e inibições que ocorrem nessas redes. E como observou Dinsmore (1992), cada um desses modelos possui seus próprios problemas, métodos e uma agenda própria de questões e pesquisas. Não obstante, como ainda destacou esse autor, parece haver nos últimos anos uma tendência para o preenchimento das "lacunas" existentes entre os dois modelos, e acrescentaríamos, para um diálogo menos dicotômico entre os mesmos. A proposta de modelos "híbridos", que congregam aspectos de ambos os modelos tradicionais, parece ilustrar essa tendência.

Os modelos simbólicos/ seriais, muito utilizados em estudos sobre o pensamento, incluindo-se a resolução de problemas, enfatizam as representações simbólicas como unidades discretas, a combinação semântica que as estruturas simbólicas podem configurar, bem como o uso de regras lógicas explícitas de manipulação de símbolos e a natureza seqüencial do processamento da informação. Na concepção desses modelos, os 
processos cognitivos, incluindo-se a memória e o pensamento, dependem da aplicação de regras que devem ser explicitamente representadas. O papel da Memória a CurtoPrazo (MCP) ou, utilizando um termo mais recorrente nas pesquisas contemporâneas, da Memória de Trabalho (MT), como na acepção de Baddeley (1986; 1990) e de seus limites de armazenamento é destacado nesse contexto, o que influenciaria a demanda de um processamento serial da informação em função da sobrecarga cognitiva envolvida.

No que se refere ao papel da MT na transferência analógica, vale observar que, quando há a demanda de integração de múltiplas relações analógicas simultâneas, bem como a presença de interferências durante o processamento analógico, a consequente sobrecarga na MT pode ter influência negativa na transferência, como apontaram estudos recentes de Cho, Holyoak e Cannon (2007). Sendo assim, como observaram esses autores, a habilidade humana para resolver problemas complexos e para processar diferentes tipos de informações vai depender da disponibilidade das representações simbólicas serem mantidas na MT, com mínimo declínio, ao longo de um intervalo de processamento.

Observa-se que os modelos seriais/ simbólicos parecem ter sido hegemônicos no âmbito dos estudos do pensamento e também nos estudos da linguagem, na medida em que explicam o uso de regras de produção na transformação do conhecimento e também a semântica combinatória que os símbolos podem compor, ou seja, o significado envolvido na interpretação dessa combinação simbólica. Sendo assim, ao pretender dar conta da "sintaxe" e da "semântica" envolvidas no processamento da informação, esses modelos trouxeram grandes contribuições para o estudo da cognição humana.

Não obstante, os modelos conexionistas de processamento que propõem uma distribuição paralela da informação (também chamados de modelos de processamento distribuído em paralelo, abreviados como modelos “PDP”), como aqueles inicialmente propostos por McClelland e Rumelhart (1981) e Rumelhart (1991), vieram a contraporse aos modelos seriais/ simbólicos ao propor a idéia de que o conhecimento seria mais bem entendido como o somatório de padrões de ativação simultânea de um grande número de unidades distribuídas em "rede". Esses modelos assumem assim um processamento paralelo e não serial da informação, ou seja, a distribuição da representação pelo sistema cognitivo e não a sua localização em símbolos discretos. Nessa perspectiva, o pensamento não seria concebido, como o foi no modelo anterior, como uma manipulação deliberada de símbolos, mas sim como uma ativação paralela de unidades interconectadas. Nota-se, nesses últimos modelos, uma ênfase em uma 
“orientação para o processo” em contraposição a uma ênfase em uma “orientação para a representação” típica dos modelos simbólicos, como destacou Dinsmore (1992).

Entretanto, no que se refere à memória humana, os modelos conexionistas tradicionais e os modelos conexionistas híbridos parecem ter trazido maiores contribuições para o entendimento do processo de recuperação de informações, especialmente quando a informação a ser recuperada não é direta e possui apenas “pistas” parciais de contexto que auxiliam em sua recuperação. Em outras palavras, para esses modelos, cada uma dessas pistas parciais conteria o "endereço” da memória total que permitiria que um determinado item ou conceito fosse recuperado quando a informação fosse incompleta. Essa habilidade de recuperação de informações, a partir de pistas parciais de contexto, é conhecida como “endereçamento de conteúdo" 1 (Stevenson, 1993).

Porém, podemos nos indagar, conjuntamente com Stevenson (1993), como poderia um sistema simbólico codificar um “endereçamento de conteúdo” de modo eficaz, se uma busca serial pela informação na memória consumiria tempo e seria trabalhosa e exaustiva? Para evitar essa sobrecarga, as redes semânticas dos modelos seriais/ simbólicos propõem o agrupamento da informação em nodos. Mas ainda assim podemos observar que a ligação unidirecional entre os nodos, proposta por essas redes, mostra-se insuficiente para explicar como as pistas parciais de contexto poderiam ajudar na recuperação de uma informação incompleta.

Em contraste, os modelos PDP parecem explicar, de modo mais simples, a possibilidade de uma rápida recuperação na memória a partir de pistas parciais de contexto com sua proposta de uma rede articulada de informações que sofreria ativações e inibições simultâneas de inúmeras pistas de contexto, sem que fosse necessário um rastreamento dispendioso de cada pista separadamente. McClelland (1981), como citado por Stevenson (1993), dá como exemplo de um modelo PDP uma rede conexionista representando membros de duas facções rivais em que seus membros possuem relações bidirecionais entre si. Esse exemplo ilustra como uma informação parcial sobre um dado membro da gang poderia ativar/ inibir outros conceitos de outros membros (idade, estado civil, escolaridade, posição social no grupo, etc.). O resultado final desse somatório de ativações e inibições seria, então, por exemplo: João, da gang da rua X, solteiro, nível médio, líder, etc.

${ }^{1}$ Do inglês: “content adressability” 
Nessa direção, os modelos conexionistas parecem dar conta das inferências indutivas, incluindo-se a abstração de princípios gerais a partir de exemplos. Não obstante, os modelos conexionistas, apesar de apresentar algumas vantagens para explicar o funcionamento da memória e da aprendizagem, sofreram críticas de autores como Fodor e Pylyshyn (1988) que, por sua vez, destacaram a natureza governada por regras do pensamento e da linguagem, regras essas não privilegiadas pelo conexionismo tradicional. Uma outra crítica que poderia se somar à desses autores, seria aquela que questiona a ativação “cega” das unidades na rede conexionista. Se as unidades de um modelo PDP fossem automaticamente ativadas por um input relevante, como propõe o conexionismo, não haveria muito espaço para a seleção voluntária das características relevantes de um dado estímulo. Os processos "bottomup" seriam vistos como determinantes no processamento inicial da informação e os processos “top-down” teriam menor influência nesse contexto.

Em uma resenha crítica do livro de Marcus (2001) a respeito da possibilidade de integração entre o conexionismo e as Ciências Cognitivas, Pylyshyn (2001), inclusive, pareceu demonstrar certo pessimismo com as tentativas de reconciliação e de "síntese" entre as abordagens conexionista e simbólica, o que parece reforçar ainda mais a sua ênfase na perspectiva serial/ simbólica do processamento da informação.

No que se refere à memória, observamos que a recuperação de informações envolve mais do que uma mera correspondência de itens na memória. Em outros termos, processos de compreensão e de inferência estão também envolvidos na recuperação de informações e podem influenciar nas “pistas” efetivas de recuperação. Como destacou Lange (1992), um modelo que aborde diretamente a recordação deveria integrar dois processos: o processo através do qual determinada "pista” é compreendida com o processo através do qual essa mesma “pista” é usada como recuperação de informação na memória. Sendo assim, os modelos conexionistas tradicionais, que não enfocam os aspectos da compreensão da linguagem, parecem possuir algumas limitações em sua tentativa de explicar os processos de recuperação na memória.

No que diz respeito aos processos de aprendizagem, os modelos PDP tradicionais também sofreram algumas críticas por não explicarem claramente como o aprendizado de padrões inteiramente novos (Schacter, 1991) ou padrões inusitados ou contraditórios (Ratcliff, 1990) seriam incorporado nas “redes”. Nessa direção, o conexionismo embora dê conta da flexibilidade do aprendizado de informações parcialmente degradadas ou incompletas, parece enfrentar alguns problemas para explicar "como" 
uma informação totalmente nova seria incorporada nas redes já construídas ou mesmo para explicar “como” os indivíduos poderiam desaprender certos padrões estabelecidos frente à apresentação de informações contraditórias.

Modelos conexionistas híbridos propostos posteriormente visaram compatibilizar algumas das características dos sistemas simbólicos com algumas das características dos sistemas distribuídos. Ao enfatizar, por um lado, a natureza simbólica da cognição e, por outro lado, as múltiplas “coações” que precisam ser satisfeitas, em paralelo, por exemplo, quando se recupera uma informação na memória, esses modelos conexionistas híbridos tentam assim compatibilizar o uso de símbolos e de regras com a distribuição em rede da informação.

Muitos modelos propostos no âmbito da transferência analógica poderiam ser considerados híbridos, como os de Holyoak e colaboradores (Holyoak \& Thagard, 1989; Hummel \& Holyoak, 1997; Hummel \& Holyoak, 2003), Forbus, Gentner e Law (1995), Kokinov \& Petrov (2001). Esses modelos, que congregam também a tradicional inspiração computacional dos modelos simbólicos/ seriais e o design neural do cérebro dos modelos conexionistas, buscam integrar memória e pensamento analógico, dois processos cognitivos que nem sempre são computados juntos em um mesmo modelo teórico.

Hummel e Holyoak (1997; 2003), apresentaram um modelo teórico de como a inferência relacional e o processo de generalização poderiam se dar em uma arquitetura cognitiva que é "realista” do ponto de vista psicológico e neural. Seu modelo conexionista-simbólico, denominado LISA ("Learning and Inference with Schemas and Analogies”) é um claro exemplo de um modelo que tenta compatibilizar aspectos de um sistema simbólico com aspectos de um sistema conexionista. Com ênfase em um sistema conexionista baseado nas representações distribuídas de significados de conceitos, os autores enfatizaram assim a sincronia temporal dos sistemas conexionistas com a ênfase representacional dos sistemas simbólicos. Esse modelo, de simulação computacional, busca explicar as inferências específicas e as novas relações de generalização e, nesse contexto, a aquisição de esquemas a partir de exemplos, que ocorrem durante o processo de transferência analógica.

Autores como Keane, Ledgeway e Duff (1994), ao comparar alguns modelos computacionais de sua época que simulavam o processamento analógico, objetivaram construir um referencial metateórico que unificasse esses modelos em um nível "supracomputacional, ou seja, em uma espécie de arquitetura cognitiva mais ampla. Na 
concepção desses autores, esses modelos teriam, do ponto de vista formal, um bom nível de implementação computacional, como na acepção de Marr e Poggio (1977), mas haveria ainda um desafio que seria o de se buscar um nível explicativo que melhor discriminasse as “coações” comportamentais apresentadas pelos indivíduos, isto é, um nível de explicação algorítmico.

Modelos mais recentes como o “AMBR” (“Associative Memory-Based Reasoning”) de Kokinov e Petrov (2001), o qual, por sua vez, buscou integrar o processamento analógico com outros processos cognitivos como a memória, teriam como base uma arquitetura cognitiva mais geral que vêm tentando aumentar a "sensibilidade” do modelo proposto às variações contextuais. Podemos assim observar que mesmo as Ciências Cognitivas com alto grau de formalização como a Inteligência Artificial (IA) que normalmente excluem o papel do significado e do contexto, bem como da afetividade, em suas computações “frias” e “insensíveis”, vêm abrindo algum espaço na contemporaneidade para a importância dos “conteúdos” e dos contextos dos indivíduos em suas formalizações. Todavia, a nosso ver, a inclusão dessas variáveis nesses modelos parece se dar de maneira incipiente, pois a ênfase continua sendo no detalhamento do processamento da informação.

No que se refere ainda à transferência analógica, cabe observar que um grande número de estudos, muitos dos quais serão discriminados nos próximos capítulos, vêm apontando para a importância da similaridade semântica entre as "pistas” no momento da recuperação e os objetos/ conceitos armazenados na memória (p.e. Holyoak \& Koh, 1987; Ross, 1987; 1989; Blessing \& Ross, 1996). A consistência estrutural entre duas situações ou dois problemas análogos também teria um impacto no processo de recuperação (p.e. Holyoak \& Thagard, 1989). De modo complementar, fatores como a existência de interferência na recuperação, especialmente quando há competição entre análogos potenciais ou quando há ambigüidade ou degradação nas informações a serem recuperadas, poderiam estar envolvidos no processo de recuperação de informações na memória. Sendo assim, modelos teóricos híbridos que suportem, por um lado, as diferentes “coações” presentes no processo de recuperação e, por outro, as representações e as regras que organizam as computações aí envolvidas, parecem ser os mais apropriados para o entendimento e para a simulação dos processos da memória e da transferência analógica.

Por último, ao nos questionar sobre as vantagens e desvantagens dos modelos simbólicos/ seriais e dos modelos PDP para o entendimento do pensamento analógico, 
encontramos em ambos os modelos contribuições e limitações. De acordo com Stevenson (1993), ambos os modelos contribuem, de modo complementar, para o entendimento dos processos conscientes e inconscientes subjacentes à resolução de problemas. A abordagem tradicional do processamento da informação tenta dar conta dos processos conscientes e inconscientes, enquanto a abordagem conexionista tenta dar conta dos processos inconscientes. Nesse contexto, os sistemas que enfatizam as regras de produção parecem explicar melhor as ações automáticas, procedimentais e a perícia em um domínio, em contraposição aos sistemas conexionistas que parecerem explicar melhor a recuperação de conhecimentos declarativos na memória. Não obstante, no contexto da transferência analógica, a simples recuperação e o mapeamento de um análogo "fonte” talvez não sejam suficientes para a resolução de um problema, pois, como observou Holyoak (1991), como citado por Stevenson (1993), uma busca deliberada através do espaço do problema seria também necessária para avaliar as implicações e a validade da analogia recuperada. Sendo assim, a aplicação de regras de produção também ajudaria no monitoramento dos resultados obtidos em cada etapa do processamento analógico.

Conclui-se que os modelos simbólicos/ seriais foram os modelos utilizados por excelência nos estudos sobre o pensamento, especialmente no contexto do raciocínio dedutivo e da resolução de problemas lógicos e/ou bem-definidos, pois permitem uma melhor explicitação das unidades simbólicas, das regras e dos operadores que manipulam esses símbolos sequencialmente. Já os modelos conexionistas tradicionais, por sua vez, contribuem para um bom entendimento do funcionamento da memória, com a assunção da idéia de uma rede de ativações paralela sujeita a múltiplas interferências e “coações”. De modo complementar, alguns modelos atuais, híbridos em sua natureza, na medida em que compatibilizam aspectos dos dois modelos clássicos, vêm trazendo inúmeras contribuições adjacentes para o entendimento do funcionamento do pensamento e da memória, em especial, do pensamento analógico.

Porém, mesmo modelos híbridos de processamento analógico, no caso o modelo denominado MAC/FAC de Forbus, Gentner e Law (1995), sofreram algumas criticas de autores como Barnett e Ceci (2002). Esses últimos autores observaram que os modelos computacionais de processamento, como o de Forbus e colaboradores, apesar de explicar as diferenças entre as similaridades de superfície e as estruturas profundas e o papel das “pistas” de recuperação fornecidas, não foram desenvolvidos para explicar “porque” a transferência analógica costuma ser difícil quando há mudança de contexto, 
especialmente no âmbito escolar. Nessa direção, apesar de sua elegância e sofisticação computacional, muitos modelos híbridos de processamento analógico parecem carecer de certa "validade ecológica”, ou seja, parecem não dar conta das inúmeras evidências, nem sempre convergentes, trazidas por pesquisas na área. Não obstante, em função dos nossos objetivos, não discutiremos a configuração desses modelos devido à complexidade computacional que os caracteriza.

Em suma, com a tentativa de maximizar as vantagens e de minimizar as desvantagens dos modelos seriais/ simbólicos e dos modelos PDP, os modelos híbridos, construídos no âmbito do pensamento analógico, tentaram assim compatibilizar as representações simbólicas, a ênfase no significado e uso de regras, típicos dos modelos simbólicos/ seriais, com a distribuição em rede da informação e a idéia de uma ativação paralela de diferentes “coações”, idéia essa típica dos modelos PDP. Como a resolução de problemas que envolvem a transferência analógica, como é o caso da interface proposta nessa pesquisa, depende, por um lado, do processo de recuperação de informações na memória a longo-prazo (MLP) e, por outro lado, de processos de mapeamento, de inferência e de adaptação das informações recuperadas, os modelos híbridos, apesar de suas limitações explicativas, parecem ser assim, a nosso ver, os mais adequados para o entendimento da transferência analógica na contemporaneidade.

\section{4-Facilitação da Transferência Analógica: Fatores que Intervém na Ocorrência da}

\section{Transferência}

Muitos fatores de diferentes naturezas parecem estar envolvidos no processo de facilitação da transferência analógica. Desde fatores como as “dicas” instrucionais fornecidas no contexto da aprendizagem, a ordem de apresentação dos problemas análogos e a construção de um esquema de aprendizagem apropriado, passando por fatores como o papel das similaridades de superfície, estruturais e pragmáticas, bem como a semelhança de contexto das situações-problema análogas, até fatores como o intervalo de tempo entre as sessões, só para citar os mais importantes, poderiam ser destacados. Em alguns casos, quando a transferência analógica envolve perícia, obviamente, o grau de conhecimento em um dado domínio também poderia ser citado. Não obstante, fatores de personalidade e/ ou fatores como o grau de motivação ou de interesse dos indivíduos, apesar de sua relevância, especialmente na facilitação da 
transferência no contexto escolar, não serão priorizados por se distanciarem dos objetivos do nosso trabalho.

Um dos principais fatores envolvidos na transferência seria assim o acesso aos conhecimentos relevantes na memória. No contexto escolar esse acesso é facilitado, normalmente, por “dicas” instrucionais deliberadas fornecidas pelos professores e/ou instrutores ao longo do processo ensino-aprendizagem, sendo a transferência espontânea mais difícil de ocorrer. Inclusive, o acesso a conhecimentos prévios vai depender diretamente da maneira como esses conhecimentos são organizados na memória, isto é, dos esquemas de aprendizagem construídos pelos indivíduos. Em outros termos, esse acesso vai depender, como sinalizaram Anderson, (1983) e Bassok e Holyoak (1989), da relação entre as condições da codificação de aplicabilidade do conhecimento de resolução de problemas e das “dicas” de recuperação fornecidas durante a tarefa de transferência. Três classes gerais de informação poderiam ser utilizadas para definir essas condições de aplicabilidade: os conteúdos de superfície, as estruturas profundas subjacentes e o contexto que envolve todo o processo de transferência.

As características de superfície, como vimos, incluindo-se os conteúdos de superfície como os enunciados de um problema, são normalmente aquelas mais visíveis, mais relacionadas a um dado domínio de conhecimento, enquanto as estruturas profundas costumam ser menos salientes e geralmente possuem um caráter relacional por natureza e estão diretamente vinculadas às condições sob as quais um dado método de solução é de fato apropriado, como observaram Bassok e Holyoak (1989).

Esses fatores costumam somar-se e interpenetrar-se na facilitação da transferência analógica, o que dificulta a separação dos mesmos em tópicos ou subseções independentes. Assim, a discriminação proposta abaixo em subseções, foi feita apenas para melhor organizar a apresentação das discussões e o destaque de alguns fatores, não para estabelecer limites rígidos da influência de cada um desses fatores separadamente.

\subsection{1-Ordem de apresentação dos problemas "fonte” e "alvo"}

Parece haver certo consenso, na literatura da área, no sentido de que a transferência analógica é facilitada quando há a apresentação inicial (ou o treinamento) de um ou mais problemas “fonte” de maior complexidade em relação ao problema "alvo”, do que quando há a apresentação inicial de um ou mais problemas “fonte” de menor complexidade em relação ao problema “alvo”. Sendo assim parece ser consenso a idéia 
de que se transfere melhor conhecimentos, incluindo-se aqui não só conceitos, mas principalmente princípios, equações, isto é, estruturas profundas, quando se parte de uma situação mais complexa, de maior “coação”/ mais “difícil” para uma situação menos complexa, de menor “coação”/ mais “fácil”.

Nesse sentido, a ordem temporal de apresentação dos problemas que facilitaria a sua resolução e transferência costuma partir do mais complexo para o mais simples, do mais abstrato para o mais concreto, ou tecnicamente falando, de um domínio mais independente de conteúdos (como a lógica e a matemática) para um domínio mais dependente de conteúdos e de exemplos (como a física), como as evidências de Bassok e Holyoak (1989) e de Bassok (1990) sugeriram.

Podemos ainda observar, em algumas pesquisas na área, uma tendência para a apresentação de problemas "fonte” de maior familiaridade e conhecimento prático dos indivíduos, após treinamento deliberado, e/ou a seleção de peritos em uma área de conhecimento e de problemas “alvo” mais distantes da sua área de conhecimento, como as pesquisas de Bassok e Holyoak (1989) e de Bassok (1990). Sendo assim, normalmente, a transferência analógica inter-domínios parte de problemas familiares, situados em um domínio, para problemas análogos de um outro domínio menos conhecido pelos indivíduos.

Evidências de Bassok e Holyoak (1989) e de Bassok (1990) sugeriram que a transferência entre domínios seria facilitada quando se parte de uma situação de maior complexidade para uma situação análoga de menor complexidade, bem como de uma situação de maior “coação” para outra de menor “coação”. Em outros termos, por exemplo, a transferência seria facilitada quando se parte de um domínio com conhecimentos mais formalizados e mais abstratos, como a matemática, para domínios com conhecimentos menos formalizados, mais concretos e mais "dependentes de contexto” (e de exemplos), como a física. Também, o grau de familiaridade do domínio para os indivíduos é um divisor de águas para muitas pesquisas que estudam a transferência interdomínios, pois, normalmente, a transferência é facilitada quando se parte de um domínio “fonte” mais familiar em direção a um domínio “alvo” não familiar.

Bassok e Holyoak (1989) estudaram a transferência analógica entre dois subdomínios de física e álgebra através da apresentação de dois tipos de problemas isomórficos: problemas algébricos de progressão aritmética e problemas físicos de aceleração constante. Os experimentos foram conduzidos em duas sessões, a primeira delas, a 
sessão de “aprendizagem”, teve uma duração que variou de 1 hora e 30 minutos a 3 horas. Nessa sessão, houve o estudo e a resolução de problemas de física, em um dos experimentos, e de álgebra, em outro experimento. Já a segunda sessão teve a duração de 30 minutos, sendo que as duas sessões foram conduzidas em dois dias consecutivos. Nessa segunda sessão, por sua vez, foram apresentados aos participantes problemas não familiares de outro domínio (física ou álgebra). Cabe observar que em nenhum momento da testagem foi dito aos participantes que havia uma relação isomórfica entre a fase de aprendizagem e o teste de transferência, ou seja, não foi fornecida nenhuma “dica” que facilitasse a transferência. Protocolos verbais foram utilizados durante a resolução de problemas na segunda sessão objetivando identificar sinais de mapeamento analógico e da transferência como um todo.

Os achados de Bassok e Holyoak, nesses experimentos, apontaram para uma boa taxa de transferência de álgebra para física nos estudantes secundaristas e universitários que participaram da pesquisa. O reconhecimento da similaridade entre os problemas dos dois domínios foi imediato e a solução dos problemas físicos, na segunda sessão, foi uma aplicação direta dos métodos aprendidos em álgebra. Em contraposição a estes resultados, a taxa de transferência analógica foi bastante reduzida nos grupos que foram submetidos primeiro ao aprendizado de problemas físicos de aceleração e depois tentaram resolver problemas análogos de álgebra. Essas evidências sugeriram que a transferência entre domínios próximos que apresentavam problemas de mesma estrutura profunda era nitidamente assimétrica. A facilidade da transferência que partia de um domínio mais "abstrato" e "sem conteúdo", como a álgebra, para um domínio mais dependente de conteúdo, como a física, contrastava com a dificuldade da transferência que partia da direção oposta, ou seja, da física para a álgebra. Esses resultados parecem sugerir que domínios mais “concretos” e mais dependentes de conteúdos de certo modo “fixariam” um dado “contexto” que poderia dificultar a transferência analógica para um outro domínio, ainda que este domínio fosse mais “abstrato”, mais formal e parcialmente independente de conteúdos como a álgebra. De modo complementar, esses achados parecem corroborar a idéia de que o conhecimento inicial em um domínio mais formalizado e independente de conteúdos permite uma melhor transferência analógica para problemas de outros domínios, quando há um isomorfismo entre os problemas em questão.

Entretanto, Bassok (1990), complementou os estudos anteriores replicando experimentos com problemas análogos de física e álgebra e problematizando essa 
questão com o acréscimo de um novo domínio, o das finanças, domínio este também com boa validade ecológica como a física, em função de sua riqueza de conteúdos. A partir dos resultados encontrados, essa autora observou que era possível aumentar a transferência que partia de domínios dependentes de conteúdos para domínios mais independentes de conteúdos desde que houvesse uma equivalência de elementos/quantidades mencionados nos problemas análogos, ou seja, desde que as variáveis que representavam tipos similares de quantidade nestes problemas fossem equivalentes. Inclusive, a diferença entre a chamada quantidade "extensiva” (que envolve uma entidade/ elemento, típica da matemática) e a chamada quantidade “intensiva” (que envolve, por exemplo, duas entidades/ elementos, típica de física, e que lida com dimensões como a velocidade que supõe a interação entre duas entidades: espaço e tempo) parece explicar, em parte, a dificuldade da transferência que parte da física para a álgebra. Também a natureza dos conteúdos embebidos nos tipos de problemas físicos e algébricos explica, de modo complementar, a diferença de desempenho nesses dois domínios, pois os princípios físicos são tipicamente de “conteúdos específicos” e os seus conceitos são complexos e não unitários, em contraposição aos princípios da álgebra e da matemática como um todo, que são, por sua vez, tipicamente unitários e não são de “conteúdos específicos”. De certo modo, como foi visto, a maior independência de conteúdos explicaria o melhor desempenho dos sujeitos submetidos anteriormente ao seu aprendizado, o que parece sugerir a idéia de uma melhor direção/ ordem para a transferência que partiria do "abstrato” para o “concreto".

Nesse sentido, podemos observar que a questão da ordem de apresentação de problemas no contexto da transferência analógica está intrinsecamente relacionada com a questão dos conteúdos, pois aquilo que muitas pesquisas manipulam, como as de Bassok (1990) e de Bassok e colaborador (1989), são os conteúdos que revestem os enunciados de problemas isomórficos de diferentes domínios, conteúdos esses que são, normalmente, “típicos” de um dado domínio. Devido a sua particular importância para a pesquisa aqui desenvolvida, o papel dos conteúdos dos enunciados dos problemas na resolução de problemas e na transferência analógica será abordado em uma seção específica destinada a esse fim em momento posterior desse trabalho.

Ainda no que se refere ao domínio da matemática, como foi sugerido por pesquisas brasileiras no âmbito do desenvolvimento cognitivo como as de Carraher, Carraher e Schliemann (1982; 1985) e Schliemann e Carraher, (1993), dentre outras, haveria a 
dificuldade na transferência que partia de situações do cotidiano que envolviam cálculo para situações formais escolares que envolviam matemática. Verificou-se, nesses conhecidos estudos, que a competência matemática apresentada por crianças pobres em situações concretas que envolviam venda e negociações nas ruas contrastava com o baixo rendimento escolar dessas crianças no mesmo domínio. A par das inúmeras implicações sócio-educacionais aí envolvidas, podemos observar nítidos efeitos de contexto e dos conteúdos que revestiam os problemas. Também aqui fica explicitada a verificação da falta da transferência que partia de uma situação informal do cotidiano, bastante dependente dos conteúdos e da vivência dos indivíduos, para uma situação formal escolar.

Goswami (1995; 2001), ao estudar a transferência analógica em crianças pequenas com a apresentação de problemas mais próximos do cotidiano dessas crianças, encontrou resultados que apontaram para a transferência analógica mesmo em crianças de dois anos. Essa autora contrastou, inclusive, seus achados à perspectiva piagetiana que, por seu turno, considerava a analogia uma construção tardia no desenvolvimento (início do pensamento formal). Trabalhando com tarefas informais, contextualizadas e bastante familiares para as crianças, ela apresentou assim evidências de uma manifestação precoce do pensamento analógico, o que parece sugerir uma base evolutiva na origem desse tipo de pensamento.

Formas precoces de imitação, tais como a imitação facial e a de gestos, poderiam ser consideradas precursoras de um pensamento analógico mais geral, sendo que o próprio processo imitativo per se (p.e. em bebês) é hoje bastante associado às suas bases biológico-evolutivas, como apontaram os estudos de Otta (1994), sobre o sorriso em bebês, e os de Bussab, Pedrosa e Carvalho (2007), sobre a manifestação precoce da empatia, dentre outros estudos. Talvez, esse tipo de pensamento não seja exclusivo da espécie humana, como sugerem Oden, Thompson e Premack (2001), em seus achados com primatas, especialmente, com chimpanzés.

Porém cabe lembrar que utilizamos como instrumentos de nossa pesquisa problemas mal-definidos, mais típicos do cotidiano e análogos ao da radiação de Duncker, problemas esses que não requisitam perícia em um domínio. Nessa perspectiva, a ordem de apresentação dos problemas que partiria de um domínio mais “concreto” para outro mais “abstrato” ou vice-versa não se apresenta como uma questão a ser considerada. Não obstante, houve a preocupação de controlar a ordem de apresentação das histórias dos problemas na situação-problema “fonte” com a divisão 
da amostra em quatro subgrupos, sendo que para cada subgrupo houve a apresentação de uma ordem diferenciada das histórias. No procedimento de pesquisa serão discriminados os subgrupos, sendo que o principal objetivo desse controle experimental foi o de minimizar os efeitos de primazia e de proximidade temporal das histórias “fonte” em relação às histórias “alvo”.

\subsection{2-As Similaridades de Superfície, Estruturais e Pragmáticas e a Facilitação da} Transferência Analógica

No âmbito da transferência analógica, a manipulação experimental das similaridades de superfície entre os problemas análogos costuma ser comum em inúmeras pesquisas que buscam investigar os fatores que influenciam os processos de transferência, como os estudos de Novick (1988), Ross (1987), Gentner, Ratterman e Forbus (1993), Catrambone (2002), dentre outros. Já as similaridades estruturais parecem ser menos manipuladas nesses estudos, na medida em que são as mesmas que “definem” dois ou mais problemas como análogos e a sua manipulação afetaria o isomorfismo entre os problemas. Porém, algumas pesquisas como as de Clement, Mawby e Giles (1994), manipularam essas últimas similaridades e outras, por sua vez, manipularam as similaridades das "estruturas profundas” de modo complementar à manipulação das similaridades de superfície, como os estudos de Holyoak e Koh (1987).

Como vimos anteriormente, Gick e Holyoak $(1980 ; 1983)$ foram uns dos primeiros autores, após o próprio Duncker, a utilizar em seus estudos, de modo mais sistemático, problemas análogos mal-definidos como o problema da radiação de Duncker e, seu análogo, o problema “O General”. Como também vimos, algumas versões destes problemas exigiam uma solução de convergência, conforme a versão “clássica” de Duncker, e outras versões continham uma estrutura profunda diferenciada da versão original (não convergência). Esses autores, em seus experimentos, demonstraram, inclusive, que havia uma tendência dos sujeitos de transferir a mesma estrutura do problema "fonte” para o "alvo" proposto, quando os sujeitos tinham acesso a "dicas" fornecidas pelos experimentadores.

Holyoak e Koh (1987), complementando esses trabalhos, em outro experimento, variaram, na situação-problema “fonte”, as similaridades superficiais e/ou estruturais de quatro versões análogas ao denominado problema do bulbo da lâmpada, problema esse por sua vez análogo ao problema da radiação, e apresentaram cada versão a quatro 
grupos de sujeitos. Um exemplo da variação semântica/ de superfície, foi a substituição, em um dos problemas, do uso de raios laser pelo uso de ondas de ultra-som e a substituição da necessidade de fundir o filamento pela necessidade de separá-lo. Já a variação estrutural que se deu em algumas versões foi relativa à variação de suas “coações”, por exemplo, na administração dos raios/ ondas pelas máquinas de radiação foram impostas diferentes “coações”. Os resultados sugeriram que as dissimilaridades estruturais entre os problemas "fonte" e "alvo" teriam um impacto mais significativo na transferência do que as dissimilaridades de superfície. Uma das principais conclusões a que chegaram os autores acima foi a de que ambas as similaridades superficiais e estruturais seriam importantes para recuperação espontânea (acesso), mas somente as similaridades estruturais seriam necessárias para o mapeamento per se (uso). Uma distinção entre os processos iniciais de “acesso/recuperação” e os de "uso/aplicação" também foi proposta por estes autores neste contexto, pois os mesmos parecem demandar mecanismos cognitivos distintos e complementares no processamento analógico.

Em suma, podemos concluir que embora as similaridades superficiais, estruturais e pragmáticas exerçam diferentes “coações”, provavelmente em níveis diferenciados do processamento analógico, são as similaridades estruturais aquelas que definem a caráter analógico entre dois ou mais problemas. Entretanto, as similaridades de superfície, incluindo-se os conteúdos semânticos dos enunciados e a valência afetiva destes conteúdos, dentre outras características de superfície, também têm a sua importância nesse contexto, pois podem facilitar a transferência analógica, especialmente nos processos iniciais de recuperação de informações na memória.

Como antes observado, a ênfase nas similaridades sintáticas/ estruturais parece ter norteado muitos dos trabalhos iniciais na área, mas pesquisas posteriores como a de Holyoak e Thagard (1990) destacaram também as similaridades pragmáticas, traduzidas em termos de objetivos compartilhados por problemas análogos. Sendo assim, como sinalizou Robertson (2001), o contexto e os objetivos dos indivíduos solucionadores seriam importantes “coações” no processo de transferência, pois reduzem a quantidade de informação a ser processada frente a uma situação-problema.

Spellman e Holyoak (1996) estudando mais especificamente os efeitos das “coações” pragmáticas no mapeamento analógico, trouxeram evidências que apontaram para a presença determinante desse tipo de “coação” no processo de transferência. Foi verificado que os indivíduos utilizavam os objetivos de um problema para eliminar 
(inibir) aspectos do problema análogo que não fossem relevantes em termos operacionais, fazendo isso antes mesmo de começar o mapeamento propriamente dito.

Ainda no que se refere às “coações” pragmáticas, Kotovsky, Hayes e Simon (1985) mostraram que a facilidade de aplicação de regras é provavelmente influenciada pela extensão em que as mesmas são consistentes com conhecimentos oriundos do mundo real, a par da carga de memória inerente ao problema e a facilidade de organizá-las de modo espacial e de imaginá-las mais facilmente. As similitudes pragmáticas poderiam assim facilitar o processo de transferência analógica, devendo-se considerar, nesse contexto, a adequação dessas regras aos conhecimentos cotidianos. Sendo assim, o impacto das similaridades pragmáticas e, como propõe também Chen (1996; 2002) de similaridades "procedimentais”, entre problemas análogos, parece fazer-se presente como uma importante “coação” no processo de transferência analógica.

Não obstante, podemos observar também que as características de superfície dos problemas podem favorecer a ocorrência de transferência negativa, quando há semelhanças entre as características de superfície de problemas e diferenças em suas estruturas profundas. Os estudos de Novick (1988), com problemas verbais de matemática, apontaram para a ocorrência de transferência negativa, especialmente em indivíduos com pouca perícia neste domínio, em contraposição ao desempenho de indivíduos com maior perícia, pois os primeiros tendiam a selecionar aspectos superficiais irrelevantes dos problemas “alvo" como “dicas” para a recuperação dos problemas “fonte". Também Ross (1987), ao estudar o uso de princípios da probabilidade em problemas verbais de matemática e o uso de exemplos anteriores na resolução de novos problemas, apresentou alguns achados que apontaram para o fato de que os indivíduos pesquisados tendiam a recuperar características de superfície relevantes e irrelevantes dos problemas durante o processo de transferência analógica e, nesse sentido, poderiam também estar sujeitos a uma transferência negativa.

Estudos anteriores de Luchins (1942), com problemas que envolviam uma solução por insight já haviam apontado para a importância das características de superfície em seus achados experimentais. No clássico problema das “jarras de água”, ele apresentou aos participantes três jarras que continham diferentes volumes e pediu para que os mesmos as utilizassem para medir uma específica quantidade de água. Os participantes que foram submetidos a um treinamento anterior ficaram "fixados" na estratégia de resolução mais complexa apresentada no treinamento e tiveram dificuldade de perceber um modo mais simples de resolver o problema. A configuração mental construída pelos 
indivíduos após o treinamento parece ter criado uma "rigidez funcional” em uma estratégia mais difícil que dificultou a transferência para um outro problema análogo que demandava uma estratégia mais simples de resolução. Apesar de essa solução mostrar-se mais dispendiosa, foi também adequada ao problema apresentado e, nesse sentido, não houve uma transferência negativa "típica". Entretanto, de modo análogo aos estudos de Ross (1987) e de Novick (1988) que apresentaram achados de que as características de superfície poderiam favorecer, em alguns casos, a transferência negativa, os estudos de Luchins (1942) parecem corroborar a importância das características de superfície na representação do problema e na escolha de uma solução que, apesar de adequada, mostrou-se mais difícil e dispendiosa, sendo, de certo modo, “contraproducente” para o problema em questão.

Concluimos assim que as características de superfície dos problemas como, por exemplo, os conteúdos dos enunciados, poderiam, por um lado, favorecer a transferência positiva de problemas isomórficos e, por outro lado, em casos onde houvesse uma dessemelhança entre as estruturas profundas dos problemas e/ou um aprendizado anterior que fixasse um tipo de estratégia e/ou uma determinada solução, poderiam favorecer a transferência negativa. Entretanto, fatores tais como a perícia dos indivíduos em um dado domínio, o grau de dificuldade dos problemas e a presença ou ausência de “dicas” dos experimentadores, a construção de um esquema da aprendizagem apropriado, dentre outros, poderiam auxiliar no incremento da transferência positiva como um todo.

Podemos observar também que problemas de diferentes naturezas, incluindo-se os problemas mal-definidos, como o da radiação de Duncker e versões análogas desse problema, poderiam sofrer a influência da semelhança/ dessemelhança entre os conteúdos dos enunciados, bem como sofrer a influência de outros tipos de características de superfície.

As analogias espontâneas são mais observadas, como muitos achados de pesquisas parecem apontar, quando há uma maior similaridade entre as características de superfície, especialmente quando há uma semelhança entre os enunciados dos problemas, do que quando não há este tipo de similaridade (p.e. Holyoak \& Koh, 1987, dentre outros). Nessa perspectiva, os processos iniciais de "acesso" às informações contidas nos problemas e a "rapidez" da sua solução e transferência poderiam sofrer a influência das semelhanças entre os conteúdos semânticos que revestem os enunciados dos problemas (dentre outras características de superfície) que estão sendo processados. 
Embora as similaridades estruturais possam ser definidoras do caráter analógico de duas situações-problemas, tendo especial impacto em estágios mais profundos do processamento analógico, as similaridades de superfície, em particular os conteúdos dos enunciados dos problemas, podem ter efeitos significativos especialmente nos estágios iniciais de acesso às informações da memória e na representação inicial do problema pelos indivíduos.

Entretanto, cabe mencionar alguns estudos como os de Catrambrone (2002) que sinalizaram para o fato de que parece haver, na literatura da área, certo desacordo quanto à contribuição das características de superfície e das características estruturais na recuperação/ acesso de um problema análogo ‘fonte”. De acordo com esse autor, uma das limitações de alguns estudos tradicionais na área, como, por exemplo, os de Gentner, Ratterman e Forbus ( 1993), refere-se à maneira como estas características são manipuladas experimentalmente por estes estudos. Catrambone, ao propor em seus experimentos, uma manipulação mais sistemática do número de características de superfície e do número de características estruturais que se correspondem em determinadas histórias, apresentou achados que parecem sugerir que ambos os tipos de características poderiam influenciar a recuperação inicial de um análogo “fonte”.

Nesse sentido, então, Catrambone (2002), ao manipular, por um lado, o “tipo” de característica (superficial ou estrutural) e por outro lado, o "grau” (número) de correspondências entre as características nas histórias, bem como ao avaliar o "tipo” de relação (de "baixa ordem” ou de “alta ordem”) que estas características estabelecem entre si, pôde avaliar os efeitos relativos de cada tipo de característica nos processos iniciais de acesso.

Conforme sinalizou Catrambone, as correspondências, envolvendo relações de "primeira ordem” entre as histórias, seriam aquelas relacionadas com certa correspondência de predicados de "baixa ordem” como, por exemplo, “atirar” e “disparar”, sendo que, nesse caso, as histórias teriam poucas semelhanças em suas características de superfície, como, por exemplo, “caçador e flecha”; “país e míssil”. Já as correspondências baseadas na similaridade das características de superfície seriam aquelas em que as histórias compartilhariam relações de predicados de baixa ordem, bem como semelhanças de entidades que envolveriam essas relações como, por exemplo, “caçador e falcão”; “desportista e águia”. Por sua vez, as correspondências baseadas nas relações de “alta ordem” seriam vistas naqueles casos em que as histórias possuiriam relações de primeira ordem, assim como uma nítida relação 
causal/estrutural, mas não apresentariam semelhanças em suas características de superfície (p. e. no caso das histórias do caçador e da flecha e do país e do míssil, ambas poderiam ser construídas tendo uma estrutura profunda similar, envolvendo um ataque, um fracasso do ataque, uma promessa de que não haveria um outro ataque, etc.)

Em alguns dos experimentos relatados por Catrambone (2002), houve a manipulação das características de superfície, relações estruturais e relações de baixa e alta ordem entre os predicados. Por exemplo, foram manipuladas entidades do problema da radiação e entidades de alguns de seus análogos, como o problema do dentista que apresentava um cisto que deveria sofrer radiação à laser. Nesses problemas manipularam-se entidades como: “médico, raios e tumor”; “dentista, laser, cisto” ou “dentista, ultra-som, dente”, etc. De modo complementar, foram igualmente manipuladas relações estruturais como "não causar danos, destruir, enviar”; "não machucar, separar, direcionar” ou "não ampliar, intensificar, direcionar”, etc. A manipulação de relações de baixa e alta ordem entre os predicados também aí se fizeram presentes.

Verificou-se nos estudos de Catrambone (2002) que o efeito relativo a cada tipo de correspondência entre as histórias seria diferenciado. Os resultados sugeriram que o impacto das características de superfície e dos predicados de baixa ordem se fez mais presente nos processos iniciais de recuperação de um problema análogo “fonte”, quando havia também uma relação de alta ordem (relações estruturais) entre os problemas análogos. Porém, quando não havia esse tipo de relação causal, os resultados sugeriram que as características de superfície ainda continuavam tendo efeitos nos processos iniciais de recuperação, enquanto as características relacionadas aos predicados de baixa ordem per se tiveram um efeito menos claro nesse contexto. Foi sugerido também, pelo autor, que o "número" de características de superfície ou de baixa ordem que se sobrepunha foi mais determinante do que o "tipo” de característica. E quando, além das relações de baixa ordem entre os predicados/ argumentos das histórias, havia a presença de relações de alta ordem (estruturais), ou seja, quando as relações estruturais “organizavam” o alinhamento dos predicados de baixa ordem, o processo de mapeamento analógico foi facilitado.

Já os estudos de Gentner, Ratterman e Forbus (1993), em contraposição aos achados acima de Catrambone, haviam inicialmente sugerido um menor impacto das características estruturais nos processos de acesso. Porém, estudos de Wharton, Holyoak, Downing, Lange, Wickens e Melz (1994), foram uns dos primeiros que 
apontaram para a necessidade de maior esclarecimento do papel das similaridades estruturais nos processos de acesso e de melhor entendimento de como se daria a “competição” entre as similaridades superficiais e estruturais nos estágios iniciais de recuperação de informações. Preenchendo esse espaço de pesquisa, Catrambone (2002) buscou assim investigar, de modo sistemático e controlado, o papel dessas similaridades.

Clement, Mawby e Giles (1994) também trouxeram contribuições para o entendimento do papel das similaridades na transferência analógica ao manipular similaridades relacionais entre problemas de domínios diferentes. Demonstraram, inclusive, que poderia haver uma "gradação" entre esses tipos de similaridades, ou seja, que algumas similaridades relacionais poderiam possuir características das similaridades de superfície e das estruturais. Seus achados sugeriram que mesmo quando as relações análogas eram embebidas em contextos dissimilares, a maneira como essas relações eram representadas nesses contextos poderia afetar a transferência analógica. Em outras palavras, a transferência foi facilitada quando as representações das relações entre os problemas análogos eram mais salientes (como as características de superfície costumam ser) e quando as mesmas requereram pouca re-representação da correspondência entre os domínios, isto é, pouca construção de novas representações. Por exemplo, o uso de termos de domínio geral que se aplicassem aos dois domínios facilitaria a transferência em oposição ao uso de termos de domínio especifico. Nessa direção, quando as similaridades relacionais tornavam mais salientes os aspectos comuns entre os problemas, pouca re-representação era necessária para “alinhar” as correspondências entre os mesmos. Os autores também sinalizaram que essas relações mais manifestas refletiriam um passo intermediário no processo de indução de esquema, pois seus achados sugeriram que o acesso aos análogos era facilitado quando as representações eram formadas em um nível intermediário de abstração.

No que diz respeito à nossa proposta de pesquisa, cabe uma observação de que a nossa ênfase no papel das tonalidades afetivas das histórias (características de superfície) na recuperação de um dos modos de solução (características estruturais) dos problemas "fonte” nos encaminha para uma direção um pouco diferente daquela seguida pelos autores citados nos últimos parágrafos. Inclusive os autores supra citados (Gentner e cols, 1993; Wharton e cols, 1994; Clement e cols, 1994; Catrambone, 2002), ao utilizar histórias análogas “neutras” em seus estudos, não pretenderam investigar o papel da tonalidade afetiva das mesmas nos processos iniciais de acesso. 
Poderíamos nos indagar se, caso este tipo de característica de superfície tivesse sido levada em consideração nesses estudos, os resultados talvez pudessem ter sido um pouco diferentes. Em outras palavras, a similaridade de características de superfície mais “neutras” como, por exemplo, de conteúdos semânticos mais neutros (por exemplo, os verbos “jogar" e "atirar") poderia ter, a nosso ver, menor "peso" nos processos de acesso do que a similaridade de conteúdos semânticos com uma nítida carga afetiva (por exemplo, os verbos “adoecer” e “desfalecer”). Acreditamos, inclusive, que há um espaço de pesquisa ainda pouco explorado no que a isso diz respeito e que, a nosso ver, mereceria, em um momento futuro, ser preenchido por estudos que trouxessem um melhor entendimento desse tipo de questão.

Concluímos assim que tanto as características de superfície como as estruturais parecem influenciar os processos iniciais de recuperação de informações, apesar de, tradicionalmente, ter sido creditado às similaridades de superfície um maior peso aos processos iniciais de acesso e um menor peso aos processos mais profundos como o mapeamento e, de modo inverso, ter sido creditado às similaridades estruturais um maior peso ao mapeamento e um menor peso aos processos de acesso. Podemos assim observar que estudos atuais na área vêm apontando para maior complexidade e maior interação e, consequentemente, menor polarização do papel dessas similaridades. De modo complementar, acreditamos que uma investigação que abordasse o papel da similaridade de tonalidade afetiva neste contexto poderia contribuir para enriquecer ainda mais as questões propostas na área.

A seguir, daremos continuidade aos fatores que intervém na ocorrência da transferência ao destacarmos a construção de um esquema de aprendizagem como um fator determinante para a facilitação da transferência analógica.

\subsection{3-Construção de um Esquema de Aprendizagem Apropriado}

Gostaríamos de salientar que se postula nesse trabalho a acepção de esquema como a proposta por Chi e Glaser (1992) e Sternberg (2000) que o consideram um constructo teórico que descreve um corpo organizado de conhecimentos, ou seja, uma estrutura cognitiva que representa conceitos inter-relacionados armazenados na memória. Em contraste à concepção de esquema pelos modelos simbólicos com sua ênfase em uma representação permanente e explícita, ou seja, com sua ênfase estrutural, a concepção de esquema pelos modelos PDP enfatiza, por sua vez, as representações temporárias e 
implícitas trazidas pela ativação/ inibição paralela de inúmeras características, como aquela proposta por Rumelhart (1991).

Hoje em dia, dependendo do domínio, novas concepções ou subdivisões do termo esquema vêm ampliando a conceituação inicial de Bartlett (1932) que propôs que os esquemas da memória organizam nosso conhecimento sobre o mundo de modo a interconectar cada evento ou objeto com uma organização interna, representacional. Termos como "scripts”, como na acepção de Schank e Abelson (1977), ao se referirem à organização de eventos seqüenciados temporalmente ou “node links”, como na acepção de Chi e Ceci (1987), ao se referirem à organização lexical das características semânticas do conceito, ilustram essa tendência.

Smith (1998), ao estabelecer uma relação entre conceito de representação mental e de esquema, definiu esquema como uma representação mental de larga-escala com uma estrutura interna significativa. Em outros termos, um esquema também poderia ser definido como uma estrutura cognitiva que está relacionada a um conhecimento abstrato e genérico que congrega diferentes instâncias particulares. Quando um esquema possui alto nível de "acessibilidade”, isso significa que ele pode ser prontamente ativado e usado. A principal função interpretativa de um esquema, para esse autor, seria a sua capacidade de afetar a interpretação das informações relacionadas ao mesmo, ou seja, determinado esquema poderia influenciar o julgamento e a avaliação de um objeto, indivíduo ou mesmo um conceito, bem como poderia influenciar o comportamento direcionado para esse objeto ou indivíduo. Um determinado esquema poderia assim influenciar a memória e as "pistas” contextuais de recuperação, tendo uma função reconstrutiva e, de certo modo, servindo, ele próprio, como fonte de algumas “pistas” de recuperação de informações. Seus efeitos são considerados como ocorrendo em um nível “pré-consciente”, pois os indivíduos não costumam ter consciência do processamento esquemático per se, mas apenas dos resultados desse processamento.

Na medida em que contém informações prototípicas, modelares, acerca de situações vivenciadas pelo indivíduo, o esquema é assim utilizado na interpretação e na integração de novos conhecimentos ao background anterior do mesmo. Entretanto, o esquema torna-se mais ativo quando há consonância entre a situação nova apresentada e as representações armazenadas na memória. Mas, caso não haja tal correspondência, o esquema pode funcionar como uma espécie de "programa” que dirige novas aquisições e adaptações ao longo do processo de resolução de problemas. Sendo assim, a construção de esquemas apropriados favorece positivamente a transferência analógica, 
sendo que diferentes níveis de abstração podem ser construídos no processo de transferência, desde níveis mais superficiais, por exemplo, semânticos, até níveis mais profundos, por exemplo, sintáticos.

Ainda no que se refere aos fatores que poderiam estar envolvidos em uma transferência analógica bem sucedida, Gick e Holyoak (1983) observaram que o sucesso nesse processo dependeria, em parte, da construção de uma representação adequada dos problemas “fonte” e "alvo”. Para estes autores, a construção de um nível de abstração apropriado dos problemas seria fundamental para uma transferência analógica bem sucedida, sendo o processo de tal construção por eles denominado de "esquema de aprendizagem”. Inclusive, de acordo com Gick e Holyoak (1980; 1983), Novick e Holyoak (1991) e Cummins (1992), a indução de esquema seria, na verdade, produto do pensamento analógico.

Outros trabalhos de Gick e Holyoak (1980), complementaram trabalhos anteriores de Kintsch e Van Dijk (1978) que, por sua vez, destacaram, no âmbito da compreensão de textos, a idéia de que processos de controle estariam envolvidos na seleção do nível de análise consistente com os objetivos dos indivíduos durante o processamento da informação. Gick e Holyoak assumiram a idéia de que um nível ótimo de abstração seria aquele em que as relações analógicas seriam representadas com o propósito de guiar efetivamente o processo de resolução de problema. Na opinião desses últimos autores, a determinação de quais fatores estariam influenciando esse nível ótimo de abstração seria uma importante questão empírica a ser considerada por muitas pesquisas na área.

Nesses estudos, Gick e Holyoak, ao relacionar o próprio conceito de esquema ao conceito de analogia, destacaram que ambos os conceitos se referem a um sistema organizado de relações na memória. Para os autores, o sistema de representação envolvido no pensamento analógico deveria ser capaz de descrever uma propriedade fundamental de um sistema relacional que seria aquela que propõe que a analogia deve ser definida em múltiplos níveis de abstração. Por exemplo, no caso do problema do general, problema esse análogo ao da radiação de Duncker, um nível mais baixo de abstração seria a variedade de detalhes de correspondência entre os dois problemas, como a correspondência entre os pequenos grupos de soldados (no problema do general) e os raios de baixa intensidade (no problema da radiação). Já um nível mais alto de abstração seria, nesse contexto, por exemplo, o objetivo de destruir o tumor (no caso do 
problema da radiação) ou o tirano (no caso do problema do general) que estariam localizados no interior de uma região que deve ser preservada e não destruída.

O esquema poderia ser então concebido, como na acepção de Gick e Holyoak (1983), como uma categoria abstrata que análogos particulares expressam de diferentes maneiras. Por exemplo, o objetivo de se chegar à meta, no caso do problema da radiação, é cumprido pela destruição do tumor e, no caso do problema “O General”, seu análogo, o objetivo é cumprido pela captura do forte. Essas “expressões” particulares de domínios específicos do mesmo esquema poderiam ser definidas como uma espécie de “estrutura que preserva diferenças” entre dois análogos. No caso do problema da radiação, a analogia médica poderia ser vista como a transformação do esquema de convergência em conceitos adequados ao domínio da medicina. No caso do problema do general, a analogia militar também pode ser vista como a transformação do mesmo esquema em conceitos adequados a esse domínio. Sendo assim, o esquema seria implicitamente “embebido” pelas particularidades de cada problema análogo. E, caso as identidades mapeadas sejam suficientes para a recuperação do esquema, suas relações causais não seriam afetadas por essas “expressões” particulares em domínios distintos do esquema.

Os autores acima, nesses mesmos estudos, destacaram assim os esquemas como importantes mediadores da transferência analógica. Eles distinguiram dois modos através dos quais determinado esquema poderia ser usado para a resolução de problemas que envolvem a recuperação de analogias. O primeiro deles seria quando um problema novo seria mapeado diretamente a partir de um análogo anterior com o objetivo de generalizar uma solução. Como as identidades mapeadas seriam mediadoras da transferência, o conceito de esquema não precisaria ser destacado como um conceito independente dos dois análogos. Os autores denominaram esse modo de mediação como um "raciocínio a partir de um análogo" (p. 9). O segundo modo de mediação, por seu turno, seria quando um esquema independente já teria sido induzido por um ou mais problemas análogos e estaria armazenado na memória. Nesse caso, os indivíduos poderiam mapear um novo análogo a partir do esquema já construído para obterem a solução. Esse modo de mediação foi denominado por Gick e Holyoak (1983) como sendo um "raciocínio a partir do esquema” (p.10). Inclusive, essa segunda forma de mediação seria a privilegiada pelos autores como a mais vantajosa para o pensamento analógico. 
Algumas evidências empíricas trazidas pelos primeiros desses estudos de Gick e Holyoak (1980) demonstraram que existe uma variação considerável no grau do mapeamento requerido para a generalização de uma solução análoga. Trabalhando com diferentes problemas análogos ao problema da radiação de Duncker, como o problema “O General” já mencionado, esses autores apresentaram inicialmente aos participantes o problema militar e posteriormente o da radiação. Em um dos experimentos, os participantes foram divididos em quatro grupos e foram submetidos a quatro condições experimentais na situação-problema "fonte": a condição onde recebiam a história do general com a solução de ataque/ dispersão (convergência); a condição onde recebiam essa mesma história com a solução da abertura de uma rota alternativa (não minada); a condição onde recebiam também a história do general e seu exército com a solução da construção de um túnel (embaixo das estradas minadas) e, por último, a condição do grupo de controle, onde nenhuma história anterior era apresentada. Na situaçãoproblema “alvo" era então apresentado o problema da radiação. Os resultados obtidos, através dos protocolos verbais utilizados, sugeriram maior freqüência da escolha da solução da história análoga relevante vista anteriormente em cada um dos três grupos experimentais. Já no grupo de controle, a solução de maior freqüência para o problema da radiação foi a da operação, não havendo nenhuma escolha da solução de convergência. Em outros termos, houve nos grupos submetidos à leitura inicial de uma versão da história “O General”, a nítida transferência e generalização da solução vista nesse problema para o problema da radiação.

O segundo experimento relatado pelos autores acima, nesse mesmo estudo, visou, por sua vez, investigar o grau do mapeamento requerido para a escolha de uma solução tendo como base uma história análoga. Nesse experimento, as histórias "fonte" e "alvo" foram apresentadas aos participantes em livretos para evitar possíveis efeitos da interação entre os participantes e o experimentador no processo de transferência. Apresentaram-se duas histórias "fonte" e os sujeitos foram divididos em três grupos: para um deles apresentou-se a história “O General” em sua versão de ataque/ dispersão (convergência), para o outro grupo, uma história sobre uma "Parada Militar”, em versão também com dispersão (convergência), sendo essa segunda história não análoga ao problema da radiação e, para o terceiro grupo, o de controle, nenhuma história.

Cabe observar que, essa última história, não tinha o objetivo de atacar um forte e nem havia o perigo de estradas minadas no caminho, mas apenas o objetivo de organizar a exibição das tropas do exército para um ditador. Sendo assim, não havia as 
“coações” do problema militar em sua versão mais conhecida (a de “ataque/dispersão”). Os resultados obtidos nesse experimento apontaram para uma maior transferência, bem como para a construção de um esquema de aprendizagem apropriado quando a analogia era mais efetiva isto é, quando havia maior grau de semelhança na estrutura profunda das histórias análogas pareadas, no caso as histórias do general na versão ataque/ dispersão e o problema da radiação. Isso ocorria mesmo quando as histórias “fonte” eram similares em termos dos seus enunciados, como foi o caso das histórias apresentadas. De modo complementar, a falta de um feedback do experimentador durante a testagem parece não ter afetado de modo significativo a transferência analógica.

Em três estudos complementares, Gick e Holyoak (1980) investigaram, em um deles, a evocação de soluções próprias pelos participantes, diferentes daquelas propostas nas histórias “fonte”, e, nos outros dois, o uso de “dicas” de recuperação em contraposição à transferência analógica espontânea (sem “dica”). É de particular interesse para nossa pesquisa destacar que uma das soluções mais comuns evocadas espontaneamente pelos sujeitos para o problema “O General” nesses estudos é aquela que propõe o envio sucessivo de pequenos grupos de soldados por um único caminho até o forte. Essa solução que supõe um efeito “acumulativo”, de certo modo semelhante à solução da abertura de um túnel proposta por Duncker (1945), foi, de modo análogo, transferida para o problema da radiação com a proposta do uso de raios seqüenciais em intervalos de tempo sucessivos para destruir aos poucos o tumor. Apesar de suas limitações por ser uma solução que também supõe um efeito acumulativo e danoso nos tecidos corporais sadios por onde passam os raios sequencialmente, parece ter a vantagem de ser espontaneamente evocada, talvez pelo fato de ser facilmente imaginada nos modelos mentais construídos pelos indivíduos. Inclusive, a nosso ver, a solução de convergência que, em tese, seria a mais eficaz e mais “criativa” para o problema da radiação, segundo Duncker, parece também apresentar limitações de outras naturezas, por exemplo, limitações “pragmáticas”, pois o acesso a múltiplas fontes de radiação simultâneas não costuma ser comum mesmo no contexto médico.

Em um dos seus estudos posteriores com o problema da radiação e seus análogos, Gick (1990) encontrou resultados que sugerem ter havido certa "competição", na situação-problema “alvo”, entre a solução de convergência e a solução serial aprendidas na situação-problema “fonte”. Manipulando, por um lado, similaridades nos conteúdos semânticos das histórias dos problemas e, por outro, similaridades nas operações 
conceituais e nos modos de solução desses problemas, essa autora propôs quatro condições experimentais na situação-problema “fonte”. Na primeira condição, foram apresentadas duas histórias que continham a solução de convergência, mas que possuiam conteúdos semânticos distintos (as histórias “O General” e “A Epidemia”). Na segunda condição, foram apresentadas três histórias: as duas primeiras histórias já mencionadas e uma outra semanticamente parecida com a história “O General” (denominada "O Ataque”), mas que continha solução que envolvia uma rota serial. Na terceira condição, por sua vez, foram apresentadas as duas primeiras histórias (com solução de convergência) e uma terceira história que diferia das primeiras nos conteúdos semânticos e no modo de solução (denominada “Os Negociantes de Vinho”). A quarta condição foi a do grupo de controle, onde não houve a apresentação de nenhuma história "fonte”. Alguns dos resultados encontrados sugeriram que, no grupo submetido à segunda condição experimental, houve certa “competição” entre a solução convergente e a solução serial aprendidas. Em outras palavras, a semelhança nas “coações” dos três problemas "fonte" parece ter favorecido, tanto a transferência da solução convergente, quanto da solução serial, para o problema “alvo” proposto (o problema da radiação).

Na pesquisa realizada por nós também fornecemos a solução de convergência em uma das histórias “fonte” e a solução serial em outra história. Essas duas soluções foram privilegiadas em nosso estudo, pois além de possuir vantagens e limitações, a nosso ver equiparadas, como as já referidas, também apresentaram boa equivalência em termos de escolha no estudo piloto que realizamos com o intuito de investigar se essas soluções seriam equivalentes entre si (anexo 3).

No que se refere à importância do fornecimento de “dicas" durante a tarefa experimental, foco dos outros dois experimentos supracitados, cabe observar que houve um aumento significativo na transferência nas condições experimentais onde eram fornecidas “dicas” de recuperação. Esses resultados parecem sugerir, conforme Gick e Holyoak (1980) sinalizaram, que um dos maiores "bloqueios” para uma transferência bem sucedida é a recuperação espontânea de um análogo “fonte” relevante. Nesse sentido, o declínio no desempenho da transferência observado em seus experimentos não poderia ser assim atribuído a uma falha na codificação de um análogo "fonte”, mas sim a uma falha no processo de recuperação, pois o uso de “dicas” favoreceu o mapeamento/ comparação entre os análogos e, consequentemente, fez com que houvesse aumento bastante significativo na transferência. Inclusive, Maier (1931), no 
passado, já havia apontado para a importância do uso de “dicas” na facilitação do insight da solução pendular no clássico problema dos “Dois Fios”. Nossa pesquisa também se encaminha nessa direção ao fornecer “dicas” explícitas, por escrito, para a recuperação de um dos problemas análogos “fonte” na situação problema-alvo.

Em uma de suas conclusões, Gick e Holyoak (1980) destacaram o processo de mapeamento analógico como de fundamental importância para uma boa generalização e abstração de esquemas. O uso de analogias envolve assim mapear as representações de dois ou mais problemas umas em relação às outras. Processos similares poderiam também estar envolvidos na abstração da “relação comum”, ou seja, da estrutura profunda compartilhada por uma série de análogos. Em seus estudos, os indivíduos que tiveram contato com vários problemas “fonte” análogos ao da radiação foram capazes de generalizar um esquema a partir de problemas com a solução de “dispersão”.

Esse esquema, como destacado pelos autores, presumivelmente seria estruturado como uma instância "concreta” de um problema de dispersão, com exceção de seus predicados e argumentos que seriam mais abstratos. Em outras palavras, os indivíduos que tivessem construído esse esquema geral poderiam resolver novos problemas do tipo “dispersão” através de mapeamento direto com o próprio esquema e não mais com um dado problema análogo específico. Processos similares de mapeamento de esquemas de outros tipos seguiriam os mesmos "passos": primeiro, comparando uma instância com outra (entre dois ou mais problemas); segundo, derivando um esquema para uma classe ou "tipo" de instâncias e, terceiro, comparando uma determinada instância com um esquema geral já construído. Nota-se aqui um duplo movimento que parte do particular/ concreto para o geral/ abstrato e vice-versa, pois estruturas abstratas como os esquemas são construídos a partir de instâncias/ exemplos concretos e depois são novamente aplicadas a novas instâncias que surgem. Nesse sentido, então, o processo de transferência analógica envolve não apenas processos de indução, mas também processos de categorização e de dedução.

Em estudos posteriores, Gick e Holyoak (1983) buscaram dar continuidade à investigação dos processos envolvidos na indução de esquema a partir da apresentação de um ou mais análogos “fonte”. Em um dos seus experimentos também utilizaram, como problema “fonte”, o problema "O General” e, como alvo, o problema da radiação. Três condições experimentais foram manipuladas por eles: uma, onde o problema militar era apresentado sozinho, outra, em que o problema militar era acompanhado pela apresentação de um princípio que explicitava a solução de convergência e uma 
condição onde era apresentado apenas esse princípio, sem o problema anexado. O fornecimento de "dicas" de recuperação ocorreu em cada uma das condições experimentais. Os resultados apontaram para uma equivalência na taxa de transferência entre os três grupos submetidos às três condições distintas, ou seja, o acréscimo do princípio ao problema análogo “fonte” não favoreceu o aumento da transferência e mesmo na condição "fonte” da apresentação do principio sozinho, os resultados foram semelhantes. Sendo assim, a simples adição de um princípio explicativo a um problema análogo parece não garantir que um esquema abstrato será mais bem construído.

Estudos recentes de Kurtz e Loewenstein (2007) também utilizando o problema da radiação e seus análogos, o problema do general e o problema do bombeiro, sugeriram que a transferência analógica era facilitada quando havia a instrução de comparação de dois análogos não resolvidos na situação-problema “alvo”. Na medida em que as soluções dos problemas “fonte” não eram apresentadas, a boa transferência encontrada foi atribuída à formação de um "esquema do problema” e não à formação de um “esquema de sua solução”, isto é, não foi atribuída à apreensão do principio de convergência ou da estratégia de resolução. Assim, verificou-se que a comparação de dois análogos na situação de teste (“alvo”) facilitava sobremodo a recuperação de um análogo "fonte” e, para os autores, isso apontou para o fato de que a generalização do esquema se daria no processo de recuperação e não no processo de codificação e de armazenamento, ou seja, se daria na situação-problema “alvo”/ teste e não na situaçãoproblema "fonte".

Essa hipótese parece recuperar a antiga idéia de Tulving e Thomson (1973) de que a qualidade de uma correspondência entre duas situações-problema se daria prioritariamente em função da codificação do problema em curso (“alvo”) e não tanto da recuperação do problema “fonte” per se. Porém, muitas pesquisas na área, como as de Gick e Holyoak (1983), Catrambone e Holyoak (1989), Ross e Kennedy (1990), parecem atribuir um papel importante ao problema "fonte” e às suas condições de codificação e de armazenamento para o processo de transferência. Essa questão, a nosso ver, permanece não conclusiva, merecendo pesquisas que manipulem outras variáveis, inclusive a tonalidade afetiva dos problemas, para a verificação dos seus efeitos em conjunto com os efeitos da instrução de comparação de problemas "alvo" não resolvidos.

Gick e Holyoak (1983), em outro experimento complementar com uso do problema da radiação e o problema militar, utilizaram procedimentos e condições experimentais 
semelhantes aos do experimento anterior, mas com uso de diagramas anexados às histórias dos problemas no lugar da apresentação de princípios. Um desses diagramas apresentava uma seta larga que representava um conjunto de forças direcionadas para um único ponto e o outro apresentava seis setas finas que partiam de diferentes pontos e convergiam para um mesmo ponto. Eram assim diagramas que representavam visoespacialmente dois princípios de solução, um deles representando uma solução que não deveria ser aplicada ao problema da radiação e o outro representando a solução desejada. Os achados desse experimento também demonstraram que a apresentação do problema militar "fonte" junto com os dois diagramas que representavam a solução desejada e a solução a ser evitada não aumentou a transferência dos indivíduos. Houve assim, como no experimento anterior, uma equivalência nos resultados dos dois grupos que viram o problema militar com e sem os diagramas. Não obstante, o grupo submetido à apresentação dos diagramas sozinhos, sem a história do problema, obteve um desempenho discrepante. A baixa transferência espontânea apresentada por esse grupo sugeriu que a falta de “dicas” semânticas dos enunciados do problema "fonte”, que ajudariam a “conectar” o problema da radiação (alvo) com a solução do diagrama, afetou diretamente a transferência.

Como conclusão, os autores observaram que, ao invés dos diagramas terem favorecido uma maior abstração na interpretação das histórias, foram as histórias que favoreceram uma interpretação mais específica dos diagramas. Assim sendo, a apresentação dos diagramas sozinhos não encorajou a abstração do esquema de convergência. A importância dos conteúdos semânticos dos problemas para a interpretação e aplicação de sua solução fica aqui nitidamente demonstrada.

Em pesquisa posterior, Gick (1985) também investigou os efeitos da apresentação de diagramas em histórias análogas à da radiação na transferência com e sem “dicas” de recuperação. Os seus achados sugeriram uma boa transferência espontânea, sem “dicas” do experimentador, quando os diagramas eram anexados para ilustrar a solução do problema. O fornecimento de “dicas” explícitas de recuperação, por parte do experimentador, também favoreceu a transferência dos sujeitos que não transferiram o princípio da solução espontaneamente. Seus achados complementaram os achados anteriores de Gick e Holyoak (1983), demonstrando que a transferência espontânea, a partir da leitura de uma única história, poderia ser aumentada com a apresentação de um diagrama (“pista” visual) também na situação-problema “alvo” (resolução do problema da radiação). Um questionário apresentado no final da sessão trouxe informações 
adicionais para se saber se houve o uso das “dicas” fornecidas pela experimentadora. Implicações educacionais relativas à maneira de se apresentar problemas para o aprendizado de seu princípio/ solução, bem como a importância do uso de “dicas” de recuperação de analogias também foram consideradas. Trabalhos posteriores dessa autora (1992) apontaram, de modo complementar, para a importância do uso pedagógico de analogias para facilitar a resolução de problemas que apresentam persistente dificuldade em sua resolução. Nesses casos, a resolução de problemas poderia ser favorecida pela correção de possíveis erros de representação dos problemas durante a fase de treinamento/aprendizagem.

Estudos de Grant e Spivey (2003), que também utilizaram diagramas para apresentar o problema da radiação de Duncker, objetivaram, por sua vez, investigar a atenção visual, medida através dos movimentos oculares, durante o processo de resolução de problema. Seus resultados sugeriram que os movimentos oculares parecem não só refletir o processamento da informação que ocorre durante a resolução de problema, como também sugeriram que a priorização de alguns aspectos dos diagramas guiou a atenção dos solucionadores, facilitando a resolução correta do problema. A ênfase na interação entre os processos mentais internos envolvidos e a situação instrucional/ ambiental do problema, bem como a ênfase na relação entre os processos cognitivos e motores foram a tônica desses estudos.

Em estudo recente, Helfenstein e Saariluoma (2006) também apresentaram diagramas semelhantes aos acima descritos para investigar a interação entre os modelos mentais construídos pelos indivíduos e os conteúdos das representações (imagens/ diagramas) apresentados na tarefa experimental. Ao estudar a transferência analógica utilizando o problema da radiação de Duncker e o papel dos conteúdos mentais na transferência, apontaram para a importância da existência de um maior número de pesquisas que possuam uma abordagem "baseada nos conteúdos” das representações mentais dos indivíduos, pois, a seu ver, uma abordagem "baseada em esquemas", sozinha, tem se mostrado insuficiente para explicar as diferenças dos conteúdos mentais dos indivíduos, bem como as diferenças entre os contextos onde estes se situam.

Estes autores focalizando, em seus estudos, os modelos de pensamento que os indivíduos traziam para a situação experimental, fizeram uma contraposição entre os conteúdos destes modelos de pensamento individuais e os conteúdos das representações do problema (imagens) apresentadas na tarefa experimental “alvo” propriamente dita. 
Na situação-problema “fonte”, os autores apresentaram aos indivíduos três tipos de modelos mentais (aditivo, balanceado e “distribuído”) e na situação-problema “alvo” dois tipos de diagramas com imagens espaciais dos raios (compacta ou divergente). $\mathrm{Na}$ concepção destes autores, o chamado modelo de pensamento aditivo pressupõe a idéia da soma de uma série de inputs individuais, já o modelo balanceado pressupõe, por sua vez, a média de inputs individuais e, por último, o modelo “distribuído” pressupõe uma confluência de inputs onde o todo final é visto como maior que a soma de suas partes individuais (modelo não-aditivo que, a nosso ver, poderia ser considerado também “gestáltico”).

Os achados experimentais apontados por Helfenstein e Saariluoma (2006) parecem sugerir que os conteúdos dos modelos de pensamento teriam um efeito decisivo no "modo" como as pessoas pensam. Foi encontrada uma interação significativa entre os modelos mentais e as imagens dos raios, ou seja, os resultados apontaram para a influência conjunta desses dois fatores. Sendo assim, podemos observar uma interação entre o modo de solução apresentado na tarefa experimental “alvo” (imagem dos raios) e o modo de pensar (modelo mental) dos indivíduos, modelo este que, por sua vez, também pode ser visto como “induzido” pela situação-problema “fonte”.

Nesse sentido, podemos observar uma interação entre os conteúdos das variáveis experimentais e os conteúdos das variáveis individuais. Em outras palavras, podemos concluir que a chamada “abordagem baseada em conteúdos”, proposta por estes autores, parece complementar, de modo significativo, a tradicional abordagem baseada em “esquemas”, típica dos autores anteriormente referidos, pois parece focalizar, mais diretamente, a complexidade da interação entre os conteúdos das representações mentais individuais e os conteúdos das representações utilizadas/induzidas pela tarefa experimental.

No que diz respeito à utilização do problema da radiação de Duncker em nossa pesquisa, vale observar que a metodologia proposta, bem como os objetivos de nossa pesquisa foram configurados de modo diferenciado daqueles propostos na pesquisa de Helfenstein e Saariluoma. Como apresentamos, na situação-problema "fonte”, apenas dois modos de solução (serial e convergente), ambos compreendendo raios singulares, houve assim a exclusão de outros modelos mentais alternativos e a focalização em um único modelo mental que poderia ser considerado "aditivo”. Como observaram os autores acima, o chamado "modelo mental aditivo" costuma ser, inclusive, o mais frequentemente evocado pelos indivíduos. 
Nessa direção, o uso de raios seqüenciais, de efeito acumulativo, ou o uso de raios simultâneos e convergentes, de efeito imediato, pressupõem, a nosso ver, a idéia de que a soma de raios (seqüenciais ou convergentes) vá alcançar o efeito desejado e, consequentemente, a solução do problema, através de duas maneiras possíveis e eficazes. Como na nossa situação-problema “alvo" consta o pedido para que os indivíduos escolham apenas uma das soluções vistas na situação-problema “fonte”, acreditamos que assim haverá o controle de outras possibilidades de representação mental e, consequentemente, um maior controle dos “conteúdos” mentais trazidos pelos indivíduos.

Cabe lembrar que a pesquisa aqui apresentada busca investigar, especialmente, os efeitos da tonalidade afetiva das histórias dos problemas na escolha de um dos modos de solução do problema “alvo”, sendo que Helfenstein e Saariluoma não investigaram este tipo de efeito em sua pesquisa. Acreditamos, inclusive, que uma investigação que focalizasse a influência da tonalidade afetiva de problemas análogos ao da radiação em um contexto onde houvesse a apresentação de diferentes modelos mentais na situação “fonte” e de diferentes representações/imagens espaciais, na situação “alvo”, pudesse trazer interessantes achados sobre a interação entre a tonalidade afetiva de um dado problema e o tipo de modelo mental construído pelo indivíduo. Nesse sentido, observamos um espaço de pesquisa ainda pouco explorado nessa esfera e que poderia vir a complementar, a nosso ver, os achados dos autores acima que, por sua vez, se referem apenas a problemas “neutros” da radiação de Duncker. Porém, a nossa pesquisa, como foi visto, se encaminha para outra direção.

Em suma, quando pensamos na construção de um esquema de aprendizagem apropriado, vale lembrar que as "dicas” semânticas de recuperação de um problema análogo "fonte” costumam guiar os processos de acesso às informações armazenadas na memória. Sendo assim, quando há dessemelhança semântica entre dois problemas análogos e, normalmente, isso acontece quando os análogos são de domínios distintos, haveria a falta dessas “dicas” que favoreceriam a transferência. Nesse caso, as ligações potenciais entre os análogos seriam as identidades estruturais compartilhadas por ambos, identidades essas que contém o esquema implícito “embebido” em cada problema análogo. Mas, se não tiver havido a abstração de um esquema apropriado, o processo de transferência torna-se mais difícil nesse contexto.

É importante ainda complementar, como posteriormente observaram Holyoak e Koh (1987), que haveria assim, no contexto da transferência analógica, a indução de um 
esquema explícito, a partir de exemplos iniciais (se for mais de um exemplo, maior a chance de abstração, como os estudos anteriores de Gick e Holyoak, 1983, já haviam apontado), de um tipo específico de problema, com informações mais gerais sobre seus objetivos, conteúdos, etc, esquema este que, como vimos, facilitaria a transferência inter-domínios. Nesse sentido, a apresentação de vários exemplos análogos poderia favorecer a construção de um esquema de aprendizagem apropriado e, consequentemente, favorecer a transferência entre domínios. Implicações educacionais e didáticas importantes poderiam, inclusive, daí advir, na medida em que o uso de vários exemplos análogos em um dado domínio poderia favorecer a transferência interdomínios. Nessa direção, também as evidências trazidas por diferentes estudos no âmbito da transferência analógica com problemas de domínios como a matemática, como aqueles de Ross (1987; 1989), Ross e Kennedy (1990), Ross e Warren (2002), destacaram a importância da apresentação de vários exemplos para o favorecimento da construção de esquemas de aprendizagem em um domínio.

Em alguns de seus experimentos Ross (1987) argumentou, a partir dos seus achados, que o uso de vários exemplos análogos poderia favorecer mais significativamente a transferência do que uso de “dicas” para a abstração do princípio de um problema. Em outros termos, a contextualização de princípios/ fórmulas de probabilidade, através de exemplos, na situação-problema "fonte", teve maior impacto na transferência do que a mera apresentação dos princípios isolados, ainda que os últimos tivessem "dicas” explícitas de recuperação na situação-problema “alvo”. Nessa perspectiva, podemos inferir que a construção de um esquema de aprendizagem apropriado seria fortemente favorecida pelas características de superfície que contextualizam os princípios/ estruturas profundas dos problemas.

Chen e Mo (2004) também investigaram a construção de esquema na resolução de problemas análogos. Através de experimentos que apresentaram problemas análogos ao clássico problema das “jarras de água” de Luchins (1942), os autores buscaram variar as características procedimentais da cada problema análogo apresentado. Seus achados sugeriram que a exposição a vários procedimentos diferentes em problemas análogos "fonte” facilitou a construção de um esquema geral que permitiu uma boa transferência para um problema “alvo” que demandava um novo procedimento em sua solução. Em contraste, os participantes submetidos a pouca variação de procedimentos nos problemas "fonte" apresentaram dificuldade de transferir a solução para um problema “alvo” que demandava um novo procedimento. Em outros termos, nesse último caso, 
parece ter havido uma “fixação” em determinados esquemas anteriores ("set” mental) em contraposição à construção de esquemas mais flexíveis e mais gerais que ocorreu frente à apresentação a uma variedade de problemas com diferentes procedimentos e mesma estrutura profunda. Esses estudos mais atuais de Chen e Mo (2004) complementaram estudos anteriores de Chen (1996; 2002), com crianças, que, por sua vez, também destacaram a importância das “coações” procedimentais durante o processo de transferência analógica.

Achados recentes de Norman, Dore, Krebs e Neville (2007) também apontaram para o incremento da transferência analógica quando havia a apresentação de vários exemplos análogos no domínio da cardiologia. Em seu experimento, os grupos foram submetidos ao aprendizado de conceitos nesse domínio, sendo que para alguns participantes houve apenas uma explicação fisiológica e para outros, uma explicação fisiológica acompanhada por uma explicação mecânica. Os grupos, que leram inicialmente apenas um tipo de explicação, tiveram pior desempenho na aplicação dos conceitos aprendidos quando diante de problemas médicos em contraposição aos grupos que leram as duas explicações. Esses autores fizeram uma ressalva a uma prática médica comum que seria a de apresentar aos alunos apenas um caso clínico após a apresentação de um conceito teórico e/ou a de apresentar uma seqüência de instruções, sem que fosse incentivada uma busca ativa da estrutura profunda conceitual compartilhada por vários problemas ou casos clínicos. Nessa direção, aspectos instrucionais que incorporem a ilustração de conceitos com muitos exemplos podem facilitar a transferência de aprendizagem de modo significativo no contexto acadêmico.

Complementando trabalhos anteriores de Holyoak e colaboradores (Gick \& Holyoak, 1980; Gick \& Holyoak, 1983; Holyoak \& Koh, 1987), Catrambone e Holyoak (1989), mencionando alguns dos resultados de seus experimentos, em comparação com outros achados, concluíram que a qualidade do esquema construído é um fator de predição para uma transferência adequada. Para esses autores, a qualidade do esquema seria medida através das descrições de similaridades, especialmente estruturais, entre problemas, sendo que quanto mais extensa for a descrição destas similaridades melhor será a qualidade do esquema construído.

Assim, uma boa abstração de um esquema, não só pode favorecer uma transferência eficaz, como também pode ser vista, como propõe Anderson (1983), como base para o processo de automação, ou seja, base para a transformação de esquemas com conhecimentos declarativos em esquemas com conhecimentos procedimentais. 
Diferentes trabalhos de Anderson (1983; 1987a; 1987b) e de Anderson e colaboradores (Anderson, Conrad \& Corbett, 1989; Anderson \& Fincham, 1994) corroboraram essa ênfase nos processos de automação e no treinamento para aquisição de perícia, inclusive com uma proposta computacional (ACT: “Adaptative Control of Thought”, 1983) que simula os passos e as computações envolvidos nesse processo.

No que se refere à resolução de problemas, uma das principais fraquezas do programa "GPS” de Newell e Simon, analisado em seção anterior, seria atribuída à falta do conhecimento de domínio em suas computações como alguns dos trabalhos de Anderson e colaboradores apontaram. Com ênfase na especificidade de domínio, esses últimos autores têm trazido inúmeras contribuições não só para a simulação computacional dos processos envolvidos na aquisição de perícia, mas também para a construção de uma "arquitetura cognitiva” mais ampla, uma espécie de "linguagem comum” capaz de unificar diferentes trabalhos desenvolvidos na área.

Em síntese, a importância da construção de um esquema de aprendizagem apropriado que seja capaz de se manter com o decurso do tempo parece ser um dos fatores mais importantes na facilitação da transferência analógica. A qualidade do esquema construído pode ser favorecida por instruções deliberadas durante o processo ensino-aprendizagem e pela apresentação de exemplos de modo sistemático que suscitem uma boa abstração/ generalização do conhecimento. A detecção de similaridades, especialmente de similaridades relacionais/ estruturais, entre duas ou mais situações-problema também se soma à construção de um esquema apropriado, e, de certo modo, determina em parte essa construção. Não obstante, as similaridades de superfície têm importante papel na construção de um esquema apropriado de aprendizagem, pois permitem uma contextualização e melhor comparação entre análogos, bem como melhor entendimento da aplicação de princípios e fórmulas que costumam ser formais e abstratos per se.

Vale observar que, em nossa pesquisa, na primeira sessão, há o pedido para que todos os participantes respondam a um questionário, após a leitura de cada uma das história “fonte", para que o aprendizado do modo de solução de cada problema seja reforçado. Este questionário tem o objetivo de auxiliar na focalização da atenção nos aspectos relevantes das histórias, aspectos estes não só relativos ao modo de solução de cada problema “fonte”, mas também relativos às tonalidade afetivas das histórias (vide anexo 5) 
Na situação problema “alvo” também consta, nas instruções do problema, o pedido para que os participantes explicitamente evoquem um dos modos de solução visto na primeira sessão (“fonte”). Em outras palavras, há o fornecimento de uma “dica” explícita que pode auxiliar os participantes no processo de transferência. Entretanto, como será visto posteriormente, como há a possibilidade "lógica” (“estrutural”) da aplicação no "alvo" dos dois modos de solução vistos na situação-problema "fonte”, a tonalidade afetiva da história do problema “alvo" será, a nosso ver, o fator determinante na escolha de um dos modos de solução.

Acreditamos que a apresentação, na situação-problema "fonte”, de um questionário e o fornecimento, na situação-problema “alvo”, de uma “dica” para que os participantes evoquem um problema “fonte” análogo, irão contribuir para a construção de um esquema de aprendizagem apropriado e, consequentemente, irão favorecer a transferência analógica. Um estudo piloto realizado anteriormente apontou para essa mesma direção, isto é, a boa transferência encontrada nesse estudo prévio parece ter sido favorecida pela apresentação de um questionário na situação-problema "fonte” e pelo fornecimento de “dicas” de recuperação na situação-problema “alvo” (anexo 3).

2.4.4-Transferência Analógica e Similaridade de Contexto: a Facilitação da Transferência Analógica pela Semelhança de Contextos

Vale ainda destacar que outras características consideradas de superfície como, por exemplo, os diferentes contextos onde são apresentadas as situações-problema “fonte” e “alvo” poderiam também influenciar o processo de transferência. Nesse caso também se aplica a mesma regra relativa à similaridade de conteúdos: quanto maior a similaridade de contextos, maior a chance de uma melhor transferência.

Spencer e Weisberg (1986), e Catrambone e Holyoak (1989) sinalizaram para o fato de que a dissimilaridade entre os contextos das situações-problema "fonte" e "alvo" poderia afetar de modo significativo a transferência analógica. Porém Spencer e Weisberg (1986) manipularam o contexto onde ocorria as sessões experimentais e Catrambone e Holyoak manipularam a mudança de contexto com a interposição de uma tarefa de uma outra disciplina. Entretanto, como foi visto, quando os indivíduos eram submetidos a uma aprendizagem mais explícita com ajuda de instruções de comparação de problemas, de “dicas” de recuperação, dentre outras condições experimentais, as diferenças entre os contextos não chegaram a afetar de modo significativo a 
transferência, provavelmente em função da construção de um esquema apropriado de aprendizagem.

No que se refere a nossa pesquisa, podemos observar que o local da testagem foi o mesmo em ambas as sessões experimentais. Acreditamos que a manutenção desse tipo de similaridade possa facilitar, em parte, o processo de transferência. Mas também acreditamos que outros fatores importantes, já mencionados, tais como o fornecimento de “dicas”, o uso de questionário para garantir a aprendizagem, o uso de termos equivalentes para descrever os problemas análogos, dentre outros fatores, possam ter efeitos mais significativos no processo de transferência.

Não obstante, há que se observar que nem sempre a similaridade de contexto parece facilitar a transferência analógica, pois dependendo do objetivo da pesquisa e do tipo de manipulação experimental proposta, essa similaridade seria vista como podendo ter efeitos negativos na transferência. Nessa direção, evidências empíricas de Hesse e Klecha (1990) sugeriram, por um lado, que a similaridade de contexto facilitava a deteç̧ão da relevância de um determinado problema "alvo”, quando o mesmo era entremeado a problemas irrelevantes. Porém, em contrapartida, havia também, nesse caso, uma maior dificuldade de abstração e de transferência do princípio visto na situação-problema “fonte”. E, como observaram os autores, a ausência das “pistas” de contexto poderia apresentar algumas vantagens como, por exemplo, menos interferências causadas pela similaridade, bem como o incentivo a uma maior abstração da estrutura profunda do problema. Vale observar que, normalmente, os indivíduos resolvem problemas análogos utilizando não só conhecimentos organizados em estruturas mais abstratas como os esquemas, mas também utilizando modelos mentais relacionados às situações concretas que vivenciam no dia a dia. Nessa perspectiva, a interação entre instâncias mais gerais, como os esquemas e os modelos mentais individuais construídos, modelos esses que, de certo modo, “concretizam” e contextualizam o conhecimento abstrato, parece tornar ainda mais complexo e dinâmico o processo de transferência analógica e o papel da similaridade de contexto na transferência.

Observa-se ainda que uma definição mais abrangente de contexto não se restringe, obviamente, aos aspectos "físicos" das instalações ou do ambiente de testagem e/ou aos objetos concretos envolvidos na situação de transferência como um todo. Sendo assim, algumas definições de contexto merecem ser aqui delineadas, devido à importância do 
contexto e do significado nas esferas da resolução de problemas e da transferência analógica.

Berg e Calderone (1994), ao abordar o papel do contexto na solução de problemas cotidianos, sinalizaram para o fato de que a definição do termo contexto costuma ser bastante diversificada, pois alguns autores destacam o "local" onde uma determinada atividade cognitiva e/ou social ocorre; outros autores focalizam o domínio ou conteúdo dessa atividade; outros, por sua vez, priorizam o funcionamento ou significado da tarefa e/ou a presença ou ausência de outras pessoas durante a execução da tarefa; e outros, por fim, enfatizam a familiaridade dos estímulos que são apresentados durante a tarefa. Nessa direção, mostra-se relevante uma concepção ampla e inclusiva do termo “contexto”, que inclua, não só os elementos físicos e sociais do ambiente, mas também toda a situação "psicológica” dos indivíduos, incluindo-se aqui as dimensões afetiva, cognitiva e conativa.

Butterworth (1993), ao discutir a definição de contexto no âmbito das teorias do desenvolvimento humano, observou que uma abordagem do senso comum de contexto costuma incluir aspectos físicos, sociais e culturais envolvidos em uma determinada tarefa intelectual. Citando Cole e Cole (1989) e sua definição de contexto, Butterworth (1993) apontou para a própria origem latina da palavra contexto que significa "colocar junto”, “compor”, ou seja, o termo contexto em sua definição é o “todo interconectado que dá sentido às suas partes” (p. 6). Esse autor também sinalizou para o fato de que uma perspectiva pluralista dos efeitos de contexto possibilita um melhor entendimento do uso de estratégias de resolução de problemas, pois o contexto apropriado possibilitaria o uso da estratégia apropriada. E, de acordo com Goodnow e Warton (1993), uma perspectiva pluralista de contexto deveria evitar a dicotomia que contrapõe, por um lado, a ênfase na construção de estruturas lógicas, como a presente nos trabalhos de Piaget, e, por outro lado, a ênfase nos diferentes contextos socioculturais onde emergem essas estruturas. Em outras palavras, essas últimas autoras vislumbraram a possibilidade de uma integração dessas perspectivas para um melhor entendimento da relação entre contexto e cognição.

Mais recentemente, Novick e Bassok (2005) enfatizaram três tipos diferentes de efeitos de contexto que costumam ser investigados por pesquisas no âmbito da transferência analógica: o primeiro desses efeitos seriam as características perceptuais do problema, o segundo, seriam os efeitos de interpretação semântica baseada no uso de objetos, e o terceiro, seriam os conteúdos das histórias dos problemas. Um exemplo de 
manipulação das características perceptuais de um problema poderia ser ilustrado quando os problemas são apresentados em formatos visuais ou diagramas, como o fizeram os estudos de Gick (1985) e de Helfenstein e Saariluoma (2006) e, no passado, os estudos de Maier (1931) com o problema dos “nove pontos”. Já a manipulação dos efeitos das inferências semânticas baseadas no uso de objetos poderia ser ilustrada em pesquisas que abordam especialmente o fenômeno da "fixação funcional”, como as pesquisas de Duncker (1945,) com o problema das velas, e as pesquisas de Chen e Mo (2004), com a ênfase nas “coações” procedimentais. Por último, a manipulação dos efeitos dos conteúdos das histórias parece ser a mais recorrente em inúmeros estudos na área, como os de Duncker (1945), Holyoak e colaboradores (1980; 1983; 1987), Ross, (1987; 1989), Blessing e Ross (1996), Bassok (1990), Bassok, Wu e Olseth (1995), Bassok, Chase e Martin (1998), Catrambone (2002), dentre outros.

Assinale-se que a pesquisa aqui desenvolvida também poderia ser considerada como manipulando alguns efeitos de conteúdos das histórias, não só os aspectos semânticos dos mesmos, mas, principalmente, a valência afetiva desses conteúdos. Inclusive, a nosso ver, esses efeitos da tonalidade afetiva das histórias talvez pudessem ser considerados como um novo tipo de efeito de "contexto" que complementaria os três tipos de efeito de contexto destacados por Novick e Bassok (2005).

Uma definição de contexto com ênfase nos aspectos socioculturais poderia ser também esboçada. Trabalhos, como os de Cole (1996), ao propor uma análise cognitiva do comportamento em diferentes contextos culturais, trouxeram à tona a importância do significado e da validade ecológica, dimensões nem sempre consideradas por estudos na área, especialmente aqueles mais voltados para a simulação computacional do processamento da informação. Esse autor, a partir do estudo desenvolvido com culturas letradas e iletradas, destacou a importância da conversação, da interação social e da compreensão da tarefa em diferentes contextos, como também a importância da atribuição de significado, tanto em situações experimentais mais formalizadas, quanto em situações cotidianas, menos formalizadas.

De modo complementar, autores como Escarabajal e Richard (1986), ao estudar a inclusão de classes e a transferência analógica em problemas matemáticos, enfatizaram a atribuição de significado ao mencionar os contextos particulares envolvidos em tarefas escolares. Observaram também que a interpretação do problema e a atribuição de significado aos seus elementos pelo sujeito costumam ser, de certo modo, minimizadas por algumas das abordagens do processamento da informação. A ênfase dada aos 
aspectos estruturais, aos procedimentos e aos esquemas de ação, comum nas perspectivas tradicionais na área, acaba deixando em segundo plano a atribuição de significado e a interpretação dada pelo sujeito aos elementos do problema e ao processo de resolução como um todo. Esses autores ainda destacaram que, ao se estudar a atribuição de significado pelo sujeito solucionador, pode-se também estudar a aplicação dos conteúdos gerais do pensamento a contextos particulares, em uma perspectiva procedimental que permite estudar quais potencialidades são "atualizadas” na situaçãoproblema e quais conhecimentos específicos são utilizados no contexto particular de uma tarefa.

Podemos complementar, no que diz respeito à resolução de problemas cotidianos, que quando este tipo de problema é contrastado com os problemas mais usados em laboratório, ou seja, quando se pensa na validade ecológica de pesquisas desenvolvidas em laboratório, há certo paradoxo, como destacaram Blanchette e Dunbar (2001), e Dunbar (2001), entre os achados de pesquisas que comprovam as dificuldades de transferência analógica no contexto experimental do laboratório e os achados de pesquisas que, em situações cotidianas, não experimentais, verificam que, neste último contexto, o uso de analogias parece ser mais fácil e recorrente.

Para os autores acima, uma espécie de paradigma de "recepção” parece determinar o uso de analogias no contexto experimental, pois há uma "recepção” (provavelmente "passiva”) dos problemas artificialmente dados pelo experimentador, em contraposição às situações cotidianas, onde há o predomínio de um paradigma de “produção”, com a evocação de analogias espontâneas, construídas pelo próprio indivíduo ou por seu interlocutor. No contexto do laboratório, inclusive, parece haver um maior impacto das características de superfície (incluindo-se aí os conteúdos semânticos) dos problemas, em função da própria ênfase “involuntária” da tarefa experimental no revestimento semântico dos problemas apresentados. Já no cotidiano é mais comum o uso de analogias interdomínios com maior ênfase nas características estruturais entre as situações-problema "fonte" e "alvo".

Dunbar (2001) e Blanchette e Dunbar (2001), ao mencionar o uso de analogias cotidianas, como, por exemplo, aquelas presentes no discurso de políticos, na conversa entre pessoas ou em artigos de jornais, e o uso de analogias "artificiais”, como, por exemplo, aquelas propostas em experimentos de psicologia, sinalizaram também para o fato de que os indivíduos em situações do dia a dia tenderiam a utilizar uma gama de conhecimentos mais genéricos, em vários setores, para a produção e para a 
compreensão de analogias inter-domínios. Já em situações mais artificiais de laboratório, o conhecimento requerido para a tarefa pode ser mais restrito a um ou a dois domínios e isso inclusive pode vir a ter influência na produção de analogias.

Ao exemplificar (e ao simular) uma situação cotidiana onde era pedido aos indivíduos que pensassem no problema governamental e financeiro de se chegar a um "déficit zero” no Canadá, Blanchette e Dunbar (2001) apresentaram a diferentes indivíduos argumentos positivos e negativos a respeito das conseqüências financeiras e sociais de um corte nos investimentos governamentais. Foi então pedido aos indivíduos que usassem analogias para defender argumentos favoráveis a uma política de mais gastos na esfera social ou argumentos mais favoráveis a um corte financeiro mais drástico nos investimentos sociais. Os resultados apontaram para o uso de analogias espontâneas que possuíam pouca semelhança "semântica" com o déficit financeiro per se ou com a linguagem política como um todo. Os tipos de analogias mais comuns produzidas pelos indivíduos foram relacionadas a animais, a contos de fadas, a tarefas domésticas, dentre outras. Em outros termos, houve, nessas analogias, um isomorfismo estrutural com o problema do déficit financeiro, mas não uma similaridade de conteúdos semânticos ou de outras características de superfície entre as analogias produzidas. Foi observado também pelos autores que, quando havia uma conotação emocional nos análogos "fonte” apresentados, havia também maior seleção de analogias não políticas na situação-problema “alvo”, o que sugeriu ser a conotação emocional um importante fator na seleção do tipo de analogia usada, analogias essas mais estreitamente vinculadas ao dia a dia dos indivíduos.

Esses autores realçaram a diferença entre as analogias mais restritas, preferencialmente intra-domínios, desenvolvidas nas ciências de um modo geral e as analogias mais “frouxas”, inter-domínios, criadas pelos políticos, jornalistas, etc., em contextos cotidianos, tais como jornais, debates, etc., onde há uma alta carga afetiva envolvida, bem como a tentativa de "convencimento" da audiência e/ou interlocutores.

Em alguns desses estudos, Dunbar e Blanchette (2001) investigaram as analogias utilizadas por pesquisadores na área da biologia molecular e da microbiologia durante reuniões em laboratório de sua equipe de cientistas. Seus achados sugeriram um recorrente uso de analogias durante a descoberta de novos problemas científicos, sendo que o tipo de analogia utilizada costumava mudar dependendo dos objetivos do pesquisador. Esses autores apontaram para a ênfase nas similaridades estruturais das 
analogias científicas utilizadas, contrapondo essas analogias às analogias com ênfase nas similaridades de superfície de experimentos da psicologia.

Os autores acima destacaram também, nesses estudos, vantagens e desvantagens de uma abordagem "in vivo" e de uma abordagem “in vitro”, porém com certa preferência por estudos "in vivo", como aqueles por eles desenvolvidos. A falta de precisão, de isolamento e de controle de variáveis que uma situação “in vivo" costuma apresentar seria compensada, na visão dos autores, pela grande vantagem de se poder entender as maneiras como os processos cognitivos se combinam, por exemplo, na transferência analógica e no raciocínio causal, e como esses processos são usados para resolver problemas reais do cotidiano, pois o contexto teria clara influência sobre o raciocínio. A generalização de novas hipóteses a partir de uma abordagem “in vivo” poderia, inclusive, servir de base para investigações em laboratório com o uso de técnicas mais precisas e de um controle experimental. As duas abordagens, então, nesse sentido, poderiam ser solidárias e complementares em suas investigações.

A pesquisa de Christensen e Schunn (2007) seria um exemplo de pesquisa recente que utilizou o método in vivo para investigar o pensamento analógico. Ao estudar o uso de analogias em uma situação-problema real que envolvia o design de engenhos no domínio da engenharia, os achados dessa pesquisa sugeriram que o uso de analogias cumpria três principais funções nesse domínio: a identificação de problemas na área, com o uso mais freqüente de analogias intra-domínio; a explicação de conceitos na área, com o uso mais freqüente de analogias inter-domínios e a resolução de problemas na área, com o uso de analogia mistas, intra-domínio e inter-domínios. Um outro achado interessante encontrado nessa pesquisa referiu-se ao fato de que o uso de exemplos/ protótipos na situação-problema "fonte" limitava a produção de analogias interdomínios, bem como limitava a criatividade na produção de um novo design pelo solucionador do problema. Podemos observar também algumas evidências da associação do uso de analogias inter-domínios com a produção inovadora e criativa em uma área do saber. Essas evidências parecem se contrapor às evidências que apontaram para o uso preferencial de analogias intra-domínio pelos cientistas de um modo geral, como Dunbar (2001) já havia sugerido.

Podemos concluir que Dunbar (2001) e Dunbar e colaboradora (Dunbar \& Blanchette, 2001; Blanchette \& Dunbar, 2001) trouxeram à tona relevantes questões sobre a validade ecológica de muitas pesquisas na área e, nessa direção, a importância de se investigar a interação entre o pensamento analógico e as situações cotidianas dos 
indivíduos. Acrescentaríamos que, nas situações cotidianas que envolvem a leitura de jornais e a participação em debates políticos, a carga afetiva das analogias utilizadas costuma ser intencionalmente manipulada por jornalistas e/ou políticos.

Em um estudo posterior, Blanchette e Dunbar (2002) investigaram como algumas analogias de cunho político apresentadas em jornais alteravam as representações das informações do problema “alvo”, em situações onde havia, inicialmente, uma situaçãoproblema “fonte”, seguida de outra situação-problema “alvo” análoga e, posteriormente, era feito um teste de reconhecimento das informações “alvo”. Foi verificado, nesse estudo, uma tendência dos sujeitos em modificarem as representações iniciais em função da transferência analógica. Uma espécie de “atualização” das informações iniciais, com uma contaminação e um falso reconhecimento, mostrou-se freqüente nesse contexto. Provavelmente, este tipo de mecanismo é bastante comum nas situações cotidianas, onde o pensamento analógico demonstra ser uma ferramenta cognitiva freqüentemente utilizada, o que explica, parcialmente, os recorrentes “deslizes” da memória e os falsos reconhecimentos. Como os achados da pesquisa de Blanchette e Dunbar (2002) sugeriram, o acesso aos conteúdos da memória na situação de reconhecimento foi “contaminado” pelos tons afetivos das analogias políticas usadas, o que nos aponta para o fato de que o acesso aos conteúdos da memória depende em parte do valor afetivo desses conteúdos.

Poderíamos argüir que estes autores não avaliaram, em seus trabalhos, a influência dos estados afetivos dos indivíduos na recuperação desses conteúdos, ou seja, não avaliaram se esses estados afetivos poderiam predispor mais ou menos os indivíduos a um falso reconhecimento. Entretanto, ao avaliar alguns efeitos do uso de analogias cotidianas com sua carga afetiva implícita no processo de transferência analógica e a interferência de um conteúdo novo na representação da informação do problema “alvo”, Blanchette e Dunbar (2002) trouxeram importantes contribuições para o entendimento da transferência analógica em situações-problema semelhantes às situações cotidianas que possuem assim boa validade ecológica.

Vale abrir breve parêntese para uma reflexão sobre a validade ecológica da pesquisa aqui proposta. Por um lado, propomos um planejamento experimental em um contexto de laboratório, que poderia, em tese, sofrer algumas das limitações referidas pelos autores acima. Porém, por outro lado, pretendemos utilizar histórias de problemas semelhantes às histórias do cotidiano, histórias essas tingidas por uma tonalidade afetiva como muitas histórias cotidianas costumam ser tingidas, como aquelas apresentadas em 
jornais, telejornais, dentre outros meios de comunicação. Acreditamos assim que, na medida em que simulamos, de certo modo, uma situação típica do cotidiano, semelhante, por exemplo, à leitura de reportagens em jornais, o problema da validade ecológica de nossa pesquisa possa ser parcialmente contornado.

Em resumo, quando se pensa no papel das similaridades de contexto que poderiam estar envolvidas no processo de facilitação da transferência analógica, há que se ter em mente, não só a discriminação do "tipo" de contexto que se pretende investigar, como também a complexidade de interações que se somam para conformar aquilo que denominamos “contexto”. A atribuição de significado pelo solucionador do problema e os diferentes tipos de contextos envolvidos no processamento da informação parecem estar intimamente relacionados com os conteúdos que revestem os enunciados dos problemas análogos, o que justifica a importância desses conteúdos na resolução de problemas e na transferência analógica.

\subsection{5-Intervalo de Tempo entre as Sessões}

A idéia de que a transferência analógica tende a decair naturalmente com o passar do tempo é praticamente um consenso na literatura da área. No senso comum, quando nos referimos à memória e às interferências que se interpõem no processo de recuperação, esse consenso também se dá. Porém, a qualidade do esquema de aprendizagem construído e fatores como o significado da informação para o individuo, incluindo-se aqui aspectos cognitivos e afetivos, poderiam favorecer a manutenção da transferência por um período maior de tempo. Mas, de modo geral, quando se compara o desempenho de indivíduos submetidos a dois intervalos de tempo entre as sessões (um mais curto e outro mais longo) e às mesmas condições experimentais, aqueles submetidos a um menor intervalo costumam apresentar maior taxa de transferência, como apontaram as evidências de Spencer e Weisberg (1986), Catrambone e Holyoak (1989), Fong e Nisbett (1991), dentre outras. Porém, os efeitos do intervalo de tempo sobre a transferência costumam ser acompanhados pela variação de contexto e/ou dos conteúdos semânticos que revestem os problemas análogos e, nesse sentido, devem ser investigados tendo em mente essa interação de fatores.

Spencer e Weisberg (1986), ao manipular o intervalo de tempo entre as sessões (teste imediato versus teste com um intervalo de 6 minutos) e o contexto (situação de testagem com o experimentador versus situação de aula com o instrutor) onde era 
apresentado o problema “alvo”, encontraram nos resultados indícios de que a similaridade de contexto facilitava a recuperação de esquemas relevantes, mas essa recuperação não foi suficiente para produzir a transferência. O papel da similaridade de contexto dos problemas como facilitadora da transferência foi investigada em experimentos onde os participantes inicialmente liam duas histórias análogas ao problema da radiação e depois tentavam resolver, na situação-problema "alvo”, o próprio problema da radiação de Duncker. Nesses experimentos, houve a variação do contexto e do intervalo de tempo entre as sessões "fonte" e "alvo". Os grupos submetidos à variação do contexto da história “alvo” e ao intervalo de 6 minutos não apresentaram nenhuma transferência em contraposição aos grupos submetidos ao mesmo contexto e ao teste imediato, que apresentaram a mais alta taxa de transferência. Não obstante, os participantes submetidos à variação de contexto, mas sem intervalo de tempo, apresentaram, por sua vez, uma taxa muito baixa de transferência. Já o intervalo maior de tempo não teve efeito significativo na transferência quando o contexto era o mesmo. O fraco desempenho dos participantes nesses experimentos, quando os contextos eram dissimilares, parece sugerir que poucos esquemas de convergência foram construídos durante a fase da leitura das histórias. Em outros termos, as descrições das similaridades entre os análogos, descrições essas que sinalizam a qualidade do esquema, só ocorreram com a similaridade de contexto.

Sendo assim, de modo semelhante aos achados dos estudos de Gick e Holyoak (1983) já referidos, Spencer e Weisberg (1986) encontraram resultados indicativos de que, quando o problema "alvo", no caso o problema da radiação, era apresentado imediatamente após a situação-problema “fonte” e sem houvesse variação de contexto, a qualidade do esquema de convergência construído favorecia um melhor desempenho na transferência.

Catrambone e Holyoak (1989), complementando os trabalhos de Gick e Holyoak (1983) e Spencer e Weisberg (1986), buscaram investigar o papel da qualidade do esquema em experimentos em que manipularam o intervalo de tempo entre as sessões (30 minutos versus uma semana), os diferentes contextos em que eram apresentados os problemas "alvo" (a mudança de contexto se deu com a interposição de uma tarefa de psicologia) e as instruções dadas aos participantes. Utilizaram também o problema da radiação como problema “alvo” e, em alguns dos experimentos, problemas "fonte” tais como “O General”, “O Chefe dos Bombeiros” e “O Aquário”, todos análogos ao da radiação, bem como outros problemas não análogos. No caso do problema dos 
bombeiros, a solução de convergência era necessária para apagar um incêndio e, no caso do problema do aquário, a solução de convergência era necessária para iluminar uma réplica de um navio submerso em um aquário de águas turvas. Em alguns desses experimentos, onde havia a comparação do desempenho dos sujeitos submetidos a dois intervalos de tempo entre as sessões (30 minutos e uma semana), os achados apontaram para uma melhor transferência, com o passar do tempo, quando havia as seguintes condições: primeiro, quando havia na situação-problema "alvo" a evocação das similaridades estruturais entre vários, e não apenas um, problemas análogos; segundo, quando havia instruções mais diretas de comparação entre os problemas "fonte”; e, terceiro, quando perguntas mais específicas (“dicas”) eram fornecidas para orientar os indivíduos na focalização dos aspectos relevantes das histórias, o que ajudava na qualidade do esquema construído.

Esses autores também atribuíram a falta de transferência encontrada em seus experimentos à dissimilaridade entre os contextos dos problemas “fonte” e "alvo" e não à passagem do tempo. Porém, quando as condições acima mencionadas eram todas satisfeitas, a variação de contexto e a passagem de tempo não afetaram de modo significativo a transferência, pois, provavelmente, a construção de esquemas de aprendizagem apropriados que aí ocorreu permitiu uma transferência mais flexível e eficaz.

Estudo anterior de Holyoak e colaborador (Holyoak \& Koh, 1987) demonstrou uma alta taxa de transferência espontânea, sem “dicas” de recuperação, mesmo após um intervalo de 3 a 7 dias entre as sessões experimentais. Esses achados contrastaram com alguns resultados obtidos em estudos anteriores de Gick e Holyoak (1980; 1983), já mencionados, onde houve pouca transferência espontânea. Um importante fator, que provavelmente contribuiu para isso, foi a proximidade semântica das histórias análogas apresentadas, em contraposição às histórias que foram apresentadas nos experimentos anteriores (o problema da radiação e o problema militar). Como vimos brevemente em seção anterior, nesse experimento, um dos problemas foi o da radiação e o outro foi uma versão análoga do mesmo, o problema denominado “O Bulbo da Lâmpada”. A história desse problema abordava a ruptura de um filamento muito caro dentro de uma lâmpada que demandava o uso de raios laser de alta intensidade para ser consertado. Todavia, uma emissão de alta intensidade poderia quebrar o vidro da lâmpada, o que não deveria acontecer. A solução de convergir raios de baixa intensidade, a partir de diferentes 
fontes de emissão, mostrou-se ser a mais eficaz, de modo análogo ao problema da radiação.

Os participantes desse experimento foram divididos em dois grupos, sendo que um grupo foi submetido à leitura de textos que versavam sobre o problema da radiação de Duncker e, nesse contexto, houve também a apresentação do problema do "Bulbo da Lâmpada”. O outro grupo, o grupo de controle, não foi submetido à leitura da história do problema da radiação e nem teve acesso ao problema do bulbo. Após o intervalo de tempo citado, na situação-problema “alvo”, os participantes resolveram primeiro o problema do bulbo e a seguir o problema da radiação. A taxa de transferência espontânea foi de mais de $80 \%$ para ambos os problemas no grupo experimental e de apenas $10 \%$ para o grupo de controle. Esses resultados parecem apontar não só para a importância da construção de um esquema de aprendizagem apropriado, mas principalmente, para a importância da similaridade das características de superfície (conteúdos dos enunciados) na facilitação da transferência. No caso, tanto o problema da radiação quanto o problema do bulbo envolviam conteúdos tais como a emissão de raios para o filamento/ tumor, a alta intensidade de raios podendo danificar o vidro da lâmpada/ os tecidos corporais sadios e uma redução da intensidade na administração dos raios nos dois problemas, etc.

Trabalhos de Fong e Nisbett (1991) investigaram também os efeitos da manipulação do intervalo de tempo na transferência analógica com ênfase na transferência de princípios de estatística. Em seus experimentos, os sujeitos, na primeira sessão, foram submetidos a um treinamento através da apresentação de vários exemplos que incorporavam esses princípios em domínios como esportes e testes de habilidades psicológicas. As condições experimentais foram as mesmas para os grupos, com exceção do grupo de controle, que por sua vez, não foi treinado. Porém, para alguns grupos o teste de transferência era imediato e para outros grupos o teste era feito após um intervalo de duas semanas. Seus achados apontaram para uma independência de domínio quando o teste era imediato, ou seja, os sujeitos obtiveram uma boa taxa de transferência dos princípios de estatística tanto para o mesmo domínio quanto para outro domínio.

Porém, quando o teste foi feito após duas semanas, houve um declínio no desempenho dos sujeitos no domínio não treinado em contraposição ao desempenho na transferência para o mesmo domínio, quando se comparou os resultados dos dois intervalos de tempo. Não obstante, apesar de um decaimento, a taxa de transferência 
inter-domínios foi razoável. Esses resultados foram interpretados por Fong e Nisbette como sendo indícios de que os efeitos do treinamento de regras de inferência permanecem por mais tempo, pelo menos por períodos de dias ou semanas. Quando o contexto e os conteúdos de um mesmo domínio foram reinstalados nos problemas da sessão “alvo", no caso após um intervalo de tempo de duas semanas, os sujeitos manifestaram uma transferência ainda maior. Entretanto, o treinamento oferecido, não só possibilitou o uso das regras de inferência, como também o uso “correto” dessas regras. Na concepção dos autores, essa capacidade de fazer bom uso dessas regras se deu em função do aprendizado de “regras de codificação”, isto é, de regras que servem para conectar as regras inferenciais mais gerais ao domínio do treinamento. No caso dos problemas utilizados em sua pesquisa, as regras estatísticas mais gerais provavelmente só puderam ser corretamente aplicadas aos problemas “alvo" porque as regras de codificação foram representadas em um nível de abstração suficiente para que pudessem acomodar as dissimilaridades entre os problemas vistos no treinamento e os problemas vistos na testagem. Esses resultados são consistentes com a assunção de que os indivíduos raciocinam usando regras com certo grau de generalização e abstração, ou seja, regras que dependem de esquemas de aprendizagem apropriados.

Podemos ainda observar, como destacou Catrambone (2002), que a existência de um intervalo de tempo entre as sessões poderia ajudar a reduzir os efeitos daquilo que ele denomina de "demanda experimental”, ou seja, os efeitos das expectativas dos sujeitos em relação ao experimentador e ao experimento como um todo. Em alguns de seus estudos, onde também utilizou o problema da radiação e versões análogas do mesmo, o intervalo de tempo manipulado foi o imediato e o de uma semana. Como vimos em seção anterior, vale lembrar que o autor buscou investigar os efeitos das similaridades de superfície e das similaridades estruturais manipulando o tipo de característica e o grau de correspondência entre as características para avaliar o efeito relativo de cada uma delas no processo de transferência.

Na concepção de Catrambone (2002), um maior intervalo de tempo entre as sessões, como o de uma semana, poderia favorecer uma avaliação mais "realista” do processo de recuperação de informações. Em outras palavras, de certo modo, um intervalo mais longo, como o de uma semana, poderia ter maior "validade ecológica”, não só por minimizar os efeitos “artificiais” da tarefa experimental, mas também por se assemelhar a situações cotidianas onde a recuperação de informações está sujeita a inúmeras fontes de interferência e de ambigüidade. Nessa direção, estudos que manipularam o 
intervalo de tempo de uma semana, como os de Gentner e colaboradores (1993) que investigaram o papel das similaridades de superfície e estruturais na transferência analógica e os de Wharton e colaboradores (1994) que, por seu turno, investigaram a competição entre as similaridades de superfície e as estruturais na transferência, são exemplos de pesquisas com esse tipo de preocupação.

Apesar da vantagem de um intervalo mais longo, do ponto de vista da validade ecológica da pesquisa, como vimos, com o passar do tempo, há, em contrapartida, um declínio natural da transferência. Em muitos estudos, como os de Gick e Holyoak (1980; 1983), Novick e Holyoak ( 1991), inclusive, o intervalo de tempo entre as sessões foi mínimo ou nenhum. Nesse sentido, apesar de o intervalo maior de tempo entre as sessões favorecer, por um lado, uma avaliação mais "realista” de como funciona a memória e das interferências que poderiam aí ocorrer, por outro lado, com o passar do tempo, dependendo do tipo de informação e de tarefa envolvidas, haveria uma tendência a um maior esquecimento e, consequentemente, a um pior desempenho na transferência. Porém, quando há instruções que encorajam um processamento cognitivo mais profundo, com a construção de um esquema de aprendizagem apropriado, haveria uma tendência na manutenção da transferência por um período maior de tempo.

Sendo assim, apesar de concordarmos com Catrambone (2002) sobre as possíveis vantagens de um intervalo maior de tempo entre as sessões, como o de uma semana (em termos de validade ecológica), também observarmos as possíveis desvantagens que a passagem de tempo poderia ocasionar, caso não existam instruções deliberadas de treinamento ou “dicas” que orientem os sujeitos experimentais.

Algumas implicações educacionais poderiam advir das considerações acima, não só no que se refere aos efeitos da passagem do tempo sobre a transferência de aprendizagem, como também no que diz respeito à importância do professor/ instrutor como facilitador dessa transferência, através de deliberada intervenção que contenha instruções/ treinamento que favoreçam a transferência.

Como sugeriu Catrambone (2002), as características de superfície, quando comparadas com outras características, talvez tenham uma vantagem nos processos iniciais de recuperação de um problema análogo, apesar de requerer, pela sua própria natureza, menos processos de inferência, especialmente quando os solucionadores/leitores dos problemas processam as histórias em um nível mais superficial. Porém, quando um processamento mais profundo e mais elaborado é requerido, as características estruturais parecem ter um papel determinante não só nos 
processos de recuperação de análogos “fonte”, mas no processamento analógico como um todo. Nessa perspectiva, a ativa participação do professor/ instrutor, como organizador/ mediador de instruções que favoreçam a aprendizagem e a apreensão de relações estruturais entre problemas análogos, mostra-se de fundamental importância para a transferência de aprendizagem e para a manutenção dessa transferência por um período de tempo mais longo.

No que se refere ao nosso estudo, a par das vantagens e desvantagens atribuídas a um intervalo maior de tempo, acreditamos que a proposta de dois intervalos de tempo para os grupos experimentais (teste imediato versus teste após uma semana) nos traz ricos subsídios para a investigação do papel das tonalidades afetivas de problemas análogos na transferência analógica. Apesar de acreditarmos em um declínio da transferência com a passagem de tempo de uma semana, também acreditamos que haverá manutenção da transferência, ainda que em menor grau, após o maior intervalo de tempo proposto. Cabe observar, como já referido, que não foram encontrados estudos que investigassem os efeitos da similaridade de tonalidades afetivas de problemas em dois intervalos de tempo distintos. Nossa pesquisa pretende, assim, responder a algumas questões relativas aos efeitos da passagem do tempo na transferência analógica, quando há similaridade de tonalidades afetivas de problemas.

Em suma, parece ser consenso na área que a passagem de tempo provoca um declínio natural na transferência analógica. Porém, conforme sugeriram as evidências de alguns estudos (p.e. Catrambone \& Holyoak, 1989), a construção de um esquema de aprendizado apropriado pode vir a favorecer a manutenção da transferência por um período maior de tempo, como o de um intervalo de uma semana entre as sessões. Vimos, também, que procedimentos como o uso de um questionário para reforçar o aprendizado dos modos de solução dos problemas aliados a procedimentos como o fornecimento de “dicas” de recuperação na situação-problema “alvo” poderiam favorecer a recuperação de um análogo “fonte” após o decurso de tempo entre as sessões.

Vale ainda destacar estudos de Chen (2004), que sinalizaram para a falta de pesquisas que investigassem o processo de transferência mais a longo-prazo, como, por exemplo, o passar do vários anos. Em seus experimentos, esse autor propôs investigar a transferência analógica de adolescentes americanos e chineses utilizando, como problemas “fonte”, contos folclóricos vistos pelos participantes em sua infância e, como problemas "alvo”, histórias que apresentavam problemas análogos. Seus resultados 
apontaram para uma boa taxa de transferência em ambos os grupos de americanos e chineses, com melhor desempenho dos participantes das séries mais adiantadas. Esses achados demonstraram que os indivíduos são capazes de resolver problemas utilizando analogias remotas com um intervalo de vários anos entre a situação-problema “fonte” e a situação-problema “alvo". Para esse autor, uma possível explicação para essa capacidade de recuperar analogias, ainda que muitas delas não tenham sido recuperadas de modo consciente, deve-se ao fato de as representações dos problemas na MLP conterem estruturas abstratas (esquemas) e características específicas dos objetos, sendo que a memória humana seria sensível a ambos os tipos de informação. Nesse sentido, em função da natureza dessas representações, a similaridade entre os objetos dos problemas em comparação parece desempenhar papel importante na transferência analógica a longo-prazo.

Quando tipos diferentes de similaridade entre os elementos/ objetos cumpriam diferentes papéis estruturais nos problemas “fonte” e "alvo", os processos envolvidos na transferência poderiam ser afetados de modo diferenciado, como observou Chen. Embora os processos de acesso tivessem sofrido “coações” das semelhanças dos objetivos e dos instrumentos utilizados para se chegar à solução (“coações pragmáticas), apenas a similaridade da solução ( “coações” estruturais) parece ter influenciado o mapeamento e os processos de execução (aplicação da solução). Nessa direção, os achados de Chen (2004) parecem reforçar os achados de autores como Gick e Holyoak $(1980 ; 1983)$ que sugeriram que as similaridades superficiais teriam mais impacto nos processos iniciais de acesso/ recuperação e menos impacto no processo de "uso", no caso, no mapeamento e na aplicação da solução análoga.

Não obstante, cabe uma observação a respeito da dificuldade metodológica de se investigar a transferência analógica a longo-prazo, por exemplo, após o intervalo de anos, em uma situação mais controlada de laboratório. No caso da pesquisa de Chen (2004) foi investigada a transferência analógica a partir de contos populares infantis americanos e chineses de amplo conhecimento dos indivíduos de ambas as culturas. Sendo assim, não houve na situação-problema "fonte", como acontece na maioria das pesquisas na área, a manipulação e o controle das variáveis apresentadas. Poderíamos nos argüir sobre as possíveis vantagens e desvantagens de tal procedimento, sendo a principal vantagem, a nosso ver, a validade ecológica das analogias utilizadas e, talvez, a principal desvantagem, a falta da discriminação da natureza (e de controle) das variáveis presentes na situação-problema “fonte”. 
No que se refere à transferência analógica a longo-prazo, podemos ainda destacar os estudos teóricos de Barnett e Ceci (2002) que propuseram uma taxionomia das dimensões envolvidas na transferência a longo-prazo. Esses autores sugeriram que o intervalo de tempo conjuntamente com a similaridade de contexto das situações "fonte” e "alvo" seriam as dimensões críticas envolvidas nesse processo. Inclusive, a proposta dos autores de uma revisão crítica da literatura no âmbito da transferência analógica, sob a luz dessas duas dimensões principais - a dimensão contextual e a dimensão do conteúdo -, encontrou algumas lacunas na área, especialmente no que diz respeito à falta de definição da natureza dessas dimensões em alguns estudos. Sua taxionomia buscou assim construir um referencial teórico que teve por objetivo criar uma espécie de eixo "bidirecional” que serviria de guia para organizar e clarificar algumas definições na área como, por exemplo, a própria natureza do conceito de transferência analógica que, na concepção desses autores, deveria incorporar essas duas dimensões principais.

Podemos assim concluir que, apesar de encontrarmos algumas divergências nas evidências que apontam para maior ou menor declínio da transferência após certo intervalo de tempo, parece existir um consenso de que o acesso e o uso das informações na MLP tendem a diminuir com a passagem do tempo. Parece ser também consenso na área o fato de que o grau da transferência depende do intervalo de tempo entre o momento da aprendizagem original e a resolução do problema "alvo”, bem como do grau de similaridade semântica e contextual entre os problemas “fonte” e "alvo”. Entretanto, como observou Chen (2004), quase todas as teorias e modelos construídos no âmbito da transferência analógica foram baseados em evidências trazidas por experimentos que focalizaram a transferência a curto-prazo (imediata) e, acrescentaríamos, “a médio-prazo” como, por exemplo, o intervalo de dias ou semanas como o da maioria das pesquisas aqui referidas (Gick \& Holyoak, 1980; 1983; Catrambone \& Holyoak, 1989; Fong \& Nisbett, 1991)

Em suma, nos estudos referidos, houve a manipulação do intervalo de tempo que variou desde sessões consecutivas (Gick \& Holyoak, 1980; 1983; Holyoak \& Koh, 1987), passando por um intervalo de minutos (Spencer \& Weisberg, 1986); ou um intervalo de dias ou de uma semana (Catrambone \& Holyoak, 1989; Catrambone, 2002), ou de semanas (Fong \& Nisbett, 1991) até o intervalo de muitos anos (Chen, 2004). Na maioria desses estudos, observou-se uma tendência a maior dificuldade na transferência espontânea, bem como uma dificuldade na transferência entre domínios (e contextos) distintos. Porém, quando havia a apresentação de vários exemplos análogos 
"fonte" com instruções diretas de comparação entre eles e/ou quando havia "dicas" que orientavam a recuperação, a transferência analógica se mostrava mais bem sucedida.

Todavia, o intervalo de tempo entre as sessões deveria ser considerado conjuntamente com outros importantes fatores que poderiam estar envolvidos na facilitação da transferência como a similaridade das características de superfície e a similaridade do contexto onde se deu a aprendizagem e, mais especificamente, da similaridade dos conteúdos entre os problemas análogos. A construção de um esquema de aprendizagem apropriado que pudesse favorecer a manutenção da transferência, apesar do decurso do tempo, também se soma a esses fatores. Inclusive, a nosso ver, a interação positiva entre os diferentes fatores envolvidos na facilitação da transferência traz inúmeros desafios para a transferência de aprendizagem no âmbito escolar. 


\section{3-Capítulo II: Papel dos Conteúdos dos Enunciados de Problemas na Resolução de Problemas e na Transferência Analógica}

\section{1-Considerações Iniciais}

Como vimos anteriormente, na perspectiva de Holyoak e Koh (1987), bem como na de outros autores, as similaridades de superfície, incluindo-se os conteúdos semânticos que revestem os enunciados dos problemas e, acrescentaríamos também, a tonalidade afetiva desses conteúdos (positiva, neutra ou negativa), seriam mais importantes nos estágios iniciais do processamento analógico, os chamados estágios de “acesso”, ou seja, de recuperação de informações “fonte” da memória. Em contraste, no processo de mapeamento per se, esses conteúdos e, acrescentaríamos também, a sua tonalidade afetiva, não teriam um impacto tão relevante como o impacto da similaridade estrutural entre os problemas.

Porém, autores como Heydenbluth e Hesse (1996) parecem não concordar com a idéia de que os conteúdos semânticos não seriam importantes no processo de mapeamento analógico, pois os seus achados empíricos, no domínio da astrofísica, apontaram para outra direção, isto é, apontaram para o impacto dos conteúdos dos enunciados nesse processamento.

Umas das possíveis explicações sugeridas por estes autores para justificar a discrepância de resultados entre pesquisas como as de Holyoak e Koh (1987) que, por um lado, minimizaram a importância dos conteúdos dos enunciados no mapeamento e pesquisas, como as de Ross (1989) que, por outro lado, apontaram para os efeitos positivos desses conteúdos no mapeamento, reside no fato de que as primeiras utilizaram problemas considerados mais "fáceis" e mais mal-definidos, enquanto as segundas, utilizaram problemas matemáticos considerados mais “difíceis” e mais bemdefinidos. Sendo assim, quando se pensa no papel dos conteúdos dos enunciados do problema no processamento analógico deve-se ter em mente que o grau de definição do problema e o conhecimento requerido para a sua resolução podem interagir entre si, produzindo diferentes graus de dificuldade para o solucionador do problema.

Podemos argüir também se, em problemas análogos mal-definidos, com baixo nível de dificuldade e que exigem pouco conhecimento para sua resolução, como aqueles utilizados em nossa pesquisa, isso também vai ocorrer. Em outros termos, se conteúdos com tonalidades afetivas distintas poderiam afetar o processamento analógico em níveis 
iniciais de acesso, mas não em níveis mais profundos de mapeamento. Apesar de não haver o pedido para que os participantes estabeleçam relações comuns entre os elementos que desempenham o mesmo papel nos problemas “fonte” e “alvo”, há, em contrapartida, o pedido para que os mesmos justifiquem a escolha da solução do problema “alvo” (anexo 7). Nesse contexto, será discutida a explicitação de algum tipo de mapeamento entre elementos compartilhados por ambos os problemas.

Como observamos, o tipo de problema a ser resolvido, problema bem-definido ou mal-definido, e o grau de conhecimento requerido para resolvê-lo, pouco ou muito conhecimento, podem ter efeitos diferenciados nos estágios de processamento analógico, bem como muitos autores já sinalizaram, nos estágios da resolução de problemas como um todo. Sendo assim, estudos que investigam o papel dos conteúdos em situações-problema que apresentam problemas que exigem pouco ou muito conhecimento específico para sua resolução podem nos ajudar no entendimento do funcionamento cognitivo envolvido em tarefas de diferentes naturezas.

3.2-Papel dos Conteúdos dos Enunciados de Problemas na Resolução de Problemas Bem-definidos e na Transferência Analógica

3.2.1-Papel dos Conteúdos dos Enunciados de Problemas na Resolução de Problemas Bem-definidos Dependentes de Domínio

O grau de definição do problema, bem como a quantidade de conhecimento requerido para a sua solução costumam ser dois parâmetros utilizados para a categorização de muitos problemas na área. Nessa perspectiva, o conhecimento requerido para a resolução de problemas chamados "problemas dependentes de domínio”, problemas esses que costumam ser bem-definidos ou parcialmente bemdefinidos como os problemas de matemática, física, etc., tem sido um parâmetro para se estudar as diferenças de processamento cognitivo entre peritos e novatos. A forma como os peritos/ especialistas e os novatos/ iniciantes representam e organizam o conhecimento costuma ser a tônica de muitas dessas pesquisas com ênfase cognitivista.

Estudos clássicos, como os de De Groot (1966) e Chase e Simon (1973) demonstraram que a organização e o uso do conhecimento por mestres e iniciantes em xadrez diferiam não só em termos “quantitativos” (conhecimento acumulado), mas 
também em termos “qualitativos”, estruturais, ou seja, no tipo de representação mental construída por esses indivíduos.

A percepção do tabuleiro e da posição das peças do jogo de xadrez pelos mestres era estruturada em forma de padrões, entroncamentos (posições de jogada), o que os levaria a ações relevantes e a produção de regras adequadas, em contraposição à percepção dos iniciantes que construíam representações mais individualizadas das peças no tabuleiro e tinham um desempenho inferior nos jogos. Entretanto, o desempenho de mestres e iniciantes se igualava quando as peças estavam fora de posição de jogada, pois, nesse caso, a memorização dessas peças não obedecia a uma regra de organização e demandava apenas uma retenção individualizada das mesmas. Sendo assim, o superior desempenho dos mestres de xadrez na representação e na memorização das peças se dava apenas em situações normais de jogo, onde as peças formavam conjuntos "lógicos" que davam um sentido às suas posições. Além da construção de representações mentais apropriadas ao domínio do problema, os peritos faziam o uso diferenciado de regras, o que os tornava mais eficazes e rápidos em seu desempenho.

Tradicionalmente, costuma-se atribuir a situações de conhecimento mínimo, a utilização de métodos denominados “fracos”, universais, também chamados de heurísticas ou estratégias gerais, em contraste com o uso de métodos “fortes”, mais específicos ao tipo de problema e utilizados, preferencialmente, em situações de conhecimento máximo. Sendo assim, a utilização de métodos “fortes”, mais específicos para o domínio do problema, por peritos em contraposição à utilização de métodos “fracos”, ou seja, de heurísticas gerais, por novatos também costuma ser um ponto de comparação entre os mesmos. Inclusive, heurísticas como a análise meios-fins, comumente utilizada em problemas bem-definidos independentes de domínio, como os problemas “modais” da já mencionada Teoria do Espaço do Problema de Newell e Simon, costumam ser utilizadas pelos peritos somente em situações-problema incomuns. Já os novatos, por sua vez, costumam utilizá-las de modo recorrente, mesmo em situações que demandam estratégias de domínio especifico.

Diversas pesquisas apontaram para os efeitos diferenciados do grau de conhecimento no desempenho de peritos e novatos em diferentes domínios tais como as de Lesgold (1991), no domínio da radiologia; as de Lesgold e Lajoie (1991), no domínio da eletrônica; Chi e Ceci (1987); Chi, Bassok, Lewis, Reimann e Glaser, (1989), no domínio da física, só para citar algumas pesquisas. Essas pesquisas, bem como as pesquisas de Schoenfeld e Hermann (1982), Novick (1988), Bassok e Holyoak 
(1989), apontaram evidências no sentido da existência de uma categorização mais complexa do problema por parte dos peritos, pois estes agrupavam os problemas em termos de suas características mais profundas, em contraposição aos novatos, que tendiam a agrupar problemas a partir de suas similaridades semânticas, superficiais, incluindo-se aqui os conteúdos dos enunciados dos problemas. Os peritos costumam possuir também ricos e bem conectados esquemas com conhecimentos declarativos sobre o domínio do problema, bem como esquemas com conhecimentos procedimentais estruturados, o que lhes conferem excelente grau de automação, em contraposição aos novatos que não os possuem em tal nível.

Entretanto, estudos como os de Ross (1989), Ross e Kennedy (1990), Blessing e Ross (1996), Ross e Warren (2002), Bassok (1990; 2001; 2003), Bassok, Wu e Olseth, (1995), Bassok, Chase e Martin (1998), Martin e Bassok (2005), especialmente nos domínios da física e da matemática, demonstraram que os aspectos semânticos, ou seja, os conteúdos semânticos do problema em foco, podiam ter uma influência mesmo na solução de problemas e na transferência analógica por peritos, principalmente quando havia uma conexão empírica entre os “tipos” de problemas e os “conteúdos” dos problemas. Nesse sentido, os peritos, ainda que focalizassem com maior eficiência as estruturas profundas dos problemas em um dado domínio, também sofreriam a influência das similaridades superficiais dos enunciados dos problemas, tanto no processo de resolução de problemas quanto em sua transferência analógica.

Ross (1987; 1989) e Ross e colaboradores (Ross \& Kennedy, 1990; Blessing \& Ross, 1996), focalizaram, em seus estudos, os conteúdos semânticos enquanto estruturas superficiais sinalizadoras de estruturas profundas, onde os conteúdos foram manipulados enquanto mais típicos ou menos típicos das estruturas profundas que recobrem. Como mencionado acima, em situações-problema de domínio específico, os peritos, não só os novatos, parecem fazer uso desses conteúdos para uma rápida categorização do “tipo” de problema com o qual estão lidando. Como vimos, também na esfera da resolução de problemas de matemática, que em tese, seria um domínio mais “abstrato” e, portanto, mais independente de conteúdos, a ênfase no papel dos conteúdos tem sido recorrente em estudos contemporâneos neste domínio e em domínios afins (como, por exemplo, nos trabalhos de Bassok e cols. 1989; 1995; 1998), dentre outros.

Ross (1987), ao investigar a importância do uso de exemplos no aprendizado de princípios de probabilidade em novatos, sugeriu, a partir de suas evidências empíricas, que similaridades de superfície como a "linha das histórias" dos problemas teria um 
impacto na recuperação de um problema análogo. Esses resultados sugeriram que diferentes tipos de similaridades de superfície teriam efeitos diferenciados no acesso e no uso dos problemas análogos vistos na situação-problema “fonte”. Nesse sentido, na concepção desse autor, o impacto das similaridades de superfície se daria não só nos processos iniciais de acesso, mas também em processos mais profundos de mapeamento analógico. Esses estudos foram, inclusive, uns dos primeiros a apresentar evidências do papel das similaridades de superfície, no caso os conteúdos dos problemas, no mapeamento analógico e complementaram evidências, no domínio da álgebra, de Reed, Dempster e Ettinger (1985) que sugeriram que o mapeamento nem sempre é baseado em um entendimento mais profundo das similaridades estruturais.

Ross (1989), em estudos posteriores da mesma natureza do estudo anterior, investigou o processo de abstração, ou seja, a construção de relações abstratas da tipicidade de problemas de probabilidade, a partir da apresentação de exemplos anteriores a indivíduos que não conheciam esses problemas (novatos). Os participantes estudaram princípios de probabilidade em problemas verbais e depois tentaram resolver outros problemas que exigiam a aplicação desses princípios. Nesses estudos, os conteúdos foram manipulados de três maneiras: a linha das histórias, os objetos mencionados nos problemas e o grau de correspondência dos papéis desempenhados por esses objetos nos problemas. As evidências obtidas apontaram para o maior impacto da variação dos papéis desempenhados pelos objetos/personagens no processo de mapeamento e não nos processos de acesso, já a variação das linhas das histórias conjuntamente com a variação dos papéis tiveram impacto tanto no acesso quanto no mapeamento.

Trabalhos de Ross e Kennedy (1990), também utilizando problemas verbais de probabilidade, deram continuidade à investigação do papel dos conteúdos das histórias no processo de transferência em novatos nesse domínio. Com ênfase na generalização de tipos de problemas a partir da apresentação de exemplos análogos e na importância da comparação entre problemas, esses autores trouxeram novas evidências da importância dos conteúdos na transferência. Muitos desses conteúdos/ características de superfície estariam correlacionados, inclusive, com as estruturas profundas e um claro exemplo disso seria a "tipicidade” de alguns problemas estudados. Esses conteúdos “típicos” de um dado problema parecem ajudar na rápida ativação de esquemas e os novatos em um domínio parecem se beneficiar de modo significativo dessas “dicas” de conteúdos. 
Nessa direção, também Blessing e Ross (1996), estudando os efeitos dos conteúdos na categorização de problemas algébricos em indivíduos experientes nesse domínio, apresentaram evidências que complementam os trabalhos anteriores de Ross (1987; 1989) e Ross e Kennedy (1990). Através da manipulação dos tipos de conteúdos apresentados nos problemas como “típicos”, “atípicos” e “neutros”, esses pesquisadores encontraram efeitos bastante positivos dos conteúdos “típicos”mesmo em peritos. Se uma das principais contraposições entre peritos e novatos baseia-se no fato de que os novatos focalizam as características de superfície em detrimento das estruturas profundas e os peritos fazem o contrário, como os estudos de Chi, Feltovich e Glaser (1981) inicialmente sugeriram, os achados de Ross e de Ross e colaboradores parecem tornar ainda mais complexa essa contraposição.

Não obstante, para apreensão da tipicidade de um problema, só aqueles conteúdos que estivessem conectados com a estrutura profunda dos problemas seriam importantes e não “qualquer” conteúdo. Por exemplo, no caso de problemas de física, conteúdos como "um barco subindo a correnteza de um rio..." poderiam dar “dicas” iniciais para um problema "típico” de velocidade. Trabalhos mais recentes de Ross e Warren (2002) com ênfase na abstração de relações, a partir do uso de categorias em problemas matemáticos que envolviam a decodificação de um código cifrado, também apontaram nessa direção, ou seja, apontaram para a importância da tipicidade e da categorização na representação abstrata de relações matemáticas. Em outros termos, seus achados sugeriram a importância da classificação de problemas, a partir de conteúdos tais como o tipo de objeto e/ou do tipo de situação concreta, para a construção de representações abstratas mais independentes de conteúdos.

Outros trabalhos empíricos, ainda no domínio da matemática, como os de Bassok e colaboradores (1995; 1998; 2005), e estudos teóricos de Bassok (2001; 2003) e Novick e Bassok (2005) apontaram para o fato de que os objetos/conteúdos de um problema costumam ativar o conhecimento semântico que evoca, por sua vez, inferências relacionais entre os conteúdos semânticos dos problemas análogos em jogo, inferências essas que os autores acima denominam de "alinhamento semântico". Na concepção desses autores, este alinhamento guia a seleção de soluções matemáticas estruturalmente análogas no processo de mapeamento analógico. Por exemplo, tulipas e rosas ativam uma relação simétrica que induz à operação de adição e tulipas e vasos, por sua vez, ativam uma relação assimétrica que induz à operação de divisão, através da idéia de conter. Inclusive, Martin e Bassok (2005) observaram que quando os conteúdos/ objetos 
dos problemas possuem uma relação funcional, como tulipas e vasos, e não uma relação categorial, como tulipas e rosas, as “dicas” semânticas fornecidas por esse tipo de relação favoreceriam bastante a operação de divisão.

Estudos empíricos de Bassok e colaboradores (1995) investigaram os efeitos interpretativos dos conteúdos na transferência analógica através da manipulação daquilo que os autores denominam de "cobertura” das histórias dos problemas. Os problemas matemáticos de permutação apresentados foram isomórficos em sua estrutura profunda, mas foram recobertos por histórias onde pessoas e objetos desempenhavam papéis simétricos e assimétricos. Nesses problemas, a relação entre pessoas e objetos (p. e. alunos e prêmios) induzia a uma estrutura assimétrica (verbo: ganhar) e a relação entre pessoas (p. e. médicos) induzia a uma estrutura simétrica (um par). Esses autores apresentaram evidências de que os conteúdos semânticos de “cobertura” afetavam diretamente a transferência por induzirem a um conhecimento semântico que modificava as estruturas dos problemas, isto é, conteúdos similares tendiam a induzir a recuperação de estruturas similares, pois traziam “coações” dos tipos de predicados que compunham as representações mentais dos problemas.

Em estudos empíricos posteriores, Bassok e colaboradoras (1998) buscaram investigar os efeitos dos conteúdos semânticos na resolução de problemas matemáticos, que como vimos, seria um domínio mais formal e abstrato, ou seja, mais independente de conteúdos e de contextos. De acordo com essas autoras, o papel desses conteúdos seria visível na maioria dos problemas apresentados em livros didáticos ou em situações de sala de aula, pois esses problemas costumam manter correspondências sistemáticas entre as relações semânticas inferidas pelos indivíduos a partir de pares de objetos do cotidiano como, por exemplo, laranjas se somam a maçãs e cestos dividem laranjas e não o contrário. Através de experimentos onde manipularam o grau de alinhamento semântico entre pares de objetos, as autoras apontaram para o impacto dos conteúdos no conhecimento formal abstrato, sendo que o alinhamento semântico entre pares de objetos demonstra a importância do componente interpretativo, ou seja, do significado, na transferência analógica.

Por último, cabe mencionar trabalhos como os de Wiley (1998) que avaliaram os efeitos do conhecimento específico de domínio na resolução de problemas “criativos” que envolviam soluções inéditas. Em seus estudos, houve a verificação de que, às vezes, o conhecimento em uma área do saber poderia funcionar como uma espécie de "set" mental que restringiria o espaço de busca do problema, levando à inibição (fixação) de 
respostas novas em situações que demandariam flexibilidade e criatividade. Seus experimentos, que utilizaram uma versão adaptada do teste de associações remotas de Mednick, demonstraram que os indivíduos, com grande experiência em uma área do saber, tendiam a se restringir à sua área de conhecimento, mesmo quando a solução do problema demandava uma busca mais ampla por associações novas, combinadas de uma maneira não padronizada. Nesse caso, podemos argüir que os problemas apresentados demandavam associações e idéias novas que não requisitavam uma especificidade de domínio, o que não é comum quando se estuda o desempenho de peritos e novatos. E o conhecimento em uma área, ao invés de favorecer o desempenho, como costuma acontecer, teve efeitos negativos, o que parece sugerir que, dependendo da natureza da tarefa, ser especialista em domínio pode ser ou não uma vantagem. De certo modo, a “fixação” nos conteúdos de uma dada área de saber não favoreceu a associação entre novos conteúdos, o que parece novamente reforçar o papel dos conteúdos na resolução de problemas, mesmo em problemas como aqueles apresentados pela autora acima.

Podemos concluir que estudos contemporâneos como os de Ross e colaboradores e de Bassok e colaboradores no âmbito da resolução de problemas e da transferência analógica, com problemas dependentes de domínio, parecem trazer maior complexidade de questões para a tradicional dicotomia similaridade superficial versus similaridade estrutural. Podemos observar que, hoje em dia, esses dois tipos de similaridades costumam ser redimensionadas em termos de um continuum mais dinâmico de interações do que em termos de polaridades qualitativamente diferentes. Mesmo em problemas mais bem-definidos que exigem expertise, como problemas matemáticos, físicos, etc., problemas estes típicos do contexto acadêmico, o impacto dos conteúdos dos enunciados dos problemas parece se fazer presente. Isto parece ocorrer tanto nos processos iniciais de representação dos problemas e de acesso, quanto, em alguns casos, no processo de mapeamento; como as evidências empíricas têm sugerido.

3.2.2-Papel dos Conteúdos dos Enunciados de Problemas na Resolução de Problemas Bem-definidos Independentes de Domínio

Já no que diz respeito aos chamados problemas bem-definidos independentes de domínio, como os “clássicos” problemas da Teoria do Espaço do Problema de Newell e Simon, especialmente os problemas dos “Missionários e Canibais” e o problema da “Torre de Hanói” e seus análogos, podemos observar que a teoria de Newell e Simon 
buscou demarcar, sob termos representacionais explícitos, os vários estados e processos hipotéticos que são utilizados para a resolução desse tipo de problema.

Muitos estudos com problemas bem-definidos independentes de domínio como, por exemplo, os estudos de Simon e Hayes (1976), e Kotovsky, Hayes e Simon (1985), trouxeram evidências empíricas de que vários aspectos do contexto do problema têm forte influência nas representações que os indivíduos constroem, tais como o efeito do fraseado, o efeito da interpretação semântica baseada no modo como os objetos são utilizados e o efeito do conteúdo da história do problema.

Abordaremos abaixo alguns desses estudos de cunho cognitivista que realçam a importância dos conteúdos dos enunciados e de outras características de superfície, como por exemplo, o fraseado e o texto como um todo, na resolução de problemas e na transferência analógica.

Apesar de não trazer evidências diretas sobre o papel do afeto na cognição, pois investigam, em sua maioria, o papel de similaridades de superfície neutras e não abordar a influência do estado afetivo dos indivíduos na resolução de problemas, os principais achados empíricos dessas pesquisas podem nos ajudar a entender o impacto destas similaridades na resolução de problemas e na transferência analógica.

Em um desses estudos, Simon e Hayes (1976) apresentaram aos sujeitos experimentais, duas versões análogas ao problema “Torre de Hanói”, no caso o problema dos "Monstros e Globos”, sendo que em uma delas, os globos eram apenas transferidos entre os monstros, enquanto na outra versão, por sua vez, havia a expansão ou encolhimento dos globos segurados pelos monstros. A principal diferença entre os dois problemas isomórficos residia nas operações envolvidas, ou seja, em uma das versões havia uma transferência entre elementos (globos e monstros) e na outra versão, além da transferência havia uma alteração do tamanho dos globos, com a aplicação de regras mais complexas que determinavam um maior grau de "coação”. E, observarmos que, embora os dois problemas fossem estruturalmente idênticos, podendo ser resolvidos pela mesma seqüência de movimentos no mesmo espaço do problema, os sujeitos não transferiam os problemas para uma representação comum. Ao invés disso, como sinalizaram Novick e Bassok (2005), eles aceitaram o revestimento semântico ou “cobertura” da história como tal e, dependendo da variante que recebiam (com ou sem alteração do tamanho), trataram de mover globos ou modificar seus tamanhos.

Cabe observar ainda que a representação construída pelos indivíduos tinha também um grande efeito no tempo de resolução desses problemas: a variante de transferência 
levou cerca de 14 minutos para ser resolvida, enquanto a variante da alteração levou 29 minutos, isto é, aproximadamente o dobro do tempo. A explicação dos pesquisadores para esta discrepância foi a de que a versão de alteração demandava regras mais difíceis de aplicação, ou seja, envolvia testes complexos para determinar as operações legais.

Kotovsky e colaboradores (1985), em seus achados, também apontaram para o fato de que as pessoas tinham dificuldades na transferência analógica quando havia a “coação” do conhecimento cotidiano em relação aos problemas análogos apresentados (Torre de Hanói/acrobatas de diferentes tamanhos). Nesse caso, havia dificuldade de aceitação de que um acrobata maior/mais pesado ficasse no ombro de um menor/mais leve em contraposição à fácil aceitação de que um disco maior ficasse em cima de um menor na Torre de Hanói. Nesse sentido, a relação simétrica/assimétrica entre os elementos (pessoas e objetos) e a plausibilidade da situação proposta parecem possuir um peso considerável na representação do problema e na capacidade de resolução e transferência analógica do mesmo.

Ainda em relação ao efeito do grau de “coação” da dificuldade do problema na resolução de problemas e na transferência analógica, podemos brevemente citar a tradicional pesquisa de Reed, Ernst e Banerji (1974) que, com problemas análogos aos “Missionários e Canibais”, mas com um grau de “coação” maior do que o presente nesse (problema dos "Maridos Ciumentos”), observaram as dificuldades dos sujeitos experimentais em transferir a aprendizagem quando um problema de menor "coação" (por exemplo, “Missionários e Canibais”) era apresentado primeiro, ou seja, uma melhor transferência sempre partia de uma situação “fonte” de maior “coação” (mais difícil) para uma situação alvo de menor “coação” (mais fácil). Nesse caso também podemos concluir que a manipulação da ordem de apresentação de problemas análogos tinha um impacto na sua resolução e posterior transferência.

Já foi verificado que as representações, que são mentalmente manipuladas na resolução de problemas, podem ser surpreendentemente concretas e particulares. Por exemplo, em um estudo de Hutchins e Levin (1981), citado por D’Andrade (1991), utilizando o problema dos “Missionários e Canibais”, houve a verificação de que os indivíduos tinham mais dificuldade em detectar que haviam tentado realizar movimentos ilegais quando eles imaginavam eventos tendo lugar na margem do rio distante deles, quando comparados com eventos imaginados na margem próxima a eles (o ponto de vista do sujeito em relação ao rio foi avaliado a partir de seus registros nos protocolos verbais). Era como se os eventos que fossem imaginados ocorrer no lado do 
rio em que o indivíduo se posicionava fossem mais fáceis de visualizar do que os eventos que eram imaginados ocorrer na margem oposta.

De modo semelhante, tem sido observado que jogadores de xadrez podem preferir jogar com conjuntos de peças de formatos familiares a jogar com peças de formas não usuais, pois, segundo eles, tais peças são mais difíceis de manipular mentalmente. Sendo assim, os modelos mentais preferidos pelos indivíduos são, normalmente, aqueles mais familiares e mais bem compreendidos por estes, como apontou Johnson-Laird (1991), em seus estudos.

Em outras pesquisas (Greeno,1974; Jeffries, Polson, Razran \& Atwood, 1977), há também evidências de que a mera variação de aspectos do revestimento da história, sem afetar outros parâmetros, como por exemplo, substituir os missionários e canibais por elfos e homens ou outros pares de criaturas, não produz efeitos significativos nos resultados. Nessa perspectiva, podemos inferir, então, que não seria a variação de “qualquer” conteúdo semântico que teria efeitos sobre a transferência analógica como, no caso, a mera substituição de personagens, mas sim a variação daqueles conteúdos que afetassem o "significado” ou o "papel” do personagem na história.

Kotovsky e Simon (1990), em estudos posteriores, pretenderam investigar o porquê de alguns problemas bem-definidos independentes de domínio serem tão difíceis de resolver, como o problema denominado “Anel Chinês” e a sua versão análoga digital. Dois tipos de dificuldades costumam ser destacados para definir um problema como “difícil”: o grau de conhecimento exigido pelo problema e o tamanho do "espaço de busca” do problema. Porém, os achados de seus experimentos evidenciaram que a maior dificuldade apresentada pelos participantes não era relativa ao tamanho do espaço do problema e nem ao grau de conhecimento exigido, pois, inclusive, o problema era independente de domínio, mas sim devido às características representacionais dos problemas, como a natureza das movimentações e a presença ou ausência de pistas legais. Se o tamanho do espaço do problema fosse a maior dificuldade seria esperado que houvesse uma boa transferência entre problemas que compartilhassem espaços idênticos, o que não ocorreu. Sendo assim, para os autores, um dos principais fatores de predição da transferência não seria o tamanho do espaço do problema, mas sim a similaridade dos operadores utilizados por ambos os problemas análogos.

Estudos de Pierce e Gholson (1994) e de Pierce, Crain, Gholson Smither e Rabinowitz (1996) também utilizaram o problema bem-definido independente de domínio “Missionários e Canibais” e versões isomórficas e não isomórficas do mesmo, 
como o problema dos "Maridos Ciumentos”, para investigar a transferência analógica em crianças. Observou-se, nesses estudos, a importância do processo de mapeamento e do principio de sistematicidade na transferência, bem como a dificuldade de transferência apresentada especialmente por crianças menores quando havia a variação dos conteúdos e do contexto do problema. Novamente aqui as evidências foram sinalizadoras da importância dos conteúdos no processo de transferência analógica.

Em síntese, no que diz respeito aos problemas bem-definidos independentes ou parcialmente independentes de domínio, podemos observar que esse tipo de problema parece estar sujeito à nítida influência dos conteúdos dos enunciados, bem como à influência de outras características de superfície. Poderíamos argumentar que esse tipo de problema, na medida em que tem maior explicitação de suas condições, limites e estados iniciais e de meta, deveria estar menos sujeito a este tipo de influência por ser mais “fechado” em suas condições. Não obstante, conforme apontam as evidências dos estudos mencionados, há efeitos positivos dos conteúdos dos enunciados nesse tipo de problema, efeitos esses, não só dos conteúdos semânticos, mas também de outras características de superfície de diferentes naturezas.

Concluímos assim que os conteúdos dos enunciados de problemas bem-definidos, tanto de problemas mais dependentes de domínio, como os problemas escolares, quanto de problemas mais independentes de domínio, como as “charadas” e os problemas utilizados por Simon e colaboradores, podem ter uma nítida influência na resolução de problemas e na transferência analógica. Ainda que não tenhamos tido a pretensão de utilizar problemas bem-definidos em nossa pesquisa, as evidências trazidas por estes estudos podem, a nosso ver, reforçar os achados de estudos mais direcionados à investigação da solução de problemas análogos que possuem um maior grau de indefinição, como aqueles que utilizamos como instrumento de nossa pesquisa.

Reforçando esta conclusão, as evidências obtidas em estudos na esfera do raciocínio convergem para a importância dos conteúdos dos enunciados nos processos de pensamento, como será abordado a seguir.

\subsection{3-Papel dos Conteúdos dos Enunciados dos Problemas no Raciocínio Humano}

Na esfera do raciocínio, as evidências de diferentes estudos também sugeriram que os conteúdos das proposições podiam influenciar de modo significativo como as pessoas raciocinam, sendo o raciocínio facilitado, por exemplo, quando a tarefa 
envolvia conteúdos mais familiares. Alguns desses estudos (p.e. Kahneman \& Tversky, 1972; Tversky \& Kahneman, 1983; Johnson-Laird, 1991, D’Andrade, 1991, Cheng \& Holyoak, 1985) sugeriram que mesmo o raciocínio hipotético-dedutivo que envolve uma necessidade lógica e uma aplicação de regras formais está sujeito à influência dos conteúdos das proposições e premissas. Esses estudos têm enfocado os diferentes aspectos dos conteúdos dos problemas a das proposições, bem como os efeitos de suas manipulações no raciocínio hipotético-dedutivo e na resolução de problemas.

Trabalhos no âmbito do raciocínio hipotético-dedutivo que priorizam o papel da representação mental ou do modelo mental, como na acepção de Johnson-Laird (1991), têm demonstrado que os conteúdos das proposições podem afetar de modo significativo a maneira como as pessoas raciocinam (p. e. os de Jonhson-Laird , 1991; D’Andrade, 1991; Evans, 1991). Aqui, tem sido muito utilizado o teste das matrizes progressivas de Raven e, particularmente, a tarefa de seleção de Wason e a variação dessa tarefa, como a versão postal proposta nos estudos de Johnson-Laird, Legrenzi e Sorrino (1972), como citados por Girotto e Light (1993).

Nesses estudos, verificou-se que o desempenho em tarefas de raciocínio hipotéticodedutivo pode ser muito pobre quando os conteúdos das premissas são formais ou muito afastados da experiência do dia a dia dos indivíduos. Por outro lado, o desempenho nessas tarefas com o uso de versões mais familiares e concretas, como a versão postal da tarefa de Wason, demonstrou ser muito superior. Entretanto, para alguns autores (p. e. Cheng \& Holyoak, 1985; Girotto \& Light, 1993), a facilitação do desempenho nesse tipo de tarefa não seria devido apenas à familiaridade per se ou à concretude per se dos conteúdos. Mas, nesse caso, as condições para a facilitação do bom desempenho não têm sido fáceis de delinear, pois as explicações têm sido diversificadas.

Para Johnson-Laird (1991), os indivíduos raciocinam utilizando modelos mentais, ao invés de sistemas lógicos. Também a essas conclusões chegaram outros autores, como Kahneman e Tversky (1972) em suas pesquisas sobre probabilidade. E consoante D’Andrade (1991), muito do raciocínio que as pessoas realizam depende de modelos culturais e esses modelos culturais seriam mais do que apenas um tipo de "pacote" de informações sobre o mundo. Inclusive, Piaget, ao longo de sua vasta contribuição teórica e empírica sobre o desenvolvimento cognitivo humano, parece ter considerado as variáveis de contexto e de conteúdo como variáveis “moderadoras” que afetariam o acesso à competência lógica subjacente, quando as competências lógicas já tivessem sido construídas 
Por outro lado, Cheng e Holyoak (1985), propuseram que o aspecto crucial dessa facilitação seria o de que na versão postal da tarefa de seleção de Wason, a regra utilizada não seria uma regra formal de raciocínio, mas sim uma regra que deriva de regras deônticas de permissão e de obrigação, isto é, seriam esquemas pragmáticos de raciocínio, o que veio a ser defendido por alguns pesquisadores direcionados para estudos de contexto e cognição (p. e. Girotto \& Light, 1993).

Os trabalhos de Cheng e Holyoak (1985), Cheng, Holyoak, Nisbett e Oliver (1986) complementaram, com a sua proposta da existência de esquemas pragmáticos de raciocínio, as abordagens teóricas prevalentes sobre o raciocínio dedutivo, uma delas com ênfase nas regras lógicas independentes de domínio e a outra, com ênfase no papel do conhecimento de domínio especifico. Através de evidências empíricas utilizando também a tarefa de Wason e problemas análogos, Cheng e colaboradores (1986) apontaram para a dificuldade da transferência quando os indivíduos eram inicialmente treinados com o uso de regras abstratas e depois tinham que resolver problemas concretos que demandavam a aplicação dessas regras condicionais de raciocínio. O treinamento do uso de regras condicionais de raciocínio só melhorou o desempenho na situação-problema “alvo” quando, junto com as regras e princípios mais abstratos, eram apresentados exemplos concretos que contextualizavam as tarefas. De modo complementar, quando havia um breve treinamento para a construção de um esquema pragmático de raciocínio, o desempenho dos indivíduos na resolução de problemas concretos era bastante facilitado. Nessa direção, mais recentemente, Stenning e Van Lambalgen (2004) utilizando também a tarefa de Wason, trouxeram achados que corroboraram a idéia inicial de Cheng e colaboradores de que o raciocínio humano é especialmente sensível ao tipo de tarefa apresentada, ao contexto, bem como aos conteúdos envolvidos na tarefa.

Estudos direcionados para o raciocínio dedutivo em crianças como os de Light, Blaye, Gilly e Girotto (1989), Light, Girotto e Legrenzi (1990), Girotto e Light (1993), também apontaram para a importância da contextualização e da inteligibilidade da tarefa para o sucesso no desempenho das crianças. Tanto no primeiro estudo empírico (1989) com crianças de 6 a 8 anos, quanto no segundo estudo empírico (1990), com crianças de 12 anos, o desempenho em tarefas de seleção que demandavam a aplicação de regras de permissão e de proibição parece ter sido facilitado pela mediação de esquemas pragmáticos de raciocínio, como as evidências de Cheng e colaboradores (1986) já haviam sugerido no contexto do raciocínio humano adulto. Estudos teóricos 
posteriores de Girotto e Light (1993), reforçaram a ênfase nos esquemas pragmáticos de raciocínio e no papel do contexto como fator moderador da competência formal ao longo do desenvolvimento humano. Inclusive, na concepção desses autores, a mediação do contexto é “sempre” requerida para a expressão da competência formal, o que realça ainda mais a importância dos efeitos de contexto, não só ao longo do desenvolvimento cognitivo, mas também na cognição adulta.

Ainda que não seja o foco de nossa investigação, podemos destacar, de modo breve, à guisa de complementação, alguns estudos brasileiros sobre raciocínio dedutivo no âmbito do desenvolvimento cognitivo. Estudos como os de Dias (1988; 2000) e de Dias e Harris (1996), com crianças; e de Dias, Roazzi e Harris (2005), com adultos não alfabetizados e adultos com baixa escolaridade, também destacaram a importância dos conteúdos em tarefas que envolviam silogismos e a compreensão de textos lidos em voz alta. Seus achados apontaram para os efeitos da familiaridade dos conteúdos dos argumentos lógicos no desempenho dos indivíduos. Porém, mesmo em indivíduos adultos com baixa ou nenhuma escolaridade, assim como acontece com crianças pequenas ainda não alfabetizadas, haveria a preservação de uma competência lógica que independe da escolarização. E, nesse contexto, a presença de instruções adequadas favorecia o raciocínio lógico que lidava com premissas não familiares, algumas delas em contradição com o conhecimento empírico cotidiano dos indivíduos.

Já os estudos de Cosmides (1989) sobre o raciocínio no contexto de uma abordagem evolucionista por sua vez destacaram a importância das trocas sociais, ou seja, da cooperação entre indivíduos na resolução de problemas adaptativos que surgiram no processo da evolução da espécie humana. A sua proposta, nesses estudos, de uma teoria computacional usando princípios evolutivos somou-se à apresentação de evidências empíricas que deram suporte para uma explicação alternativa, baseada na idéia de que a mente humana possui processos cognitivos mais especializados para raciocinar sobre as trocas sociais. Utilizando também a tarefa de seleção de Wason, essa autora, inclusive, creditou à sua teoria do contrato social, teoria essa que enfatiza os custos e benefícios envolvidos nessas trocas, os diferentes efeitos de conteúdo encontrados no raciocínio.

Cosmides (1989) sugeriu, em contraste à perspectiva dos esquemas pragmáticos de raciocínio de Cheng e colaboradores (1986), que os efeitos de conteúdo que influenciariam as regras de produção envolvidas na tarefa de Wason dependeriam, principalmente, da relação custo/ benefício do tipo "se você usufrui o benefício, então pague o custo", o que a autora também chamou de "teoria do contrato social”. Nesse 
contexto, sua versão da tarefa de Wason envolveria uma troca social entre duas pessoas, onde a relação custo/ benefício que cada pessoa arcaria seria avaliada, bem como a violação das regras e a detecção de possíveis “trapaceiros” que pretendessem usufruir dos benefícios sem pagar os custos. E, na concepção dessa autora, a boa competência humana na detecção de "trapaças", em tarefas que envolvem relações sociais, seria facilitada por "algoritmos de contrato social" da mente humana, algoritmos esses de origem evolutiva.

Entretanto, estudos de Sperber e Girotto (2002) que, por sua vez, defendiam uma abordagem com ênfase nos esquemas pragmáticos de raciocínio, argüiram que estudos posteriores de Fiddick, Cosmides e Tooby (2000) que também utilizaram a tarefa de Wason para validar a sua teoria baseada nas trocas sociais, não utilizaram essa tarefa de maneira adequada, em seus experimentos, pois a utilizaram como uma tarefa de categorização e não como uma tarefa de raciocínio dedutivo.

Porém, autores como Wagner-Egger (2001), buscando superar as contradições (e as críticas) entre as teorias dos esquemas pragmáticos de raciocínio e a teoria do contrato social, propôs uma compatibilidade e uma síntese dessas duas teorias. Ao considerá-las teorias complementares e não excludentes, esse último autor utilizou, em seus estudos, princípios de ambas as teorias e, através de evidências empíricas, sugeriu que o desempenho nas tarefas de raciocínio era afetado tanto pelos esquemas pragmáticos quanto pelos aspectos utilitários (relação custo/ benefício) envolvidos nas tarefas.

Em suma, podemos concluir que diferentes evidências empíricas na esfera do raciocínio vêm também apontando para o efeito positivo da proximidade dos conteúdos dos enunciados dos problemas com as experiências concretas dos indivíduos e, consequentemente, para uma maior dificuldade no desempenho de tarefas que envolvem o raciocínio em uma situação-problema mais “abstrata” e mais formal do ponto de vista lógico. Aspectos relacionados às trocas sociais e à cooperação entre indivíduos frente a tarefas que envolvem a aplicação de regras de permissão/ proibição, como a clássica tarefa de Wason, também parecem se somar aos aspectos pragmáticos, o que parece tornar ainda mais dinâmico e mais dependente de contexto e de conteúdo o raciocínio humano. 
3.2.4-O Papel dos Conteúdos dos Enunciados de Problemas na Resolução de Problemas Mal-definidos e na Transferência Analógica

Os denominados problemas “mal-definidos” ou “mal-estruturados”, por definição, supõem a falta de um caminho explícito, com etapas e representações do problema mais definidas, e, principalmente, supõem a falta de um estado final ou de meta claro que possa ajudar na movimentação por um “espaço do problema” em direção à solução.

Muitos problemas cotidianos poderiam ser considerados mal-definidos pois, muitas vezes, não costumam apresentar uma explicitação dos operadores ou mesmo uma explicitação das condições iniciais do problema e, frequentemente, não costumam acenar claramente para um estado de meta/solução. Problemas que surgem, inclusive, nas inúmeras situações que envolvem a intervenção do psicólogo poderiam ser considerados mal-definidos. Não só na clínica psicológica, mas em dinâmicas grupais ou em qualquer situação que envolva interação social, conflitos pessoais e/ou de interesses pessoais, os problemas que aí surgem costumam ser mal-definidos e costumam possibilitar o uso de diferentes estratégias que, por sua vez, traçam diferentes caminhos para diversificadas soluções.

Como foi visto, em seção anterior, as pesquisas que focalizam problemas cotidianos (in vivo) (Dunbar, 2001; Blanchette \& Dunbar, 2001; Dunbar \& Blanchette, 2001; Blanchette \& Dunbar, 2002; Christensen \& Schunn; 2007) têm trazido muitas contribuições e indagações para as pesquisas desenvolvidas em laboratório (in vitro). Acrescentaríamos, a mesma regra parece valer para as pesquisas in vitro, pois acreditamos que as pesquisas de laboratório também trazem inúmeras contribuições e indagações para os estudos in vivo, por apresentar, normalmente, um maior rigor metodológico e uma melhor definição das variáveis envolvidas.

Vários problemas mal-definidos foram utilizados ao longo da história da psicologia em especial no contexto do gestaltismo. Os tradicionais problemas dos “dois fios” de Maier (1931), das “jarras de água” de Lunchins (1942), o problema da "vela” e o da “radiação” de Duncker (1945), o problema dos “nove pontos” de Scheerer (1963), dentre outros problemas mal-definidos, são alguns mais conhecidos nessa esfera. Do ponto de vista gestaltista, são problemas que demandam um processo de insight, ou seja, uma solução que envolve uma reestruturação súbita do campo perceptivo e que demandam um processo de recriação e de compreensão do significado do problema. 
No que se refere ao conceito de insight, cabe destacar que esse conceito hoje em dia extrapola a ênfase na reestruturação perceptiva proposta pelo gestaltismo clássico. De acordo com Mayer (1996) o insight poderia ser hoje visto sob várias óticas: a primeira delas como "completando um esquema"; a segunda como "reorganizando as informações visuais”; a terceira como "reformulando um problema”; a quarta como “vencendo um bloqueio mental” e a quinta, por sua vez, como "encontrando um problema análogo”. No que diz respeito a essa última perspectiva, estudos de Holyoak (1990) também apontaram para essa direção.

Tendo em vista que o conceito de insight poder ser dimensionado sob várias perspectivas, como apontou Mayer (1996), a perspectiva que aqui nos interessa é aquela que destaca a relação entre analogia e insight. Wertheimer (1959) no passado já havia sugerido que o processo de insight às vezes envolve a apreensão da organização estrutural de uma situação e a aplicação dessa organização a um novo problema. Porém a ênfase nas características de superfície entre os problemas poderia “limitar” a aplicação de uma solução apenas para problemas muito similares, por isso haveria a necessidade da apreensão das relações estruturais entre os problemas para que houvesse a transferência para “qualquer” problema isomórfico.

Poderíamos lembrar que o processo de transferência analógica não envolve apenas a aplicação de uma solução anteriormente vista a uma nova situação-problema, pois isso demandaria um pensamento mais “reprodutivo" do que "produtivo" e, nesse sentido, não envolveria processos de insight, como na acepção do gestaltismo tradicional. Na verdade, o processo de transferência analógica implica não só em recuperar na memória uma solução análoga anterior, mas sim em “adaptar” essa solução aos limites impostos por uma nova situação-problema pois, como vimos anteriormente, “coações” de diferentes naturezas se fazem presentes nesse processamento. Nesse sentido, então, o pensamento analógico parece compatibilizar a "reprodução” de uma informação vista com a "produção” de uma adaptação dessa solução a um novo contexto.

Mayer, nesse mesmo estudo teórico, também observou que é comum a discriminação de duas fases no processo de resolução de problema nas teorias na área: uma inicial de representação do problema e uma fase de solução. Na fase de representação, o solucionador construiria uma representação mental do problema que traria a sugestão do plano de solução e, na fase de solução propriamente dita, o solucionador colocaria esse plano em ação. Não obstante, para esse autor, a maioria dos pesquisadores que focalizou o processo de insight priorizou os processos iniciais de 
representação e não os processos de solução. Inclusive, o conceito inicial de insight com sua ênfase na reestruturação perceptiva parece indicar essa priorização. Podemos destacar que uma das críticas das abordagens do processamento da informação ao gestaltismo e, em especial, ao conceito de insight, se deve à essa ênfase na mudança representacional inicial em detrimento dos processos de solução propriamente ditos. De modo complementar, a idéia de uma mudança "súbita” entre um estado inicial e um estado de meta sem a mediação de processos graduais e mais diferenciados parece, hoje em dia, um pouco dissonante frente à hegemonia do detalhamento do processamento da informação nas teorias na área. A falta de rigor metodológico e de clareza de alguns de seus conceitos teóricos também foi alvo da crítica de autores como Dellarosa (1991), dentre outros.

Buyer e Dominowski (1989) apresentaram evidências de que a generalização da solução de um problema poderia ser ineficaz se não for feito o pedido para que o solucionador compreenda todas as relações entre os problemas análogos apresentados. Ao testar a recuperação de analogias após o intervalo de uma semana, esses autores observaram que os participantes que resolveram completamente o problema na primeira sessão apresentaram melhor taxa de transferência do que aqueles que apenas leram a sua solução ou que, após errarem a solução, viram a resposta correta. Esses resultados seriam consistentes com a proposta dos autores de que a compreensão da estrutura de um ou mais problemas é um fator determinante para a retenção de sua solução na memória.

Sendo assim, no que se refere também ao conceito de insight e à transferência analógica, podemos observar, conjuntamente com Dominowski e Dallob (1996), que não só uma reestruturação perceptiva estaria envolvida na apreensão da solução de um problema, mas, especialmente, na compreensão do significado das relações estruturais entre problemas. Processos metacognitivos adjacentes que incluem o planejamento, o monitoramento e a avaliação da solução também estariam envolvidos para a garantia da eficácia da generalização da solução.

Fonte de inúmeras pesquisas na atualidade, a ênfase nos processos metacognitivos tem sido alvo de controvérsias e de algumas dificuldades metodológicas em sua avaliação. Nessa direção, Berardi-Coletta, Buyer, Dominowski e Rellinger (1995) assinalaram a importância de estudos teóricos e empíricos que definam os processos metacognitivos como aqueles que são orientados pelo "processo" de resolução e não apenas pelo problema em si ou por simples verbalizações. Em seus estudos, os 
participantes, que utilizaram esse recurso metacognitivo, conformaram representações mais sofisticadas e desenvolveram melhores estratégias de resolução de problema. Dominosvki (1990) também já havia enfatizado os processos metacognitivos como capazes de suscitar considerável aumento no desempenho dos indivíduos, ainda que as situações-problema não requeressem conhecimento específico, como seria o caso dos problemas mal-definidos do cotidiano.

Mais recentemente, Ormerod, Chronicle e MacGregor (2002), Chronicle, Ormerod e MacGregor (2004) apresentaram experimentos onde investigaram o processo de insight em problemas mal-definidos. O problema utilizado nesses estudos foi um novo problema mal-definido denominado das “Oito Moedas” (nos estudos de 2002) e uma versão do mesmo com "Seis Moedas" (nos estudos de 2004), problemas esses semelhantes ao dos "Seis Palitos de Fósforo", proposto por Scheerer (1963). Esses estudos se complementaram na discussão da dinâmica dos objetivos, das heurísticas e das “coações” envolvidos em problemas de insight a partir de um olhar da abordagem do processamento da informação. Em uma das suas principais conclusões, esses autores destacaram que a teoria do processamento da informação poderia ser utilizada para o entendimento das movimentações, das heurísticas e dos objetivos de problemas de insight, como os problemas propostos por eles. Nesse sentido, esses autores tentaram compatibilizar a abordagem do processamento da informação com alguns conceitos da abordagem gestaltista e, de certo modo, tentaram “atualizar” alguns desses conceitos como o próprio conceito de insight.

Como vimos em seções anteriores, um dos principais problemas mal-definidos utilizados por pesquisas na área é o clássico problema da radiação de Duncker e versões análogas do mesmo. Os estudos já referidos do próprio Duncker (1945) e os de Holyoak e colaboradores (1980; 1983; 1987; 1989), de Gick (1985; 1990) e de Helfenstein e Saariluoma (2006) são exemplos de pesquisas empíricas que tiveram como instrumento o problema da radiação e/ou seus análogos. Através de diferentes manipulações e procedimentos experimentais, esses pesquisadores parecem se complementar em sua ênfase no papel dos conteúdos dos enunciados dos problemas na transferência analógica.

No que se refere ao problema da radiação de Duncker (1945), ainda consideramos oportuno mencionar que, nos próprios estudos realizados por Duncker, foram usadas variações no fraseado do problema e em diagramas utilizados para sua descrição. Duncker verificou que diferentes apresentações de diferentes fraseados ou de diferentes 
diagramas levavam os indivíduos a focalizar diferentes aspectos do problema, influenciando significativamente as representações que eles formavam, algumas sendo mais efetivas do que outras em levar a uma solução. Como vimos, estudos posteriores de Gick e Holyoak (1983), Gick (1985) e Helfestein e Saariluoma (2006), que também manipularam diagramas que explicitavam visualmente princípios de problemas, também apontaram para a importância das representações mentais construídas e/ou dos modelos mentais dos indivíduos para a efetiva solução e transferência dos problemas apresentados.

Duncker também encontrou um efeito da interpretação semântica baseado em como os objetos são usados. De fato, os indivíduos podem fazer inferências a partir de entidades específicas que aparecem no problema e estas, inferências podem, por sua vez, afetar a representação construída. O exemplo clássico de tais inferências seria o fenômeno da “fixação funcional”, fenômeno esse introduzido por Duncker (1945) em seus estudos.

Como já havíamos referido, os estudos acima (Gick \& Holyoak, 1980; 1983; Gick, 1985; 1990; Holyoak \& Koh, 1987; Catrambone \& Holyoak, 1989), utilizando também o problema da radiação e/ou seus análogos, apresentaram achados que corroboram a importância da semelhança entre os conteúdos como um fator positivo no processo de transferência analógica. Como foi também visto, alguns destes estudos, como os de Holyoak e Koh (1987), variaram o grau de similaridade das características de superfície, incluindo-se aí os conteúdos semânticos dos enunciados, em problemas análogos ao problema da radiação. Por exemplo, ao contrapor os conteúdos do problema do "Bulbo da Lâmpada”, que possui conteúdos similares aos da radiação, com conteúdos mais distantes, como os do problema do general, apontaram evidências do impacto da similaridade de conteúdos na transferência analógica, especialmente na transferência espontânea. Manipulando o grau de similaridade entre os conteúdos dos problemas análogos como, por exemplo, o uso de ultra-som, a aplicação de raios laser, a aplicação de raios $X$, a convergência de tropas do exército, etc., os autores acima puderam investigar, de modo mais sistemático, o papel da proximidade semântica dos conteúdos dos enunciados na transferência analógica.

Em nosso estudo também tivemos a preocupação de equiparar os conteúdos semânticos envolvidos na descrição do modo de solução dos dois problemas "fonte" para que estes problemas mantivessem não só aspectos comuns (por exemplo, o uso de raios ultravioleta, o uso de raios infravermelhos, etc.), mas também para que esses 
aspectos mantivessem o mesmo grau de proximidade em relação aos conteúdos dos problemas "alvo". Entretanto, apesar de certa semelhança entre os conteúdos que descrevem os modos de solução dos problemas “fonte” propriamente ditos, as histórias como um todo remetem a contextos temáticos diferentes, pois descrevem situações distintas vivenciadas por diferentes narradores ( anexo 1).

Em suma, no que se refere ao papel dos conteúdos dos enunciados dos problemas mal-definidos na resolução de problemas e na transferência analógica, podemos concluir que esses conteúdos teriam efeitos positivos na facilitação da transferência, como o próprio Duncker (1945) já havia destacado no passado. Estudos mais contemporâneos com uma abordagem do processamento da informação, que também utilizaram o problema da radiação ou outros problemas mal-definidos, vêm complementando os estudos, hoje considerados clássicos, de Duncker e de outros expoentes do gestaltismo. Como vimos, esses estudos trouxeram novas evidências que corroboraram para o importante papel das características de superfície, em especial os conteúdos dos enunciados, no processo de transferência analógica.

Por fim, como vimos anteriormente ao longo desse capítulo e do capítulo anterior, as evidências trazidas pelos estudos empíricos iniciais de Holyoak e colaboradores (1980; 1983; 1987) sugeriram que os efeitos positivos dos conteúdos se dão mais nos processos iniciais de acesso e de recuperação de informações na memória e não no processo de mapeamento per se, pois, a seu ver, o mapeamento depende prioritariamente da percepção da similaridade estrutural dos problemas. Porém, evidências trazidas por pesquisadores como Ross (1987; 1989) e Ross e colaboradores (1990; 1996) sugeriram que os conteúdos também exercem um importante papel, não só nos processos iniciais de acesso a um ou mais problemas análogos anteriores, mas também nos processos de “aplicação”, como o processo de mapeamento analógico. Não obstante, estudos teóricos mais recentes de Hummel e Holyoak (1997), Holyoak e Hummel (2001), Holyoak (2005) vêm propondo um modelo conexionista-simbólico, onde os conteúdos semânticos dos enunciados são enfatizados, não só nos processos iniciais de acesso, mas também no processamento analógico como um todo, incluindo-se aqui o processo de mapeamento, o que realça ainda mais o papel que estes conteúdos representam na transferência analógica.

Em resumo, apresentamos aqui evidências de uma gama de estudos que se somam para destacar a importância dos conteúdos dos enunciados dos problemas no processo de resolução de problemas e de transferência analógica. Podemos observar, inclusive, 
que o impacto desses conteúdos parece se manifestar em tarefas de diferentes naturezas. Em outras palavras, mesmo quando há a variação do conhecimento requerido para a solução - muito ou pouco- do tipo de problema envolvido - bem ou mal-definido - o impacto dos conteúdos dos enunciados e de outras características de superfície parece se fazer presente em maior ou menor grau. Nessa direção, uma investigação que também manipule a tonalidade afetiva dos conteúdos dos enunciados de problemas maldefinidos, como aquela aqui proposta, pode vir a complementar as investigações que enfatizaram a manipulação de conteúdos semânticos "neutros”, como os estudos apresentados nos dois primeiros capítulos.

A seguir, complementaremos as evidências apresentadas com uma abordagem mais específica sobre a influência do afeto na memória, na resolução de problemas e na transferência analógica. A proposta de um capítulo destinado a essa interface objetivou a apresentação de estudos mais diretamente relacionados a esse tipo de investigação, estudos esses que se mostraram de particular importância para a fundamentação das nossas principais hipóteses de pesquisa. 


\section{4-Capítulo III: Afeto, Memória, Resolução de Problemas e Transferência Analógica}

\section{1-Definições Iniciais}

Como já sinalizamos anteriormente, somente nas últimas duas décadas houve um interesse mais sistemático em estudar os efeitos do afeto na cognição. A hegemonia da perspectiva cognitivista tradicional e sua ênfase no processamento da informação de certo modo justificou o tardio interesse pelo estudo do afeto na Psicologia Cognitiva.

Antes de apresentarmos, na próxima seção, as evidências de estudos mais direcionados para a nossa pesquisa, cabe esclarecer que os termos “afeto" e "estados afetivos” são aqui considerados termos sinônimos, como costuma ser feito na área, possuindo assim um sentido amplo que abrange não só as emoções propriamente ditas, mas também os estados de humor, os sentimentos ou qualquer outra manifestação de caráter "afetivo". Sendo assim, torna-se sobremodo difícil definirmos afeto de modo mais preciso e excludente, pois tal definição pode não vir a refletir os diferentes estudos na área que utilizam esta terminologia.

De acordo com Fredrickson (2001), apesar de haver uma variação na definição “operacional” de conceitos como “emoção” e “afeto” na literatura científica e do longo debate envolvido nessa conceituação, haveria certo consenso de que as emoções poderiam ser consideradas como uma ampla classe de fenômenos afetivos. Na perspectiva dessa autora, o conceito de afeto poderia ser visto como um conceito mais geral, o continente mais amplo que inclui as emoções, os sentimentos, as atitudes, os humores e toda ordem de sensações físicas, endócrinas e neurais correlacionadas.

A concepção de afeto no senso comum, por sua vez, parece enfatizar os sentimentos, incluindo-se aqui a amizade, a simpatia e a afeição por algo ou por alguém como formas de afeto (nota-se essa ênfase nas primeiras definições de afeto nos dicionários Houaiss, 2001 e Novo Aurélio, 1999). Nessa perspectiva, observa-se, no senso comum, uma priorização dos sentimentos como sinônimo de afeto, em especial, os sentimentos dirigidos a pesssoas.

Não obstante, alguns autores como Dai e Sternberg (2004), ao esboçar uma contraposição entre os termos “afeto” e “emoção”, destacaram o fato de que são termos que costumam ser usados de modo intercambiável, mas que, em uma definição estrito senso, poderiam ser diferenciados em seus referentes. Em uma definição mais 
excludente, a palavra afeto seria mais indicada para definir estados afetivos mais difusos, nem sempre acompanhados por uma alteração nítida no sistema nervoso autônomo, como os estados de humor. Nessa perspectiva, apesar de se referir a estados subjetivos que nem sempre possuem um referente bem definido, o termo afeto parecer carrear um “tom” avaliativo que se expressa através de uma valência positiva ou negativa, valência essa que qualifica o estado subjetivo de modo mais amplo.A palavra emoção, por seu turno, seria mais indicada para definir estados afetivos acompanhados por uma alteração visceral e autonômica precisa e identificável. Desse modo, o termo afeto seria mais apropriado para qualificar estados subjetivos menos definidos em sua origem e intensidade e o termo emoção, por seu turno, seria mais apropriado para qualificar estados subjetivos mais diferenciados em sua origem, intensidade e duração temporal, como, por exemplo, as emoções medo e raiva.

Autores como Schwarz e Skurnik (2003), de modo complementar, assinalaram que o termo emoção poderia estar mais relacionado a reações específicas frente a situações que envolvem desejos e necessidades individuais, enquanto o termo afeto, em contraste, poderia estar mais relacionado a vivências subjetivas difusas que não costumam ter uma nítida qualificação do motivo que as desencadeou e nem mesmo do alvo a que se dirigem.

Porém Cacioppo, Klein, Berntson e Hatfield (1993) assinalaram que o termo emoção poderia, assim como o termo afeto, ter uma conotação abrangente, pois as emoções humanas representariam um fenômeno psicológico que engloba aspectos de diferentes naturezas como os aspectos cognitivos (p.e. lembranças, sentimentos, etc.), aspectos viscerais, endócrinos e imunológicos, expressões corporais e vocais, dentre outras manifestações fisiológicas e comportamentais. Nessa mesma direção, Marino (1975), no passado, já havia destacado o conjunto de aspectos cognitivos, vivenciais e expressivos, bem como o grau de excitação dos processos mentais, que estariam conformando aquilo que definimos como “emoção”.

Smith e Kirby (2001), por sua vez, propuseram uma definição de emoção como um sistema sofisticado de monitoramento do bem-estar dos indivíduos que teria a função de regular a atenção e de direcionar a motivação. Essa função regulatória das emoções também foi destacada por Simon (1967), no passado, pois, em sua perspectiva, as emoções representariam um sistema que possibilitaria que os indivíduos tivessem uma reação flexível frente aos desafios de um ambiente incerto e complexo. Simon, inclusive, considerava as emoções como representando um mecanismo de "interrupção" 
na atividade dos indivíduos, mecanismo esse que demandaria o monitoramento das condições ambientais para que ações relevantes fossem desencadeadas, bem como demandaria o monitoramento da urgência dessas ações. Porém, como observaram Smith e Kirby (2001), as emoções poderiam ser vistas, não apenas como envolvendo um mecanismo de “interrupção", mas também como envolvendo mecanismos de feedback, ou seja, envolvendo o monitoramento dos resultados das ações em curso para que as mesmas possam ser mais bem ajustadas às condições ambientais e aos objetivos dos indivíduos. Por exemplo, emoções positivas sinalizariam o bom andamento das ações e o cumprimento dos objetivos, enquanto emoções negativas sinalizariam o contrário.

Damásio (1994; 2000; 2004) também parece utilizar de modo mais inclusivo o termo emoção, na medida em que propõe um modelo hierárquico das emoções, onde emoções mais indefinidas, difusas, as chamadas emoções de fundo, serviriam de "base” para as chamadas “emoções primárias”, ou seja, emoções de origem inata, como o medo e a raiva, que, por sua vez, seriam seguidas por emoções secundárias ou sociais, como a empatia. Na concepção desse autor, o termo afeto poderia ser usado como sinônimo de emoção e de humor, embora possa ter uma conotação mais genérica, ou seja, possa se referir às emoções, aos estados de humor e aos sentimentos como um todo. Sendo assim, tudo que um indivíduo sente ou manifesta em relação a outro indivíduo, a um objeto ou a uma situação poderia ser considerado como uma forma de "afeto”. Porém, podemos observar que Damásio, em muitos de seus trabalhos (1994; 2000; 2004), fez pouca referência ao termo afeto per se, sendo uma de suas principais diferenciações conceituais voltadas para os conceitos de emoção e de sentimento. Observa-se ainda, nesses estudos, uma abordagem evolucionista das emoções, abordagem essa compartilhada por muitos autores contemporâneos, que enfatizam a relação entre os processos emocionais e os processos cognitivos, como Ornstein (1991), LeDoux (1992; 1998), dentre inúmeros outros.

Clore e Huntsinger (2007), em contraposição ao pouco uso do termo afeto por Damásio nesses trabalhos, utilizaram, por sua vez, o termo afeto de modo mais recorrente em seus estudos e parecem seguir o ponto de vista mais prevalente na área, na medida em que destacam o caráter abrangente e inclusivo dos termos afeto e estado afetivo. Para esses autores, tanto os estados de humor como as emoções poderiam ser vistos como representações de um valor pessoal que se expressariam em diferentes 
níveis: neurológico, fisiológico, experiencial, comportamental, cognitivo, dentre outras formas de expressão e poderiam ser, ambos, considerados “afetivos” em sua origem.

Se, por um lado, observamos algumas diferenciações entre os termos afeto e emoção como aquelas propostas por Schwarz e Skurnik (2003) e Dai e Sternberg (2004), também observamos, por outro lado, autores como Damásio (2000), Clore e Huntsinger (2007), dentre outros, que parecem destacar o caráter inclusivo do termo afeto. Mas, enquanto emoções específicas, como as emoções primárias, e emoções mais difusas, como os estados de humor, poderiam ser consideradas como possuindo um caráter “afetivo”, nem tudo que é considerado “afetivo” é, necessariamente, um estado de humor ou uma emoção. Um exemplo disso seria a valência afetiva positiva ou negativa de um dado estímulo apresentado em uma tarefa experimental, como a valência de filmes, reportagens, narrativas ou histórias e, nesse contexto, a tonalidade afetiva dos conteúdos dos enunciados de um problema.

Concluímos assim que parece não haver na literatura na área um consenso absoluto na definição do termo afeto. E embora as emoções e os estados afetivos sejam considerados “afetos", eles poderiam ser diferenciados entre si em, pelo menos, três dimensões: em termos de sua intensidade, de sua especificidade e pelo fato de serem ou não estados difusos, imprecisos. Sendo assim, frente às definições apresentadas, foi feita a opção pelo uso do termo afeto como uma terminologia mais ampla que abrange os estados subjetivos mais difusos de humor, os sentimentos e as emoções mais específicas, com sua qualificação mais demarcada e precisa do ponto de vista fisiológico. Tendo isso em vista, uma conotação mais genérica e inclusiva dos termos “afeto” e “estado afetivo” será mantida ao longo do presente trabalho.

Porém, devido ao nosso particular interesse por estudos direcionados à influência dos estados de humor no processamento cognitivo, este tipo de estudo será aqui priorizado e não estudos que priorizam a influência de emoções específicas na memória, na resolução de problemas e na transferência analógica.

Cabe aqui uma observação, como sinalizaram Tobias, Kihlstrom e Schacter (1992), de que o humor poderia ser visto não meramente como um "estado" como a hipnose ou o sono, mas principalmente como uma espécie de "pista” de contexto que seria processada na memória em conjunto com outras “pistas” contextuais e, nesse sentido, teria um papel importante na recuperação de informações. Entretanto, por ser uma “pista” contextual que nem sempre é forte e aparente, como outras “pistas” de contexto, 
o humor parece ter mais efeitos na memória implícita do que na memória explícita, como esses autores sugeriram.

Na interface entre o afeto e a cognição, em especial entre o afeto a e resolução de problemas e a transferência analógica, enfatizaremos os efeitos dos estados afetivos na cognição, tanto no que se refere à influência do afeto nos “conteúdos” da cognição, quanto no que se refere a sua influência no "processamento" e nas estratégias de processamento da informação.

Sendo assim, esse capítulo tem por objetivo apresentar, inicialmente, evidências de estudos que focalizam os efeitos dos estados afetivos, em especial dos estados de humor, na memória, na resolução de problemas e na transferência analógica. Por último, mas não menos importante, o objetivo foi o de apresentar estudos que abordam a influência das tonalidades afetivas dos conteúdos dos enunciados de problemas no processo de transferência analógica. Como já mencionamos, foram encontrados poucos estudos mais direcionados para este último tipo de investigação.

Como também já mencionamos, quando utilizamos o termo “tonalidade afetiva” dos conteúdos dos enunciados e da história como um todo, estamos nos referindo à valência afetiva (positiva, negativa ou neutra) que "tinge” estes conteúdos ou conceitos. Por exemplo, uma história que narra uma situação de insucesso, perdas, morte, etc. poderia ser considerada como tendo uma tonalidade afetiva desagradável/triste, em contraposição a uma história que narra uma situação de sucesso, brincadeiras, nascimento, etc., que poderia ser considerada como tendo uma tonalidade afetiva agradável/alegre. Por último, uma história que relata, por exemplo, uma expedição de cientistas, poderia ser considerada, por sua vez, de tonalidade "neutra” (nem triste, nem alegre).

Por fim vale lembrar que, em nossa pesquisa, pretendemos discriminar dois tipos de influências “afetivas” no processo de transferência analógica: a primeira delas poderia ser considerada como "verdadeiramente afetiva", no sentido mais comum do termo, pois se refere ao estado de humor dos participantes como auto-relatados pelos mesmos. A segunda, por sua vez, ao se referir à tonalidade afetiva dos conteúdos dos enunciados (positiva ou negativa), poderia ser considerada como sendo afetiva em função de sua valência, sendo que pode vir ou não a provocar alterações no estado de humor dos participantes. Esse segundo tipo de influência do afeto na transferência analógica nos interessa sobremodo, pois inclusive consideramos que ela possa se manifestar sem que haja uma alteração do estado de humor dos indivíduos. Em outras palavras, acreditamos 
que os efeitos da similaridade afetiva de histórias de problemas possam se dar sem que haja, necessariamente, uma alteração do humor dos indivíduos.

Sendo assim, a apresentação, nas próximas seções, de estudos que investiguem, por um lado, a influência dos estados de humor dos indivíduos na memória, na resolução de problemas e na transferência analógica e, por outro lado, de estudos que investiguem a influência da tonalidade afetiva dos conteúdos dos enunciados nesses processos, mostrase de fundamental importância para a fundamentação das nossas principais hipóteses de pesquisa.

\section{2- Considerações Iniciais sobre o Papel do Afeto na Cognição}

Muitos estudos vêm explicitando na contemporaneidade a influência do afeto e de suas múltiplas manifestações em praticamente todos os aspectos da vida mental humana. O entendimento do papel do afeto em nossa memória, nossos pensamentos, julgamentos e tomadas de decisão e em outros processos cognitivos têm sido foco de inúmeras investigações nos últimos tempos.

Do ponto de vista histórico, a tradição platônica e, especialmente, o dualismo mente/ corpo cartesiano parecem ter inspirado muitas das abordagens psicológicas do passado, especialmente na sua concepção da relação entre o afeto e a cognição. Nesse contexto, muitas vezes, a influência do afeto na racionalidade humana foi vista como perniciosa, como fonte de distúrbio e manifestação de forças "primitivas” que deveriam ser controladas pela superioridade da razão. Mesmo a psicanálise freudiana, que de certo modo resgatou a importância do afeto e explicitou sua nítida influência no comportamento humano, poderia ser vista, sob determinada perspectiva, como reforçando uma idéia negativa da influência do afeto na cognição. A abordagem behaviorista, de modo geral, também não se preocupou em investigar essa influência e a abordagem do processamento da informação que a substituiu em hegemonia, por sua vez, voluntariamente deixou em segundo plano o papel do afeto na cognição. Nota-se uma exceção a essa regra, por exemplo, nas abordagens evolucionistas da psicologia, onde a relação entre o afeto e a cognição alcançou um status positivo há mais tempo, inclusive, a nosso ver precursor do atual quadro extremamente fecundo de pesquisas situadas nessa interface.

A ênfase no processamento da informação iniciada em fins da década de 50, com sua especial focalização nas computações “frias”, racionais, colocou em segundo plano o 
papel dos estados afetivos e das influências socioculturais neste processamento. Sob a égide do arcabouço do processamento da informação foram, inclusive, construídos muitos modelos teóricos de inspiração computacional, alguns destes com excessiva formalização computacional, como apontaram vários autores, entre eles Neisser (1976), Searle (1987), e Bruner (1997). De certo modo, alguns desses modelos, especialmente aqueles construídos pela chamada Inteligência Artificial (I.A.) “forte”, teriam tomado a metáfora computacional de forma literal, na medida em que deixaram de considerar o ser humano como um "sistema aberto", ou seja, um sistema que está em constante interação com seu meio ambiente físico e social, vendo-o, em contrapartida, como um sistema "fechado" em suas computações.

Podemos observar, ao longo da história da psicologia, que os dois paradigmas hegemônicos, inicialmente o paradigma behaviorista, com sua ênfase nos aspectos conativos, ou seja, no comportamento motivado e orientado para a ação e, posteriormente, o paradigma cognitivista, com sua ênfase nos aspectos cognitivos, ou seja, no processamento da informação per se, não deram muita importância ao estudo dos processos afetivos e nem ao estudo da relação entre as dimensões afetiva, conativa e cognitiva do comportamento humano.

Historicamente falando, o estudo dos afetos na psicologia ficou, no passado, quase que circunscrito a teorias tais como a psicanálise e a outras teorias psicodinâmicas, que apesar de sua heterogeneidade teórica, possuíam uma preocupação mais clínica e terapêutica.

Não pretendemos entrar no mérito das contribuições dessas teorias para o estudo dos afetos e nem mesmo pretendemos ir muito longe em nossa delimitação teórica. Não obstante, vale fazer um breve parêntese para destacar o fato de que alguns estudos no passado com uma abordagem mais psicodinâmica, tais como os de Murray (1933), de Feshbach e Singer (1957), de Izard (1964), dentre outros, ao enfocar a influência do afeto em situações-problema que exigiam, por exemplo, um julgamento cognitivo em um contexto inter-pessoal, foram, de certo modo, precursores de muitos estudos contemporâneos e merecem menção, ainda que breve.

Bruner, Goodnow e Austin (1956), mentores do movimento denominado "New Look in Perception", foram também precursores da ênfase dada aos aspectos afetivos e motivacionais envolvidos na percepção. Para Bruner e colaboradores, a percepção e categorização social de pessoas, situações e experiências, seriam nitidamente influenciadas pelo afeto, pois o que levaria alguém a dizer que uma dada experiência o 
faz lembrar de tal pessoa ou de tal evento seria a evocação de uma resposta afetiva associada a essa pessoa e/ou evento.

Os trabalhos de Murray (1933) mostraram-se pioneiros na verificação do papel dos estados afetivos em situações-problema que envolviam um julgamento inter-pessoal. Com ênfase na influência dos estados afetivos positivos e negativos na avaliação e no julgamento de pessoas, Murray apresentou, em um dos seus experimentos, uma série de fotografias para que fosse avaliado, pelos sujeitos experimentais, o grau de benevolência e de malícia das faces apresentadas. Foram duas as condições experimentais manipuladas nessa pesquisa: uma delas envolvia o desempenho de uma atividade prazerosa em um dia de sol e a outra envolvia um jogo que simulava assassinatos em uma situação de escuridão. E após essas duas condições iniciais eram então apresentadas as fotografias para serem avaliadas. Os resultados apontaram para um aumento do julgamento negativo de malícia e de hostilidade das faces, após a vivência do medo e, de modo oposto, para o julgamento positivo das faces, após a vivência de uma brincadeira prazerosa.

Feshbach e Singer (1957) também estudaram os efeitos da expressão do medo, bem como o da supressão do medo em situações experimentais que envolviam uma percepção social. Três tipos de tratamentos experimentais foram propostos para os grupos: no primeiro tratamento havia o incentivo da expressão do medo nos participantes, após os mesmos terem sido submetidos a estímulos aversivos (choques elétricos) administrados em intervalos de tempo intermitentes durante a apresentação de um filme; no segundo tratamento, por sua vez, havia o incentivo da supressão do medo, após o recebimento do mesmo estímulo e a apresentação concomitante do mesmo filme; e, por último, no terceiro tratamento, o do grupo de controle, o filme era apresentado sem que houvesse a administração de um estímulo aversivo. Os resultados obtidos apontaram para uma percepção pessoal dos personagens do filme como mais agressivos e/ou amedrontadores nas condições experimentais que envolviam a estimulação aversiva, tanto na situação de expressão quanto na situação de supressão do medo. Já o grupo de controle, que não sofreu esse tipo de manipulação, não apresentou tal percepção. Como os autores observaram, os dados também sugeriram maior “projeção" de sentimentos pessoais, especialmente no grupo submetido à supressão do medo, pois houve nesse grupo maior uso de categorias relacionadas ao medo no julgamento dos personagens do filme. 
Posteriormente, Izard (1964) relatou um estudo em que eram apresentadas quatro condições experimentais a quatro grupos de sujeitos, onde em cada uma das condições uma atriz desempenhava um papel: na primeira condição, um papel de uma pessoa ansiosa e com medo, na segunda condição, o papel de uma pessoa raivosa e hostil, na terceira condição, o papel de uma pessoa entusiasmada e alegre e, por último, na quarta condição, o papel de uma pessoa amigável e gentil. Os sujeitos avaliaram seus sentimentos antes e após a apresentação da atriz e desempenharam diferentes tarefas após terem assistido à encenação. Os sujeitos que foram submetidos às condições em que os papéis teatrais eram positivos (alegre e amigável) tiveram um comportamento mais construtivo durante a execução das tarefas e os sujeitos submetidos às condições em que os papéis eram negativos (raivoso e ansioso) tiveram um comportamento menos construtivo durante as tarefas. Esses achados parecem reforçar os achados anteriores de Murray (1933) e Feshbach e Singer (1957) sobre a importância dos estados afetivos no julgamento inter-pessoal e no desempenho de tarefas de diferentes naturezas.

Já no que se refere às pesquisas desenvolvidas no contexto behaviorista, podemos destacar alguns estudos do passado, onde a influência do afeto na cognição foi a tônica, como os de Byrne e Clore (1970), sobre julgamento social e atração inter-pessoal, e os de Gouaux (1971) e Griffitt (1970), sobre a atração inter-pessoal, dentre inúmeros outros.

Byrne e Clore (1970) propuseram, em seus estudos, um modelo de condicionamento que foi um dos primeiros a destacar a importância do estado afetivo interno dos sujeitos como fator determinante no julgamento e na atração inter-pessoal. Os resultados de sua pesquisa também foram em direção àqueles dos últimos estudos citados, com a assunção de que o estado afetivo dos indivíduos tinha influência direta no julgamento social e na atração inter-pessoal, pois quando o mesmo era positivo havia um melhor julgamento e uma maior atração inter-pessoal e quando era negativo a situação inversa ocorria. Gouaux (1971), em estudos posteriores, buscou complementar os estudos de Byrne e Clore investigando os efeitos da indução dos estados afetivos na atração interpessoal, reafirmando a idéia de que o grau de atração inter-pessoal se dava em função dos estados afetivos positivos e negativos dos indivíduos.

Griffitt (1970), por sua vez, ao estudar os efeitos da temperatura do ambiente na atração inter-pessoal, combinou dois níveis de temperatura (quente e normal) com dois níveis de atitude inter-pessoal (positiva e negativa). Os achados de seu experimento sugeriram que, quando o aumento da temperatura ambiental chegava a um nível 
desconfortável, os indivíduos tendiam a ter uma atitude inter-pessoal mais negativa do que em condições normais de temperatura. Sendo assim, a manipulação da temperatura afetou nitidamente a experiência subjetiva e, consequentemente, influenciou no julgamento inter-pessoal desses indivíduos.

Porém, como observou Forgas (2001a), as teorias psicodinâmicas e as teorias de condicionamento poderiam ser, ambas, criticadas por sua inabilidade em explicar a maneira como múltiplas fontes de informações, afetivas ou não afetivas, poderiam ser combinadas e integradas, por exemplo, quando as pessoas fazem um julgamento social. Talvez essas teorias tenham falhado em uma explicação mais convincente da relação entre afeto e cognição por não terem como referência um modelo teórico bem articulado que precisasse as operações mentais envolvidas nesse contexto. Entretanto, apesar das limitações teóricas, empíricas e, por que não dizer, de zeitgeist dessas teorias, a abordagem psicodinâmica proposta por Feshbach e Singer (1957) foi uma das precursoras de muitas teorias contemporâneas, por ter sugerido, de modo mais explicito, que a cognição poderia ser diretamente influenciada pelo afeto.

Sendo assim, a hipótese que se explicita mais claramente hoje em dia de que os estados afetivos seriam capazes de influenciar os processos cognitivos tem suas raízes em pesquisas do passado, mas que se situam hoje em territórios menos demarcados na psicologia como, por exemplo, na interface denominada “cognição social”. Ao apresentar evidências da influência do afeto na cognição, especialmente na resolução de problemas que envolvem escolha, julgamento social, avaliação, categorização, muitas dessas pesquisas, como as de Bless, Schwarz e Wieland (1996), Forgas (1998), Fredrickson (2001), Innes-Ker e Niedenthal (2002), dentre inúmeras outras, vêm contribuindo para um melhor o entendimento de como se dá essa influência. Inclusive muitos desses estudos abordam o duplo papel do afeto, especialmente a influência dos estados de humor, nos “conteúdos” do pensamento (o que as pessoas pensam), bem como no "processamento" cognitivo e nas estratégias cognitivas utilizadas neste contexto (como as pessoas pensam), sendo o afeto hoje em dia considerado não mais uma mera fonte de "distúrbio” no processamento cognitivo, como já o foi no passado, mas sim uma fonte de "informação" e um meio de "regulação” da própria cognição.

Ainda que não seja o foco do nosso trabalho, vale mencionar brevemente que a abordagem evolucionista contemporânea, com suas inúmeras evidências empíricas e ricas reflexões teóricas como as de Cosmides e Tooby (2000), Seidl de Moura (2005) e Oliva, Otta, Ribeiro, Bussab, Lopes, Yamamoto e Seidl de Moura (2006), vem trazendo 
instigantes questões para o entendimento da filogênese e da ontogênese da mente humana e, em especial, da relação entre a emoção e a cognição a partir de um olhar evolucionista que integra evidências de diferentes disciplinas. Inclusive, a clássica dicotomia razão versus emoção parece ser substituída por novos modos de integração e, como observaram Oliva e colaboradores (2006), razão e emoção devem ser vistas como complementares, desempenhando diferentes funções em distintos momentos da filogênese e da ontogênese. Apesar de não priorizarmos aqui os aspectos filogenéticos e ontogenéticos envolvidos na relação entre o afeto e a cognição, a ênfase na complementaridade e na estreita articulação entre essas duas instâncias nos interessa sobremodo.

Como destacaram Schwarz e Skurnik (2003) o papel do afeto, em especial de estados afetivos, como os estados de humor, na cognição, vai variar de acordo com a natureza da tarefa cognitiva em jogo, pois dependendo do tipo de tarefa, diferentes estados afetivos poderiam facilitar ou dificultar a solução de problemas e, acrescentaríamos, a transferência analógica, bem como poderiam afetar, de maneira diferenciada, a memória. Para esses autores, um determinado tipo de estado de humor poderia ter diferentes efeitos em momentos diferenciados do processamento da informação. Nessa direção, torna-se mais complexo o entendimento de quais seriam estes efeitos, pois, por exemplo, um mesmo estado de humor positivo ou negativo, poderia facilitar ou dificultar o processamento cognitivo em determinados momentos do processamento, bem como poderia ter maiores ou menores efeitos frente a tarefas menos ou mais complexas e /ou menos ou mais estruturadas.

Entretanto, não são apenas os estados afetivos que poderiam suscitar algum tipo de modificação no curso do processamento cognitivo, pois, na concepção desses autores, estados não afetivos tais como, sensações corporais e experiências cognitivas como, por exemplo, maior ou menor dificuldade experimentada no processo de recordação, também poderiam influenciar a resolução de problemas. Assim sendo, diferentes processos parecem ocorrer em paralelo, alguns desses podendo influenciar em maior ou menor grau a resolução de problemas, sendo que alguns também poderiam somar forças entre si ou neutralizá-las, ou seja, poderiam, juntos, ter efeitos diferenciados na resolução de problemas e na transferência analógica.

Já no que se refere à nossa proposta de pesquisa, vale lembrar que tivemos o objetivo de investigar dois tipos de influências que aqui chamamos “afetivas” no 
processamento analógico: por um lado, a possível variação do estado de humor dos indivíduos e, por outro, a tonalidade afetiva das histórias dos problemas. Buscamos, inclusive, investigar se estes dois tipos de influências poderiam interagir na recuperação de um problema análogo de mesma tonalidade afetiva.

Estudos teóricos de Schwarz e Skurnik (2003) e estudos empíricos de Hesse e colaboradores (1997), apontaram para o fato de que a conotação afetiva de um problema assim como o estado afetivo do solucionador poderiam influenciar o tipo de informação que se torna acessível na memória, informação esta que pode servir como input para a escolha de estratégias para a resolução de problemas análogos. Acrescentaríamos também, no que se refere à nossa pesquisa, que tanto o estado de humor do solucionador quanto a tonalidade afetiva do problema poderiam servir como input para a escolha de um modo de solução, quando há a possibilidade de escolha entre duas soluções igualmente legítimas. Acreditamos, inclusive, que esses dois tipos de input de naturezas independentes possam vir a interagir entre si.

A indução experimental do humor em muitos estudos na área costuma ser feita através de estímulos como filmes (p.e. Isen, Daubman \& Nowicki, 1987; Martin, Abend, Sedikides \& Green, 1997; Innes-Ker \& Niedenthal, 2002), hipnose (p.e. Bower, 1981), música (p.e. Clark \& Teasdale, 1985), recompensas como presentes e/ou doces (Isen \& Daubman, 1984), reportagens de jornais (p.e. Johnson \& Tversky, 1983), feedback do desempenho em um teste ou prova (p.e. Forgas \& Bower, 1987), recordação de lembranças pessoais positivas ou negativas (p.e. Schwarz \& Clore, 1983; Bless, Schwarz \& Mackie, 1992; Bless, Schwarz \& Wieland, 1996), ou mesmo através de estímulos como um dia chuvoso ou um dia ensolarado (p.e. Schwarz \& Clore, 1983; Parrot \& Sabini, 1990).

Gerrards-Hesse, Spies e Hesse (1994), em estudo de revisão sobre os principais procedimentos experimentais de indução de humor em pesquisas na área, compararam a eficácia dos procedimentos de indução de humor e chegaram à conclusão de que estímulos como filmes e histórias alegres e recompensas como presentes seriam mais eficazes para induzir um humor positivo, enquanto a apresentação de filmes e histórias tristes e o recurso de imaginar vivências ou eventos negativos seriam mais eficazes para induzir um humor negativo.

Cabe assinalar que em nossa pesquisa não houve a manipulação explícita do humor, como grande parte das pesquisas que investigam os efeitos do humor na cognição o fazem, mas sim a avaliação do humor dos participantes antes e depois da leitura da 
história “alvo”. Esse procedimento, como será visto no item "Procedimento", teve o objetivo de controlar os possíveis efeitos da alteração do humor após a leitura da história “alvo” triste e alegre.

No que se refere à influência mais especifica do afeto na memória, buscamos na literatura da área estudos mais diretamente preocupados com a influência dos estados de humor positivo e negativo nos processos de codificação, armazenamento e recuperação de informações. Trabalhos como os de Bower (1981), Bower e Forgas (2001), Eich e Macaulay (2001), dentre muitos outros, serviram de base para complementar os estudos mais direcionados para a resolução de problemas e/ou para a transferência analógica e nos auxiliaram nas principais argumentações que irão convergir para as principais hipóteses do nosso trabalho.

Podemos ainda observar que um número significativo de estudos investigou os efeitos do estado de humor per se na solução de diferentes tipos de problemas (p.e. Bless \& cols., 1992; Luce, Betmann \& Payne, 1997; Friedman \& Foster, 2000; Linnenbrink \& Pintrich, 2004), mas poucos estudos investigaram a influência dos efeitos do humor conjuntamente com os efeitos da tonalidade afetiva dos problemas (Hesse e cols., 1997). Não obstante, como já referido, os achados de pesquisas que investigaram os efeitos do humor per se na resolução de problemas podem trazer questões teóricas e evidências empíricas importantes para fundamentação das nossas hipóteses de pesquisa.

Em estudos que focalizaram os processos de categorização (Urada \& Miller, 2000; Innes-Ker \& Niedenthal, 2002), de julgamento (Schwarz \& Clore, 1983; Tiedens \& Linton, 2001) e da tomada de decisão (Luce, Bettman \& Payne, 1997), os estados afetivos são vistos como capazes de influenciar os processos de categorização, de julgamento e de tomada de decisão, bem como de influenciar as estratégias adotadas e o tipo de informação que está sendo recuperada na memória.

Os estudos acima referidos que investigaram, em especial, a influência do afeto na categorização, no julgamento e na tomada de decisão em situações que envolviam algum tipo de ambigüidade em um contexto inter-pessoal, poderiam ser complementados por estudos mais direcionados para a influência do afeto, em especial dos estados de humor, nos processos de memória propriamente ditos (p.e. Bower 1981; 1992; Blaney, 1986; Tobias, Kinlstrom \& Schacter, 1992; Eich \& Macaulay, 2001; Bower \& Forgas, 2001; Hadley \& MacKay, 2006; Curran, 2007; Collins, Pillemer, Ivcevic \& Gooze, 2007). 
Muitos estudos desenvolvidos na interface entre o afeto e a memória poderiam ser considerados precursores de estudos direcionados para a interface entre o afeto e a resolução de problemas e a transferência analógica. Modelos e conceitos construídos no âmbito da memória, como os de Bower (1981), também serviram de base para a construção de modelos mais direcionados para o processamento da informação durante a resolução de problemas, como, por exemplo, os estudos de Schwarz e Clore (1983), Forgas (1995; 2001a), Martin (2001), só para citar alguns. Sendo assim, uma apresentação de pesquisas e modelos situados na interface entre o afeto e a memória se torna ponto de partida para a investigação da influência dos estados afetivos na resolução de problemas e na transferência analógica.

\section{3-A Influência dos Estados Afetivos na Memória}

Os estudos que focalizam a influência do afeto na memória são de particular importância para o nosso trabalho, pois nos ajudam a entender como a recuperação de um problema análogo fonte pode ser influenciada pelos estados afetivos dos indivíduos e pela tonalidade afetiva dos problemas.

Como vimos em capítulo anterior, podemos observar uma relação estreita entre os processos de memória e de transferência analógica, pois ambos envolvem a recuperação de informações armazenadas. Como vimos, uma diferença básica entre esses processos poderia ser aqui destacada: no processamento analógico, a recuperação das informações na memória exige que haja um novo processo de “adaptação” ou "aplicação” dessas informações, em contraposição àquilo que chamamos de memória, onde esta recuperação é mais “direta”, apesar de parcialmente “reconstruída”. Em outras palavras, a transferência analógica não é uma mera recuperação de informações, pois, apesar de estar estreitamente relacionada a processos de memória, implica, por sua vez, processos de comparação, inferência, aplicação de conhecimento e adaptação a uma nova situação que se apresenta. Nesse sentido, a transferência analógica depende da memória, mas vai além dela.

No que se refere aos estudos sobre memória per se, inúmeras evidências empíricas vêm apontando para o fato de que a recuperação de conteúdos na MLP é melhor quando o material armazenado tem alto valor afetivo/emocional. Para alguns autores, isso se deve ao fato de este tipo de material ser processado mais profundamente e de modo mais elaborado, como já haviam sugerido os estudos de Craik e Tulving (1975), Jacoby 
e Craik (1979), Lockhart (1979), dentre outros. Porém, além da influência do valor afetivo de um dado estímulo, do seu grau de familiaridade (Mandler, 1989; 1992), ou do fato de o mesmo ser “inconfundível” (Eysenck, 1979), pode haver a influência dos estados afetivos, como os de humor, na recuperação, como sugerem os estudos de Bower (1981; 1992); Blaney (1986), Baddeley (1990), Mandler, (1992), Eich e Macaulay ( 2001), Bower e Forgas ( 2001), Martin ( 2001), dentre outros. Fatores, como o estado de consciência dos indivíduos, também podem exercer uma nítida influência no processo de recuperação, como já sugeriu no passado Eich (1980), bem como sugerem inúmeras evidências atuais de estudos experimentais e clínicos da psicologia, da neuropsicologia e da psiquiatria.

Não obstante, apesar de reconhecermos a possível interação de fatores de diferentes naturezas no processo de codificação, de armazenamento e de recuperação, temos, em nossa pesquisa, especial interesse pelos efeitos da valência afetiva dos estímulos, no caso, dos conteúdos das histórias dos problemas, e pelos efeitos do estado de humor dos participantes nos processos de memória e de transferência analógica.

Segundo Bower e Forgas (2001), investigações recentes de como o afeto influencia a memória costumam caminhar em duas direções principais, sendo uma delas com ênfase nos substratos neurais envolvidos nessa interface e a outra com ênfase na identificação das causas e das conseqüências do afeto na cognição e/ou nas interações sociais. Estudos de Tranel e Damásio (1988), Damásio, Bechara, Tranel e Damásio (2005) e Adolphs \& Damásio (2001) poderiam ilustrar a primeira dessas ênfases e estudos de Forgas (2001a; 2001b) e Bower e Forgas (2001) poderiam ilustrar a segunda.

Adolphs e Damásio (2001) destacaram diferentes sistemas neuroendócrinos cerebrais mediadores da memória para eventos neutros e para eventos com carga emocional. Eventos fortes do ponto de vista emocional ativariam uma cascata de processos neuroendócrinos nos sistemas catecolamínicos que teriam maior impacto no complexo amigdalóide do cérebro, estrutura cerebral cuja atividade modularia a consolidação da memória para os eventos de maior carga emocional.

Esses trabalhos de Adolphs e Damásio (2001) complementam estudos anteriores de Damásio (1994; 2000; 2004), Damásio e colaborador (1988), Adolphs, Tranel e Damásio (2003), Damásio e colaboradores (2005) e de Bechara (2003) que, através de inúmeros relatos clínicos e experimentais, vêm trazendo cada vez mais evidências da importância das emoções na regulação do comportamento humano. Esses estudos 
somam-se a inúmeros outros estudos contemporâneos (p.e. os de Rorie \& Newsome, 2005; Maia \& Mc Clelland, 2005; Coricelli, Dolan \& Sirigu, 2007; Koechlin \& Summerfield, 2007; Moll \& Oliveira-Souza, 2007) que trazem evidências clínicas e neuroanatômicas de que interrupções nas conexões entre os substratos neurais envolvidos no processamento afetivo e cognitivo poderiam afetar não só emoções primárias e funções cognitivas mais simples, mas especialmente, poderiam ter efeitos nas emoções secundárias/ sociais. De modo correlato, muitas desconexões neurais, especialmente em áreas associativas, como nas áreas pré-frontais, costumam afetar comportamentos sociais complexos envolvidos na resolução de problemas e na tomada de decisão.

Hamman (2001), ao abordar os mecanismos cognitivos e neurais da memória emocional, destacou a especificidade de ambos os mecanismos, bem como a natureza adaptativa dessa especificidade. A emoção influenciaria a memória especialmente através de fatores, como a atenção e a elaboração, que agiriam durante o processo de codificação da memória, e de fatores que ajudariam a modular a consolidação da memória. Nesses estudos também foram destacadas as inúmeras evidências empíricas das Neurociências que vêm corroborando o papel chave da amígdala na consolidação de eventos de maior carga emocional, tanto positivos quanto negativos.

Ainda no que diz respeito aos substratos neurais envolvidos na interface entre afeto e cognição, incluindo-se aqui a memória, vale uma breve reflexão sobre as bases evolutivas das funções cognitivas superiores. A partir de trabalhos como os de Mac Lean (1973; 1993), Damásio (1994; 2000; 2004), Mithen (2002), dentre outros, podemos inferir que o design do cérebro que provavelmente prevaleceu ao longo da seleção natural foi aquele onde os subsistemas mais complexos relacionados à tomada de decisão e ao raciocínio em um contexto pessoal e social (por exemplo, as situações cotidianas) permaneceram ligados a sistemas mais simples, relacionados à regulação biológica/ homeostática, devido ao papel fundamental destes últimos na sobrevivência. Sendo assim, do ponto de vista evolutivo, a regulação biológica é essencial para a orientação do comportamento pessoal e social humano.

Podemos aqui observar que o princípio de conservação e de continuidade (além do princípio de modificação) darwiniano parece nortear a evolução cerebral, pois a presença de estruturas consideradas “inferiores” do ponto de vista filogenético (arquicórtex) soma-se à presença de estruturas filogeneticamente intermediárias, como as estruturas paleocorticais, bem como à presença de estruturas cerebrais mais recentes 
(neocórtex). Aliás, Mac Lean (1973; 1993), com sua concepção de cérebro “triuno”, foi uns dos primeiros que destacou, de modo mais sistemático, essa “conservação” de estruturas cerebrais na espécie humana, bem como sinalizou sua base evolutiva.

Já no que se refere às causas e conseqüências das emoções e dos afetos como um todo, nosso principal interesse, a idéia prevalente na área é a de que a interação social seria a força predominante que modularia a vida emocional e afetiva dos indivíduos. Uma das principais argumentações seria a de que os estados afetivos dos indivíduos desempenhariam um papel central no processamento da informação social com conseqüentes efeitos no julgamento inter-pessoal, na categorização, na tomada de decisão em situações de conflito e no comportamento social como um todo. Evidências apresentadas por estudos como os de Forgas (1981) como relatadas por Bower e Forgas (2001) já haviam sugerido que as representações mentais dos episódios sociais vividos pelos indivíduos são em grande parte determinadas pelas características afetivas e conativas dos encontros sociais, mais do que pelas características descritivas dos mesmos. Em outras palavras, por exemplo, o fato de um encontro social ter sido prazeroso, íntimo, com confiança mútua ou de ter sido um episódio desagradável, conflituoso, definiriam as representações mentais desses encontros, mais do que as características físicas do ambiente ou dos indivíduos.

A hipótese de que seriam as características afetivas e conativas dos encontros sociais que determinariam as representações mentais construídas, ou seja, os sentimentos que emergiram nesses encontros e o significado dos mesmos para os indivíduos, parece reforçar a hipótese de Zajonc (1980; 2001) sobre a primazia das reações afetivas nas impressões sociais. Nesse sentido, então, quando nos lembramos de um episódio, de uma pessoa, de uma história, etc., a qualidade afetiva do input original é o primeiro elemento a se sobressair nas lembranças. Emoções, sentimentos e humores teriam assim um papel bastante significativo nas memórias sociais e na sua reconstrução, sendo a memória dos episódios sociais particularmente influenciada pela intensidade da emoção vinculada ao episódio. Nessa direção, trabalhos como os de Loftus e Hoffman (1989) e de Loftus (2003), dentre inúmeros outros, também sugerem que as emoções podem ter influência na reconstrução de falsas memórias.

Bower e Forgas (2001) também destacaram que as reações emocionais desempenhariam importante papel na fixação do aprendizado e no modo como os indivíduos processam os eventos sociais. Na medida em que as reações emocionais geralmente acompanham expectativas frustradas e a interrupção de objetivos, essas 
reações dirigiriam a atenção para os eventos precedentes que as acompanham como importante item a ser aprendido. Essas reações também mobilizariam a atenção para aquelas características de uma situação que os indivíduos acreditam ser significativas e/ou as causas da expectativa frustrada e, nesse sentido, facilitariam a codificação e a memorização dessas características. Além disso, a ativação de uma emoção, o seu declínio gradual e o reviver da situação também parecem facilitar a consolidação dos eventos que os indivíduos associam, de modo causal, às respostas emocionais. Por último, de modo complementar, por sua própria natureza, os eventos com uma alta carga emocional costumam ser relativamente raros no meio da rotina dos acontecimentos cotidianos, sendo assim, a raridade e a "interferência” desses eventos na rotina parecem fazer com que os mesmos sejam menos sujeitos ao esquecimento. $\mathrm{O}$ fato de serem eventos “inconfundíveis”, como na acepção de Eysenck (1979), faz com que os mesmos se tornem mais salientes e, assim, sejam priorizados nos processos de memorização frente a outros eventos mais corriqueiros.

O estudo de Hadley e MacKay (2006) seria exemplo de uma pesquisa mais recente que evidenciou que palavras com alta carga afetiva costumam ser prioritariamente recuperadas na memória. Foi verificado, em seus estudos, que o reconhecimento imediato de palavras que envolviam um tabu costumava ser melhor do que de palavras neutras em listas de palavras. Diferenças no decurso de tempo, na expectativa dos indivíduos, no tempo de processamento individual, dentre outras diferenças, tiveram um menor impacto no reconhecimento das palavras. Essas evidências foram atribuídas ao fato de que as reações emocionais tenderiam a priorizar mecanismos que conectariam a fonte de uma emoção ao seu contexto especifico e que, a nosso ver, parecem ser mecanismos com uma função adaptativa de origem evolutiva.

Como ainda observaram Bower e Forgas, embora o sentimento emocional per se não seja uma pista de recuperação para um evento especifico, pois o “quando” e o “onde” seriam pistas melhores, o sentimento emocional do momento da codificação, muitas vezes revivido no momento da recuperação, seria um fator de predição da recordação quando “dicas” efetivas de contexto são fornecidas. Achados de Zajonc (1980) apontaram nessa direção, ou seja, apontaram para a primazia da emoção na recordação de uma pessoa ou de um evento, pois as pessoas tendem a se lembrar de suas reações emocionais frente a determinados estímulos mesmo quando não se lembram das razões de suas preferências ou rejeições. 
Achados clínicos com amnésicos, no contexto da neuropsicologia, e achados experimentais com indivíduos sem amnésia parecem ir ao encontro da idéia de Schacter (1986; 1991) da existência de uma memória implícita que, nesses casos, estaria razoavelmente preservada, apesar de uma não consciência dos eventos vividos. Uma das hipóteses possíveis para explicar dissociações funcionais em amnésicos que preservam certo reconhecimento implícito, mas apresentam, em contrapartida, graves déficits de registro, como o famoso paciente H.M., estudado por Scoville e Milner (1957), diz respeito à idéia de que isso se explica porque os efeitos da memória explícita e da memória implícita refletem operações de diferentes sistemas cerebrais. Cabe uma observação de que as aprendizagens que envolvem conhecimentos procedimentais também costumam estar preservadas nesses amnésicos talvez pelo fato de envolverem habilidades motoras implícitas, não-declarativas.

Não obstante, a nosso ver, a mera contraposição entre as dissociações entre as memórias explícita e explícita como um todo não deixa muito claro qual seria o papel dos subsistemas que compõem a chamada memória implícita e dos subsistemas que compõem a chamada memória explícita. Nessa direção, dissociações funcionais encontradas “dentro" de cada um desses sistemas de memória poderiam contribuir para o entendimento, não só dos correlatos neurais desses subsistemas, mas principalmente para o entendimento do funcionamento de cada um desses “processadores” na memória. De modo correlato, nesse contexto, pode-se argüir se alguns estados afetivos, positivos ou negativos, poderiam afetar mais um determinado tipo de processamento do que outro.

A postulação de que a organização da Memória a Longo-Prazo não seria unitária, como apontaram os “clássicos” estudos de Tulving (1979), Cohen e Squire (1980), dentre outros, exige melhor explicitação de que "tipo" de informação estaria mais comprometida em seus processos de registro ou de acesso. Por um lado, costumam-se observar dissociações entre os aspectos declarativos e procedimentais da memória e da aprendizagem e, por outro lado, costumam-se observar dissociações entre os aspectos semânticos e episódicos da memória declarativa. Sendo assim, quando se pensa na influência de aspectos afetivos nos processos de memória, uma complexidade de subsistemas qualitativamente diferentes poderiam estar envolvidos nessa interface.

No que se refere aos aspectos cognitivos envolvidos na relação entre o afeto e a memória, modelos de rede associativa da memória como os de Bower (1981) e de Forgas (1995) poderiam fornecer, a nosso ver, alguns subsídios teóricos para o 
entendimento da primazia de um reconhecimento implícito encontrada tanto em amnésicos quanto em indivíduos com a memória preservada, como muitos estudos experimentais, como os de Schacter, Cooper \& Delaney (1990), evidenciaram. A idéia básica desses modelos é a de que para cada fato sobre um determinado objeto, pessoa ou evento, o sistema de memória armazenaria uma breve descrição dessa informação, assim como a correspondente avaliação dessa informação (positiva, negativa ou neutra) que é, por sua vez, ativada pelo sistema afetivo do indivíduo. Na medida em que mais informações sobre um dado objeto são adquiridas, cada uma dessas informações só teria uma chance de ser retida e a memória para detalhes individuais tenderia a ficar mais fraca. Porém, se cada fato individual causar a mesma avaliação, por exemplo, positiva, então uma forte associação seria construída ligando a atitude e a opinião sobre o objeto ao nodo de valência positiva na memória. Quanto mais importante for um fato para um indivíduo, mais o mesmo seria pensado e mais fortemente a conexão objeto/valência seria ativada. Por exemplo, diferentes associações viriam em mente, caso fosse perguntado a alguém sua opinião a respeito de uma dada pessoa, sendo que as associações mais fortes, mais repetidas e com maior vinculação com o nodo de valência predominante, seriam privilegiadamente recuperadas. Nesse sentido, os modelos de rede parecem predizer a primazia do afeto antes mencionada.

Não obstante, como assinalaram Bower e Forgas (2001) não haveria razão para que as reações emocionais fossem consideradas primárias e totalmente separadas dos processos cognitivos, como a hipótese de Zajonc (1980; 2001) propõe. Para os autores, seria quase o oposto, ou seja, seria a forte dependência entre "como" os fatos cognitivos e "como” as avaliações afetivas são processados pelo sistema de memória que seria a responsável pela aparente primazia das avaliações afetivas.

Os modelos de redes associativas parecem fornecer uma boa base para a construção de modelos, não só diretamente relacionados à memória, como o de Bower (1981), mas também para modelos como o modelo algébrico de formação de atitudes de $\mathrm{N}$. Anderson (1996), como citado por Bower e Forgas (2001). Para esse modelo, quando novas crenças ou fatos são acrescentados a uma atitude em relação a uma dada pessoa ou a um objeto, o julgamento vai sendo gradualmente mudado e o novo julgamento vai depender do grau de significância pessoal e da intensidade da emoção desencadeados por esses novos fatos. Esse tipo de modelo algébrico de integração da informação cognitiva e afetiva poderia ser também utilizado para explicar os efeitos de estados de humor positivo ou negativo na memória social e nos julgamentos sociais. Caso haja 
predomínio de um nodo ligado a uma valência afetiva positiva ou negativa sobre outros nodos na rede, os modelos de rede predizem que o julgamento positivo ou negativo feito pelos indivíduos tende a ser mais extremado e com baixa latência de decisão.

Em relação ao tempo de resposta ou de latência de decisão, podemos citar estudos como os de Fazio, Sanbonmatsu, Powell e Kardes (1986) que demonstraram que o tempo requisitado para classificar palavras que possuíam uma avaliação afetiva como amoroso, pútrido, dentre outras, costumava ser reduzido quando essas palavras eram precedidas de palavras com valência positiva ou negativa (p.e. racista, aborto, desarmamento). Melhor dizendo, os participantes desses estudos apresentaram rápidos julgamentos positivos quando havia um priming positivo entre as palavras e rápidos julgamentos negativos, quando havia priming negativo entre as palavras. Porém, quando havia uma incongruência na valência das palavras (palavras positivas e negativas), o tempo de resposta para sua classificação mostrava-se mais lento.

A redução do tempo de resposta para a recuperação de lembranças afetivas também foi estudada por Teasdale e Fogarty (1979) que destacaram que os efeitos do priming do humor influenciaria o tempo que se leva para recuperar as memórias emocionais. Em seus experimentos, as pessoas deprimidas gastaram menos tempo para lembrar de eventos negativos do seu passado e mais tempo para lembrar de eventos positivos, e as pessoas não deprimidas apresentaram resultados opostos.

A idéia de que o afeto e a memória poderiam ser articulados em um sistema representacional cognitivo integrado foi inicialmente formalizada por Bower (1981). Ao tentar fornecer um modelo conceitual para o entendimento dos mecanismos que ligam o afeto à cognição, em especial à memória, Bower (1981), propôs um modelo de rede associativa, destacando, em especial, os nodos cognitivos subjacentes a situações afetivas onde há uma congruência de humor entre o momento de codificação e de registro de informações e o momento de recuperação. Nesse trabalho e em trabalhos mais recentes como, por exemplo, os de Bower e Forgas (2001) já mencionados, foi destacado o fato de que a recuperação de informações é dependente de dois tipos de fatores: a associação entre o estado atual de humor e o estado de humor do momento da codificação e do registro e a congruência entre o estado atual de humor e a valência do estímulo ou conceito.

Uma das implicações do modelo de rede de Bower refere-se ao fato de que as informações mais congruentes com o estado atual de humor do indivíduo tornam-se mais salientes, ou seja, mais ativadas na rede, o que leva a uma maior atenção e a um 
processamento mais profundo desta informação. Por exemplo, um indivíduo em um estado de humor alegre tende a recuperar, de modo preferencial, informações que possuam uma tonalidade também alegre, compatíveis com seu estado atual de humor. Já um indivíduo em um estado de humor triste ou em um estado de depressão tende, por sua vez, a recuperar informações com a mesma tonalidade de seu estado afetivo, como apontaram os estudos de Isen e colaboradores (Isen, Shalker, Clark \& Karp, 1978; Isen \& Daubman, 1984), Snyder \& White (1982), Forgas, Bower e Krantz (1984), Clark e Teasdale (1985), Bless, Schwarz e Mackie ( 1992), Forgas ( 1998), Urada e Miller (2000), dentre outros.

Um outro tipo de implicação do modelo de Bower pode ser vista quando a recuperação de determinadas palavras, imagens ou eventos frente a um humor positivo é maior quando essas palavras, imagens ou eventos estão associados a um humor também positivo no passado. De modo similar, as informações associadas a um humor negativo no passado seriam mais recuperadas no presente quando o humor também fosse negativo. Porém, como observaram Clark e Teasdale (1985), os indivíduos variam entre si no que diz respeito às palavras, imagens e eventos que estão associados com seus humores no passado. Sendo assim, o modelo de rede associativa da memória e do humor precisa levar em consideração que os efeitos diferenciados do humor na recuperação de informações positivas e negativas podem variar muito entre os indivíduos e entre os tipos de informações armazenadas pelos mesmos.

Podemos observar, então, dois tipos de efeitos do estado de humor na memória: o primeiro se refere ao chamado efeito de "congruência de humor" e o segundo se refere ao efeito de recuperação “dependente do estado de humor”. O chamado efeito de “congruência de humor” prediz que as pessoas tendem a reter mais e a recuperar melhor eventos que tenham uma correspondência com a valência do seu estado atual de humor. Já o chamado efeito de recuperação “dependente do estado de humor” prediz que as pessoas tendem a recuperar melhor determinados eventos quando elas estão em um estado de humor equivalente àquele em que estavam no momento da codificação e do armazenamento. Em outras palavras, o efeito da "congruência de humor” implica que algumas informações, em função de seus conteúdos positivos, neutros ou negativos, ou seja, de sua valência, são mais facilmente recuperadas quando o indivíduo está em um estado de humor congruente com estes conteúdos. Já o efeito da “dependência do estado de humor” implica que aquilo que se recupera na memória durante um estado de humor é determinado, em parte, por aquilo que foi aprendido ou focalizado quando se estava 
em um estado de humor semelhante, sendo a valência afetiva per se da informação irrelevante nesse caso.

O modelo de Bower também propôs que o processo de evocação da emoção envolveria um conjunto de regras de produção que avaliariam e reconheceriam as situações particulares que demandariam diferentes respostas emocionais. Os conteúdos específicos dessas regras de produção e os mecanismos envolvidos na avaliação da emoção têm sido objeto de pesquisas contemporâneas como as de Smith e Kirby (2001) que objetivaram explicitar os antecedentes das emoções e as diferentes funções das emoções na chamada “cognição social”. Para esses últimos autores, os modelos de redes associativas parecem prover a mais promissora integração entre as pesquisas que se preocupam com os antecedentes cognitivos do afeto e as pesquisas que se preocupam com suas conseqüências cognitivas.

Cabe aqui um parêntese para uma observação de que o modelo de rede associativa de Bower (1981; 1992) e de Bower e colaboradores (Bower \& Cohen, 1982; Bower \& Forgas, 2001) apresenta características de um modelo de memória “híbrido”, como muitos modelos relacionados à transferência analógica costumam ser, pois conjuga o design das redes neurais dos modelos conexionistas com o uso de regras de produção típicas dos modelos seriais/ simbólicos.

Podemos fazer uma breve menção ao modelo de J. Anderson (1983) que, com sua ênfase nos sistemas de produção e na idéia de uma ativação de nodos em uma rede associativa, também poderia ser considerado "híbrido”. Porém, esse modelo, a par de sua importância e de seu caráter inaugural, pretende construir uma "arquitetura" cognitiva mais ampla, aplicável ao pensamento como um todo e não só à memória ou à transferência analógica.

Privilegiaremos aqui modelos mais diretamente relacionados à memória, em especial, modelos que focalizam a influência do afeto na memória, como o modelo de Bower e de Bower e colaboradores já referidos.

O modelo de Bower e Cohen (1982), que se seguiu ao modelo inicial de Bower (1981), pressupõe que as emoções são representadas como nodos em uma rede associativa na MLP. Três nodos emocionais foram propostos por esses autores: um nodo relacionado à “emoção-conceito”, outro nodo relacionado à "emoção-palavra” e um nodo relacionado à “emoção-sentimento”. O nodo relativo à “emoção-conceito” representaria o conhecimento sobre uma dada emoção, bem como as situações que a evocam e a sua relação com outros conceitos. O nodo relativo à “emoção-palavra”, por 
sua vez, representaria as características lingüísticas relacionadas à palavra emoção, por exemplo, seu aspecto fonológico. Já o terceiro nodo representaria o sentimento vinculado a uma dada emoção e estaria, por sua vez, associado a lembranças emocionais relevantes, bem como teria uma vinculação com o sistema nervoso autônomo e com a expressão da emoção. Para esse modelo, os nodos “emoção-palavra” e “emoçãosentimento" estariam relacionados com o nodo “emoção-conceito”. A partir desse modelo, podemos também inferir que dois conceitos poderiam ter uma conotação emocional/afetiva semelhante se ambos estiverem conectados ao mesmo nodo "emoçãoconceito”.

Para esse modelo de rede associativa, uma vez que a emoção é evocada em uma dada situação, o nodo vinculado a essa emoção espalha a excitação para uma variedade de indicadores com os quais o nodo está conectado. Esses indicadores incluem reações fisiológicas, expressões corporais, faciais, verbais, os episódios que estiveram associados com essa emoção no passado, etc. Por exemplo, quando se pergunta a um indivíduo com um humor triste sobre a lembrança de um amigo falecido, ele poderá evocar a lembrança do funeral do amigo e não uma lembrança alegre, pois essa cena se torna mais saliente do que outras. Uma espécie de somatório de ativação que envolve as pistas contextuais de recuperação, incluindo-se aqui o humor, e o nodo da emoção vinculado ao episódio armazenado prediz se a memória será mais dependente do estado de humor corrente ou mais dependente da emoção no passado. Em particular, como observaram Bower e Forgas (2001), o registro da memória de um evento deveria estar armazenado em associação com a emoção evocada e vivenciada durante o evento. Isso implica que uma maneira eficiente para as pessoas recuperarem a memória de um evento é quando elas voltam para o mesmo ou similar estado emocional ou de humor de quando houve a aprendizagem.

Além do efeito da "dependência do estado de humor”, como vimos, o segundo maior efeito da emoção implicado pelo modelo de rede de Bower e de Bower e colaboradores é o chamado "processamento congruente com o humor”, isto é, o efeito de "congruência do humor”. Para o modelo de Bower (1981; 1992) e de Bower e Forgas (2001) isso ocorre quando as pessoas se tornam mais seletivamente sensibilizadas para uma informação que está de acordo com seu estado afetivo prevalente. Quando as emoções são fortemente vivenciadas, conceitos, palavras, regras de inferência, etc. que estão associadas com essas emoções se tornam prontamente disponíveis para serem usadas pelos indivíduos. Seria também esperado, nesse contexto, o uso de processos top-down, 
incluindo-se as expectativas dos indivíduos em relação ao ambiente. Nessa perspectiva, o estado afetivo corrente dos indivíduos traria à tona categorias, temas, modos de interpretação e de atribuição de significado ao mundo, etc., que seriam congruentes com esse estado afetivo. Esses estados afetivos/ mentais então agiriam como "filtros" interpretativos e como base para o julgamento e a avaliação de objetos, eventos e pessoas. Para o modelo de rede associativa de Bower e de Bower e colaboradores o material congruente com o humor se tornaria mais saliente na "rede" e chamaria a atenção para si suscitando assim um processamento mais profundo.

Como conseqüência de um processamento mais profundo de material congruente com seu humor, os sujeitos tendem a se engajar em maior elaboração/associação dessa informação e assim tendem a apreender melhor aquela informação. Assim, quando pessoas felizes são expostas a estímulos agradáveis e desagradáveis, elas aprendem e retém melhor os estímulos agradáveis.

Eich e Macaulay (2001) observaram que, por definição, os efeitos da "dependência do estado de humor” são mais nítidos quando há uma significativa “perda” de memória quando os eventos são codificados em um tipo de humor e recuperados em outro tipo. Em outras palavras, a chamada “memória dependente do humor” refletiria nesse contexto uma "falha” na generalização da informação que foi adquirida em um estado para outro estado, ou seja, esta generalização tenderia a falhar mais quanto mais forem dissimilares os estados de humor em questão.

Blaney (1986), ao avaliar os achados de algumas pesquisas voltadas para os efeitos da "dependência do estado de humor" na memória, como alguns dos estudos iniciais de Bower e colaboradores, observou que esses efeitos nem sempre são encontrados em determinadas situações. Por exemplo, na pesquisa de Bower, Monteiro e Gilligan (1978), como citada por Blaney (1986), os pesquisadores, após pedir a indivíduos hipnotizados que imaginassem eventos positivos ou negativos de suas vidas para provocar uma alteração de humor compatível com estes eventos, forneciam listas de palavras para memorização. A recordação dessas palavras em um teste imediato e em um teste com intervalo de um dia, recordação esta feita em um estado de humor similar ao do registro, não apresentou efeitos significativos de dependência do estado afetivo do indivíduo. Entretanto, quando a tarefa de recordação sofria interferência, no caso, a leitura de duas listas, uma em um estado de humor positivo e outra em um estado de humor negativo, os achados apontaram para uma maior recordação quando o indivíduo estava em um estado de humor compatível com aquele do momento da aprendizagem. 
Porém, como sinalizou Blaney, há, nos estudos da área, evidências contraditórias sobre os efeitos da “dependência do estado de humor” na recordação, sendo que estes efeitos parecem se manifestar mais quando há algum tipo de ambigüidade ou interferência na tarefa.

Nessa direção, também Eich e Macaulay (2001) observaram que, apesar de os efeitos da “dependência do estado de humor” não serem mais vistos hoje como tão prevalentes, os mesmos poderiam ser explicitados sob certas condições como, por exemplo, quanto maior for a intensidade dos estados afetivos envolvidos, maior seria a influência da congruência entre esses estados.

Já os efeitos de “congruência de humor”, isto é, os efeitos da congruência entre um dado estado afetivo com a valência dos conteúdos do material a ser armazenado e recuperado, foram também testados em muitas pesquisas na área. Em algumas delas (p.e. Bradley \& Mathews, 1983; Dunbar \& Lishman, 1984 ) eram apresentados, a sujeitos que se sentiam deprimidos, estímulos como uma série de palavras ou de frases que variavam em sua valência. Em um teste de reconhecimento desse material, os achados apontaram para um maior reconhecimento de palavras com valência negativa por parte destes sujeitos. Também os achados de Snyder e White (1982), com indivíduos deprimidos, em tarefa de livre recordação dos eventos do seu passado, apontaram para uma congruência entre seus estados afetivos e a tonalidade dos conteúdos que foram preferencialmente recuperados.

Ainda no que se refere aos efeitos de estados afetivos, como a depressão, na memória, Lewinsohn e Rosenbaum (1987), ao investigar as lembranças de indivíduos com um quadro clínico de depressão, também encontraram evidências de que esses indivíduos apresentavam um número significativamente maior de lembranças de episódios recentes tristes. Nos estudos de Watkins, Mathews, Williamson e Fuller, (1992), por sua vez, houve o relato de que pacientes deprimidos apresentavam um melhor aprendizado de palavras com valência negativa do que de palavras com valência positiva. Bower (1981) também encontrou resultados semelhantes na congruência entre o humor dos indivíduos e a associação livre na construção de histórias. Quando cartões do TAT (Teste de Apercepção Temática) eram apresentados aos participantes de seus experimentos, frente às cenas dos cartões, os sujeitos com um humor negativo construíam mais histórias tristes e aqueles com um humor positivo construíam mais histórias alegres. 
Para o modelo de rede associativa esses tipos de "congruência do humor" sugeridos pelos estudos de Lewinsohn e Rosebaum (1987), Watkins e colaboradores (1992) e Bower (1981), dentre outros, seria comum, nesses casos, porque o estado afetivo do indivíduo colocaria a sua memória em "prontidão", facilitando assim a recuperação de lembranças, bem como o uso de temas com valência congruente com o seu estado de humor, temas esses a partir dos quais as histórias seriam construídas. A idéia original na proposta de explicação desses exemplos da recuperação dependente do humor é a de que uma emoção sentida em um dado momento se tornaria associada, pela contigüidade temporal, a qualquer idéia ou pensamentos que ocupasse a MT naquele momento.

A ativação do nodo “emoção-sentimento", que chamaríamos também de nodo “afeto-sentimento”, poderia explicar, para Bower e Cohen (1982), esses efeitos de recuperação congruente com o humor. Em outros termos, indivíduos com um humor positivo ou negativo ficariam “em prontidão” para a recuperação (e para o aprendizado) de informações que tivessem a mesma valência do seu estado de humor. Nessa perspectiva, a ativação inicial do nodo “afeto-sentimento" se espalharia, na rede, afetando nodos relacionados a conceitos, situações e eventos que tivessem correspondência com o estado afetivo do indivíduo naquele momento. O papel da MT é aqui também privilegiado, conjuntamente com a ênfase nos processos de retenção e de recuperação da MLP, devido à clara limitação em sua capacidade de armazenamento temporário.

Como sinalizaram Bower e Forgas (2001), soma-se à essa idéia de uma associação por contigüidade temporal a curto-prazo, a idéia de que a aprendizagem estaria mais diretamente vinculada às associações entre o episodio vivenciado e a reação emocional causada por ele. Em outros termos, para uma associação ocorrer, uma pessoa deveria atribuir a sua reação emocional ao episódio que a causa (Bower, 1992; Eich 1995; Eich \& Macauley, 2001). Isso pode ser visto mais nitidamente na recordação de episódios autobiográficos, onde pessoas tristes se lembram de mais eventos tristes e pessoas alegres, de mais eventos alegres. Assim, relembrar eventos congruentes com seu estado atual de humor é presumivelmente mais fácil porque parece haver uma ligação causal entre o evento vivenciado e o estado de humor vinculado ao evento na época da aprendizagem.

De modo complementar, em alguns estudos empíricos (Bower, 1981; Snyder \& White, 1982), houve a indução direta dos estados de humor dos indivíduos através da apresentação de estímulos de tonalidade triste ou alegre. Após essa apresentação, era 
pedido aos sujeitos que evocassem algumas vivências pessoais. Os achados apontaram, por exemplo, para uma maior recuperação de vivências tristes por indivíduos que tinham sido expostos a estímulos de valência afetiva triste. Sendo assim, esses achados sugeriram que os conteúdos positivos/ alegres ou negativos/ tristes presentes nestes estímulos tinham um peso importante para suscitar alterações no estado de humor, alterações estas que, por sua vez, guiavam a evocação preferencial de vivências de mesma tonalidade afetiva.

Inúmeros estudos contemporâneos vêm se dedicando à investigação da memória episódica e do papel do afeto nas lembranças pessoais. Pesquisas recentes como as de Bohn e Berntsen (2007) apontaram para um processamento cognitivo diferenciado em situações que envolviam a recuperação de lembranças autobiográficas relacionadas ao importante episódio histórico da queda do Muro de Berlim por alemães orientais e ocidentais. O relato de lembranças negativas associadas a esse fato histórico foi bastante acurado e as conseqüências desse fato foram priorizadas nesse contexto. Já o relato de lembranças positivas foi menos acurado, mas houve, em contrapartida, a produção de maior número de imagens mentais, bem como uma associação mais direta com a história de vida dos indivíduos. Do ponto de vista evolutivo, esses achados parecem apontar para um comportamento adaptativo na medida em que, por um lado, seria importante lembrar de situações potencialmente perigosas de modo mais acurado, mas, por outro lado, ter muitas lembranças negativas associadas a sua história de vida seria disfuncional, como observaram Bohn e Berntsen. Lembranças positivas parecem favorecer a consolidação de uma identidade pessoal e social mais adaptada e se tornariam assim uma referência para a generalização de expectativas de vida mais otimistas. King, Hicks, Krull e Del Gaiso (2006) também verificaram forte relação entre o humor positivo e a maior atribuição de significado à vida, com uma ênfase prospectiva dirigida por objetivos e planos de ação.

Ainda no que diz respeito ao processamento diferenciado da informação frente a recuperação de lembranças vividas positivas e negativas, podemos citar os estudos de Collins, Pillemer, Ivcevic e Gooze (2007). Seus estudos examinaram a distribuição temporal de lembranças de eventos positivos e negativos vividos na infância e na adolescência de universitários e de adultos de meia-idade. Tanto em homens, quanto em mulheres, bem como em jovens e adultos de meia-idade, os resultados apresentaram um padrão que sugeriu que as lembranças positivas apresentavam um pico no final da adolescência (17/18 anos). Já as lembranças negativas mostraram-se mais espalhadas 
ao longo do tempo estudado. Esses resultados foram ao encontro da hipótese proposta por Berntsen e Rubin (2004) de que as expectativas culturais, os denominados "scripts" de vida, organizariam a recuperação de eventos positivos, mas não a recuperação de eventos negativos. Por exemplo, estereótipos relacionados ao fim da adolescência tais como sucesso nos esportes, na vida acadêmica, nos relacionamentos, etc., parecem ter tido uma nítida influência na aglutinação de lembranças positivas nessa fase da vida.

Já Curran (2007), ao examinar os efeitos de “congruência de humor" e de “dependência de humor”, como previstos inicialmente por Bower (1981), em memórias autobiográficas, apresentou evidências que sugerem que a memória dependente do humor e a memória congruente com o humor seriam mais efetivas para o humor negativo e eventos negativos do que para o humor positivo e eventos positivos na recuperação de memórias autobiográficas. Seus experimentos foram divididos em duas fases, sendo que, na primeira fase, os participantes relataram em um diário, durante 90 dias, eventos positivos e negativos, conjuntamente com a intensidade emocional vinculada a esses eventos, bem como seu estado de humor. Na segunda fase, iniciada dez dias depois da primeira, foi inicialmente avaliado o humor inicial dos participantes e a seguir houve a indução do humor através da apresentação de filmes (tristes e alegres) com nova avaliação do humor antes do pedido de recordação dos eventos autobiográficos. Os seus achados também apontaram para o fato de que a indução do humor negativo foi mais efetiva do que a indução do humor positivo e isso, provavelmente, favoreceu a prevalência de lembranças de eventos negativos.

Como observou Curran, haveria, inclusive, a necessidade de pesquisas que explorassem melhor os procedimentos para a indução do humor positivo em situações de laboratório. Porém, seu estudo ao utilizar um material com boa validade ecológica, no caso memórias autobiográficas, se contrapõe a estudos tradicionais que utilizaram listas de palavras para examinar os efeitos de "congruência de humor" e de “dependência de humor” (Teasdale \& Fogarty, 1979; Clark \& Teasdale, 1985, dentre outros)

Em contraste com este tipo de estudo, onde os procedimentos de indução do humor envolvem filmes, histórias, lembranças autobiográficas e/ou a recuperação de palavras, eventos, pessoas, etc., Parrot e Sabini (1990), propuseram um experimento onde os eventos que provocavam alterações de humor (positivo e negativo) tinham pouco conteúdo cognitivo, pois, nesse caso, as variáveis manipuladas foram: um belo dia de sol versus um dia chuvoso e cinzento. Ao pedir aos participantes a evocação de eventos 
do seu passado recente, esses pesquisadores não encontraram uma congruência na memória entre o humor provocado por um dia "triste” ou "alegre” e a tonalidade afetiva das narrativas por eles evocadas. Talvez apenas um "sentimento” positivo ou negativo mais difuso, mais leve, sem uma associação mais explícita com conteúdos semânticos positivos ou negativos não seja eficaz o suficiente para provocar uma congruência de humor entre duas situações, isto é, talvez não funcione como uma "dica” de contexto eficaz.

Os achados de Parrot e Sabini (1990) parecem apontar para a hipótese de que os efeitos de humor na memória envolveriam um "priming” conceitual e não tanto um “priming” "afetivo”, como muitos autores, como Bower (1981), pareciam suspeitar. Outros achados complementares, como aqueles destacados por Clore e colaboradores (Clore, Gasper \& Garvin, 2001), também sugeriram que a recordação de um evento que tenha uma tonalidade positiva ou negativa vai depender mais da congruência do “priming” conceitual entre os eventos atuais e passados do que da congruência entre o humor atual do indivíduo e o evento em si. Sendo assim, experimentos que variam o tipo de humor e o tipo de priming, de modo mais independente, poderiam avaliar melhor o efeito de cada um deles na memória e na recuperação de informações.

Porém Forgas e colaboradores (Forgas, Bower \& Krantz, 1984) e mais recentemente Eich e Macaulay (2001), dentre outros, já haviam destacado o fato de que os efeitos da “congruência de humor” não são achados universais. Os efeitos desse tipo de priming podem variar muito, pois dependem de vários fatores contextuais tais como: a natureza da tarefa, a complexidade da informação, a personalidade e a motivação do indivíduo e as características da situação.

Em relação à natureza da tarefa de memorização, podemos observar conjuntamente com Eich e Macaulay (2001), que tarefas que envolvem uma recordação livre são mais sensíveis às medidas da dependência do humor do que aquelas que envolvem, por exemplo, um mero reconhecimento ou uma recordação dirigida por pistas (como apontaram os estudos de Bower, 1981; Forgas, 1995; Forgas, 2001a; Bower e Forgas, 2001). Nessa direção, muitos achados empíricos parecem apontar para maiores efeitos do humor na recordação livre do que em outras tarefas mnemônicas.

Cabe ainda destacar estudos como os de Nelson, Goodman e Ceo (2007) que verificaram os efeitos da passagem do tempo e da mudança de contexto sobre a memória implícita em tarefas que envolviam a associação de palavras. Os autores destacaram dois tipos de efeitos de contexto comumente atribuídos ao decaimento do 
desempenho nos testes de reconhecimento após o decurso de tempo: os efeitos da “influência de contexto” 2 e os efeitos das "pistas de contexto".

A hipótese da "influência de contexto" assume que a informação contextual se espalha em uma rede associativa durante a fase do aprendizado, sendo que, com o tempo, haveria um decaimento dessa ativação na rede. Já a hipótese da existência de "pistas de contexto" assume que o contexto está associado apenas à fase de aprendizado, ou seja, não haveria a "incorporação” das informações do contexto, como a proposta pelo modelo de rede de associação semântica, e, assim, o reconhecimento seria baseado, prioritariamente, na recuperação de informações a partir das pistas do contexto fornecidas no teste de reconhecimento. Para a primeira hipótese, os efeitos das interferências sobre o reconhecimento dependeriam da distância entre as duas situações “fonte” e “alvo” e, para a segunda hipótese, essa distância temporal não teria efeito, pois as pistas do momento de recuperação na situação “alvo” seriam mais importantes. Nos experimentos desses últimos autores foram manipuladas variáveis como o decurso de tempo (imediato, 5 minutos, 10 minutos e 20 minutos), tamanho da lista (grande, pequeno) e a intensidade da pista de associação (forte e fraca). Os resultados sugeriram que as "pistas de contexto" tiveram maior influência no reconhecimento das listas de palavras.

Poderíamos lembrar também que, em nossa pesquisa, a principal “pista” de contexto manipulada na situação-problema “alvo” foi a variável “tonalidade afetiva” das histórias dos problemas, pois houve a equiparação de outras variáveis que poderiam aí ter influência, tais como o tamanho da história, a freqüência de palavras nas histórias, o tipo de história que revestiu os dois problemas “alvo" de tonalidades opostas, dentre outros controles experimentais. Os estudos de Nelson e colaboradores, supra citados, apresentaram listas de palavras neutras, em contraposição à nossa pesquisa que apresenta histórias que competem entre si em termos de suas tonalidades afetivas. Nessa perspectiva, a recordação da solução do problema análogo “fonte” não é apenas uma recordação direta ou mera associação de palavras, mas sim uma recordação que envolve processos implícitos de tomada de decisão a partir de dois problemas análogos que apresentam soluções, ambas factíveis, que competem entre si.

Podemos ainda observar, conjuntamente com Bower e Forgas (2001) que apesar de evidências do priming afetivo e da congruência do humor, a ausência desse tipo de 
efeito ou mesmo a uma inversão dos efeitos do humor podem ocorrer em algumas situações. Embora a teoria de rede associativa argumente que a congruência entre a memória e o afeto seria uma tendência natural quando as pessoas experimentam uma forte emoção, os indivíduos poderiam superar essa tendência, por exemplo, quando possuem uma alta motivação (Kunda, 1990) ou devido a outros fatores individuais (Rusting, 2001).

Os achados de Parrot e Sabini (1990), como vimos, também evidenciaram uma incongruência entre o humor, frente a um dia de sol ou a um dia chuvoso, e a recuperação de eventos autobiográficos, pois um dia chuvoso e o conseqüente favorecimento de um humor negativo não suscitaram inicialmente lembranças negativas. Para os autores isso se deu, pois os indivíduos tentaram superar o mau humor que um dia chuvoso provocou através da recuperação inicial de eventos positivos de suas vidas e só depois evocaram eventos negativos, compatíveis com seu estado de humor.

Podemos então concluir que o priming do afeto e a congruência do humor não são achados universais, pois fatores relacionados às diferenças individuais, tais como a personalidade e a motivação, também têm seu papel no aumento ou na diminuição dos efeitos do afeto na memória. Fatores positivos, como por exemplo, uma alta motivação e uma boa auto-estima parecem diminuir esses efeitos, sendo que, por sua vez, fatores negativos, inversos, parecem potencializar estes mesmos efeitos, como sugerem os achados de Rustings ( 2001), Suls ( 2001), Salovey, Detweiler, Steward e Bedell, (2001). Nessa direção, o priming do afeto pode variar dependendo de fatores contextuais como a natureza da tarefa, a complexidade da informação, a personalidade e o grau de motivação e as características da situação.

Em determinadas situações de recuperação, onde a tarefa requeria apenas um acesso direto de informações ou envolvia uma alta motivação, os efeitos da congruência de humor eram diminuídos (Forgas, 1992; 1994; 1995; 2001a; 2001b). Estados afetivos temporários também poderiam ser vistos como tendo uma menor influência na memória e no julgamento quando as tarefas envolvem atitudes mais familiares, cristalizadas, que demandam uma "resposta pronta” e/ou quando as tarefas não requerem muita elaboração cognitiva (Bower \& Forgas, 2001). Trazer à consciência dos indivíduos o seu humor corrente e a fonte irrelevante que causou sua alteração de humor também pode fazer com que o estado de humor tenha um menor impacto na memória e no julgamento (Clore, Schwarz \& Conway, 1994). Clore e colaboradores relataram nesses estudos que quando a fonte irrelevante do humor positivo ou negativo era trazida à tona 
para a atenção dos participantes, os efeitos de congruência do humor nos julgamentos sobre satisfação pessoal na vida eram diminuídos ou mesmo eliminados.

No que se refere à nossa pesquisa, o pedido para que os próprios participantes avaliem seu humor antes e depois da leitura da história “alvo” triste ou alegre talvez possa chamar a atenção dos indivíduos para a história do problema "alvo" que estará sendo a fonte da possível alteração de humor. Se por um lado, essa metodologia pode vir a chamar a atenção dos participantes sobre a importância da avaliação do humor para a pesquisa e, nesse sentido, talvez, possa minimizar os efeitos do humor, por outro lado, a auto-avaliação do humor pelos participantes mostra-se de fundamental relevância, pois permite, de modo mais explícito, a mensuração dessa alteração. Nossos procedimentos são semelhantes aos de Hesse e colaboradores (1997) e acreditamos que os benefícios do uso da auto-avaliação do humor pelos participantes superam a possível minimização dos efeitos do humor provocada pela conscientização do papel do humor na pesquisa.

Podemos ainda observar que os efeitos do humor na memória, como explicados pelo modelo de rede associativa, enfatizam a recuperação de informações nas estruturas da memória através de uma "busca” ativa e “aberta”. Mas nem toda recuperação de informações envolveria esse tipo de busca, pois, dependendo do tipo de informação, modos alternativos de recuperação podem ocorrer. Inclusive, quando isso acontece, os efeitos da congruência de humor poderiam ser minimizados, como observaram Bower e Forgas (2001). O tipo de estratégia de processamento da informação, usada em tarefas que envolvem memória, seria de fundamental importância para se entender porque esses efeitos se dariam em algumas circunstâncias, mas não em outras. Foi com esse objetivo que Forgas (1995; 2001a; 2001b) propôs o modelo de "influência do afeto” ${ }^{3}$, o denominado “AIM”, modelo esse designado especialmente para especificar em que circunstâncias esses efeitos seriam mais propensos de ocorrer.

O modelo de Forgas de "influência do afeto" poderia ser também considerado um modelo híbrido, como o modelo de Bower, por utilizar constructos dos modelos conexionistas e dos modelos seriais/ simbólicos. A sua principal ênfase se dá nas estratégias do processamento da informação, mas é um modelo que também pretende predizer que determinados tipos de estratégias seriam adotadas frente a variáveis sociais e individuais, tais como a relevância da tarefa para os indivíduos e a 
complexidade da situação. Esse modelo, por ser um modelo de processamento da informação mais amplo que pretende dar conta, não apenas dos processos de memória, será descrito na próxima subseção quando abordarmos a influência do afeto em diferentes tipos de situações-problema.

Concluímos que os modelos de redes associativas fornecem uma base conceitual para o entendimento da influência do afeto na memória que tem se mostrado promissora, apesar das limitações e das reformulações que os mesmos vêm sofrendo frente aos desafios impostos por novas evidências empíricas. Esses modelos fornecem, a nosso ver, uma explicação relativamente simples de "como” os estados afetivos, incluindo-se aqui, as emoções, os humores e os sentimentos, poderiam ter efeitos nos processos de memória. Parecem também possuir boa validade ecológica, pois explicam, ainda que com certa parcimônia, o papel do afeto na recuperação de diferentes tipos de informações envolvidas em situações cotidianas, tais como a lembrança autobiográfica, o julgamento inter-pessoal, a tomada de decisão, etc.

Não obstante, modelos integrativos como o AIM de Forgas vêm trazendo maior complexidade para a interface entre o afeto e a memória. Esses últimos modelos fornecem, a nosso ver, um referencial teórico para o delineamento das condições e das estratégias que estariam mais diretamente relacionadas com os efeitos do priming do afeto e da congruência de humor na memória. Uma das principais condições para influência do afeto na recuperação das informações na memória seria a demanda de um processamento mais “aberto” e construtivo dessas informações.

Em suma, os estudos mais direcionados à investigação da influência do afeto na memória mostram-se assim de fundamental importância para a nossa proposta de pesquisa situada no âmbito da transferência analógica, na medida em que trouxeram inúmeros achados empíricos, bem como instigantes questões a respeito do papel dos estados afetivos, em especial dos estados de humor, nos processos de memória. A seguir, estudos mais direcionados à interface entre o afeto e a resolução de problemas complementarão as evidências e as argumentações aqui apresentadas.

4.4-A Influência dos Estados Afetivos na Resolução de Diferentes Situações-problema e na Transferência Analógica

Quando pensamos na influência dos estados afetivos na resolução de problemas e na transferência analógica, cabe observar, conjuntamente com Schwarz e Skurnik (2003), 
que estados afetivos como os estados de humor positivo ou negativo poderiam facilitar ou inibir, dependendo da natureza da tarefa, a resolução de problemas e a sua transferência. Inclusive, um mesmo estado afetivo poderia ter efeitos diferenciados ao longo do processamento da informação durante a resolução de um dado problema, o que parece tornar ainda mais complexa a relação entre o afeto e o pensamento. Nesse contexto, os estados afetivos dos indivíduos poderiam privilegiar, de modo diferenciado, o uso de estratégias do tipo “top-down” ou “bottom-up”, bem como poderiam influenciar a forma de representação do problema e a busca de uma solução no "espaço" do problema. Porém, quando os estados afetivos dos indivíduos podem vir a interagir com a conotação afetiva dos enunciados dos problemas, como é o caso da pesquisa aqui proposta, acreditamos que a relação entre afeto e pensamento se torna ainda mais complexa e multifacetada.

Sendo assim, quando pensamos nessa interface, o impacto dos estados afetivos dos indivíduos no processo de resolução de problemas poderia se dar em maior ou menor intensidade, dependendo do grau de definição do problema, da natureza da tarefa, do conhecimento requerido para a execução da mesma, bem como de características de personalidade e do grau de motivação dos solucionadores.

No que se refere à nossa pesquisa, acreditamos que a influência de fatores de personalidade e/ou o grau de motivação dos indivíduos possa ser controlada pelo tipo de planejamento experimental que aqui propomos. Já no que diz respeito ao conhecimento requerido para a compreensão e execução da tarefa, será requerido dos participantes um conhecimento mais geral, compatível com aquele que os estudantes universitários costumam possuir. Cabe mencionar que os participantes do estudo piloto 2 (anexo 3) não apresentaram dificuldade na compreensão ou na execução da tarefa proposta nesse teste. Por último, em relação ao tipo de problema apresentado, como já mencionamos, esse possui um grau de indefinição que, a nosso ver, pode vir a se assemelhar aos problemas comuns do cotidiano.

Estudos contemporâneos mais direcionados para a influência do afeto, em especial dos estados de humor, na resolução de problemas, costumam investigar, por sua vez, os efeitos diferenciados dos estados de humor positivo, neutro e/ou negativo na recuperação de informações e na solução de problemas de diferentes naturezas. Muitos desses estudos apontaram para uma associação entre o humor positivo e o julgamento e a avaliação mais positiva de eventos, de pessoas ou mesmo de situações-problema 
(p.e. Clore, Schwarz \& Conway, 1994; Forgas, 1995; Salovey, Detweiler, Steward \& Bedell, 2001; Martin, 2001; King, Hicks, Krull \& Del Gaiso, 2006).

Os estudos de Clore e colaboradores (Schwarz \& Clore, 1983; Clore, Schwarz \& Conway, 1994; Clore, Gasper \& Garvin, 2001) destacaram o fato de que o afeto poderia ser visto como uma "fonte de informação" e não apenas como capaz de suscitar um tipo de "priming" afetivo na memória, como o modelo de Bower (1981) de certo modo supunha. Os autores acima assinalaram para a necessidade de se fazer uma distinção entre conceitos afetivos e sentimentos, pois, na sua opinião, a congruência do afeto pode ocorrer porque as pessoas se baseiam em seus estados afetivos ou sentimentos como fonte de informação. Uma espécie de estratégia heurística do tipo "como me sinto a respeito disso?” poderia explicar alguns efeitos de “congruência de humor”, especialmente em situações-problema que requerem um julgamento e/ ou uma tomada de decisão.

Na concepção de Clore e colaboradores, quando os indivíduos fazem um julgamento de um dado estímulo, durante o curso do processamento da informação, recebem um feedback afetivo dos pensamentos e dos sentimentos que surgem durante esse processamento. Porém esse tipo de feedback não se mostra diferente do feedback que esses indivíduos recebem quando estão vivenciando um determinado estado de humor. Melhor dizendo, quando os indivíduos fazem um julgamento, haveria a possibilidade de uma "sobreposição" mental dessas duas fontes de feedback e, consequentemente, uma certa confusão em relação à origem de seus sentimentos poderia vir a ocorrer. Uma conseqüência disso, como sinalizaram Martin, Abend, Sedikines e Green (1997), poderia ser a formulação de um julgamento pessoal que tivesse a mesma valência do estado de humor dos indivíduos. Nessa direção, ao invés de processar um julgamento complexo, os indivíduos simplesmente avaliariam seus sentimentos durante o processamento da informação e incorporariam essa avaliação para tecerem um julgamento sobre dado estímulo, evento ou pessoa. E quando essa avaliação é mediada por sentimentos não relacionados diretamente ao estímulo, haveria uma tendência da incorporação, pelos indivíduos, da valência dessa avaliação (positiva ou negativa) aos sentimentos relacionados ao próprio estímulo.

Schwarz e Clore (1983) apresentaram evidências, em dois estudos, de que os indivíduos relatavam maior grau de satisfação pessoal e faziam julgamentos mais positivos da vida após a indução positiva do humor. Em um dos experimentos a indução do humor foi feita através do pedido do relato de lembranças recentes tristes ou alegres. 
Em outro, a indução do humor foi provocada pelas condições climáticas do dia, ou seja, por um dia ensolarado ou chuvoso. Não obstante, o efeito negativo do mau tempo sobre o humor e sobre o grau de satisfação pessoal foi eliminado quando o pesquisador perguntou aos participantes quais eram as condições do tempo. Foi verificado assim que, quando os indivíduos se conscientizavam de que uma fonte irrelevante como o mau tempo estava afetando sua avaliação, os efeitos negativos do humor puderam ser minimizados. As evidências desses estudos apontaram para duas direções principais: a primeira sugerindo que os indivíduos usariam seu estado afetivo momentâneo, como uma fonte de informação para fazer julgamentos, e a segunda sugerindo que os indivíduos com um humor negativo estariam mais propícios a usar informações e justificativas para explicar seu estado de humor do que os indivíduos com um humor positivo. Isso talvez ocorra, como observaram os autores, porque os indivíduos estariam mais motivados a procurar explicações para seu estado de humor negativo, pois esse estado seria percebido como “desviante” em relação aos seus sentimentos positivos mais usuais. A nosso ver, as expectativas sociais, normalmente, costumam favorecer um humor positivo como o mais socialmente adequado e isso também deve ter alguma influência na avaliação e no julgamento que os indivíduos costumam fazer do seu próprio humor.

Niedenthal e Halberstadt (2001) ao discutir a heurística do "como me sinto a respeito disso?”, proposta por Clore, Schwarz e Conway (1994), Clore, Gasper e Garvin (2001), observaram que estímulos sociais não relacionados poderiam formar uma categoria distinta, mesmo quando não possuam aparentemente nada em comum, exceto pelo fato de que eliciam uma resposta emocional similar. Por exemplo, para o modelo de rede, quando pensamos em alguém, o julgamento que fazemos dessa pessoa vai depender da ativação acumulada no nodo negativo e no nodo positivo, bem como de um processo de comparação entre as valências. Essa comparação de valências pode dar suporte para a experiência de produzir uma resposta avaliativa através da heurística do “como eu me sinto a respeito disso?”. Embora Clore e colaboradores (1994) tenham argumentado que consultar nossos sentimentos não dependeria de processos baseados na memória declarativa, Niedenthal e Halberstadt (2001) sugeriram que a estratégia heurística de “como me sinto a respeito disso?” poderia ser o último estágio reconhecido no processo de comparação de valência baseado na memória.

Para Clore e colaboradores (2001), muitos dos efeitos encontrados, como alguns dos efeitos de “congruência de humor” supostos por Bower (1981; 1992) e por Bower e 
colaboradores (1984; 1987; 2001) em seus estudos sobre memória, poderiam ser considerados efeitos de um priming conceitual na memória declarativa, mas não necessariamente efeitos da influência do humor em si no processamento cognitivo com um todo. Para Clore e colaboradores (2001), os sentimentos podem ativar conceitos específicos na memória, mas esses sentimentos ou estados afetivos não seriam armazenados na memória declarativa e, sendo assim, não influenciariam automaticamente o acesso a conceitos de valência similar na memória. Por exemplo, na concepção desses autores, quando uma pessoa ouve uma outra relatar uma experiência triste e começa também a relatar uma experiência de mesma tonalidade triste, isso poderia ilustrar um priming conceitual e não necessariamente um efeito do sentimento ou estado afetivo no processo de recuperação. Alguns achados de Wyer, Clore e Isbell (1999), como citados por Clore e colaboradores (2001), apontaram nessa direção.

De modo complementar, evidências empíricas como, por exemplo, as de Parrot e Sabini (1990), já mencionadas na seção anterior, sugeriram que estímulos como um dia de chuva versus um dia de sol não seriam traduzidos em conceitos semânticos específicos tingidos por uma tonalidade afetiva e, consequentemente, não favoreceriam um priming conceitual que pudesse favorecer os chamados efeitos de "congruência de humor".

Em suma, podemos concluir, conjuntamente com Schwarz e Clore (2003), que os estados de humor poderiam influenciar o processamento cognitivo de duas maneiras: por servir como uma “fonte de informação” ou por influenciar aquilo que é recuperado na memória. Nesse sentido, podemos observar que os indivíduos poderiam chegar a uma congruência de humor através de dois caminhos distintos.

No que se refere à nossa pesquisa sobre transferência analógica, investigamos a possibilidade da existência de dois tipos de "priming”: o primeiro e mais importante para as nossas hipóteses diz respeito ao "priming” entre as tonalidades afetivas per se das histórias, que não necessariamente depende da mediação do estado de humor do indivíduo para ocorrer, como foi verificado nos estudos de Hesse e colaboradores (1997). O segundo tipo de "priming”, por sua vez, diz respeito à influência do estado de humor dos participantes no processo de escolha de um análogo “fonte”. Em outros termos, os chamados efeitos de "congruência de humor”, ou seja, de congruência entre o estado de humor e a tonalidade dos conteúdos das histórias. 
Autores como Martin (2001) teceram outras argumentações a respeito da heurística do “como me sinto a respeito disso?”, proposta por Clore e colaboradores (1994; 2001), pois, para eles, as pessoas consideram não só aquilo que elas sentem a respeito de algo ou alguém, mas, de modo simultâneo, consideram o contexto onde vivenciam tais sentimentos. Ao abordar uma idéia alternativa que destaca a natureza "dependente do contexto" do humor e dos sentimentos, Martin propôs uma abordagem do "humor como input”, abordagem esta que insere o humor numa relação configural de contexto com outros inputs. Nessa perspectiva, o significado de uma experiência de humor, não apenas sua relevância, poderia ser mudado com a mudança do contexto que lhe dá suporte e sentido.

Forgas (2001b), ao fazer uma reflexão sobre os modelos de Bower e de Clore e colaboradores, também observou que a congruência do afeto não é facilmente observável no pensamento e nem mesmo no comportamento. Como vimos anteriormente, para esse autor, esses modelos pecaram por não especificar em que circunstâncias a congruência do afeto poderia ser esperada ou mesmo estar ausente ou revertida. Em defesa do seu próprio modelo, que pretendeu especificar essas circunstâncias e as diferentes estratégias cognitivas que seriam afetadas de modo diferenciado pela influência do afeto, Forgas (1995; 2001a, 2001b, 2001c, 2001d, 2001e) tentou explicar as condições que facilitam ou inibem os efeitos da congruência afetiva em diferentes situações-problema. Em outros termos, ao tentar esclarecer “quando" e "porque” os estados afetivos influenciariam mais diretamente o processamento cognitivo como um todo e não só a memória, Forgas enfatizou as estratégias de processamento requeridas nesse contexto.

Forgas distinguiu basicamente quatro tipos de estratégias: a primeira, chamada de “estratégia direta” de processamento cognitivo, diz respeito ao acesso direto ao material armazenado na memória, acesso este que por ser mais automático, está menos sujeito à interferência dos efeitos do estado afetivo. A segunda, por sua vez, chamada de “estratégia motivada” de processamento e que, por depender da motivação e dos objetivos do indivíduo para guiarem o processamento, também está menos sujeita aos efeitos do afeto, pois o grau de motivação envolvido na tarefa é determinante para o controle atencional e para o processamento da informação. Já a terceira estratégia, chamada de "estratégia heurística”, como o próprio nome sugere, vai envolver um processamento mais amplo, baseado em esquemas cognitivos gerais, mais independentes de domínio e mais abertos aos efeitos da influência do afeto. Por último, 
a chamada "estratégia substantiva” de processamento vai envolver um processamento elaborado e extensivo, também “aberto” e construtivo e, nesse sentido, também passível de ser influenciado pelo afeto.

Nos estudos de Forgas acima referidos e de Bower e Forgas (2001), os autores chegaram à conclusão, como vimos, a partir de diferentes tipos de evidências empíricas, que a extensão da congruência do humor estava diretamente relacionada à complexidade e à ambigüidade da tarefa e ao grau de "abertura” e de "construção" que eram requeridos para, por exemplo, fazer um julgamento de uma pessoa ou de uma situação social.

Nessa direção, poderemos inferir que situações-problema com um maior grau de indefinição, ambíguas e/ ou que envolvem algum tipo de conflito e de tomada de decisão seriam mais sensíveis à influência dos estados afetivos e, acrescentaríamos, à influência das tonalidades afetivas dos enunciados do problema, como veremos na próxima seção. Acreditamos que a nosso estudo contempla esse tipo de condição.

Ainda podemos observar que os estados de humor negativos e positivos poderiam ter efeitos diferenciados no processamento cognitivo, ou seja, poderiam afetar de modo diferenciado o uso de estratégias e a focalização da atenção durante a resolução de diferentes situações-problema que envolvem um maior grau de indefinição, como apontam inúmeros estudos na área ( Isen \& Daubman, 1984; Bless, Schwarz \& Wieland, 1996; Urada \& Miller, 2000; Kenworthy, Canelas, Weaver \& Miller, 2003; sobre categorização; Bless, Schwarz \& Mackie, 1992; sobre julgamento de atitudes; Luce, Bettman e Payne, 1997; sobre tomada de decisão, dentre outros). De modo complementar, estudos que associam o afeto positivo a um maior controle cognitivo (Dreisbach \& Goschke, 2004), à motivação (Custers \& Aarts, 2005), à confiança (Dunn \& Schweitzer, 2005), à prosperidade (Fredrickson \& Losada, 2005), dentre outros, também pressupõem um processamento cognitivo diferenciado dos afetos positivo e negativo nesse contexto.

De modo geral, nesses estudos, dois tipos de convergências empíricas são sugeridas: em primeiro lugar, que um estado de humor positivo/ alegre costuma favorecer o uso de estratégias mais heurísticas, ou seja, o acesso a esquemas mais gerais, com um processamento mais "top-down”, e com uma categorização e um julgamento mais inclusivo, menos detalhista e envolvendo maior sentimento de confiança. Já um estado de humor negativo/ triste costuma favorecer o uso de estratégias mais sistemáticas, com 
um processamento mais "bottom-up”, com a atenção mais direcionada a detalhes, com maior percepção de risco e menor confiança nos resultados do desempenho.

Schwarz e Clore (1983) também já haviam sugerido que os estados de humor positivo ou negativo funcionariam como "sinais" de origem evolutiva que ativariam um processamento mais ou menos vigilante, onde o afeto negativo nos sinalizaria para uma maior cautela na ação, enquanto o afeto positivo nos daria um sinal para agirmos mais prontamente.

Poderíamos destacar, também, alguns estudos desenvolvidos no contexto das Neurociências, como os de Damásio (1996), Adolphs e Damásio (2001) e Damásio e colaboradores (2005). Nesses estudos, a postulação da hipótese da existência de “marcadores somáticos” que funcionariam como sinais de origem evolutiva que guiariam o processo de tomada de decisão, parece ir ao encontro da idéia de Schwarz e Clore (1983). Uma das funções destes marcadores seria, na concepção de Damásio e de Adolphs e Damásio, a de convergir a atenção, tal como um sinal de alerta automático, para as alternativas mais adequadas no processo de tomada de decisão, excluindo aquelas “emocionalmente” marcadas de modo negativo e ativando aquelas marcadas positivamente. Nessa direção, as alternativas marcadas positivamente seriam mais prontamente ativadas enquanto as alternativas de valência negativa demandariam maior cautela e atenção em sua ativação. Entretanto, Damásio e colaboradores não pretenderam investigar o papel do estado de humor dos indivíduos neste contexto e sim investigar, prioritariamente, os efeitos de determinadas lesões cerebrais no comportamento de indivíduos frente a diferentes situações-problema.

Entretanto, vale mencionar que trabalhos atuais de Maia e Mc Clelland (2005) apontaram para algumas questões ainda não respondidas pelos estudos de Damásio (1996) e de Damásio e colaboradores (2001; 2005) e, especialmente, para problemas de interpretação de seus achados clínicos. Como Damásio e colaboradores, Maia e Mc Clelland investigaram pacientes com lesões no córtex pré-frontal ventro-medial. Porém, assinalaram que a hipótese dos marcadores somáticos não seria suficiente para explicar os resultados encontrados em seus estudos. Suas evidências clínicas apontaram para duplas dissociações funcionais entre pacientes pré-frontais ventro-mediais, ou seja, foram encontrados achados clínicos discrepantes entre esses pacientes. Também foi sugerida a possibilidade de uma explicação alternativa, não necessariamente vinculada à hipótese dos marcadores somáticos, o que parece tornar ainda mais complexa essa questão. 
Em um estudo teórico de reflexão crítica sobre algumas contribuições das chamadas Neurociências para o estudo da relação entre o afeto e a cognição (Cagnin, 2008), buscamos apresentar várias evidências do importante papel do afeto na regulação da cognição humana. Através da apresentação de achados empíricos de diferentes naturezas (clínicos, experimentais e neuroanatômicos), nem sempre convergentes como aqueles acima referidos, fica cada vez mais evidenciado, na contemporaneidade, o impacto dos processos afetivos nos processos cognitivos.

As divergências teóricas e metodológicas encontradas nos estudos situados nessa área do saber não impedem que haja uma convergência de questões a serem respondidas pelos mesmos. Como observaram na contemporaneidade Ochsner e Phelps (2007), as pesquisas que se situam nesta interface vêm tentando responder a quatro importantes questões na área. Uma delas indaga “como” os processos considerados "cognitivos” são alterados pelos processos considerados "afetivos” e vice-versa. A outra, por seu turno, indaga “como” os mecanismos neurais subjacentes à emoção e à cognição interagem para permitir uma aprendizagem adaptativa e para dar suporte às escolhas dos indivíduos. Uma outra questão complementa as anteriores e realça a importância da “validade ecológica” dos experimentos realizados em laboratório, ou seja, indaga se as pesquisas experimentais de laboratório poderiam explicar também as psicopatologias ou mesmo o comportamento dos indivíduos em situações do cotidiano. Uma última questão soma-se às anteriores e argüi o que haveria “em comum” entre os processos emocionais e cognitivos. Esses processos, que parecem envolver sistemas neurais distintos em sua origem, articulam-se e integram-se especialmente frente a situações sociais e/ou tarefas cognitivas mais complexas que envolvem escolhas, julgamento e tomada de decisão. O desafio de responder a estas e a outras indagações trazidas por novos estudos permanece lançado o que, a nosso ver, torna ainda mais multifacetado e complexo cenário cientifico da área.

Todavia, apesar das inúmeras evidências das Neurociências que convergem para a nítida influência do afeto na cognição, não pretendemos nos alongar sobre essas contribuições, a não ser em momento oportuno, pois o nosso principal interesse são os estudos desenvolvidos no âmbito da psicologia, especialmente da Psicologia Cognitiva.

Não obstante, dando continuidade aos efeitos dos estados de humor negativo e positivo na cognição, vale mencionar que alguns estudos como os Ito e Cacciopo (2001) e Mitchell e Phillips (2007) apresentaram evidências das Neurociências que apontaram para a existência de substratos neurais diferenciados subjacentes a esses dois tipos de 
humor. Distintos neurotransmissores e distintas bases anatômicas parecem estar envolvidos no processamento “dual” desses dois tipos de humor na cognição, ou melhor dizendo, o fato de serem sistemas separados ou parcialmente separados indica que cada um desses sistemas pode estar associado com distintos efeitos na cognição.

Mitchell e Phillips (2007), ao abordar os efeitos cognitivos e neurais dos estados de humor negativo e positivo nas funções executivas, sugeriram que variações nos estados de humor de indivíduos normais teria efeitos nessas funções. Para as autoras, um humor negativo, quando não muito forte, teria poucos efeitos nessas funções, enquanto um humor positivo poderia ter mais efeitos, provavelmente devido a um processamento heurístico suscitado por um humor positivo. Neurotransmissores diferenciados mediariam esses efeitos, a dopamina provavelmente responsável pela mediação dos efeitos cognitivos do humor positivo, e a serotonina, provavelmente responsável pelos efeitos cognitivos do humor negativo. O córtex pré-frontal estaria particularmente ativado durante essas funções com certa lateralização do humor positivo no hemisfério esquerdo e do negativo no direito. Esses achados parecem corroborar a hipótese de um processamento cognitivo diferenciado associado à valência do estado de humor.

Ito e Cacioppo (2001) também apresentaram evidências que se referem à descoberta de que estímulos de valência negativa seriam avaliados mais precocemente e seriam mais profundamente processados pelos sujeitos quando comparados com os de valência positiva. Isso se daria tanto em situações-problema que demandam uma avaliação mais automática, espontânea, como em situações-problema que demandam uma avaliação mais intencional e consciente. Esses achados parecem reforçar as hipóteses de Forgas (1995; 1998; 2001e), Schwarz e Clore (1983) e Clore e Huntsinger (2007), de que frente a um estimulo negativo ou mesmo de um estado de humor negativo, haveria um processamento mais sistemático, do tipo bottom-up, em contraposição ao processamento mais top-down e heurístico suscitado por estímulos ou estados de humor mais positivos. Nota-se assim certa "modularização" acompanhada de um processamento paralelo desses dois sistemas e, como observaram Ito e Cacioppo (2001), essa organização do sistema do afeto sugere que esse sistema é flexível e funcionalmente adaptativo.

Em suma, quando nos indagamos sobre essa “dependência do estado afetivo” na cognição e quando a correlacionamos com estruturas cerebrais identificáveis, uma hipótese de certa independência de processamentos emocionais e cognitivos parece se delinear. Porém essa mesma hipótese se complementa com a hipótese de haver uma influência mútua e uma integração entre os sistemas neurais subjacentes a esses 
processamentos. Essa complementaridade parece ficar clara nas situações cotidianas onde o afeto nitidamente influencia a percepção, a memória, a atenção, o pensamento, dentre outros processos cognitivos.

No que se refere a um processamento mais detalhista e sistemático frente a um estado de humor negativo, poderíamos indagar, conjuntamente com Linnenbrink e Pintrich (2004), se, diante de problemas mais bem-definidos dependentes de domínio e/ou que exigem uma atenção a detalhes, como alguns problemas físicos ou matemáticos, um humor mais negativo favorecia a sua resolução. Os achados empíricos desses autores com problemas relativos a esses domínios apontaram para evidências contraditórias, ou seja, encontraram discrepâncias não explicadas pelos modelos de processamento produzidos na área. Esses autores, reivindicaram, inclusive, um melhor refinamento destes modelos, bem como a necessidade de estudos com maior validade ecológica, como, por exemplo, em situações acadêmicas.

Em relação ao papel dos estados afetivos na resolução e na transferência analógica de problemas bem-definidos independentes de domínio, estudos como os de Brand, Reimer e Opwis (2007) também apresentaram evidências dos efeitos dos estados de humor durante a resolução e a transferência analógica desse tipo de problema. Em um dos seus experimentos, inicialmente, os participantes aprenderam a resolver o problema da Torre de Hanói com três e quatro discos e em seguida, tiveram o humor induzido (positivo e negativo) e, por último, tiveram que resolver problemas análogos (o problema dos Missionários e Canibais, dentre outros problemas). Os resultados sugeriram que os participantes com humor negativo foram menos eficientes nas tarefas de transferência. Em outro experimento complementar, com a replicação das mesmas condições experimentais, apenas variando o momento da indução de humor que, nesse caso, se deu antes da fase inicial do aprendizado da solução, o desempenho dos participantes com um humor negativo foi nitidamente afetado, tanto na fase de aprendizado quanto na fase de transferência.

Brand e Opwis (2007), em outro estudo onde também utilizaram problemas semelhantes, buscaram investigar o papel da indução de humor na resolução de problemas e na transferência analógica. Porém, além da investigação dos efeitos do humor positivo e negativo na transferência, eles investigaram se a resolução dos problemas em díade, na fase inicial de aprendizagem, teria efeitos positivos na transferência. Foi verificado, em um dos experimentos, que os participantes que sofreram uma indução positiva do humor e um aprendizado em díade foram os que 
apresentaram melhor desempenho na transferência. Porém, foi verificado em um experimento complementar que a indução do humor foi o principal fator que afetou a resolução dos problemas “alvo” e não o aprendizado em díade. Os resultados encontrados também sugeriram que os efeitos do aprendizado em díade só foram sentidos quando as tarefas “fonte” e "alvo” possuíam maior proximidade temporal. Um outro achado interessante que se mostrou incongruente com muitas evidências na área, como as de Clore e colaboradores (1994), foi o de que o humor negativo não favoreceu um processamento sistemático da informação. E, como observaram Brand e colaborador, a complexa interação entre a situação social e instrucional de aprendizagem, o estado de humor e o desempenho cognitivo parece trazer inúmeros desafios metodológicos e teóricos para as pesquisas na área.

Os estudos de Brand e colaboradores acima referidos trouxeram, assim, evidências dos efeitos do humor no aprendizado e na transferência de problemas bem-definidos independentes de domínio, problemas esses que, por sua própria definição, parecem ser menos "sensíveis" à influência do afeto. Em outras palavras, esse tipo de problema, na medida em que possui um alto grau de definição de suas regras, condições e limites, poderia se mostrar menos sujeito a influência de processos “top-down”, incluindo-se aqui os processos afetivos. Porém, como vimos no capítulo anterior, problemas bemdefinidos independentes e dependentes de domínio parecem sofrer a influência da variação de características de superfície de diferentes naturezas e, de modo complementar, como apontaram os estudos de Brand e colaboradores, parecem sofrer a influência dos estados de humor dos indivíduos.

Já em situações-problema mais “abertas”, mal-definidas, que envolvem a solução de problemas criativos e/ou problemas de insight como aqueles estudados por Isen, Daubman e Nowicki (1987) e Friedman e Foster (2000), a influência do afeto parece se mostrar mais nítida, pois inúmeras evidências empíricas vêm apontando para efeitos positivos de um estado de humor positivo/ alegre na resolução desse tipo de problema. No estudo de Friedman e Forster (2000) foi, inclusive, verificado que um estado de humor mais alegre/ positivo facilitaria a transferência analógica desse tipo de problema sem que houvesse a necessidade de “dicas” mais explícitas por parte do experimentador. Os achados desses estudos sugeriram que o afeto positivo favoreceria a abertura à novidade e à exploração do ambiente, bem como ao uso privilegiado de estratégias heurísticas, o que está em consonância com outros achados complementares relacionados ao julgamento de atitudes (como os de Bless, Schwarz e Mackie, 1992), à 
categorização (como os de Isen e Daubman, 1984; Bless, Schwarz e Wieland, 1996; Urada e Miller, 2000), e à tomada de decisão (como os de Luce, Bettman e Payne, 1997).

Estudos mais recentes, como os Verleur, Verhagen e Heuvelman (2007), investigaram os efeitos da apresentação de filmes (vídeo clips) com histórias tristes e alegres no humor e na resolução de problemas em um ambiente computacional de rede. Essas histórias continham materiais afetivos e temáticos não relacionados às tarefas de resolução de problemas, procedimento esse comum na área. Em alguns dos seus experimentos, um dos problemas apresentados envolvia insight (uma versão do problema dos “Dois Fios” de Maier) e as outras tarefas apresentadas envolviam pensamento divergente. Os resultados encontrados sugeriram que os efeitos facilitadores do humor se fizeram mais presentes no problema de insight do que nas outras tarefas que envolviam um pensamento divergente. Também foram encontrados resultados que sugeriram que as características da tarefa poderiam ajudar a moderar os efeitos do humor. Por exemplo, quando a solução do problema correspondia a critérios objetivos de solução, como o caso do problema de insight que demandava apenas uma solução, esse tipo de condição foi favorecida pelo humor negativo. Essa associação entre um humor mais negativo e uma solução por insight parece, inclusive, ir de encontro a outros achados na área que sugeriram que o humor positivo favorecia os processos de insight e a criatividade (p.e. Isen, Daubman \& Nowicki, 1987; Friedman e Foster, 2000). Porém quando as condições da tarefa envolviam critérios pessoais de satisfação do solucionador em relação à solução dada e não critérios objetivos de acerto e erro, esses efeitos do humor não se fizeram presentes, o que não confirmou a hipótese dos autores a respeito dos efeitos facilitadores de um humor positivo nesse tipo de tarefa.

No que se refere à evidência de que um humor negativo poderia favorecer, pelo menos em alguns casos, a resolução de problemas de insight, cabe argumentar que, talvez, o fato de ter havido uma "coação" experimental, que demandava apenas a resposta correta, tenha criado uma condição que exigia cautela e um maior monitoramento do feedback do processamento da informação. E como um humor negativo costuma estar associado a um processamento mais sistemático e cauteloso das informações, os benefícios de um humor positivo em termos de uma maior “divergência” do pensamento foram, a nosso ver, aí minimizados. 
Bless, Schwarz e Mackie (1992) observaram que o impacto dos estados afetivos no processamento cognitivo não se restringe a um único estágio de processamento, pois consideram que o aumento no processamento heurístico, provocado por um humor positivo, e o aumento no processamento sistemático, provocado por um humor negativo, parecem demonstrar diferentes efeitos em diferentes estágios de processamento, o que adiciona maior complexidade à relação entre afeto e cognição.

Em trabalhos mais recentes, Bless (2001) observou também que não basta apontar para o fato de que os indivíduos em um estado de humor positivo tenderiam a utilizar estratégias mais heurísticas de processamento, pois é preciso especificar “como” este processamento é mediado nessas situações. Em outros termos, por exemplo, se a hipótese for a de que os indivíduos alegres usam esse tipo de estratégia porque se sentem mais confiantes, haveria a necessidade de se encontrar evidências empíricas adicionais que dessem suporte ao papel mediador da confiança neste contexto. De modo complementar, haveria também a necessidade de se fazer uma distinção entre as condições necessárias e as condições suficientes envolvidas no uso dessas estratégias, ou seja, fazer uma discriminação se seria apenas o estado de humor o único fator que estaria determinando o uso prioritário dessas estratégias de processamento.

Bless, Schwarz e Wieland (1996), ao abordar a categorização de pessoas, incluindose aí o uso de estereótipos, apontaram para efeitos diferenciados do humor nesse processamento, como uma maior tendência a um processamento mais heurístico, mais geral, suscitado por um humor positivo em contraposição a um processamento mais sistemático, detalhista, suscitado por um humor negativo, conforme é idéia corrente na área. Entretanto, indagando se haveria também efeitos da motivação e/ou de uma diminuição da capacidade de processamento associados a um processamento mais heurístico suscitado por um humor positivo, esses autores não creditaram à redução de capacidade cognitiva como justificativa para um processamento mais heurístico, mas sim destacaram o fato de que um humor mais positivo tenderia a levar a um sentimento de confiança, ou seja, à percepção de que determinada situação teria menos riscos. Haveria certa tendência, também, no humor positivo, a uma categorização mais “típica”, como os achados da pesquisa desses autores também apontaram, o que poderia levar a um uso maior de estereótipos nesse caso. Já um humor negativo, por sua vez, tenderia a suscitar nos indivíduos uma postura mais cautelosa, com a percepção de determinada situação como mais problemática, o que levaria a um processamento mais sistemático, 
mais "rastreador" dos detalhes da situação e menos confiante nos resultados de seu desempenho.

No que se refere ao papel da motivação nesse contexto, esses autores questionaram a idéia vigente de que o processamento mais heurístico suscitado por um humor positivo seria sinal de um decréscimo na capacidade de processamento em função de uma diminuição da motivação frente à tarefa. Para eles, não seriam, necessariamente, estes os motivos que levariam os indivíduos com um humor positivo ao uso de heurísticas mais gerais, mas sim o fato de que, ao avaliar uma situação com um "olhar” mais positivo, mais confiante, esses indivíduos tenderiam a usar estruturas gerais de conhecimento (esquemas) já prontos. Sendo assim, na concepção desses autores, a ativação desses esquemas gerais de conhecimento seria um "antecedente" do processamento mais simplificado e padronizado e não “conseqüência” da falta de motivação.

Porém Martin (2001) apresentou uma perspectiva diferenciada da de Bless e colaboradores (1996) ao assumir que um estado de humor positivo não suscitaria, necessariamente, um processamento mais heurístico e um estado de humor negativo não suscitaria, necessariamente, um processamento mais sistemático. Para esse autor, quando os indivíduos se sentem confiantes de que um processamento heurístico vai ser suficiente para se chegar a um bom resultado, tendem a privilegiar esse tipo de estratégia, caso contrário, mesmo com um humor positivo, eles se engajariam em um processamento mais extensivo, sistemático. Martin também argumentou que o sentimento de confiança dos indivíduos seria determinado principalmente pelo humor e pelo contexto onde esse humor ocorre. O contexto forneceria uma espécie de "regra de suficiência” para o uso de determinada estratégia, ou seja, forneceria o feedback do desempenho, bem como da eficiência desse desempenho.

Martin e colaboradores (1997), em estudo anterior, observaram que o modelo de Forgas de influência do afeto não se mostrou suficiente para explicar as evidências empíricas sugeridas por seu estudo, pois para esse modelo os julgamentos incongruentes com o humor só ocorreriam quando os indivíduos não fizessem uso do seu humor em seus julgamentos, o que não ocorreu com seus achados. Em seus experimentos, os participantes submetidos à leitura de histórias tristes usaram seu humor para fazer julgamentos, mas os seus julgamentos se mostraram de valência oposta à valência das histórias e do seu humor. De modo complementar, os autores argumentaram que a heurística “como me sinto a respeito disso?” de Clore e 
colaboradores (1994; 2001) mostrou-se insuficiente para explicar seus achados. Eles chegaram à conclusão de que não haveria razão para que sentimentos de confiança, no caso de um humor positivo, ou o oposto, no caso de um humor negativo, levassem a determinados tipos de avaliação ou de motivação. Para os autores, inclusive, com a mudança de contexto poderia haver a mudança do significado do humor para o indivíduo.

Cabe aqui breve observação de que o argumento no sentido de que um humor positivo reduziria a capacidade cognitiva no processamento da informação é um argumento comum nos modelos de redes associativas, pois, para alguns desses modelos, o estado afetivo positivo ativaria muitos nodos conceituais simultaneamente e isso, conseqüentemente, criaria um estado de “sobrecarga” cognitiva. Já o argumento do impacto da motivação baseia-se na hipótese de que em um estado afetivo negativo, o indivíduo buscaria evitar essa condição e por isso se lançaria em um processamento sistemático, preventivo e cauteloso da informação. Mackie e Worth (1989) também atribuíram a uma "sobrecarga” na capacidade cognitiva o uso preferencial de heurísticas por indivíduos com um humor positivo, como pressupunham os modelos de rede semântica, como o de Bower e colaboradores já referidos.

Entretanto, Isen e colaboradores (1987), ao estudar a resolução de problemas criativos, atribuíram a outros fatores o uso de heurísticas frente a um humor positivo. Na concepção desses autores, a recuperação de informações positivas que costumam estar mais interconectadas e mais organizadas na memória do que as informações negativas, criaria uma espécie de “contexto cognitivo complexo" que, por sua vez, facilitaria uma abertura à novidade e à exploração do ambiente.

Em síntese, os estudos referidos nessa seção, que investigaram as diferenças de processamento cognitivo frente a um determinado estado de humor, não avaliaram as tonalidades afetivas dos problemas como capazes de suscitar um processamento cognitivo diferenciado. A principal preocupação da maioria desses estudos foi a de investigar o papel dos estados de humor positivo, negativo ou neutro, no uso de estratégias de processamento.

No que diz respeito à nossa proposta de pesquisa, podemos argüir se os efeitos da congruência entre as tonalidades afetivas dos problemas "fonte" e “alvo" serão potencializados quando houver uma solução serial vinculada ao problema "fonte” de tonalidade triste e uma solução convergente vinculada ao problema "fonte" de tonalidade alegre. Em outros termos, se a tonalidade afetiva positiva/ alegre do 
problema “alvo" poderia favorecer a escolha, por exemplo, do modo de solução convergente, por ser este um modo de solução mais evocado por “insight” e, talvez, mais relacionado a estratégias mais gerais, heurísticas, conforme o próprio Duncker (1945) sugeriu. Em contraste, a tonalidade afetiva negativa/ triste, por sua vez, poderia, talvez, favorecer a escolha do modo de solução serial por ser este mais “cauteloso” e direcionado às “coações” impostas por uma situação médica como, por exemplo, a dificuldade de acesso a múltiplas fontes de radiação simultâneas.

Por último, podemos ainda destacar, de acordo com Bless (2001), que todo estado afetivo é altamente "contextualizado” e que sua exata natureza depende de variáveis que influenciam a avaliação da situação como um todo, variáveis estas que podem estar interagindo como mediadoras em dada situação. Apesar de esse autor dirigir sua crítica àqueles modelos de processamento cognitivo que supõem maior parcimônia dos efeitos do afeto no processamento cognitivo, como, por exemplo, o uso de estratégias heurísticas frente a um humor positivo, podemos ampliar esta questão e ponderar que qualquer situação-problema que sofre a influência do afeto, tem dimensões e sentidos mais complexos que, provavelmente, não serão capturados por um único modelo ou abordagem de processamento.

Concluímos, assim, que ao buscar a fundamentação de pesquisas que focalizam o papel dos estados afetivos na resolução de problemas e na transferência analógica e, nesse contexto, na recuperação de informações na memória, transitamos por evidências empíricas que, por um lado, apresentaram uma convergência de achados que são parcialmente explicados por alguns modelos produzidos na área. Por outro lado, alguns estudos também apresentaram evidências que deixaram em aberto questões teóricas ainda não respondidas ou, talvez, não formuladas, no que se refere ao papel do afeto, em especial dos estados de humor positivo e negativo, no processamento da informação.

Como vimos, muitos efeitos do estado de humor foram avaliados em diferentes situações-problema com diferentes graus de definição. Porém, acreditamos que uma das questões ainda não respondidas na área diz respeito à influência das similaridades entre as tonalidades afetivas dos problemas nesse contexto. Como já mencionamos, encontramos apenas um estudo (Hesse e cols., 1997) mais direcionado à investigação da influência do estado de humor conjuntamente com a influência da tonalidade, entretanto este estudo foi configurado em moldes diferentes daqueles da pesquisa aqui desenvolvida. 
Sendo assim, o objetivo principal da próxima seção é focalizar o papel das tonalidades afetivas dos conteúdos dos enunciados no processo de resolução de problema e, em especial, no processo de transferência analógica.

4.5-Influência das Tonalidades Afetivas dos Conteúdos dos Enunciados dos Problemas na Resolução de Problemas e na Transferência Analógica

Nessa última seção, como mencionamos, iremos focalizar, em especial, a similaridade entre as tonalidades afetivas dos conteúdos dos enunciados dos problemas no processo de transferência analógica, pois essa similaridade é o cerne da nossa principal hipótese de pesquisa.

Como vimos, tanto o estado afetivo dos indivíduos solucionadores, quanto a tonalidade afetiva dos enunciados do problema podem influenciar, como observaram Hesse e colaboradores (1997), Schwarz e Skurnik (2003), o processo de resolução de problemas e de transferência analógica, pois podem influenciar que tipo de conhecimento se torna acessível na memória, conhecimento este que servirá de “input” para o uso de estratégias de resolução de problemas análogos.

Tendo isso em vista, quando se busca investigar os efeitos do afeto na resolução de problemas e na transferência analógica, há que se fazer uma diferença entre esses dois tipos de efeitos que, por sua vez, devem ser avaliados de modo mais independente, como o fizeram Hesse e colaboradores (1997) e como também fizemos em nosso trabalho.

Nas seções anteriores, conforme abordado, as evidências empíricas de diferentes estudos mais direcionados para a investigação da influência do estado de humor na memória e na resolução de problemas apontaram, em sua maioria, para dois tipos de congruências: a primeira relacionada à congruência entre os estados de humor (efeito de “dependência do humor”) no momento do registro e da recuperação. Esse efeito independe da tonalidade afetiva dos conteúdos que são recuperados na memória, pois é a congruência entre os estados de humor nos dois momentos o fator determinante na recuperação das informações. A segunda congruência, por sua vez, está relacionada à congruência entre o estado de humor atual do indivíduo e a tonalidade afetiva dos conteúdos recuperados na memória. Esse tipo de congruência, inclusive, parece ser a mais estudada em diferentes estudos na área. 
Não obstante, um outro tipo de congruência poderia ser destacada: a congruência entre as tonalidades afetivas dos conteúdos dos enunciados de duas situações-problema, congruência essa que poderia ser estudada de modo independente do estado de humor dos indivíduos. Talvez, pelo fato de esse tipo de congruência não depender, necessariamente, da mediação do estado de humor para ocorrer, costuma ser menos investigada em estudos mais direcionados à influência do afeto na memória e na resolução de problemas.

No que se refere especificamente ao âmbito da transferência analógica, podemos, conjuntamente com Schwarz e Skurnik (2003), traduzir estes três tipos de congruência da seguinte maneira: a primeira prediz que uma analogia teria mais chance de ser recuperada quando o humor do indivíduo na situação-problema "alvo" corresponde ao seu humor na situação-problema “fonte”, sendo a tonalidade do problema irrelevante nesse caso. A segunda prediz, por sua vez, que a recuperação de um análogo fonte teria mais chance de ocorrer quando houvesse a correspondência, na situação-problema “alvo”, da valência do estado de humor do individuo com a valência da tonalidade da analogia vista anteriormente. Por último, o terceiro tipo de congruência prediz que os solucionadores poderiam preferir determinadas analogias que tivessem uma correspondência de tonalidade entre si, de modo independente de seu estado de humor, não só porque essas seriam de mais fácil acesso, mas especialmente, porque as similaridades afetivas de superfície seriam salientes nesse contexto.

Gostaríamos de esclarecer que, no caso da nossa pesquisa, o termo "tonalidade afetiva” se refere especialmente à valência afetiva das histórias dos problemas que serão apresentados aos participantes. Através do estudo piloto 1 (anexo 2), buscamos investigar se os participantes desse estudo consideravam as histórias lidas como realmente tristes ou alegres. Para este tipo de avaliação, utilizamos as escalas de Hesse e colaboradores (1997), escalas estas adaptadas a partir das escalas de diferencial semântico de Osgood (1952; 1955). Foram apresentados aos participantes, após a leitura das histórias, escalas com pares de adjetivos opostos, como por exemplo, agradável e desagradável, triste e alegre, lenta e rápida, etc., com 7 intervalos entre eles, sendo 0 o ponto neutro. E de acordo com Hesse e colaboradores, a dimensão "valência afetiva” (avaliada especialmente nas escalas “tristeza - alegria” e “desagradável/ desprazeroso agradável/ prazeroso) é que seria de fundamental importância para a recuperação de um análogo "fonte" de mesma tonalidade. 
A única pesquisa encontrada na área que abordou mais diretamente os efeitos da congruência entre as tonalidades afetivas de problemas na transferência analógica foi a de Hesse e colaboradores (1997). Esses autores estudaram a transferência analógica utilizando problemas de raciocínio físico, com ênfase no chamado “efeito Magnus”. Eles manipularam as tonalidades afetivas dos problemas, embebendo-os em histórias de tonalidades tristes ou alegres. Isso foi feito tanto no que se refere aos problemas "alvo" quanto em relação aos problemas "fonte” e distrativos. Foram utilizados dois problemas “fonte”, cada um deles sendo apresentado já solucionado por um princípio físico aos participantes. Protocolos verbais, registrados por um período de 10 minutos, iniciados imediatamente após a leitura da situação-problema “alvo” alegre ou triste, mostraram que as palavras evocadas pelos participantes se referiam, predominantemente, aos problemas “fonte” que correspondiam ao problema “alvo" (história ou princípio) na tonalidade afetiva. Estes efeitos foram observados na ausência de qualquer influência dos estados de humor auto-relatados pelos indivíduos.

A pesquisa de Hesse e colaboradores (1997), conforme mencionado, apresentou dados sobre a influência da tonalidade afetiva das histórias dos problemas, obtidos através de protocolos verbais que registravam a freqüência da emissão de palavras em um curto período de tempo. Podemos observar que, nesse caso, parece estar implicado um acesso mais direto às informações da memória. Não houve, nessa pesquisa, uma avaliação da eficácia da aplicação na solução do problema "alvo” dos princípios físicos contidos nos problemas "fonte”. Nesse sentido, na medida em que houve, na situação “alvo”, um registro verbal de palavras que evocavam similaridades presentes na situação “fonte”, mas não a avaliação do grau de acerto na aplicação do princípio, não ficou muito claro, a nosso ver, em que grau se deu a transferência. E se, como vimos, na verdadeira transferência analógica há a necessidade de adaptação e de aplicação de conhecimentos e não meramente uma recuperação de informações, o fato de não ter sido bem avaliado, nesse estudo, o “quanto” dessa adaptação ocorreu, foi, a nosso ver, uma questão que permaneceu não conclusiva.

Como vimos anteriormente, Forgas (1995; 1998; 2001e), ao abordar as estratégias de processamento da informação relacionadas ao acesso direto de informações na memória, supunha que este tipo de estratégia seria menos suscetível de ser influenciada pelo afeto, em contraposição às estratégias heurísticas ou mais sistemáticas. Os achados de Hesse e colaboradores (1997) que sugeriram a importância das similaridades afetivas das tonalidades dos problemas, quando havia um acesso mais direto às informações na 
memória, parecem apontar em outra direção. Porém Forgas quando se referia à influência do afeto no processamento cognitivo estava se referindo à influência dos estados de humor neste processamento e não à influência da tonalidade afetiva dos estímulos. Nesse contexto, talvez, os efeitos da similaridade afetiva de conteúdos de problemas sejam mais significativas do que os efeitos do próprio estado de humor, pois são capazes de influenciar, inclusive, as chamadas estratégias mais diretas de processamento.

Não obstante, permanece a questão: quando, na situação-problema “alvo” trata-se de um processo mais deliberado de escolha de uma solução que está em competição com outra solução igualmente possível, e que não envolve um acesso direto, mas sim um certo conflito e uma tomada de decisão, podemos observar a influência da congruência entre as tonalidades afetivas das histórias dos problemas?

A literatura da área, como vimos, tem sugerido que quanto mais uma situaçãoproblema for “aberta” e indeterminada, mais essa situação é passível de ser influenciada pelos estados afetivos dos indivíduos. Seria essa situação também mais suscetível de ser influenciada pela tonalidade afetiva das histórias, de modo independente do estado de humor dos indivíduos?

Autores como Linnenbrink e Pintrich (2004), já referidos, ao apontar para a existência de evidências empíricas contraditórias sobre a influência do estado de humor positivo e negativo na resolução de problemas matemáticos, sinalizaram para a maior dificuldade de avaliar esse tipo de influência em problemas mais dependentes de domínio, em contraste com a maior facilidade de avaliar este tipo de influência em problemas mal-definidos e cotidianos. Como também vimos, autores como Isen e Daubman (1984), Bless, Schwarz e Mackie (1996), Luce, Bettman e Payne (1997), Urada e Miller (2000), Friedman e Foster (2000), dentre outros, já haviam apontado para uma maior "sensibilidade" à influência do afeto frente a problemas mais ambíguos, mal-definidos, que envolvem algum tipo de escolha ou conflito.

Hesse e colaboradores (1997), trabalhando com problemas bem-definidos e dependentes de domínio (princípios da física), obtiveram resultados que apontaram para efeitos da congruência entre as tonalidades afetivas das histórias, mas não efeitos da congruência entre o estado de humor dos indivíduos e as tonalidades das histórias, o que parece ir ao encontro dos achados de Linnenbrink e Pintrich (2004). Não obstante, Hesse e colaboradores não avaliaram, em seus estudos, a influência da congruência 
entre as tonalidades afetivas de problemas mal-definidos, ambíguos e que suportam mais de uma solução, como aqueles que pretendemos utilizar em nossa pesquisa.

Apesar de termos encontrado pesquisas como as de Isen e colaboradores (1987), dentre outras, já mencionadas, que investigaram a influência do estado de humor na resolução de problemas mal-definidos como, por exemplo, o problema da vela de Duncker, não houve nestes estudos, a manipulação da tonalidade afetiva dos problemas, mas sim a manipulação do estado de humor dos indivíduos frente a problemas de tonalidade afetiva mais neutra.

Já os estudos de Holyoak e colaboradores (1980; 1983; 1987; 1989), de Gick (1985; 1990), de Helfenstein e Saariluoma (1996), dentre outros, com problemas maldefinidos como o clássico problema da radiação de Duncker e/ou seus análogos, apesar de ter sinalizado para a importância das características de superfície na transferência analógica, não investigaram as similaridades nas tonalidades afetivas desses problemas.

Podemos ainda observar que a maioria dos estudos que destacou o papel dos conteúdos dos enunciados na resolução de problemas e na transferência analógica de problemas bem-definidos, como os de Simon e colaboradores (1976; 1985; 1990), com problemas independentes de domínio, e como os de Ross (1987; 1989), Ross e colaboradores (1990; 1996; 2002), Bassok (1990), Bassok e colaboradores (1989; 1995; 1998), com problemas de diferentes domínios, também não focalizou a valência afetiva desses conteúdos e sim seu caráter semântico.

Nesses estudos, como vimos, as similaridades de superfície, apesar de não se mostrar necessárias para a transferência analógica, como as similaridades estruturais, costumam oferecer “dicas” de contexto para a recuperação do problema análogo. E, quando os problemas análogos são muito dessemelhantes em suas características superficiais, a transferência espontânea, sem “dicas”, mostrou-se mais difícil.

Vale ainda destacar os trabalhos de Innes-Ker e Niedenthal (2002) que, ao abordar os efeitos do afeto na categorização e no julgamento, encontraram achados empíricos que se coadunam com a hipótese de que a categorização preferencial do estímulo em termos de uma resposta afetiva é devida à atenção seletiva direcionada para uma resposta afetiva equivalente. Em outras palavras, alguns resultados apontaram para a evidência de que estados afetivos orientam a atenção seletiva, não só em direção à informação afetiva, ou seja, aos conceitos afetivos em jogo, mas também aumentam a utilização dessa informação em julgamentos de similaridade. 
Innes-Ker e Niedenthal (2002) também trouxeram evidências empíricas mais recentes que são consistentes com achados empíricos anteriores como os de Hesse e colaboradores (1997) e Halberstadt e Niedenthal (1997). Ao investigar o papel de conceitos semânticos afetivos e dos estados afetivos em tarefas que exigiam um julgamento social e uma categorização, esses autores apontaram para evidências que sugeriram, por um lado, que os conceitos semânticos afetivos poderiam ser ativados sem que houvesse uma alteração no estado de humor dos indivíduos. Por outro lado, evidências complementares também sugeriram que a ativação semântica desses conceitos não teve o mesmo efeito como indutora de um estado afetivo.

Nessa direção então, apesar de não focalizar a transferência analógica nesses estudos, Niedenthal e colaboradores também parecem apontar para a independência dos efeitos dos conteúdos afetivos em relação ao estado de humor dos indivíduos nesse tipo de situação-problema.

Já em relação à passagem do tempo no processo de transferência analógica quando há similaridades afetivas entre as tonalidades dos problemas análogos, não encontramos estudos que abordassem os efeitos do decurso do tempo nesse contexto.

Como vimos, estudos como os de Spencer e Weisberg (1986) e de Catrambone e Holyoak (1989), dentre outros, investigaram os efeitos do decurso do tempo no processo de transferência e apontaram para evidências que sugeriram que a qualidade do esquema de aprendizagem construído poderia favorecer a manutenção da transferência por mais tempo. Entretanto, não houve a manipulação das tonalidades afetivas dos problemas nesses estudos.

Poderíamos nos indagar se, por um lado: quando há similaridades afetivas dos conteúdos dos problemas haveria a manutenção da transferência analógica após um maior decurso de tempo. E, por outro lado, de modo complementar, se, haveria, nesse contexto, a manutenção da congruência entre a tonalidade afetiva do problema “alvo” e a escolha do problema “fonte”, quando mais de uma solução é possível. Em outros termos, se os efeitos da congruência entre as tonalidades afetivas de problemas "fonte” e “alvo” permanecerão positivos após a passagem de tempo de uma semana.

Concluímos assim que, apesar dos resultados obtidos em estudos que têm sido desenvolvidos na área, permanecem questões, a nosso ver, importantes ainda não respondidas como aquelas acima mencionadas e como outras que delineamos abaixo.

Quando se trata da transferência analógica de problemas mal-definidos, mais próximos das situações cotidianas, as similaridades das tonalidades afetivas entre os 
problemas “fonte” e "alvo" terão efeitos significativos, mesmo quando não houver uma congruência com o estado de humor dos indivíduos?

E se houver uma congruência entre o estado de humor dos indivíduos, na situaçãoproblema "alvo", com a tonalidade afetiva do problema "fonte" escolhido, haverá uma associação positiva entre a valência do estado de humor e a valência da tonalidade do problema na escolha de um dos modos de solução?

A tonalidade afetiva triste ou alegre do problema "alvo" poderia afetar a escolha de um modo de solução convergente ou serial? Em outras palavras, uma tonalidade positiva/ alegre dos problemas “fonte” e “alvo” poderia suscitar, preferencialmente, a escolha do modo de solução convergente por este tipo de solução demandar um processamento mais heurístico e um processo de insight? Já a tonalidade afetiva negativa/ triste poderia, por sua vez, suscitar, preferencialmente, a escolha do modo de solução serial por este tipo de solução demandar um processamento mais sistemático, detalhista, cauteloso e mais focalizado nas “coações” percebidas no problema?

Em suma, os Problemas aqui delineados podem, então, ser explicitados nas seguintes questões:

1- Na transferência analógica, a similaridade entre as tonalidades afetivas dos problemas "fonte” e "alvo" poderia influenciar a escolha de um modo de solução para o problema “alvo”, quando este problema comporta mais de uma solução possível?

2- A tonalidade afetiva, positiva ou negativa, do problema “alvo” poderia influenciar o estado de humor dos indivíduos?

3- A similaridade entre as tonalidades afetivas dos problemas "fonte” e alvo" seria mais significativa do que o estado de humor dos indivíduos para a escolha da solução do problema "alvo"?

4- E quando houvesse a similaridade entre as tonalidades afetivas dos problemas e o estado de humor dos indivíduos (modificado negativamente ou positivamente), haveria uma associação positiva entre esses dois fatores?

5-A tonalidade afetiva, positiva ou negativa, de um problema poderia favorecer a escolha de uma solução convergente ou serial, quando as duas estivessem disponíveis? 
O favorecimento seria na direção da escolha da solução serial, quando a tonalidade fosse triste, e da escolha da solução convergente, quando a tonalidade fosse alegre?

6- Apesar do declínio natural da transferência analógica no curso do tempo, poderia haver a persistência dos efeitos da similaridade entre as tonalidades afetivas dos problemas "fonte" e "alvo"?

Essas questões permanecem, a nosso ver, ainda não respondidas na área. A investigação dessas questões constitui o principal objetivo desse estudo. Acreditamos que uma pesquisa que tenha por objetivo esclarecê-las pode vir a trazer subsídios importantes para um melhor entendimento do papel das similaridades afetivas de problemas no processo de resolução de problemas e de transferência analógica. 


\section{5-Hipóteses Experimentais e Plano Experimental}

\section{1.-Hipóteses Experimentais Principais:}

1-A similaridade entre as tonalidades afetivas dos problemas “fonte” e “alvo” terá efeito positivo na determinação do modo de solução escolhido para o problema “alvo”.

2- A taxa de transferência analógica apresentará um declínio, mas será ainda significativa, quando medida em sessões consecutivas e após uma semana.

3- O efeito positivo da similaridade entre as tonalidades afetivas dos problemas "fonte" e "alvo" na transferência analógica apresentará um declínio, mas será ainda significativo, quando medido em sessões consecutivas e após uma semana.

\section{2-Hipóteses Experimentais Secundárias:}

1- A tonalidade afetiva do problema “alvo" terá influência sobre o humor dos indivíduos, sendo que a tonalidade triste favorecerá uma variação negativa do humor e a tonalidade alegre favorecerá uma variação positiva do humor.

2- O efeito da similaridade entre as tonalidades afetivas dos problemas "fonte" e "alvo" na escolha da solução do problema "alvo" prevalecerá sobre o efeito da variação do estado de humor suscitada pela leitura das histórias “alvo”.

3- O efeito da similaridade entre as tonalidades afetivas dos problemas "fonte” e "alvo" na escolha da solução do problema “alvo” será potencializado quando houver também a congruência entre as tonalidades dos problemas e as variações do estado de humor dos indivíduos.

4- As tonalidades afetivas dos problemas “alvo” terão efeito positivo na escolha do modo de solução, serial ou convergente, do problema "alvo”.

5.3-Plano Experimental: CRD, dois grupos independentes. 


\section{6-Método}

6.1-Variáveis:

\subsection{1-Variáveis Independentes}

6.1.1.1-Tonalidade afetiva dos problemas “alvo”, em 2 níveis:

-Tonalidade agradável/alegre

-Tonalidade desagradável/triste.

Foram apresentados dois problemas "alvo", equivalentes do ponto de vista formal, que utilizam a situação-problema de Duncker (“problema da radiação”) em um contexto médico. Em ambas, há uma narrativa feita por um narrador que relata, em um dos problemas, situações desagradáveis/ tristes e, em outro problema, situações agradáveis/ alegres.

6.1.1.2- Intervalo de tempo entre a apresentação dos problemas “fonte” ( $1^{\mathrm{a}}$ sessão) e a apresentação do problema “alvo”( $2^{\mathrm{a}}$ sessão), em dois níveis:

-Sessões consecutivas

-Sessões com intervalo de uma semana

\subsection{2-Variáveis Dependentes}

-Modo de solução do problema "alvo" vinculado à tonalidade afetiva do problema "fonte".

-Modo de solução serial ou convergente do problema "alvo”, independentemente de sua vinculação à tonalidade afetiva do problema "fonte".

-Variação do humor.

\section{$\underline{6.2-\text { Sujeitos }}$}

A amostra foi constituída de 443 estudantes universitários com idade média de 24 anos, de ambos os sexos, sendo 316 mulheres e 127 homens, que cursavam diferentes 
cursos das áreas das Ciências Humanas. Os cursos abrangidos foram: Psicologia, Direito e Comunicação Social de três instituições de ensino superior situadas em diferentes cidades dos estados do Rio de Janeiro e do Espírito Santo (Universidade do Estado do Rio de Janeiro, Universidade de Vila Velha e Faculdade de Direito de Cachoeiro de Itapemirim).

Houve a participação de 263 sujeitos nas sessões consecutivas e de 180 sujeitos nas sessões com intervalo de uma semana. O menor número de sujeitos nas sessões com intervalo de uma semana deveu-se, principalmente, ao não comparecimento para a segunda sessão.

\section{$\underline{\text { 6.3-Instrumentos }}$}

\subsection{1-Problemas utilizados:}

Foram utilizados quatro problemas "fonte", dois problemas distrativos e dois problemas “alvo”. As histórias dos problemas “fonte”, dos problemas distrativos e dos problemas “alvo” foram listadas integralmente no anexo 1.

Com o intuito de controlar as variáveis “intervenientes” relacionadas a esses problemas foram feitos dois estudos pilotos que se encontram nos anexos 2 e 3.

\subsubsection{1-Problemas "Fonte" utilizados:}

Os problemas “fonte” utilizados foram versões análogas ao problema de radiação de Duncker, apresentados com dois modos diferentes de solução. Um desses modos de solução é a tradicional solução convergente, onde diferentes raios convergem simultaneamente para um mesmo ponto, e o outro modo de solução é a solução serial, onde raios são emitidos de uma mesma fonte em seqüência, solução esta também focalizada pelo próprio Duncker, em um dos seus experimentos.

A tonalidade afetiva das histórias dos problemas variou também de dois modos:

-Uma história com tonalidade afetiva desagradável/triste

-Uma história com tonalidade afetiva agradável/alegre

A história de tonalidade desagradável/triste refere-se a uma viagem de avião que requer uma "aterrissagem forçada" e apresenta o problema da necessidade da limpeza de um transistor mofado através da utilização de raios infravermelhos. Porém esse 
transistor está protegido por uma frágil película e está contido em um compartimento lacrado no centro do avião, o que requer a emissão de raios infravermelhos de modo que estes não danifiquem a frágil película que protege o transistor.

A história de tonalidade afetiva agradável/alegre diz respeito a uma viagem de navio, uma espécie de “cruzeiro de sonho”, que apresenta o problema de um filamento com fungo dentro de um contêiner refrigerado que armazena alimentos perecíveis. De modo semelhante ao problema anterior, o fungo do filamento precisa ser removido (esterilizado) pela emissão de raios, no caso raios ultravioletas (UV), sendo que as frágeis paredes do contêiner não podem ser danificadas por esta emissão.

Foram utilizados quatro problemas "fonte":

-Um com tonalidade afetiva desagradável/triste e modo de solução serial (uma versão da “Aterrissagem Forçada”)

-Um com tonalidade afetiva desagradável/triste e modo de solução convergente (uma versão da “Aterrissagem Forçada”)

-Um com tonalidade afetiva agradável/alegre e modo de solução serial (uma versão do “Cruzeiro de Sonho”)

-Um com tonalidade afetiva agradável/alegre e modo de solução convergente (uma versão do "Cruzeiro de Sonho”)

Desses quatro tipos de problemas apenas dois foram apresentados a cada sujeito (com tonalidades afetivas opostas e modos diferentes de solução).

Em um primeiro estudo piloto proposto (anexo 2), procurou-se avaliar a valência das tonalidades afetivas das histórias desses problemas.

Também foi avaliado, através de um segundo estudo piloto (anexo 3), o grau de equivalência das soluções propostas (serial e convergente), no que se refere às preferências dos indivíduos em condições de neutralidade da tonalidade afetiva das histórias dos problemas.

A existência de quatro problemas "fonte" visou o controle das interferências de efeitos da ordem de apresentação dos problemas (efeitos de primazia e de proximidade temporal), tanto em relação à tonalidade afetiva, quanto em relação ao modo de solução. Visou também que cada modo de solução pudesse ser apresentado com duas diferentes tonalidades afetivas. Isso será explicitado no item “Procedimento”. 


\subsubsection{2- Problemas “Distrativos” utilizados:}

Os problemas distrativos utilizados foram apresentados com as respectivas soluções. A tonalidade afetiva das histórias também variou de dois modos:

-Tonalidade afetiva desagradável/triste.

-Tonalidade afetiva agradável/alegre.

A história desagradável/triste refere-se a uma viagem de ônibus por uma região árida do sertão. Já a história agradável/alegre refere-se a um passeio por um parque florestal aprazível.

No primeiro estudo piloto também se procurou avaliar a valência das tonalidades afetivas das histórias destes problemas.

O uso de problemas distrativos teve por objetivo tornar a tarefa menos óbvia. Nesse sentido, os problemas distrativos foram intercalados aos problemas "fonte” na primeira sessão experimental.

\subsubsection{3-Problemas “Alvo” utilizados:}

Os problemas “alvo” utilizados referem-se a situações-problema análogas ao problema da radiação de Duncker, onde não é apresentada a solução do problema, a qual ficará a cargo dos sujeitos.

Há duas versões da história do problema da radiação de Duncker, uma com uma tonalidade afetiva agradável/alegre e outra com uma tonalidade afetiva desagradável/triste.

As duas histórias dos problemas se referem a um relato de episódios, ocorridos na vida do narrador das histórias, episódios esses que culminam em uma situação médica, onde se faz necessário o tratamento de um tumor cancerígeno com alta malignidade em um dos rins (em uma das versões) ou o tratamento de um tumor benigno em um dos rins (na outra versão). Cada sujeito recebeu apenas uma dessas duas versões.

As duas histórias foram construídas de modo que se tornassem similares do ponto de vista formal. As tonalidades afetivas foram obtidas a partir da oposição de idéias e de palavras com conotações opostas (por exemplo: ganhar um filho/perder um filho).

Procurou-se equiparar as duas histórias “alvo” no que se refere às suas palavras em comum, bem como à contraposição de idéias entre elas (anexo 4). Houve também uma preocupação com a equivalência no tamanho dos textos. 
No primeiro estudo piloto (anexo 2), procurou-se avaliar também a valência das tonalidades afetivas das histórias desses problemas.

Houve também a preocupação de manter constante o grau de correspondência entre as palavras utilizadas nas histórias dos problemas “fonte” e "alvo", em particular evitar que as similaridades nas palavras sejam maiores para pares "fonte" / "alvo" afetivamente congruentes do que para pares fonte/alvo afetivamente incongruentes (anexo 4). Desse modo, a preferência por um problema fonte afetivamente congruente com o problema alvo não seria atribuída a uma maior correspondência nas palavras utilizadas.

Foram computadas as palavras iguais presentes nas histórias dos problemas e houve a preocupação de manter um número equivalente de palavras repetidas nas histórias. Cabe observar que foram excluídos dessa computação: artigos, pronomes, conjunções e preposições, pois estes termos não parecem ter o mesmo impacto no texto quanto têm os substantivos, os adjetivos, os verbos e os advérbios.

\subsection{2-Questionários}

Foram utilizados quatro questionários de múltipla escolha relativos aos problemas “fonte” e distrativos, sendo que os dois questionários relativos às histórias dos problemas "fonte" apresentaram seis questões cada e os dois questionários relativos às histórias dos problemas distrativos apresentaram, por sua vez, três questões cada.

As questões das histórias dos problemas “fonte” versaram sobre:

.A opinião dos sujeitos sobre a tonalidade da história.

.Algumas características da história e/ou principal objetivo dos personagens.

.O modo de solução do problema contido na história.

As questões das histórias dos problemas distrativos versaram sobre:

.A opinião dos sujeitos sobre a tonalidade da história

.Algumas características da história e/ou principal objetivo dos personagens

.O modo de solução do problema contido na história

Esses questionários tiveram como principal objetivo auxiliar a compreensão e o aprendizado dos problemas (“fonte” e distrativos) no que diz respeito às suas principais características, incluindo-se aqui a opinião dos sujeitos sobre a tonalidade afetiva das histórias, bem como sobre o modo de solução dado para cada problema contido nas histórias. Os questionários propostos encontram-se no anexo 5. 


\subsection{3-Escala de avaliação da variação do estado de humor dos sujeitos:}

Foi pedido aos sujeitos que fizessem uma avaliação de seu estado de humor através da atribuição de uma nota, em uma escala de 0 a 100, no início e no final das sessões consecutivas e no início e no final da segunda sessão quando o intervalo foi de uma semana. A avaliação da variação do estado de humor teve por objetivo verificar se a preferência por um problema “fonte”, afetivamente congruente com o problema "alvo”, poderia ser devido ao fato de que a leitura do problema “alvo” induziu uma alteração de humor. Nesse sentido, a variação do estado de humor é considerada uma variável de controle.

\section{4- Material}

-Lápis, papel e canetas coloridas para a marcação das folhas de rosto dos subgrupos.

\section{5- Procedimento}

Os sujeitos foram testados em grupos constituídos por suas respectivas turmas de graduação. As sessões foram anteriormente agendadas com os professores das disciplinas e, em alguns casos, também com os coordenadores de curso. Cerca de 50\% das turmas de cada instituição participaram das sessões consecutivas e cerca de 50\% participaram das sessões com intervalo de uma semana.

$\mathrm{Na}$ primeira sessão, inicialmente, houve a apresentação da pesquisadora pelo professor da disciplina. Em seguida, foi dado um esclarecimento sobre a natureza da pesquisa, sobre a participação voluntária dos alunos e sobre os termos do compromisso ético assumido pela pesquisadora. O “Termo de Consentimento Livre e Esclarecido” foi apresentado aos alunos para leitura e assinatura, caso houvesse concordância na participação (anexo 8).

O experimento foi realizado em duas sessões. Na $1^{\text {a }}$ sessão, cada sujeito recebeu folhas grampeadas contendo esclarecimentos e instruções sobre as tarefas, os problemas "fonte” e distrativos e os respectivos questionários. Para cada sujeito foram apresentados dois problemas “fonte” análogos ao problema da radiação de Duncker, cujas histórias foram revestidas com tonalidades afetivas diferentes (agradável/alegre e 
desagradável/triste) e modos de solução também diferentes (serial e convergente). Houve também a apresentação de dois problemas distrativos, com histórias revestidas de tonalidades afetivas agradável/alegre ou desagradável/triste e modos de solução também diferentes.

Os participantes de cada turma foram, inicialmente, subdivididos em quatro subgrupos de modo randômico. Isso foi feito com o intuito de evitar a interferência da ordem de apresentação dos problemas “fonte” (efeitos de primazia e de proximidade temporal) tanto no que diz respeito à tonalidade afetiva quanto em relação ao modo de solução dos problemas. Isso foi feito também para garantir que as histórias dos problemas “fonte” de tonalidades afetivas triste/ desagradável e alegre/ agradável pudessem estar associadas, cada uma delas, de modo equivalente, aos dois modos de solução serial e convergente. Os resultados relativos à ordem de apresentação dos problemas "fonte" e ao modo de vinculação das soluções aos problemas "fonte" encontram-se no anexo 6.

Para cada subgrupo foi apresentado:

-Em primeiro lugar, um problema com solução serial e tonalidade afetiva desagradável/triste e, em segundo lugar, um problema com solução convergente e tonalidade afetiva agradável/alegre.

-Em primeiro lugar, um problema com solução serial e tonalidade afetiva agradável/alegre e, em segundo lugar, um problema com solução convergente e tonalidade afetiva desagradável/triste.

-Em primeiro lugar, um problema com solução convergente e tonalidade afetiva desagradável/triste e, em segundo lugar, um problema com solução serial e tonalidade afetiva agradável/alegre.

-Em primeiro lugar, um problema com solução convergente e tonalidade afetiva agradável/alegre e, em segundo lugar, um problema com solução serial e tonalidade afetiva desagradável/triste.

Após a apresentação do primeiro problema distrativo, houve a apresentação de um problema "fonte" de mesma tonalidade afetiva desse problema e, após a apresentação do segundo problema “fonte”, houve a apresentação de um outro problema distrativo de mesma tonalidade afetiva desse segundo problema.

Após cada um dos problemas foi apresentado um questionário de múltipla escolha para ser respondido por cada sujeito, versando sobre os principais episódios das 
histórias, sobre sua tonalidade afetiva, bem como sobre o modo de solução de cada problema.

Os integrantes de cada um desses subgrupos foram distribuídos, em número aproximadamente igual e de modo aleatório, para a constituição de dois grupos experimentais: um grupo em que os integrantes receberam o problema “alvo" de tonalidade triste/ desagradável e outro grupo em que os integrantes receberam o problema “alvo” de tonalidade alegre/ agradável.

Os sujeitos participaram das sessões em grupo e foram apresentados aos problemas individualmente.

Quando as sessões foram consecutivas, houve, no início da primeira sessão, a solicitação para que os sujeitos avaliassem seu estado de humor através de uma escala destinada a esse fim. Já no que se refere às duas sessões com intervalo de uma semana, essa solicitação foi apresentada no início da segunda sessão. Foi pedido a cada sujeito que atribuísse uma nota de 0 a 100 a seu estado de humor.

Na segunda sessão relativa aos dois intervalos de tempo foi feito novo pedido para que os sujeitos atribuíssem uma nota a seu estado de humor após a apresentação do problema “alvo". Para 50 \% dos sujeitos de cada uma das sessões foi apresentado o problema “alvo" de tonalidade afetiva desagradável/triste e para os outros 50 \%, o problema "alvo" de tonalidade afetiva agradável/alegre.

Cada um desses dois grupos, como já referido, teve um número equivalente de sujeitos submetidos às quatro ordens de apresentação dos problemas “fonte”.

Após a apresentação do problema “alvo" foi também solicitado aos sujeitos que escolhessem, por escrito, apenas um modo de solução para este problema, aquele que lhe parecesse mais adequado. Por último, foi pedido que, só após a resolução do problema, os sujeitos fizessem a leitura da folha seguinte que, por sua vez, foi apresentada separadamente. Nessa folha foi feito um pedido de justificativa da escolha do modo de solução do problema "alvo". Nessa sessão, do mesmo modo que na primeira, os sujeitos participaram da sessão em grupo e resolveram, individualmente, o problema "alvo".

A identificação dos sujeitos que pertenceram a cada um desses quatro subgrupos foi feita através da combinação de uma letra e um número coloridos nas folhas de rosto da primeira e da segunda sessões. Desse modo, cada participante pôde ser identificado pela letra e pelo número arbitrário que recebeu. Esse procedimento visou, por um lado, preservar o anonimato dos participantes e, por outro, permitir que houvesse uma 
correspondência entre as folhas das histórias e dos questionários da primeira sessão com as folhas dos problemas “alvo” da segunda sessão.

Nas sessões com intervalo de uma semana, para evitar o possível esquecimento da combinação da letra e do número que identificava o participante, foi pedido aos participantes, em uma folha destinada à esse fim, que associassem o seu número de matrícula ao código de letra e número que receberam. Assim, houve a possibilidade de discriminar o subgrupo ao qual o sujeito pertencia.

As sessões consecutivas tiveram a duração de cerca de 50 minutos e nas sessões com intervalo de uma semana, a primeira sessão durou cerca de 40 minutos e a segunda durou cerca de 15 minutos.

Ao final da sessão foi feito um agradecimento pela participação no experimento, bem como foram feitos comentários sobre os objetivos da pesquisa e sobre o retorno dos resultados a ser feito posteriormente.

As folhas de instrução/ respostas fornecidas a cada participante da pesquisa acham-se exemplificadas, em uma de suas versões, no anexo 7.

Após a aprovação do projeto de pesquisa pelos membros da Banca do Exame de Qualificação, tal projeto foi submetido e aprovado pelo Comitê de Ética em Pesquisa com Seres Humanos do Instituto de Psicologia da Universidade de São Paulo. 


\section{7- Resultados e Discussão}

\section{1-Resultados}

Foi utilizado para comparação entre os grupos o teste não paramétrico Qui-quadrado, através do programa SPSS (Statistical Package for the Social Sciences) v. 13.0. O nível de significância (ou probabilidade de significância) mínimo adotado foi de 5\%.

Quando a análise dos resultados compreendeu mais do que duas variáveis, foi efetuada uma análise de correspondência múltipla obtida também através do programa SPSS v. 13.0 .

\subsection{1-Resultados para as sessões consecutivas.}

\subsubsection{1-Transferência analógica.}

Na avaliação da transferência analógica foram discriminadas três categorias:

• Transferência integral - quando a solução do problema “alvo” pôde ser classificada inequivocamente como de natureza serial ou convergente.

- Transferência parcial - quando a solução do problema alvo conteve elementos da história ou da solução de um dos dois problemas "fonte” (p. e.“usaria raios de baixa intensidade”; "usaria a solução que está na história do avião”; etc.) ou ainda quando a solução mostrou-se ambígua, contendo elementos da solução serial e da solução convergente.

. Sem transferência - quando a solução do problema "alvo” foi constituída por outros modos de solução diferentes daqueles vinculados aos problemas "fonte” (p. e.“ faria uma quimioterapia”; “faria uma cirurgia para retirar o tumor”, etc.)

Nenhuma das soluções vinculadas aos problemas distrativos foi utilizada pelos sujeitos na resolução dos problemas “alvo” nos dois intervalos de tempo pesquisados.

A tabela 1 mostra que o número de transferências integrais feitas pelos sujeitos foi maior do que o número de transferências parciais e do que o número de soluções sem vinculação com os problemas “fonte”, isto é, sem transferência.

A diferença entre as freqüências foi significante, $X^{2}(2)=256,34, p<0,001$ 


\begin{tabular}{|c|c|c|}
\hline $\begin{array}{l}\text { TRANSFERÊNCIA DOS } \\
\text { MODOS DE SOLUÇÃO }\end{array}$ & FREQUÊNCIA & PERCENTAGEM \\
\hline $\begin{array}{l}\text { TRANSFERÊNCIA } \\
\text { INTEGRAL }\end{array}$ & 210 & 79,8 \\
\hline $\begin{array}{l}\text { TRANSFERÊNCIA } \\
\text { PARCIAL }\end{array}$ & 23 & 8,7 \\
\hline SEM TRANSFERÊNCIA & 30 & 11,4 \\
\hline TOTAL & 263 & 100,0 \\
\hline
\end{tabular}

A distribuição das freqüências das três categorias de transferência analógica, acima discriminadas, na condição de problema alvo de tonalidade triste e na condição de problema alvo de tonalidade alegre é mostrada na tabela 2.

A diferença observada entre os dois grupos não foi significante. $X^{2}(2)=0,182$, $\mathrm{p}>0,05$.

TABELA 2- FREQUÊNCIA DE TRANSFERÊNCIAS NAS CONDIÇÕES DE PROBLEMA ALVO TRISTE E ALEGRE

\begin{tabular}{l|c|c|c}
\hline \multirow{2}{*}{ TRANSFERENCIA } & \multicolumn{3}{|c}{ PROBLEMA ALVO } \\
\cline { 2 - 4 } & TRISTE & ALEGRE & TOTAL \\
\hline $\begin{array}{l}\text { TRANSFERÊNCIA } \\
\text { INTEGRAL }\end{array}$ & 108 & 102 & 210 \\
$\begin{array}{l}\text { TRANSFERÊNCIA } \\
\text { PARCIAL }\end{array}$ & 8 & 15 & 23 \\
$\begin{array}{l}\text { SEM } \\
\text { TRANSFERENCIA }\end{array}$ & 18 & 12 & 30 \\
TOTAL & 134 & 129 & 263 \\
\hline
\end{tabular}


7.1.1.2-Efeitos das tonalidades afetivas dos problemas "alvo" na escolha dos modos de solução serial e convergente

A preferência pelos modos de solução serial e convergente (210; 79,85\%) foi maior do que a preferência por outros modos de solução (53; 20,15\%). O número escolhido de soluções seriais foi um pouco maior $(114 ; 43,34 \%)$ do que o número de soluções convergentes (96; 36,5\%).

Verificou-se uma freqüência maior de sujeitos que escolheram o modo de solução serial na condição de problema "alvo” triste 4 do que na condição de problema “alvo” alegre. E vice-versa para a solução convergente (tabela 3).

A diferença entre os dois grupos foi significante. $X^{2}(2)=6,84, p<0,05$.

\begin{tabular}{|c|c|c|c|}
\hline \multirow{2}{*}{$\begin{array}{l}\text { MODO DE } \\
\text { SOLUÇÃO }\end{array}$} & \multicolumn{3}{|c|}{ PROBLEMA ALVO } \\
\hline & TRISTE & ALEGRE & TOTAL \\
\hline SERIAL & 68 & 46 & 114 \\
\hline CONVERGENTE & 40 & 56 & 96 \\
\hline OUTRO & 26 & 27 & 53 \\
\hline TOTAL & 134 & 129 & 263 \\
\hline
\end{tabular}

7.1.1.3- Efeitos de similaridades de tonalidades afetivas dos problemas "alvo" e "fonte" no modo de solução do problema "alvo".

$\mathrm{Na}$ computação dos modos de solução dos problemas “alvo”, vinculados aos problemas “fonte", foram discriminadas três categorias:

. Modos de solução vinculados aos problemas "fonte” de tonalidade afetiva triste.

4 Com o intuito de simplificar, utilizaremos, ao longo do texto, termos como "triste” e "alegre" ou "de tonalidade triste” ou “de tonalidade alegre”, no lugar de termos como "de tonalidade triste/ desagradável” e “de tonalidade alegre/agradável”. 
. Modos de solução vinculados aos problemas “fonte” de tonalidade afetiva alegre.

. Modos de solução não vinculados aos problemas “fonte” (ou “outra opção”).

Considerou-se como modos de solução vinculados aos problemas “fonte" de tonalidades afetivas triste e alegre apenas as soluções passíveis de serem caracterizadas inequivocamente como soluções de natureza serial ou convergente. Todos os outros modos de solução utilizados na resolução do problema “alvo”, incluindo não apenas os casos em que não houve transferência, mas também os casos em que houve transferência parcial, foram computados como modos de solução não vinculados aos problemas "fonte".

No que se refere aos modos de solução do problema “alvo", a tabela 4 apresenta os resultados relativos às preferências dos sujeitos de acordo com as tonalidades afetivas dos problemas "fonte" nas condições de problema "alvo" de tonalidade triste e de problema "alvo" de tonalidade alegre.

\begin{tabular}{l|c|c|c} 
TABELA 4 - PREFERÊNCIA POR & MODOS DE SOLUÇÃO DO PROBLEMA \\
ALVO EM FUNÇÃO DAS TONALIDADES AFETIVAS DOS PROBLEMAS \\
ALVO E FONTE
\end{tabular}

Como se pode observar, o número de sujeitos que escolheu os modos de solução dos problemas "alvo" em função das tonalidades afetivas dos problemas "alvo" e "fonte" (210) foi maior do que o número de sujeitos que escolheu outros modos de solução, ou seja, que escolheu a categoria "outra opção” (53).

Os resultados relativos aos modos de solução não vinculados aos problemas "fonte" foram similares para as condições de problema "alvo” de tonalidade afetiva triste”(26) e de problema "alvo" de tonalidade afetiva alegre (27). 
Por outro lado, para os modos de solução vinculados aos problemas "fonte" foi verificado que os sujeitos que resolveram o problema "alvo" de tonalidade afetiva triste apresentaram um número maior de soluções vinculadas aos problemas "fonte" de tonalidade triste do que de soluções vinculadas aos problemas "fonte" de tonalidade alegre. E vice-versa para os sujeitos que resolveram o problema “alvo” de tonalidade afetiva alegre. Esses resultados podem ser vistos como freqüências relativas na figura 1.

A diferença entre os dois grupos foi significante. $X^{2}(2)=35,98, p<0,001$.

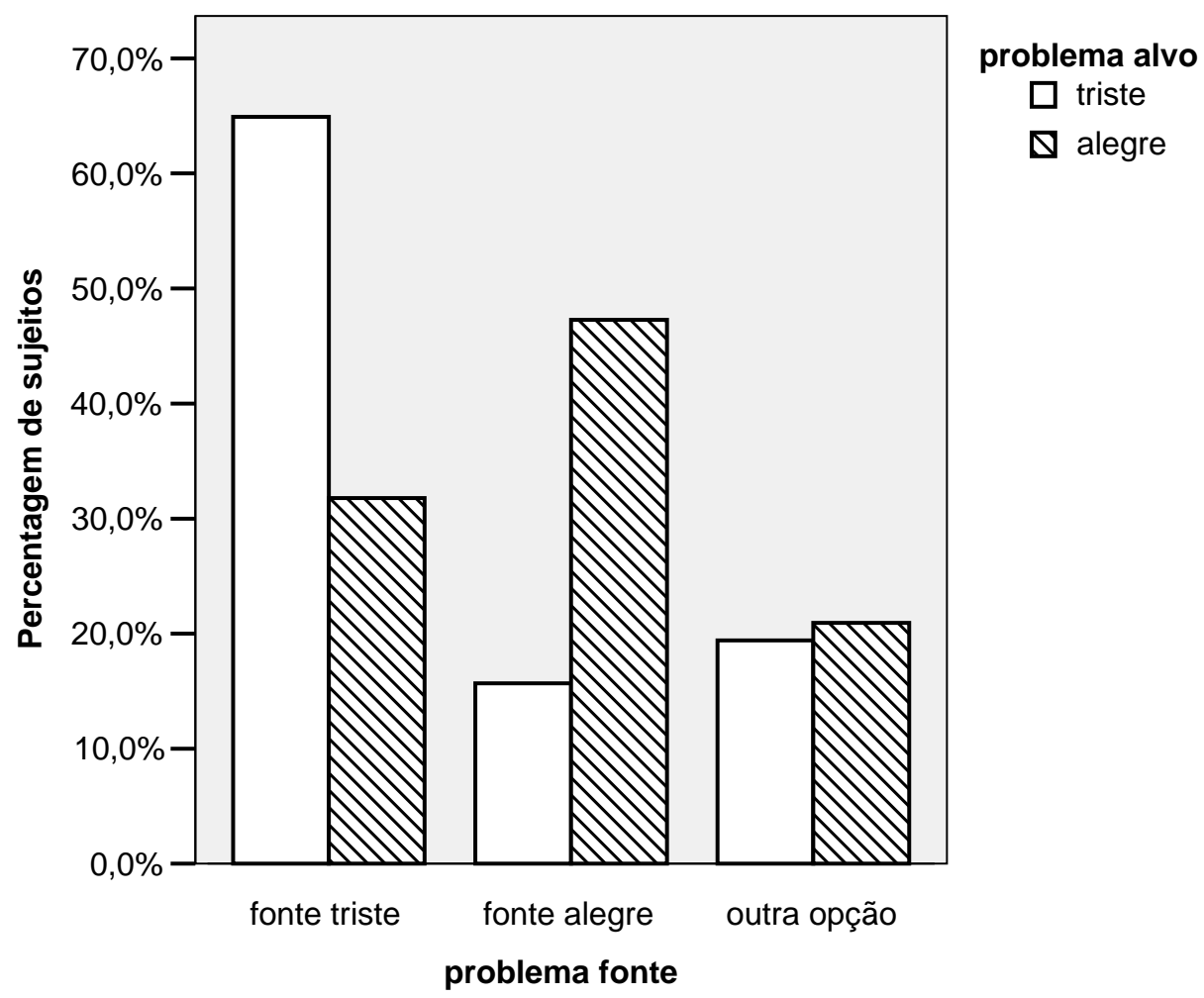

FIGURA 1 - PREFERÊNCIA POR MODOS DE SOLUÇÃO DO PROBLEMA ALVO EM FUNÇÃO DAS TONALIDADES AFETIVAS DOS PROBLEMAS ALVO E FONTE

7.1.1.4- Variação do estado de humor exibida pelos sujeitos.

Para avaliar os efeitos do humor, os sujeitos foram divididos em três sub-grupos, de acordo com as variações de humor por eles apresentadas, como o fizeram Hesse e colaboradores (1997), em seus experimentos, onde utilizaram uma escala correlata de auto-avaliação do humor. Os sujeitos que apresentaram um aumento de mais de 10 pontos na escala utilizada foram classificados como tendo exibido variação positiva de 
humor. Os sujeitos que apresentaram uma diminuição de mais de 10 pontos na escala foram classificados como tendo exibido variação negativa de humor. Já os sujeitos com um aumento ou uma diminuição de 10 pontos ou menos na escala foram considerados como não tendo apresentado variação de humor, assim como os sujeitos que não exibiram nenhuma diferença de pontos na escala. Os resultados são mostrados na tabela 5.

\begin{tabular}{|c|c|c|c|}
\hline \multirow{2}{*}{$\begin{array}{l}\text { VARIAÇÃO } \\
\text { DE HUMOR }\end{array}$} & \multicolumn{3}{|c|}{ PROBLEMA ALVO } \\
\hline & TRISTE & ALEGRE & TOTAL \\
\hline POSITIVA & 1 & 10 & 11 \\
\hline NEGATIVA & 29 & 5 & 34 \\
\hline SEM ALTERAÇÃO & 104 & 113 & 217 \\
\hline TOTAL & 134 & 128 & 262 \\
\hline
\end{tabular}

Como pode ser visto na tabela 5, houve um número maior de sujeitos que não exibiu variação de humor (217) do que de sujeitos que exibiu variação (45).

Quando houve variação de humor, observou-se que um número maior de sujeitos na condição de problema "alvo” triste apresentou variação negativa e um número maior de sujeitos na condição de problema “alvo” alegre apresentou variação positiva do humor. Esses resultados podem ser vistos como freqüências relativas na figura 2.

A diferença entre os dois grupos de sujeitos foi significante. $X^{2}(2)=24,55, p<0,001$ 


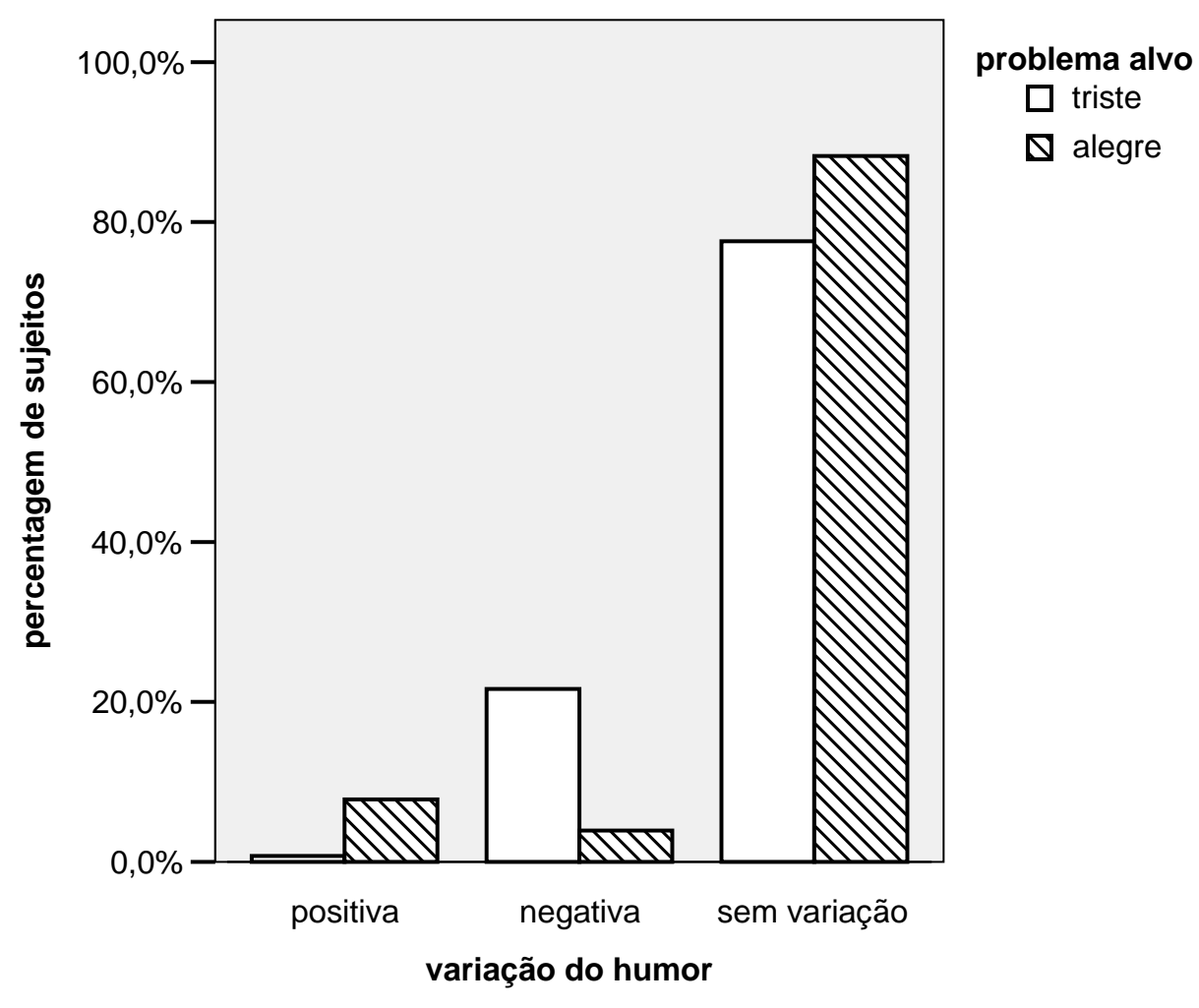

FIGURA 2 - VARIAÇÃO DE HUMOR EXIBIDA PELOS SUJEITOS NAS CONDIÇÕES DE PROBLEMA ALVO TRISTE E ALEGRE

7.1.1.5- Associações entre as variáveis tonalidade afetiva dos problemas "alvo", tonalidade afetiva dos problemas "fonte" e variação do humor, no que se refere à escolha dos modos de solução do problema "alvo".

Foi efetuada uma análise de correspondência múltipla, tendo em vista os efeitos positivos de similaridades das tonalidades afetivas dos problemas "alvo" e "fonte" na escolha do modo de solução do problema "alvo" e também a variação diferenciada do humor nas condições de problema "alvo” triste e de problema "alvo” alegre. (figura 3) 


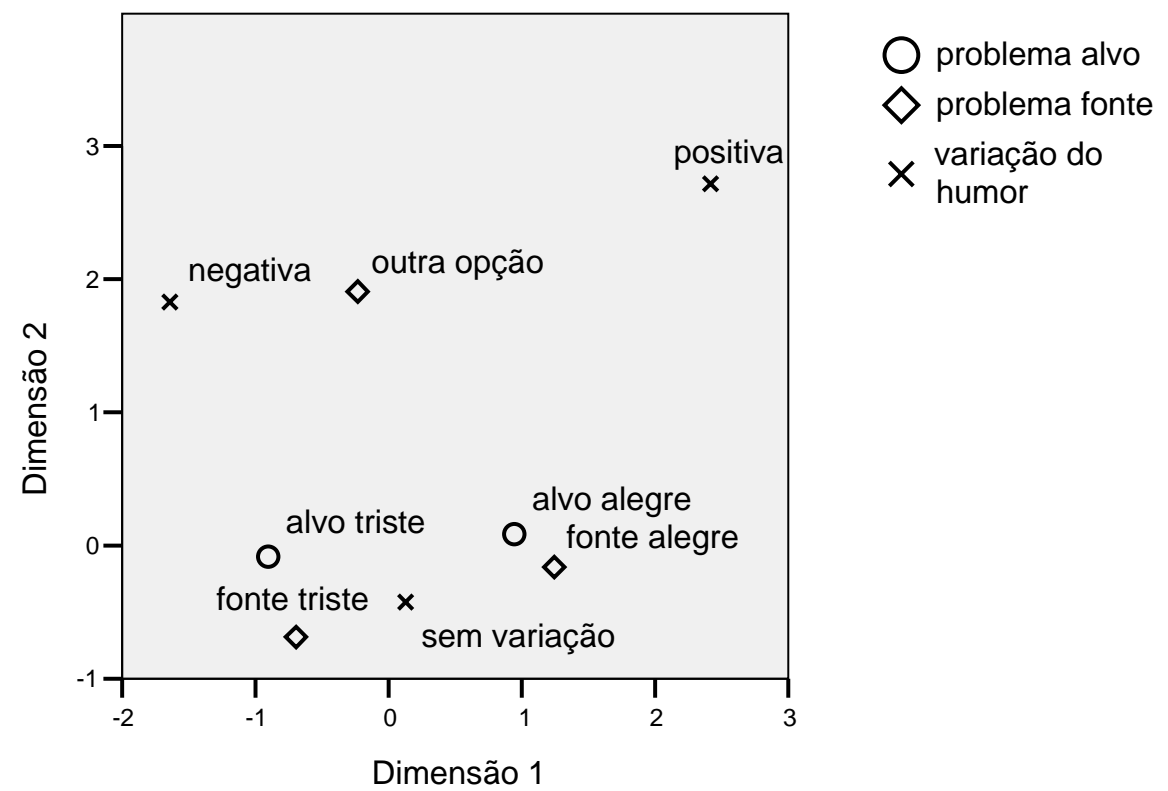

FIGURA 3 - ASSOCIAÇÕES ENTRE AS VARIÁVEIS PROBLEMA ALVO, PROBLEMA FONTE VINCULADO AO MODO DE SOLUÇÃO E VARIAÇÃO DE HUMOR: MAPA GERADO POR ANÁLISE DE CORRESPONDÊNCIA MÚLTIPLA.

Pode-se ver no mapa gerado pela análise de correspondência múltipla a existência de proximidade espacial entre as categorias problema “alvo" de tonalidade triste e problema "fonte" de tonalidade triste que parecem formar um agrupamento, por um lado, e entre as categorias problema "alvo" de tonalidade alegre e problema "fonte" de tonalidade alegre que parecem formar outro agrupamento, por outro lado.

O mapa gerado pela análise de correspondência múltipla aponta, então, para a existência de uma associação positiva entre essas categorias.

No que diz respeito à variação do humor, pode-se observar que a categoria variação negativa acha-se mais próxima dos problemas "alvo" e "fonte" tristes do que dos problemas “alvo” e “fonte” alegres. E vice-versa para a categoria da variação positiva. Entretanto, essas duas categorias mostram-se, no mapa, muito distanciadas das categorias de problemas "alvo" e "fonte" tristes, bem como das categorias de problemas “alvo” e “fonte” alegres, e mais próximas, por sua vez, da categoria “outra opção”. Já a 
categoria "sem variação do estado de humor” encontra-se relativamente próxima e eqüidistante das categorias "problema alvo e problema fonte de tonalidade triste”, por um lado, e "problema alvo e problema fonte de tonalidade alegre”, por outro lado.

A análise de correspondência múltipla sugere, então, não haver uma associação relevante entre as variações do estado de humor, por um lado, e as tonalidades afetivas dos problemas "alvo" e "fonte”, por outro.

\subsection{2- Resultados para o intervalo de tempo de uma semana entre as sessões.}

Os critérios utilizados na discriminação das categorias das variáveis estudadas foram iguais aos usados para as sessões consecutivas.

\subsubsection{1- Transferência analógica.}

O número de transferências integrais, feitas pelos sujeitos no intervalo de tempo de uma semana entre as sessões, foi maior do que o número de transferências parciais e do que o número de soluções sem vinculação com os problemas “fonte” (tabela 6).

A diferença entre as freqüências foi significante, $X^{2}(2)=116,43, \quad p<0,001$.

\begin{tabular}{|c|c|c|}
\hline $\begin{array}{l}\text { TRANSFERÊNCIA DOS } \\
\text { MODOS DE SOLUÇÃO }\end{array}$ & FREQUÊNCIA & PERCENTAGEM \\
\hline $\begin{array}{l}\text { TRANSFERÊNCIA } \\
\text { INTEGRAL }\end{array}$ & 128 & 71,1 \\
\hline $\begin{array}{l}\text { TRANSFERÊNCIA } \\
\text { PARCIAL }\end{array}$ & 21 & 11,7 \\
\hline SEM TRANSFERÊNCIA & 31 & 17,2 \\
\hline TOTAL & 180 & 100,0 \\
\hline
\end{tabular}

A distribuição das freqüências das três categorias de transferência analógica, antes discriminadas, na condição de problema "alvo" de tonalidade triste e na condição de problema "alvo" de tonalidade alegre, com o intervalo de uma semana, é mostrada na tabela 7. 
A diferença observada entre os dois grupos não foi significante. $X^{2}(2)=0,869$, $p>$ 0,05 .

TABELA 7- FREQUÊNCIA DE TRANSFERÊNCIAS NAS CONDIÇÕES DE PROBLEMA ALVO TRISTE E ALEGRE

\begin{tabular}{l|c|c|c}
\hline \multirow{2}{*}{ TRANSFERÊNCIA } & \multicolumn{3}{|c}{ PROBLEMA ALVO } \\
\cline { 2 - 4 } & TRISTE & ALEGRE & TOTAL \\
\hline $\begin{array}{l}\text { TRANSFERÊNCIA } \\
\text { INTEGRAL }\end{array}$ & 65 & 63 & 128 \\
$\begin{array}{l}\text { TRANSFERÊNCIA } \\
\text { PARCIAL }\end{array}$ & 10 & 11 & 21 \\
$\begin{array}{l}\text { SEM } \\
\text { TRANSFERÊNCIA }\end{array}$ & 17 & 14 & 31 \\
TOTAL & 92 & 88 & 180 \\
\hline
\end{tabular}

7.1.2.2- Efeitos das tonalidades afetivas dos problemas "alvo" na escolha dos modos de solução serial e convergente.

Para o decurso de tempo de uma semana entre as sessões, a tabela 8 mostra os resultados obtidos.

TABELA 8 - FREQUÊNCIA DE SUJEITOS QUE RESOLVERAM O PROBLEMA ALVO UTILIZANDO MODOS DE SOLUÇÃO SERIAL, CONVERGENTE OU OUTRO MODO, NAS CONDIÇÕES DE PROBLEMA ALVO TRISTE E ALEGRE

\begin{tabular}{l|c|c|c}
\hline \multirow{2}{*}{$\begin{array}{l}\text { MODO DE } \\
\text { SOLUÇÃO }\end{array}$} & \multicolumn{3}{|c}{ PROBLEMA ALVO } \\
\cline { 2 - 4 } & TRISTE & ALEGRE & TOTAL \\
\hline SERIAL & 39 & 31 & 70 \\
CONVERGENTE & 26 & 32 & 58 \\
OUTRO & 27 & 25 & 52 \\
TOTAL & 92 & 88 & 180 \\
\hline
\end{tabular}


Pode-se ver que a preferência pelos modos de solução serial e convergente (128; $71,1 \%$ ) foi maior do que a preferência por outros modos de solução (52; 28,8\%). A solução serial teve um número de escolhas um pouco maior (70) do que a solução convergente (58). Pode-se também observar que a freqüência de sujeitos que escolheu o modo de solução serial foi maior na condição de tonalidade afetiva triste do problema “alvo” do que na condição de tonalidade alegre. E vice-versa para o modo de solução convergente.

Apesar de haver diferença entre os dois grupos, essa diferença não foi significante. $\mathrm{X}^{2}(2)=1,52 \mathrm{p}>0,05$.

7.1.2.3- Efeitos de similaridades de tonalidades afetivas dos problemas "alvo" e "fonte" no modo de solução do problema "alvo".

Os resultados obtidos para o intervalo de tempo de uma semana entre as sessões encontram-se discriminados na tabela 9.

\begin{tabular}{|c|c|c|c|}
\hline \multirow{2}{*}{ PROBLEMA FONTE } & \multicolumn{3}{|c|}{ PROBLEMA ALVO } \\
\hline & TRISTE & ALEGRE & TOTAL \\
\hline TRISTE & 42 & 27 & 69 \\
\hline ALEGRE & 23 & 36 & 59 \\
\hline OUTRA OPÇÃO & 27 & 25 & 52 \\
\hline TOTAL & 92 & 88 & 180 \\
\hline
\end{tabular}

Pode-se ver nessa tabela que a freqüência de escolhas dos modos de solução em função das tonalidades afetivas dos problemas “fonte” e "alvo" foi, para esse intervalo de tempo, também maior (128) do que a freqüência de escolhas de outros modos de 
solução, ou seja, da categoria “outra opção”(52). Aqui, também, os resultados relativos aos outros modos de solução foram similares para as condições de problema "alvo" triste (69) e de problema “alvo” alegre (59).

Já para os modos de solução vinculados aos problemas “fonte”, verificou-se, como nas sessões consecutivas, que os sujeitos que resolveram o problema "alvo" de tonalidade triste apresentaram um número maior de soluções vinculadas aos problemas "fonte" de tonalidade triste do que de soluções vinculadas aos problemas fonte de tonalidade alegre. E vice-versa para a condição de problema “alvo” alegre. Esses resultados podem ser vistos como freqüências relativas na figura 4.

A diferença entre os grupos foi significante. $X^{2}(2)=6,11, p<0,05$.

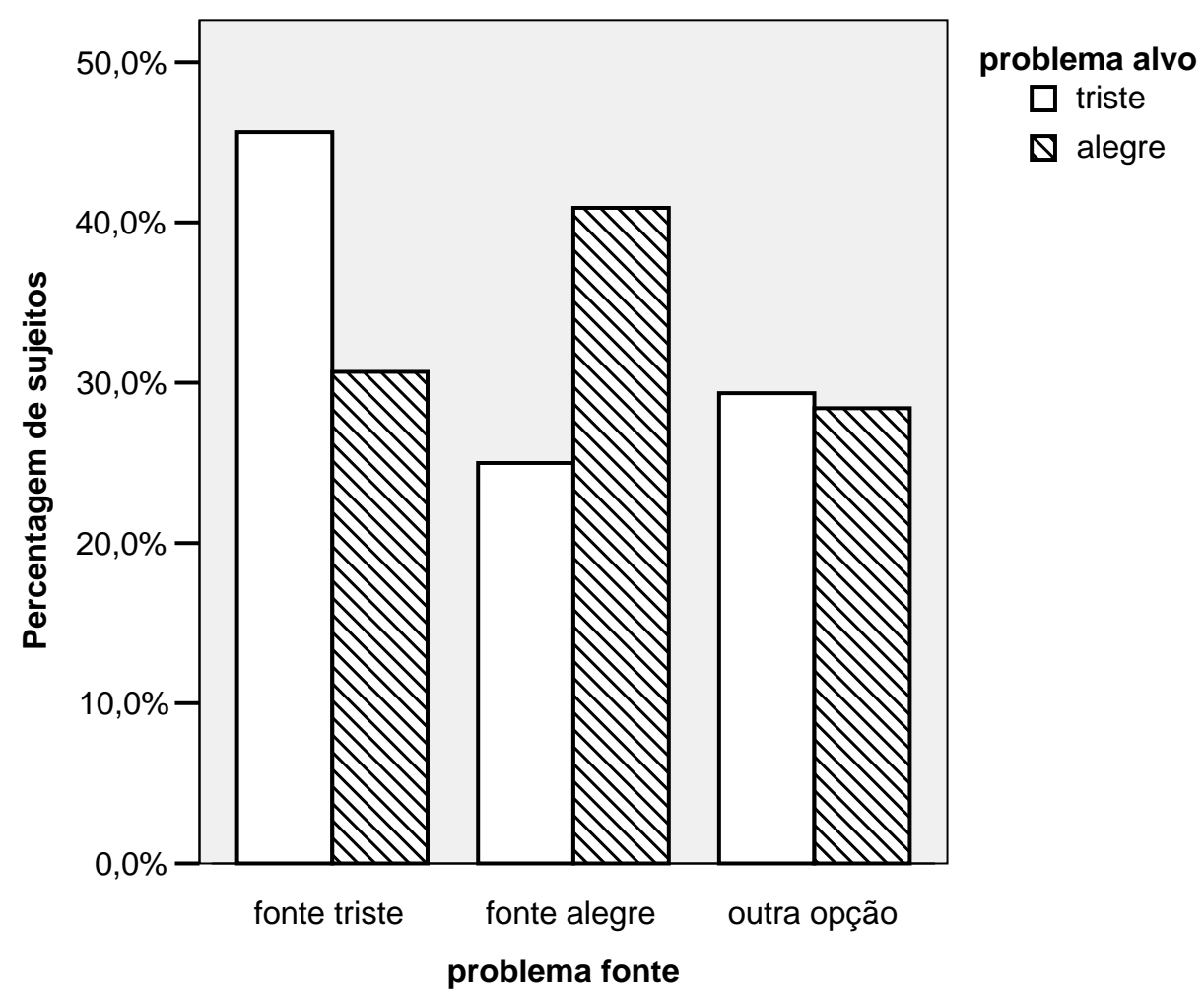

FIGURA 4 - PREFERÊNCIA POR MODOS DE SOLUÇÃO DO PROBLEMA ALVO EM FUNÇÃO DAS TONALIDADES AFETIVAS DOS PROBLEMAS FONTE E ALVO 
7.1.2.4- Variação do estado de humor exibida pelos sujeitos.

No que se refere ao decurso de tempo de uma semana entre as sessões, a tabela 10 mostra os resultados obtidos.

\begin{tabular}{|c|c|c|c|}
\hline \multirow{2}{*}{$\begin{array}{l}\text { VARIAÇÃO } \\
\text { DE HUMOR }\end{array}$} & \multicolumn{3}{|c|}{ PROBLEMA ALVO } \\
\hline & TRISTE & ALEGRE & TOTAL \\
\hline POSITIVA & 1 & 13 & 14 \\
\hline NEGATIVA & 23 & 2 & 25 \\
\hline SEM ALTERAÇÃO & 65 & 68 & 133 \\
\hline TOTAL & 89 & 83 & 172 \\
\hline
\end{tabular}

O número de sujeitos que não apresentou variação de humor (133; 77,33\%) foi maior do que o número de sujeitos que apresentou variação (39; 26,67\%).

Nos casos em que ocorreu variação de humor, houve um número maior de sujeitos na condição de problema “alvo” triste, que exibiu uma variação negativa, e um número maior de sujeitos na condição de problema “alvo” alegre, que exibiu variação positiva. Esses resultados acham-se apresentados como freqüências relativas na figura 5.

A diferença entre os grupos foi significante. $X^{2}(2)=27,81 p<0,001$. 


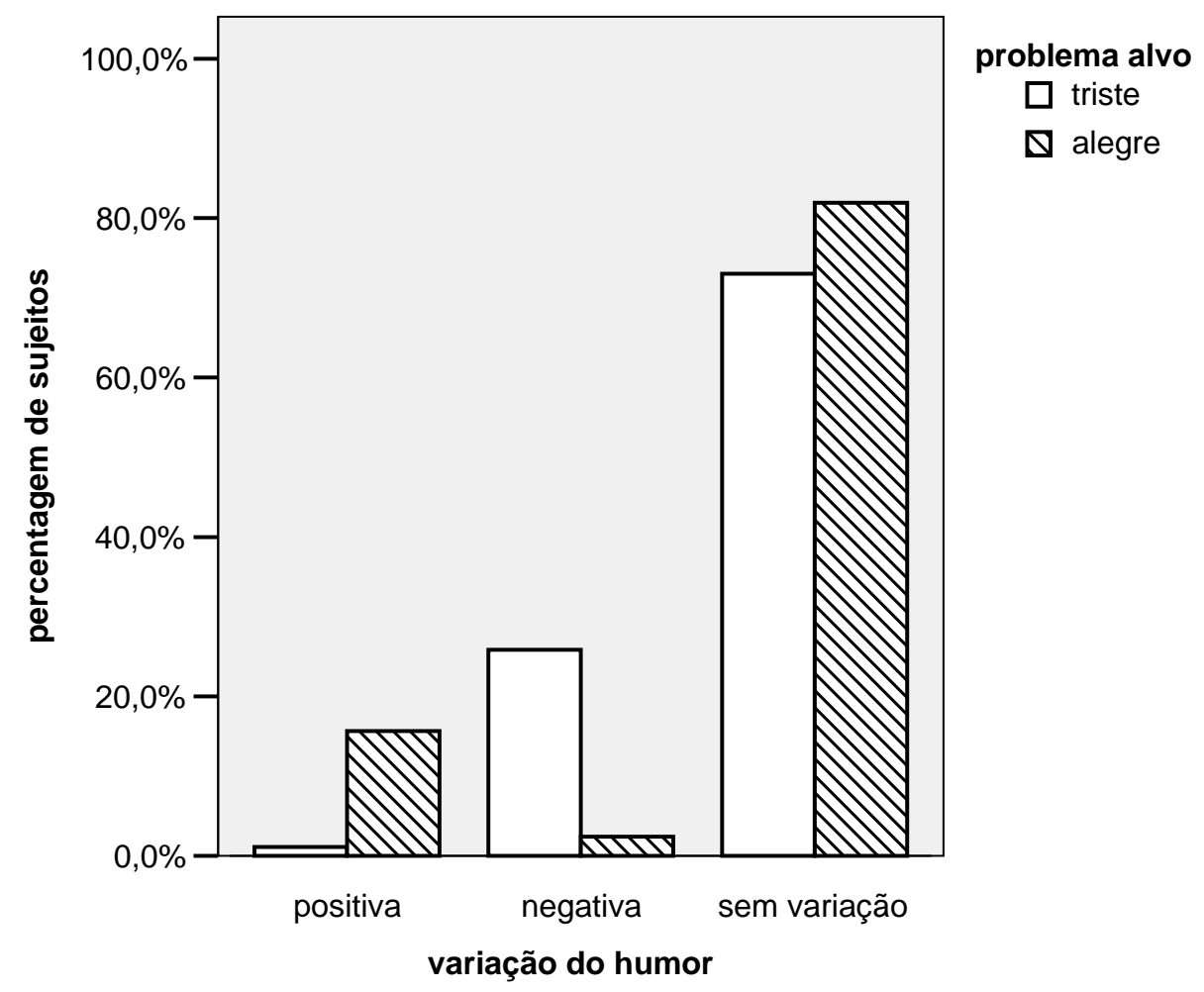

FIGURA 5 - VARIAÇÃO DO HUMOR EXIBIDA PELOS SUJEITOS NAS CONDIÇÕES DE PROBLEMA ALVO TRISTE E ALEGRE

7.1.2.5- Associações entre as variáveis tonalidade afetiva dos problemas "alvo", tonalidade afetiva dos problemas "fonte" e variação de humor, no que se refere à escolha dos modos de solução dos problemas "alvo".

Foi efetuada também uma análise de correspondência múltipla relativa aos dados obtidos com uma semana de intervalo entre as sessões (figura 6). 


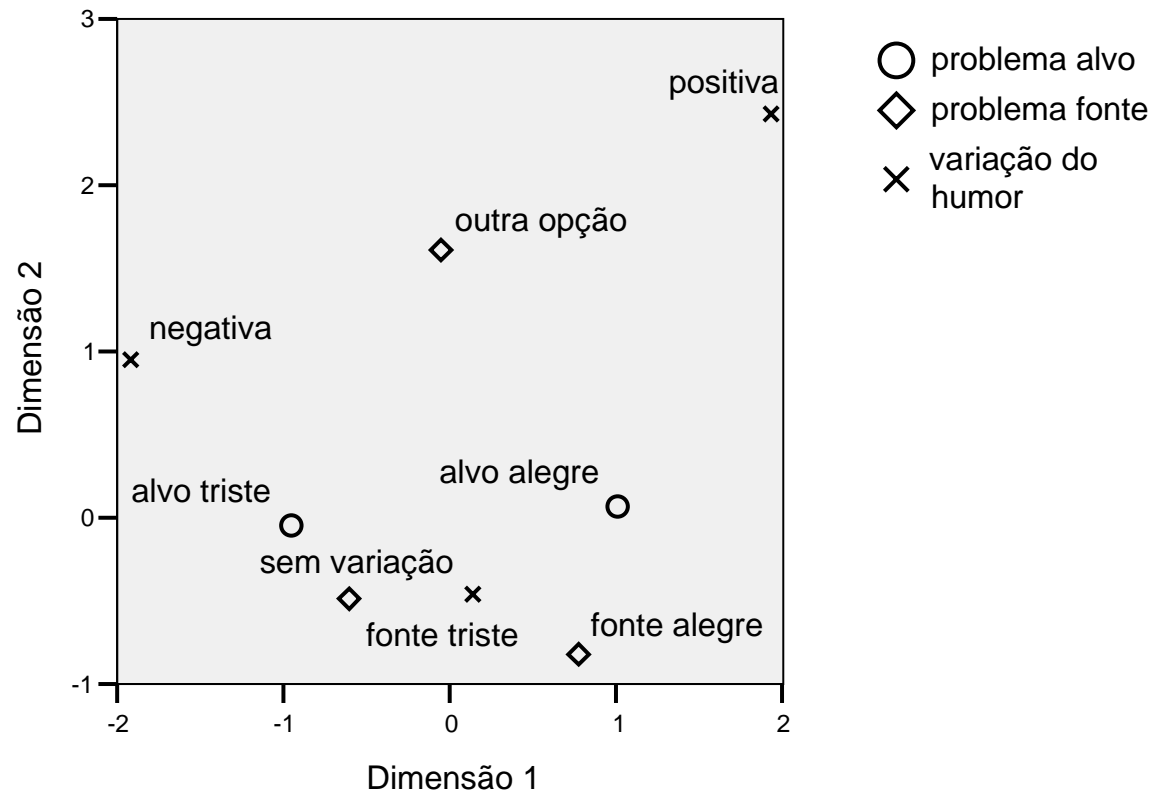

FIGURA 6 - ASSOCIAÇÕES ENTRE AS VARIÁVEIS PROBLEMA ALVO, PROBLEMA FONTE VINCULADO AO MODO DE SOLUÇÃO E VARIAÇÃO DE HUMOR: MAPA GERADO POR ANÁLISE DE CORRESPONDÊNCIA MÚLTIPLA

O mapa gerado mostra proximidade espacial entre as categorias problema alvo"e problema "fonte" de tonalidade triste. Pode-se visualizar também proximidade espacial entre as categorias problema "alvo" e problema "fonte" de tonalidade alegre, com distância entre elas um pouco maior do que a observada para as categorias de tonalidade triste.

Esse mapa sugere, assim, haver uma associação positiva entre as categorias de problema "alvo" e problema "fonte" de tonalidades similares, parecendo ser essa associação um pouco mais estreita para as categorias de tonalidade triste do que para as categorias de tonalidade alegre.

No que diz respeito à variação do humor, observa-se que a variação negativa acha-se menos afastada das categorias de problemas "alvo" e "fonte" de tonalidade triste do que a variação positiva em relação às categorias de tonalidade alegre. De qualquer modo, as categorias de problemas “alvo" e "fonte” de tonalidades similares encontram-se bem mais próximas entre si do que as variações de humor positiva e negativa em relação às categorias de problema "alvo" e "fonte" de tonalidades similares. 
Esse quadro sugere, então, ser improvável a existência de associação relevante entre as tonalidades tristes dos problemas “alvo" e “fonte”, por um lado, e a variação negativa de humor, por outro lado. E sugere ser mais improvável, ainda, a existência de associação relevante entre as tonalidades alegres dos problemas "alvo" e "fonte" e a variação de humor positiva.

7.1.3- Decurso de tempo: Comparação de resultados relativos às sessões consecutivas e às sessões com intervalo de uma semana

São comparados aqui os resultados relativos à transferência analógica e à transferência com similaridade entre as tonalidades afetivas dos problemas "fonte” e “alvo" obtidos para os dois intervalos de tempo estudados.

Os resultados relativos à transferência analógica verificados nos dois intervalos de tempo são apresentados na tabela 11.

TABELA 11- FREQUÊNCIA DE TRANSFERÊNCIAS NAS SESSÕES CONSECUTIVAS E NAS SESSÕES COM INTERVALO DE UMA SEMANA

\begin{tabular}{|c|c|c|c|c|c|c|}
\hline \multirow{3}{*}{ TRANSFERÊNCIA } & \multicolumn{6}{|c|}{ INTERVALO DE TEMPO ENTRE AS SESSÕES } \\
\hline & \multicolumn{2}{|c|}{ SESSÕES CONSECUTIVAS } & \multicolumn{2}{|c|}{ INTERVALO DE 1 SEMANA } & \multicolumn{2}{|c|}{ TOTAL } \\
\hline & Freqüência & Percentagem & Freqüência & Percentagem & Freqüência & Percentagem \\
\hline $\begin{array}{l}\text { TRANSFERÊNCIA } \\
\text { INTEGRAL }\end{array}$ & 210 & 79,8 & 128 & 71,1 & 338 & 76,3 \\
\hline $\begin{array}{l}\text { TRANSFERÊNCIA } \\
\text { PARCIAL }\end{array}$ & 23 & 8,7 & 21 & 11,7 & 44 & 9,9 \\
\hline $\begin{array}{c}\text { SEM } \\
\text { TRANSFERÊNCIA }\end{array}$ & 30 & 11,4 & 31 & 17,2 & 61 & 13,8 \\
\hline TOTAL & 263 & 100,0 & 180 & 100,0 & 443 & 100,0 \\
\hline
\end{tabular}

A transferência integral foi bem maior do que os casos de transferência parcial e de não transferência nos dois intervalos de tempo. Nas sessões consecutivas a taxa de transferência integral $(79,8 \%)$ foi maior do que nas sessões com intervalo de uma semana $(71,1 \%)$. 
As diferenças encontradas nas freqüências de transferência entre os dois intervalos não foi significante. $X^{2}(2)=4,62, p>0,05$.

Os resultados referentes à transferência com e sem similaridade entre as tonalidades dos problemas “fonte" e "alvo" nos dois intervalos de tempo são mostrados na tabela 12.

TABELA 12 - FREQUÊNCIA DE SUJEITOS QUE REALIZARAM TRANSFERÊNCIA DE ACORDO COM AS SIMILARIDADES ENTRE AS TONALIDADES AFETIVAS DOS PROBLEMAS FONTE E ALVO NAS SESSÕES CONSECUTIVAS E NAS SESSÕES COM INTERVALO DE UMA SEMANA

\begin{tabular}{l|c|c|c|c|c|c|}
\hline \multirow{2}{*}{$\begin{array}{l}\text { MODOS DE } \\
\text { TRANSFERÊNCIA }\end{array}$} & \multicolumn{2}{|c|}{ SESSÕES CONSECUTIVAS } & \multicolumn{2}{c|}{$\begin{array}{c}\text { INTERVALO DE 1 } \\
\text { SEMANA }\end{array}$} & \multicolumn{2}{c}{ TOTAL } \\
\cline { 2 - 7 } & Freqüência & Percentagem & Freqüência & Percentagem & Freqüência & Percentagem \\
\hline $\begin{array}{l}\text { TRANSFERÊNCIA } \\
\text { COM SIMILARIDADE }\end{array}$ & 148 & 56,3 & 78 & 43,3 & 226 & 51,0 \\
$\begin{array}{l}\text { TRANSFERÊNCIA } \\
\text { SEM SIMILARIDADE }\end{array}$ & 62 & 23,6 & 50 & 27,8 & 112 & 25,3 \\
$\begin{array}{l}\text { SEM } \\
\text { TRANSFERÊNCIA }\end{array}$ & 53 & 20,1 & 52 & 28,9 & 105 & 23,7 \\
TOTAL & 263 & 100,0 & 180 & 100,0 & 443 & 100,0 \\
\hline
\end{tabular}

Para os dois intervalos de tempo estudados foram verificadas freqüências de transferência com similaridade entre as tonalidades afetivas dos problemas "fonte" e "alvo" maiores do que as observadas para os casos de transferência sem similaridade e sem transferência. Nas sessões consecutivas (56,3\%), observou-se uma percentagem maior de transferência com similaridade do que nas sessões com intervalo de uma semana $(43,3 \%)$.

A diferença verificada entre as freqüências foi significante. $X^{2}(2)=7,7, p<0,05$. 


\section{2-Discussão}

\subsection{1-Transferência analógica}

A transferência analógica verificada em nosso estudo foi, como vimos, significativa para as sessões consecutivas $(79,8 \%)$ e para o intervalo de uma semana entre as sessões (71,1\%). Houve, como esperado, declínio na taxa de transferência com o decorrer de uma semana, embora não significativo.

Vários fatores podem ter contribuído para esses resultados. No que se refere aos dois problemas "fonte”, alguns fatores facilitadores da transferência podem ser destacados. Em primeiro lugar, as similaridades semânticas entre seus enunciados podem ter facilitado a retenção dos dois problemas “fonte”, embora os conteúdos de suas histórias como um todo fossem diferentes. Em segundo lugar, a equivalência de suas "coações" do ponto de vista funcional pode ter facilitado certo mapeamento, ainda que de modo não consciente, das principais características dos dois problemas. De modo complementar, a apresentação de duas soluções, envolvendo diferentes esquemas de aprendizagem (serial e convergente), ambas consideradas adequadas para a resolução dos problemas “alvo”, pode ter contribuído para a facilitação da transferência. Como vimos, as soluções serial e convergente podem ser consideradas como incluídas em um modelo mental do tipo "aditivo” que, por sua vez, supõe a soma de inputs individuais e, no caso específico dos problemas “fonte”, supõe a soma de raios de baixa intensidade. E, como observaram Helfenstein e Saariluoma (2006), esse tipo de modelo mental parece ser o mais frequentemente evocado pelos indivíduos.

O requisito de responder a um questionário, após a leitura de cada problema "fonte", pode ter sido um outro fator facilitador da transferência, pois favoreceu o aprendizado dos problemas e de suas soluções. Além disso, o fornecimento de “dicas” de recuperação na situação-problema "alvo" pode ter também facilitado a recuperação de uma das soluções vistas, em detrimento de outros modos de solução espontâneos que poderiam ter sido evocados pelos sujeitos. A semelhança de contexto entre as duas sessões experimentais pode ter também tido um efeito facilitador da transferência, somando-se aos outros fatores já mencionados.

Os resultados obtidos em nosso estudo podem ser considerados convergentes com investigações realizadas na área que relataram taxas de transferência relevantes, quando um ou mais fatores facilitadores da transferência estiveram presentes (p. e. os estudos de 
Gick \& Holyoak, 1980; 1983; Holyoak \& Koh, Spencer \& Weisberg, 1986; Holyoak e Koh, 1987; Catrambone \& Holyoak, 1989; Kurtz \& Loewestein, 2007, dentre inúmeros estudos).

Nossos resultados estão também de acordo com alguns achados relativos aos efeitos do decurso de tempo sobre a transferência que, por sua vez, apontaram para certo declínio na transferência com um maior intervalo de tempo, bem como para a manutenção da transferência por mais tempo, quando alguns fatores facilitadores da transferência mostraram-se presentes, como, por exemplo, dicas de recuperação (p. e. Gick \& Holyoak, 1980; Holyoak \& Koh, 1987; Catrambone \& Holyoak, 1989) e/ou o treinamento ou apresentação de mais de um exemplo na situação-problema “fonte” (p. e. Ross, 1987; 1989; Fong \& Nisbett, 1991; Kurtz \& Loewenstein, 2007) ou mesmo a semelhança de contexto entre as sessões experimentais (p. e. Spencer \& Weisberg, 1986; Catrambone \& Holyoak, 1989).

Como vimos, estudos como os de Gick e Holyoak (1980; 1983), com o problema da radiação de Duncker e seus análogos, demonstraram que os sujeitos experimentais, quando submetidos a apresentação de “dicas” de recuperação, tendiam a apresentar melhores taxas de transferência em comparação às condições experimentais que requisitavam uma transferência espontânea, sem “dicas”. Nossos achados parecem ir ao encontro de alguns resultados apresentados por esses autores, pois acreditamos que o fornecimento de “dicas” de recuperação na situação-problema “alvo” pode ter parcialmente contribuído para a boa taxa de transferência encontrada, em ambos os intervalos de tempo por nós pesquisados.

De modo complementar, Gick e Holyoak (1983) destacaram que uma transferência analógica bem-sucedida depende da construção de uma representação adequada dos problemas “fonte” e “alvo”, ou seja, da construção de um nível de abstração desses problemas em um “esquema de aprendizagem” apropriado. Várias condições experimentais poderiam facilitar tal construção, como, por exemplo, a comparação de vários análogos "fonte" (Ross, 1987; Ross, 1989; Ross \& Warren, 2002), a apresentação de diagramas ou outras formas de representação dos problemas “fonte” (Gick, 1985; Helfenstein \& Saariluoma, 2006), o treinamento inicial em um domínio mais abstrato (Bassok \& Holyoak, 1989; Bassok, 1990), a apresentação de um questionário para destacar a relevância da solução e da história como um todo (Gick \& Holyoak, 1983) dentre outras condições experimentais manipuladas. No que se refere aos nossos resultados, a boa compreensão das histórias e de seus problemas, bem como 
sua semelhança com histórias cotidianas e o uso de questionários para garantir o aprendizado das soluções dos problemas "fonte” podem ter favorecido o aprendizado das soluções serial e convergente e, consequentemente, ter também facilitado o processo de transferência. O bom índice de acerto das soluções dos problemas “fonte” nesses questionários (anexo 5) parecem apontar para essa direção.

Como já referido, trabalhos como os de Spencer e Weisberg (1986), Catrambone e Holyoak (1989) demonstraram que a semelhança de contexto nas duas sessões experimentais pode ser um outro fator facilitador da transferência analógica, mesmo quando há um intervalo de tempo entre as sessões. No nosso caso, ambas as sessões experimentais foram realizadas nos mesmos locais e conduzidas pela mesma experimentadora, o que pode ter facilitado também a recuperação, na situação-problema “alvo”, das soluções anteriormente aprendidas.

Em síntese, acreditamos que a soma de fatores facilitadores da transferência, especialmente daqueles acima destacados, pode ter contribuído para a boa taxa de transferência encontrada nos dois intervalos de tempo pesquisados. Porém, em função dos objetivos do nosso estudo, não investigamos o papel de cada um desses fatores separadamente para que pudéssemos concluir qual fator foi mais importante na facilitação da transferência. Sendo assim, podemos apenas concluir que a boa taxa de transferência analógica observada nos dois intervalos de tempo pesquisados pode ter sido devida a um conjunto de fatores considerados facilitadores da transferência.

A maior parte dos sujeitos que apresentou outras soluções (sem transferência) em nossa pesquisa o fizeram tendo em vista suas vivências e/ou aspectos pragmáticos da situação-problema “alvo”. As soluções sem transferência mais freqüentes apresentadas pelos sujeitos nas sessões consecutivas e nas sessões com intervalo de uma semana foram a realização de uma cirurgia e o uso de medicamentos. Essa verificação está de acordo com a observação feita pelo próprio Duncker (1945) e, posteriormente, por autores como, por exemplo, Gick e Holyoak (1980) de que os indivíduos, não expostos a problemas "fonte”, tendem a fornecer soluções espontâneas com essas características, sendo especialmente freqüente a proposta da realização de uma cirurgia para a extirpação do tumor no problema da radiação.

Está também de acordo com essas observações, a inexistência de escolha de soluções vinculadas aos problemas distrativos, tendo em vista a inadequação de suas aplicações aos problemas “alvo”. 
7.2.2-Efeitos das tonalidades afetivas dos problemas "alvo" na preferência pelos modos de solução serial e convergente.

Os resultados relativos às sessões consecutivas mostraram, como vimos, preferência significativa pela solução serial na condição de problema “alvo” triste e pela solução convergente na condição de problema “alvo” alegre. Por outro lado, os resultados relacionados às sessões com intervalos de uma semana não foram significativos, embora tenha havido, também, um número maior de soluções seriais na condição de problema “alvo” triste e de soluções convergentes na condição de problema “alvo” alegre.

A possível influência da tonalidade do problema "alvo" na escolha entre os modos de solução serial e convergente parece, então, restringir-se a curtos intervalos de tempo entre a exposição a esses modos de solução e a possível escolha dentre eles frente ao problema “alvo".

Os resultados relativos às sessões consecutivas, em particular, devem ser contrastados com a verificação feita em um dos nossos estudos pilotos (anexo 3) de que não há diferenças nas preferências entre os dois modos de solução quando se trata de problema “alvo” neutro quanto à tonalidade afetiva.

Pelo menos no que se refere a efeitos imediatos, podemos considerar que os resultados obtidos na presente pesquisa parecem convergir com estudos que focalizaram a possibilidade de haver diferenças no processamento cognitivo associadas aos estados de humor positivo e negativo. Os estudos realizados sobre essa questão, em sua maioria, têm observado que o humor positivo parece favorecer o uso de estratégias heurísticas e um processamento mais global, enquanto o humor negativo parece favorecer um processamento mais sistemático e detalhista da informação (p. e. Schwarz \& Clore, 1983; Isen \& Daubman, 1984; Forgas, 1995; Urada \& Miller, 2000; Friedman e Foster, 2000; Salovey \& cols, 2001; King \& cols, 2006, dentre outros).

A convergência dessas verificações com os resultados por nós obtidos se dá na medida em que, por um lado, a solução convergente parece ser mais próxima de um processamento top-down, heurístico e que pode envolver um processo de insight, como o próprio Duncker (1945) já apontara. Por outro lado, a solução serial parece ser mais próxima de um processamento mais sistemático, bottom-up, detalhista e, nesse sentido, parece ser mais sensível às “coações” pragmáticas das situações-problema "alvo". 
Não encontramos, na literatura, pesquisas que focalizassem especificamente efeitos de tonalidades afetivas de problemas na escolha de um tipo de solução que pudessem ser cotejados com os nossos resultados. Mostra-se, então, oportuno o desenvolvimento de estudos direcionados para a investigação de possíveis associações entre as tonalidades afetivas de histórias e os diferentes processamentos cognitivos

7.2.3-Efeitos de similaridades de tonalidades afetivas dos problemas "alvo" e "fonte" no modo de solução do problema “alvo”.

Em relação à influência das tonalidades afetivas dos problemas "alvo” e "fonte” na escolha do modo de solução dos problemas “alvo”, há que se considerar, em primeiro lugar, as diferenças significativas entre as freqüências de escolhas de modos de solução vinculados aos problemas "fonte" de tonalidades triste e alegre nas duas condições do problema “alvo", observadas nos dois intervalos de tempo.

Como foi verificado em nossos resultados, os sujeitos que resolveram o problema “alvo” de tonalidade triste apresentaram um número maior de soluções vinculadas aos problemas "fonte" de tonalidade triste do que de soluções vinculadas aos problemas "fonte" de tonalidade alegre. Por outro lado, os sujeitos que resolveram o problema “alvo” de tonalidade afetiva alegre apresentaram um número maior de soluções vinculadas aos problemas "fonte” de tonalidade alegre do que de soluções vinculadas aos problemas "fonte" de tonalidade triste. Esses resultados foram observados para ambos os intervalos de tempo.

Em segundo lugar, deve-se considerar o contraste evidenciado entre esses dados e a inexistência de diferenças nas freqüências observadas entre as condições do problema “alvo” triste e alegre quando da escolha de outros modos de solução não vinculados aos problemas "fonte".

Parece-nos relevante que esse contraste se tenha dado, não apenas quando as sessões foram consecutivas, mas também com o intervalo de uma semana entre elas. Desse modo, quando a escolha do modo de solução não foi baseada na exposição que os sujeitos tiveram aos problemas "fonte", os resultados não revelaram efeitos das tonalidades triste e alegre dos problemas "alvo".

Parece-nos que os resultados obtidos podem ser considerados indicativos, como previsto em nossa hipótese, de que os indivíduos preferem modos de solução vinculados 
a problemas "fonte" de tonalidades afetivas similares às tonalidades dos problemas "alvo".

Esses resultados foram significativos, como vimos, mesmo com o decurso de tempo de uma semana, ainda que tenha havido um declínio na freqüência relativa de sujeitos que apresentaram respostas de similaridade após esse intervalo de tempo.

Os dados encontrados mostram concordância com a verificação de inúmeros estudos que apontaram para a existência de um efeito positivo das similaridades de superfície de diferentes naturezas na transferência analógica (p. e. Koh, 1987; Ross \& Kennedy, 1990; Bassok e cols., 1995; 1998; Martin \& Bassok, 2005; Holyoak \& cols., 1983; 1987; dentre inúmeros estudos).

No que se refere especificamente aos efeitos de similaridades afetivas de superfície na transferência analógica, podemos apenas comparar nossos achados mais diretamente com os de Hesse e colaboradores (1997), não obstante as diferenças metodológicas entre as duas pesquisas.

Hesse e colaboradores (1997) obtiveram, para as sessões consecutivas, único intervalo de tempo por eles estudado, efeitos positivos de similaridades afetivas no âmbito de problemas bem-definidos dependentes de domínio, utilizando como medida a taxa de palavras emitidas pelos sujeitos relacionadas aos problemas “fonte”, sem focalização, portanto, na resolução de problema per se.

Em nosso estudo foi ainda verificado um maior percentual de escolhas de modos de solução vinculados a problemas "fonte" de tonalidade triste do que de tonalidade alegre para as sessões consecutivas e para as sessões com intervalo de uma semana. Hesse e colaboradores também observaram, para as sessões consecutivas, maior emissão de palavras relacionadas à história de tonalidade triste do que relacionadas à história de tonalidade alegre.

Há, pelo menos, duas possibilidades explicativas para esses resultados. Por um lado, esses achados poderiam estar relacionados aos escores, um pouco mais elevados da avaliação da valência do problema “fonte” de tonalidade triste/ desagradável em comparação com o problema “fonte” de tonalidade alegre/ agradável, como verificado em um dos nossos estudos pilotos (anexo 2). Nesse caso, a diferença observada entre as freqüências de escolhas dos modos de solução vinculados aos dois problemas "fonte" poderia ser decorrente da não equivalência das intensidades das valências das histórias dos problemas "fonte". 
Por outro lado, esses achados poderiam ser atribuídos à existência de um predomínio dos efeitos de estímulos de tonalidade triste/ desagradável na codificação, retenção e/ou recuperação de informações na memória, em comparação com os efeitos de estímulos de tonalidade alegre/ agradável. Ito e Cacioppo (2001) observaram que estímulos de tonalidade negativa seriam mais precoce e profundamente processados do que estímulos de tonalidade positiva, o que estaria de acordo com essa possibilidade explicativa. No que se refere aos efeitos diferenciados dos estados de humor na memória autobiográfica, Curran (2007) também observou que a congruência, entre um humor negativo e a recuperação de eventos negativos na memória, mostrou-se mais pronunciada do que a congruência entre um humor positivo e a recuperação de eventos positivos.

Tendo isso em vista, mostra-se oportuno o desenvolvimento de pesquisas destinadas à investigação dessa questão, a nosso ver, não conclusiva.

\subsection{4-Variação do estado de humor exibida pelos sujeitos}

Foi verificado, em nossa pesquisa, um número muito maior de sujeitos que não apresentou variação de humor do que o número de sujeitos que apresentou variação nas duas condições do problema “alvo”. Mas, quando houve variação do humor, observamos congruência significativa entre a tonalidade do problema “alvo” e a valência da variação do humor para os dois intervalos de tempo. Esse resultado sugere que as tonalidades afetivas dos problemas “alvo” podem ter efeito positivo nos estados de humor. Contudo, o número elevado de sujeitos que não apresentou variação de humor sugere cautela na interpretação dos dados obtidos.

Hesse e colaboradores (1997) também mediram a variação de humor através de uma escala de auto-avaliação. Seus resultados, nas condições dos problemas “alvo” triste e alegre, foram similares aos nossos, inclusive no que diz respeito ao maior número de sujeitos que não apresentou variação de humor. Essa convergência parece relevante, embora, como já referido, haja importantes diferenças metodológicas entre os dois estudos.

Quando se focalizam esses resultados e os dados relativos às similaridades afetivas dos problemas “fonte” e “alvo” parece lícito supor que os indivíduos, frente a problemas com histórias de tonalidades afetivas triste ou alegre, podem ser cognitivamente influenciados por essas tonalidades, embora não se sintam afetivamente afetados, em seu humor, por elas. Mas, quando se sentem afetados, a variação do estado de humor 
tende a apresentar congruência com a tonalidade da história. Nesse caso, como será visto na subseção seguinte, uma análise de correspondência múltipla envolvendo as variáveis "tonalidades afetivas dos problemas "fonte”, "tonalidades afetivas dos problemas 'alvo' " e “variação do humor” pode trazer importantes subsídios para uma análise qualitativa dos resultados observados.

$\mathrm{Na}$ análise dos resultados obtidos, há que se levar em conta as limitações da medida de variação do humor por nós utilizada, incluindo as limitações decorrentes dos possíveis efeitos da conscientização da avaliação do humor, como mostram os estudos de Schwarz e Clore (1983), já referidos.

Na revisão de estudos desenvolvidos na área, vimos que os estados de humor podem ter efeitos significativos sobre processos cognitivos de diferentes naturezas. Entretanto, há muitas dificuldades para um cotejamento dos resultados desses estudos com os dados obtidos em nossa pesquisa.

Essas investigações têm como principal objetivo o estudo dos estados de humor na cognição, em geral induzidos através de estímulos considerados eficazes para tal finalidade. Esses efeitos foram verificados em diversos processos cognitivos tais como, retenção e recuperação de informações (p.e. Bower, 1981; Bower, 1992; Eich \& Macaulay, 2001; Bower \& Forgas, 2001; Martin, 2001, Curran, 2007); solução de problemas (Isen, Daubman \& Novicki, 1987; Brand \& Opwis, 2007; Brand e cols., 2007) ; categorização (p. e. Isen \& Daubman, 1984; Urada \& Miller, 2000; Innes-Ker \& Niedenthal, 2002); julgamento (p. e. Schwarz \& Clore, 1983; Forgas \& Bower, 1987; Bless e cols., 1997; Tiedens \& Linton, 2001, Clore \& Huntsinger, 2007); tomada de decisão (p. e. Luce e cols., 1997), dentre outros.

Estudos de Bower (Bower, 1981; 1992) e Bower e colaborador (Bower \& Forgas, 2001) destacaram, como já referido, dois principais tipos de congruência do estado de humor na memória, o chamado "efeito de congruência do humor” e o chamado “efeito da dependência do humor”, sendo esses dois tipos de efeitos os mais frequentemente investigados por pesquisas na área (Clark \& Teasdale, 1985; Eich e \& Macaulay, 2001; Curran, 2007, dentre outras). Porém, ambos são efeitos do humor em si, ou seja, no primeiro caso, da congruência entre a valência de um dado estado de humor corrente e a valência dos conteúdos recuperados na memória. Já no segundo caso, essa congruência é relativa à valência dos estados de humor no momento do aprendizado e no momento da recuperação da informação. 
Nossa pesquisa, por outro lado, teve como principal objetivo o estudo de um outro tipo de efeito que parece não depender da mediação do humor para ocorrer: a congruência entre tonalidades afetivas de histórias na solução de problemas análogos. Em nosso estudo, procurou-se avaliar, não o estado de humor em si, mas sim a possível variação de humor que poderia ser eliciada pela leitura dos problemas “alvo”, sendo essa avaliação utilizada, principalmente, como controle para os efeitos de similaridades das tonalidades afetivas dos problemas “fonte” e “alvo”. Em conseqüência, não foi utilizado qualquer estímulo que tivesse o papel específico de induzir um dado estado de humor.

De qualquer modo, consideramos oportuna a realização de pesquisas direcionadas, especificamente, para a avaliação dos efeitos de histórias tristes e alegres sobre os estados de humor na transferência analógica de problemas de diferentes naturezas.

7.2.5-Análise de correspondência múltipla: associação entre as variáveis "tonalidades afetivas das histórias dos problemas "fonte", "tonalidades afetivas das histórias dos problemas “alvo" e "variação de humor".

As análises de correspondência, relativas aos dois intervalos de tempo investigados geraram, como vimos, mapas perceptuais que apontaram para a provável existência de associações relevantes entre as categorias "problema alvo" e "problema fonte” de tonalidades afetivas similares.

Essas verificações foram convergentes com os resultados relativos à análise estatística das freqüências das escolhas dos modos de solução associados às tonalidades afetivas dos problemas “fonte” nas duas condições do problema “alvo".

Observamos ainda no mapa perceptual relativo ao intervalo de uma semana, uma distância um pouco maior entre os problemas “fonte” e “alvo" de tonalidade alegre, quando comparada com as sessões consecutivas. Essas disposições nos mapas parecem convergir com os resultados obtidos para o intervalo de uma semana que, embora tenham sido significativos, evidenciaram um declínio na freqüência relativa de sujeitos que apresentaram respostas de similaridade.

No que se refere à variação do humor vimos, nos mapas perceptuais, que a variação negativa acha-se mais próxima dos problemas “alvo" e "fonte” de tonalidade triste do que dos problemas de tonalidade alegre, e vice-versa para a variação positiva. Entretanto, apesar dessas proximidades relativas, essas variações do humor encontramse, em realidade, bem distanciadas espacialmente dos problemas "alvo" e "fonte” de 
tonalidades similares, sendo que a variação positiva acha-se ainda mais distanciada do que a variação negativa. O mapa relativo ao intervalo de uma semana mostra um distanciamento ainda maior da variação positiva e um distanciamento um pouco menor da variação negativa, quando comparado com as sessões consecutivas.

A categoria “sem variação do humor” encontra-se mais próxima do agrupamento constituído pelos problemas "fonte" e "alvo" de tonalidade triste e do agrupamento representado pelos problemas “fonte” e “alvo” de tonalidade alegre, em comparação com as categorias “com variação positiva” e "com variação negativa” do humor.

O mapa relativo ao intervalo de uma semana mostra uma aproximação maior da categoria "sem variação do humor” dos problemas "fonte” e "alvo” alegres do que dos problemas “fonte” e “alvo" tristes, quando comparado às sessões consecutivas.

Esse quadro sugere não ser provável a existência de associação positiva relevante entre a variação de humor negativa e a tonalidade triste dos problemas “fonte” e "alvo”. Sugere, também, ser ainda mais improvável a existência de associação positiva relevante entre a variação de humor positiva e a tonalidade alegre dos problemas “fonte” e "alvo".

Os resultados das análises de correspondência múltipla parecem apoiar a suposição, expressa anteriormente, de que os indivíduos, frente a problemas com histórias de tonalidades afetivas triste e alegre, podem ser cognitivamente influenciados por essas tonalidades, embora não se sintam afetivamente afetados, em seu humor, por elas. Em outras palavras, a preferência por modos de solução vinculados aos problemas “fonte” de tonalidade afetiva similar à do problema “alvo” não parece depender de uma alteração de humor eliciada pela leitura da história alvo.

No que se refere aos possíveis mecanismos subjacentes a esses efeitos, encontra-se nas teorias de rede da memória (p.e.Bower, 1981, Bower \& Cohen, 1982; Bower, 1992; Bower \& Forgas, 2001) apoio para a suposição de que os nodos que representam o problema "alvo" possam estar associados com nodos de conceitos afetivos que correspondem à valência afetiva da história do problema “alvo”. A preferência por problemas "fonte" de tonalidade afetiva similar poderia, então, ser devido ao nodo afetoconceito ativado. E, na medida em que, em nosso estudo, a preferência por problema "fonte” de tonalidade afetiva similar à do problema "alvo" não parece ter sido devida a um efeito de congruência do humor, não seria aqui aplicável a dependência de uma ativação do nodo afeto-sentimento, descrito por Bower e colaboradores. 


\section{$\underline{\text { 8-Justificativas Encontradas para as Respostas Dadas }}$}

Para complementar a análise e a discussão dos resultados, será feita, a seguir, uma análise qualitativa das justificativas encontradas para as respostas dadas nos dois intervalos de tempo pesquisados.

O pedido para que os participantes justificassem as respostas dadas aos problemas “alvo" teve por objetivo obter informações mais detalhadas que complementassem as escolhas das soluções dos problemas "alvo”, bem como obter dados sobre os motivos que levaram os sujeitos a escolher determinada solução.

Autores como Nisbett e Wilson (1977), Kulkarni \& Simon (1988) e Simon e Kaplan (1991), dentre outros, já haviam assinalado a importância do uso de protocolos verbais e de relatos retrospectivos, como um todo, para se estudar o pensamento humano e a resolução de problemas, pois as informações obtidas poderiam fornecer dados sobre a natureza dos processos mentais envolvidos no processamento da informação. Nesse contexto, a análise das justificativas encontradas para as respostas dadas, a nosso ver, pode trazer importantes subsídios para o entendimento dos motivos que levaram os indivíduos a uma determinada escolha e também trazer informações a respeito do processo de mapeamento analógico que possa ter favorecido uma dada resposta.

A seguir, serão apresentados os resultados relativos às justificativas encontradas para as respostas dadas nas sessões consecutivas e nas sessões com intervalo de uma semana, bem como será apresentada a tabela 13, que discrimina os tipos de justificativas dadas pelos sujeitos nos dois intervalos de tempo pesquisados.

$\underline{\text { 8.1-Resultados Relativos às Justificativas Encontradas para as Respostas Nas Sessões }}$ Consecutivas e nas Sessões com Intervalo de Uma Semana

A tabela 13 apresentada abaixo mostra os resultados relativos às justificativas encontradas para as respostas dadas nas sessões consecutivas e nas sessões com intervalo de uma semana. 
TABELA 13 - FREQUÊNCIA DOS TIPOS DE JUSTIFICATIVAS DAS SOLUÇÕES DADAS AO PROBLEMA ALVO NAS SESSÕES CONSECUTIVAS E NAS SESSÕES COM INTERVALO DE UMA SEMANA

\begin{tabular}{|c|c|c|c|c|}
\hline \multirow{3}{*}{ JUSTIFICATIVA } & \multicolumn{4}{|c|}{ INTERVALO DE TEMPO } \\
\hline & \multicolumn{2}{|c|}{$\begin{array}{l}\text { SESSÕES } \\
\text { CONSECUTIVAS }\end{array}$} & \multicolumn{2}{|c|}{1 SEMANA } \\
\hline & FREQUÊNCIA & PERCENTAGEM & FREQUÊNCIA & PERCENTAGEM \\
\hline $\begin{array}{l}\text { CONSIDEREI A SOLUÇÃO MELHOR, } \\
\text { MAIS ADEQUADA, MAIS EFICAZ, } \\
\text { MENOS PREJUDICIAL }\end{array}$ & 133 & 50,57 & 86 & 47,78 \\
\hline LEMBREI-ME DAS HISTÓRIAS LIDAS & 46 & 17,49 & 41 & 22,77 \\
\hline $\begin{array}{l}\text { PORQUE VI NA HISTÓRIA DO AVIÃO/ DO } \\
\text { NAVIO (CITA TEMA, TÍTULO OU UM } \\
\text { ELEMENTO PRESENTE NAS HISTÓRIAS } \\
\text { FONTE) }\end{array}$ & 21 & 7.98 & 6 & 3,33 \\
\hline $\begin{array}{l}\text { PORQUE VI NA HISTORIA DO AVIAÕ/ DO } \\
\text { NAVIO (CITA TEMA, TÍTULO E/OU MAIS } \\
\text { DE UM ELEMENTO PRESENTE NAS } \\
\text { HSITÓRIAS FONTE) }\end{array}$ & 20 & 7,60 & 8 & 4,44 \\
\hline FOI A SOLUÇÃO QUE LEMBREI PRIMEIRO & 11 & 4,18 & 13 & 7,22 \\
\hline $\begin{array}{l}\text { POR CAUSA DE MINHA VIVÊNCIA } \\
\text { PESSOAL }\end{array}$ & 6 & 2,28 & 5 & 2,77 \\
\hline $\begin{array}{l}\text { PARA DESTRUIR ALGO NOCIVO SEM } \\
\text { DANIFICAR O QUE ESTÁ EM VOLTA, } \\
\text { PARA NÃO AFETAR ALGO DELICADO QUE } \\
\text { ESTÁ NO CENTRO DE ALGUMA COISA }\end{array}$ & 5 & 1,90 & 3 & 1,67 \\
\hline $\begin{array}{l}\text { TIVE UM INSIGHT, FOI A SOLUÇÃO MAIS } \\
\text { CRIATIVA }\end{array}$ & 2 & 0,76 & 0 & 0,0 \\
\hline $\begin{array}{l}\text { PORQUE A HISTÓRIA ERA } \\
\text { DESAGRADÁVEL COMO ESSA, ERA } \\
\text { DEPRIMENTE COMO ESSA }\end{array}$ & 2 & 0,76 & 0 & 0,0 \\
\hline SEM JUSTIFICATIVA & 17 & 6,46 & 18 & 10,0 \\
\hline TOTAL & 263 & 100 & 180 & 100 \\
\hline
\end{tabular}


Como podemos observar na tabela 13, as principais justificativas para a escolha da solução dos problemas “alvo” nas sessões consecutivas e nas sessões com intervalo de uma semana referem-se, respectivamente: à eficácia e à adequação da solução escolhida e ao fato de a mesma ser menos prejudicial (50,57\% dos sujeitos nas sessões consecutivas e 47,78\% dos sujeitos nas sessões com intervalo de uma semana) e à lembrança da leitura da solução escolhida nas histórias anteriores, sem mencionar nenhum elemento ou o tema da história; (17,49\% dos sujeitos nas sessões consecutivas e 22,77 dos sujeitos nas sessões com intervalo de uma semana). De modo complementar, foram escolhidas justificativas que mencionam a lembrança da leitura da solução em uma das histórias “fonte” anteriores, mencionando um (7,98\% dos sujeitos nas sessões consecutivas e 3,33 nas sessões com intervalo de uma semana) ou mais elementos e/ou o título ou tema da história (7,60\% dos sujeitos nas sessões consecutivas e 4,44\% nas sessões com intervalo de uma semana) e a lembrança da primeira solução que veio à cabeça (4,18\% dos sujeitos nas sessões consecutivas e 7,22\% dos sujeitos nas sessões com intervalo de uma semana). As outras categorias de justificativas apresentadas na tabela 13 foram menos mencionadas pelos participantes, pois menos de $3 \%$ dos sujeitos as escolheram. Foi verificado, também, que 17 sujeitos (6,46\% dos sujeitos) nas sessões consecutivas e 18 sujeitos (10,0\%) nas sessões com intervalo de uma semana não apresentaram justificativas para as soluções escolhidas.

Para melhor apresentação e discussão das justificativas encontradas, será, a seguir, discriminado, por categoria, cada tipo de justificativa dada para a escolha da solução dos problemas “alvo” em ambos os intervalos de tempo estudados.

$\underline{\text { 8.1.1- Justificativa a "Considerei ser esta a melhor solução/ a mais adequada/ a }}$ menos prejudicial”.

Esse tipo de justificativa, que realça a eficácia da solução proposta e/ou o fato de a mesma ser menos prejudicial à situação-problema "alvo" apresentada, teve a maior freqüência dentre todas as categorias encontradas, tanto nas sessões consecutivas, quanto nas sessões com intervalo de uma semana. Como foi visto, 50,57\% dos sujeitos (133 sujeitos) nas sessões consecutivas e 47,78\% (86 sujeitos) nas sessões com intervalo de uma semana justificaram sua escolha tendo em vista o aspecto pragmático da 
solução, ou seja, houve a preocupação com a eficácia da solução nas justificativas da escolha da solução do problema “alvo” proposto.

Como já referido, os dois modos de solução (serial e convergente) apresentados nas histórias dos problemas “fonte” foram ambos considerados factíveis e foram escolhidos, de modo equivalente, pelos sujeitos participantes da pesquisa. Sendo assim, a eficácia de uma dada solução não poderia estar associada a um modo de solução específico (serial ou convergente). Poderíamos, então, indagar por que o critério de maior adequação e eficácia da solução foi o mais utilizado nas justificativas. Talvez, o tipo de problema "alvo" apresentado que objetiva, por um lado, eliminar um tumor pelo uso de forte radiação e, por outro, possui como principais “coações” a preservação dos tecidos corporais sadios ao redor do tumor e a necessidade do uso de raios de baixa intensidade, tenha favorecido esse tipo de justificativa. Em outras palavras, os enunciados dos problemas "alvo", que destacam a eficácia da solução e o fato de a mesma ser menos prejudicial, podem ter favorecido a escolha de justificativas que utilizem o mesmo tipo de argumento.

Cabe ainda observar que, nas sessões consecutivas, dos 133 sujeitos que forneceram esse tipo de justificativa, 73 apresentaram transferência associada à similaridade de tonalidade afetiva das histórias “fonte” e “alvo”, 32 apresentaram transferência não associada à tonalidade afetiva dessas histórias, 7 apresentaram transferência parcial e 21 escolheram outras soluções diferentes das soluções serial e convergente.

Já nas sessões com intervalo de uma semana, dos 86 sujeitos que forneceram essa justificativa, 38 apresentaram transferência associada à similaridade de tonalidade afetiva das histórias “fonte” e “alvo”, 22 apresentaram transferência não associada à tonalidade afetiva dessas histórias, 9 apresentaram transferência parcial e 17 escolheram outras soluções diferentes das soluções serial e convergente.

Serão abaixo apresentados alguns exemplos de justificativas dadas pelos sujeitos que destacam a eficácia, a adequação e/ou o fato de a solução escolhida ser a menos prejudicial.

Exemplo 1: Solução: “Emitir raios de baixa intensidade aos poucos, uns após os outros, em série, para não agravar o estado da paciente". Justificativa: “Porque com pouca emissão de raios, ou seja, com raios emitidos aos poucos, em intervalos, seria melhor para a paciente, seria a solução mais eficaz e que não a prejudicaria”. 
Exemplo 2: Solução: “Emissão de raios em baixa intensidade, porém de diferentes pontos, com vários raios simultâneos e focalizados todos juntos no tumor para que seu somatório fizesse uma alta radiação". Justificativa: “Para combater o tumor sem danificar os outros tecidos é preciso usar a emissão de raios de vários pontos diferentes focalizando internamente em direção ao tumor, eliminando assim o mal sem prejudicar os tecidos do corpo. Foi a solução menos prejudicial para a paciente”.

Exemplo 3: Solução: “Fazer o tratamento de radiação em etapas,, com radiações com intensidades menores e em uma quantidade maior de vezes, com intervalos de tempo entre as radiações”. Justificativa: “Essa solução seria a mais adequada, pois com intensidade de radiação menor, os tecidos saudáveis não iriam se danificar e com várias sessões daria uma grande quantidade de radiação no local preciso, sem que houvesse maiores problemas".

Por último, vale observar que muitas das justificativas que destacaram apenas a eficácia, adequação ou o fato de a solução escolhida ter sido a menos prejudicial, foram sucintas, ou seja, tiveram em média de duas a quatro linhas, como a maioria das justificativas apresentadas pelos sujeitos. De modo complementar, vale observar que alguns sujeitos apresentaram em ambos os intervalos de tempo pesquisados, como segunda justificativa, a eficácia da solução e/ou fato de a solução escolhida ser a menos prejudicial. Entretanto, foi aqui priorizada a primeira justificativa apresentada por todos os sujeitos para a inclusão nas categorias propostas. Sendo assim, só foram aqui computados os sujeitos que escolheram determinada solução, por considerá-la a mais eficaz e/ou a menos prejudicial em primeira instância.

\subsection{2- Justificativa b "Lembrei-me das histórias lidas".}

A lembrança da leitura da solução escolhida nas histórias "fonte”, como vimos na tabela 13, foi a justificativa fornecida para a escolha da solução do problema "alvo” por 46 sujeitos (17,49\% dos sujeitos) nas sessões consecutivas e por 41 sujeitos (22,77\%) nas sessões com intervalo de uma semana.

Dos 46 sujeitos que nas sessões consecutivas justificaram sua escolha pela lembrança da solução escolhida nas histórias lidas, apenas 4 discriminaram que a solução escolhida foi vista em uma das histórias lidas e 42 mencionaram que viram a solução nas histórias 
lidas, sem a discriminação de que a solução escolhida estava associada a apenas uma das duas histórias “fonte”. Já nas sessões com intervalo de uma semana, de 41 sujeitos que disseram se lembrar das histórias lidas, apenas um discriminou que leu a solução em apenas uma das histórias.

Dos 46 sujeitos que forneceram esse tipo de justificativa nas sessões consecutivas, 30 apresentaram transferência associada à similaridade afetiva das histórias "fonte" e “alvo”, 11 apresentaram transferência não associada à tonalidade afetiva das histórias e 5 apresentaram transferência parcial. Não houve nenhum sujeito que tenha escolhido outra solução e tenha usado esse tipo de justificativa. Já nas sessões com intervalo de uma semana, dos 41 sujeitos que escolheram esse tipo de justificativa, 19 apresentaram transferência associada à similaridade da tonalidade afetiva das histórias "fonte" e “alvo”, 14 apresentaram transferência não associada à tonalidade afetiva das histórias, 4 apresentaram transferência parcial e 4 escolheram outra solução diferente das soluções serial e convergente. Sendo assim, apesar de ter havido a escolha, na maioria dos sujeitos, de apenas uma das soluções vistas (serial ou convergente), um número significativo desses (42 sujeitos nas sessões consecutivas e 40 sujeitos nas sessões com intervalo de uma semana) não discriminou que viu a solução escolhida em apenas uma das histórias "fonte".

Serão apresentados abaixo alguns exemplos de justificativas encontradas que destacam o fato de que a solução escolhida na situação-problema "alvo" foi influenciada pela lembrança da leitura da solução nas histórias “fonte”.

Exemplo 1: Solução: “O médico faria a emissão dos raios disparados de vários pontos, todos juntos em direção ao tumor, porém com baixa intensidade que assim fariam com que o que estivesse ao redor, no caso os tecidos corporais, não fossem afetados. Desse modo, não haveria nenhum prejuízo à saúde da mulher e o tumor poderia ser combatido”. Justificativa: "Porque foi o que li nos textos anteriores. Que é assim que se atinge um alvo ladeado de estruturas sem destruí-las”.

Exemplo 2: Solução: “Ele usou emissão de raios contínuos, mas com baixa intensidade, em dias seguidos, em série, de modo acumulativo, para não atingir os tecidos corporais que envolviam o tumor e que pudessem danificá-los". Justificativa: "Escolhi esta solução porque em uma das histórias que li anteriormente o método utilizado para a resolução do problema foi parecido". 
Exemplo 3: Solução: “O médico emitiu raios de baixa intensidade um após o outro por um longo período, assim não danificaria o tecido corporal e eliminaria o tumor pelo acúmulo de radiação". Justificativa: "Escolhi essa solução tendo como base a leitura das histórias anteriores e utilizando uma analogia, pois aqui se trata de um ser humano e não de maquinas”.

Cabe observar que no último exemplo de justificativa apresentado houve, não só a menção da lembrança da leitura das histórias "fonte”, mas também de que se tratava de uma analogia e de que o contexto "médico" seria diferente do contexto “'técnico" apresentado nas histórias “fonte”. Entretanto, essa foi uma das poucas justificativas que fizeram referência mais direta ao fato de que a solução do problema "alvo" envolvia uma transferência “analógica” e de que haveria a necessidade de “adaptação” da solução vista nas histórias anteriores, que mencionavam aparelhos, à uma nova situaçãoproblema que lidava com a vida humana.

Por fim, no que se refere às justificativas que destacam a influência da leitura das histórias “fonte” na escolha da solução dos problemas “alvo”, podemos concluir que a maioria dos sujeitos que escolheu esse tipo de justificativa não discriminou que a sua escolha foi influenciada por uma, e apenas uma, das histórias lidas. Observamos, em contrapartida, certa generalização da influência da leitura das histórias vistas na primeira sessão, em ambos os intervalos de tempo pesquisados, apesar de a maioria dos sujeitos ter escolhido apenas uma das soluções vistas nas histórias “fonte”.

8.1.3-Justificativa c: "Porque vi na história do avião/ do navio" (citando tema, título ou um elemento presente nas histórias “fonte” ).

Como foi visto na tabela 13, 21 sujeitos (7,98\%) nas sessões consecutivas justificaram a escolha da solução do problema “alvo” através da justificativa "porque vi na história do avião/ do navio (citando tema, título ou um elemento presente nas histórias “fonte”). Já nas sessões com intervalo de uma semana, houve uma queda nessa percentagem, pois apenas 6 sujeitos (3,33\%) justificaram sua escolha através desse tipo de justificativa.

Dos 21 sujeitos que mencionaram um elemento das histórias “fonte” nas sessões consecutivas, 12 sujeitos incluídos nessa categoria (57,14\%) apresentaram transferência associada à tonalidade afetiva das histórias “fonte” e “alvo, 5 (23,81\%) apresentaram 
transferência não associada à tonalidade afetiva das histórias, 4 (19,05\%) apresentaram transferência parcial e nenhum sujeito escolheu solução diferente das soluções serial e convergente.

Nas sessões com intervalo de tempo de uma semana, por sua vez, dos 6 sujeitos que mencionaram na justificativa de sua escolha um elemento e/ou o tema ou título das histórias "fonte", 5 apresentaram transferência associada à tonalidade afetiva das histórias “fonte” e “alvo” e um sujeito apresentou transferência parcial.

Abaixo serão exemplificadas algumas justificativas das soluções dos problemas "alvo" que apresentaram apenas um elemento das histórias “fonte” nas sessões consecutivas.

Exemplo 1: Solução: “O médico deveria emitir raios de baixa intensidade sequencialmente, uns após os outros, em sessões alternadas”. Justificativa: "Porque foi aparentemente a solução utilizada no texto sobre o avião”.

Exemplo 2: Solução: “O médico utilizou a emissão de raios de baixa intensidade diretamente no tumor, de forma gradual e continua e com intervalos de tempo que permitiam a defesa dos tecidos corporais". Justificativa: "Porque foi a solução que li no texto “Cruzeiro do Sonho" e que de todos os demais textos pareceu mais adequada”.

Exemplo 3: Solução: “O médico com certeza decidiu emitir os raios com baixa intensidade, emitidos de diferentes fontes e focalizados no tumor, devendo essa emissão ser ao mesmo tempo”. Justificativa: “Eu escolhi essa solução porque achei a que mais se enquadra na questão apresentada, apesar da história escolhida tratar de um avião e esta de um ser humano, a preocupação em ambas as histórias é a mesma”.

Por fim, no que se refere às justificativas encontradas para as respostas dadas que fazem alguma referência a um elemento das histórias “fonte”, nas sessões consecutivas e nas sessões com intervalo de uma semana, podemos observar que, relativamente, poucos sujeitos mencionaram o tema, o título ou um elemento contido nessas histórias, especialmente nas sessões com intervalo de uma semana. Em outros termos, observamos poucos indícios de mapeamento analógico e de uma recuperação explícita dos conteúdos semânticos presentes nas histórias “fonte” em ambos os intervalos de tempo 
pesquisados, em especial, nas sessões com intervalo de uma semana. Discutiremos melhor, no próximo item, esse tipo de questão.

8.1.4-Justificativa d: "Porque vi na história do avião/ do navio" (citando tema, título e/ou mais de um elemento presente nas histórias “fonte”).

Nas sessões consecutivas, dos 20 sujeitos (7,69\%) que mencionaram mais de um elemento das histórias “fonte”, 12 incluídos nessa categoria (60\% desse total) apresentaram transferência associada à tonalidade afetiva dessas histórias, 5 (25\%) apresentaram transferência não associada à tonalidade afetiva das histórias, 3 (15\%) apresentaram transferência parcial e nenhum sujeito escolheu outra solução diferente das soluções serial e convergente. Cabe ainda observar que 4 sujeitos (do total de 20) apresentaram elementos contidos na história “fonte” do navio (pe. contêiner, fungo e/ou gel) e elementos contidos na história “fonte” do avião (p.e. transistor, mofo e/ou película). Em outras palavras, apresentaram elementos mistos de ambas as histórias.

Nas sessões com intervalo de uma semana, observamos uma queda na taxa de sujeitos que mencionaram mais de um elemento das histórias "fonte" em suas justificativas, pois apenas 8 sujeitos (4,44\%) o fizeram. E desses 8 sujeitos, a maioria (5 sujeitos) misturou elementos de ambas as histórias “fonte” e apenas 3 recuperaram elementos de uma única história. Apenas um sujeito nesse grupo apresentou transferência associada às tonalidades afetivas das histórias “fonte” e “alvo” e 7 apresentaram transferência não associada às tonalidades dessas histórias.

Serão abaixo exemplificadas algumas justificativas dadas para a escolha da solução dos problemas “alvo” que ilustram a categoria “porque vi na história do avião/do navio (citando tema, título e/ ou mais de um elemento presente nas histórias “fonte”).

Exemplo 1: Solução: “Acredito que o médico vai utilizar raios de baixa intensidade uns após os outros, em série, em sessões seqüenciais, com intervalos entre elas”. Justificativa: "Lembrei-me da história anterior onde se deveria atingir um equipamento com mofo, mas sem que fossem danificadas as paredes do equipamento. A solução dessa história serviu perfeitamente para solucionar esta outra história. Como no caso do avião que se assemelha a esse problema, pois no avião não podia danificar a película e eram utilizados vários raios uns após os outros, em série, mas sem danificar 
tal película. Assim é o caso dessa paciente, o tumor maligno precisava ser atingido por raios de alta intensidade, mas sem danificar o tecido”.

Exemplo 2: Solução: “O médico utilizou a emissão de raios de baixa intensidade de forma que o somatório pelo acúmulo de radiação dessas emissões que viriam de várias fontes fosse capaz de gerar a intensidade necessária para o sucesso do procedimento”. Justificativa: "Escolhi esta solução por me parecer a mais aplicável ao caso, considerando que se pode aplicar o mesmo princípio que foi utilizado no caso do gel das paredes do contêiner do navio. No meu entender, os tecidos humanos podem ser comparados ao gel e por isso se deve adotar o mesmo procedimento".

Exemplo 3: Solução: “Escolhi a solução de jogar vários raios de baixa intensidade de diferentes ângulos convergindo em direção ao tumor, para que a soma dos raios destruísse o tumor sem afetar os tecidos corporais. Justificativa: "Escolhi esta solução verificando as outras experiências com os fungos do navio. Estes fungos precisavam ser combatidos com raios, mas não poderia haver danos nas paredes do contêiner, como acontece com os tecidos corporais que precisam ser protegidos. Esta, talvez, seria a melhor solução, no caso da paciente, pois foi realizada com sucesso no caso do contêiner do navio".

Nas justificativas acima podemos observar indícios de mapeamento analógico através da contraposição de elementos como "para não danificar a película/ para não danificar o tecido” (justificativas 1); “pois os tecidos humanos poderiam ser comparados ao gel do contêiner” (justificativa 2); “combater fungos/ combater o tumor”, “para não haver danos nas paredes do contêiner como acontece com os tecidos corporais que precisam ser protegidos” (justificativa 3).

Observamos, também, em algumas justificativas que mencionam mais de um elemento das histórias “fonte”, a menção à eficácia da solução escolhida e/ou ao fato de a solução ser a menos prejudicial. Entretanto, optamos por incluir essas justificativas que apresentam indícios de mapeamento em um item separado daquelas justificativas que só fazem referência à eficácia, à adequação e ao fato de a solução ser menos prejudicial, sem a menção a elementos das histórias “fonte”.

Muitos estudos que buscam investigar o mapeamento analógico per se, costumam utilizar protocolos verbais com o pedido para que os sujeitos “pensem em voz alta” para 
a contagem das palavras relativas aos problemas "fonte" que foram emitidas pelos sujeitos na situação-problema “alvo” (p. e. Gick \& Holyoak, 1980; Hesse e cols., 1997), protocolos escritos e/ou um sumário das similaridades dos problemas análogos (p.e. Gick \& Holyoak, 1983), ou instruções explícitas para que sejam extraídas as similaridades entre dois ou mais problemas análogos (p.e. Spellman \& Holyoak, 1996). Esses tipos de procedimentos permitem investigar (e medir) mais diretamente os sinais de mapeamento analógico. Como já referido, houve em nosso estudo, em contrapartida, o pedido para que os sujeitos respondessem a um questionário, na primeira sessão, após a leitura das histórias “fonte” e distrativas, o que pode ter contribuído, por um lado, para o aprendizado das soluções serial e convergente e, por outro, para a percepção das tonalidades afetivas das histórias e de alguns elementos presentes nas mesmas. Nesse sentido, apesar de nosso estudo ter sido configurado em moldes diferentes das pesquisas supracitadas que, por sua vez, estudaram o mapeamento analógico per se, também parece ter encontrado alguns indícios de mapeamento, ainda que não tenha sido observada uma correspondência mais sistemática entre os elementos presentes nos problemas “fonte” e “alvo” análogos.

Entretanto, consideramos que os indícios de mapeamento explícito encontrados em nosso estudo não parecem significativos, pois verificamos que apenas um número relativamente pequeno de sujeitos nas sessões consecutivas $(7,60 \%)$ mencionou mais de um elemento das histórias “fonte” nas justificativas da escolha da solução dos problemas “alvo" e um número menor ainda de sujeitos (4,44\%) mencionou mais de um elemento dessas histórias nas sessões com intervalo de uma semana. Mesmo que se faça uma soma dos sujeitos que recuperaram um elemento (21 sujeitos) com aqueles que recuperaram mais de um elemento (20 sujeitos) nas sessões consecutivas, teríamos um total de 41 sujeitos (15,67\%), o que consideramos ainda um número relativamente pequeno frente ao tamanho da amostra (263 sujeitos). Nas sessões com intervalo de uma semana, essa soma decresce ainda mais (14 sujeitos em um total de 180).

A queda na taxa de sujeitos que destacaram o tema, o título e/ou alguns elementos presentes nas histórias "fonte” nas sessões com intervalo de uma semana sugere que, na situação-problema “alvo”, houve uma maior dificuldade de recuperação de elementos e/ou conteúdos semânticos de histórias “fonte” lidas com uma semana de antecipação. Sendo assim, o mapeamento analógico, ou pelo menos, os indícios de mapeamento analógico encontrados em nosso estudo, parece ter sido facilitado pela proximidade 
temporal das histórias “fonte” e “alvo” nas sessões consecutivas, o que seria, de certo modo, esperado.

Não obstante, apesar do baixo índice de mapeamento encontrado, especialmente nas sessões com intervalo de uma semana, foi verificado, como vimos anteriormente, em ambos os intervalos de tempo pesquisados, uma transferência analógica significativa, o que nos leva a supor que a demanda de um mapeamento analógico explícito, como requisito para a transferência, não seja uma condição universal. Nessa direção, os estudos de Ripoll e colaboradores (2002) e Day e Gentner (2007), já mencionados, sugeriram que não haveria a necessidade de um mapeamento detalhado, uma espécie de correspondência “termo a termo" entre os predicados dos problemas análogos para que houvesse a extração das propriedades relevantes dos problemas “fonte”. Como vimos, na concepção desses autores, o processo de mapeamento, tradicionalmente visto como explícito e deliberado, poderia ocorrer, em contrapartida, de modo mais implícito, sem que houvesse um engajamento consciente dos indivíduos.

8.1.5- Justificativa e: "Foi a solução que lembrei primeiro/ foi a solução que me veio à cabeça”.

A justificativa "foi a solução que lembrei primeiro/ foi a solução que me veio à cabeça” foi destacada por 11 sujeitos (4,18\%) nas sessões consecutivas e por 13 sujeitos (7,22\%) nas sessões com intervalo de uma semana. Desses 11 sujeitos que apresentaram esse tipo de justificativa nas sessões consecutivas, 7 apresentaram transferência associada à similaridade afetiva das histórias "fonte" e "alvo", 2 apresentaram transferência não associada às tonalidades afetivas dessas histórias, um sujeito apresentou transferência parcial e um outro sujeito escolheu uma solução diferente das soluções serial e convergente. Já dos 13 sujeitos que apresentaram essa justificativa nas sessões com intervalo de uma semana, 9 apresentaram transferência associada às tonalidades afetivas das histórias “fonte” e “alvo”, 2 apresentaram transferência não associada às tonalidades afetivas dessas histórias e 2 escolheram outras soluções diferentes das soluções serial e convergente.

Serão apresentados abaixo alguns exemplos de justificativas dadas que destacam o fato de que a solução escolhida foi a primeira a ser lembrada/ a primeira que veio à cabeça dos sujeitos. 
Exemplo 1: Solução: "Se eu fosse o médico, aplicaria uma fonte de bombardeio de raios em intervalos, um após o outro, em dias diferentes, de modo gradativo, a partir de uma fonte de emissão". Justificativa: "Foi a solução que me veio à cabeça primeiro de forma mais completa. Não me recordo de detalhes, mas me lembrei que essa solução pode ser aplicada pelo médico ao caso do tumor da paciente”.

Exemplo 2: Solução: “Atingir o tumor com vários raios de baixa intensidade que vêm de várias direções em direção ao tumor, isto é, usar vários raios simultaneamente, pois várias intensidades baixas formam uma alta intensidade”. Justificativa: “Foi a primeira solução que me veio à mente, após a leitura dos textos anteriores”.

Exemplo 3: Solução: “A melhor solução é usar uma baixa intensidade de raios com intervalo entre as aplicações para que, com o tempo, de modo acumulativo, o tumor seja eliminado aos poucos”. Justificativa: "Escolhi essa solução porque foi a primeira que me veio à cabeça e também achei que era a melhor”.

Cabe ainda observar que alguns sujeitos que apresentaram a justificativa "foi a solução que lembrei primeiro/ foi a solução que me veio à cabeça”, também destacaram, como segunda justificativa, o fato de que a solução seria a melhor na sua opinião. Entretanto, como a primeira justificativa foi a lembrança prioritária de uma das soluções, mantivemos o critério já referido de inclusão nas categorias.

Em suma, apesar de ter sido um número relativamente pequeno de sujeitos que escolheu a justificativa "foi a solução que lembrei primeiro/ foi a solução que me veio à cabeça” nas sessões consecutivas (11 sujeitos) e nas sessões com intervalo de uma semana (13 sujeitos), há indicações de que a maioria dos sujeitos que a escolheu nas sessões consecutivas (7 sujeitos, ou seja, 63,64\% desse grupo) tenha sido influenciada pela similaridade afetiva das histórias “fonte” e “alvo", bem como a maioria que a escolheu nas sessões com intervalo de uma semana (9 sujeitos, ou seja, 69,24\% desse grupo). Ainda que não tenha demonstrado uma recuperação explícita, consciente, de elementos das histórias “fonte”, ou tenha tido consciência da influência de sua tonalidade afetiva, há indicações de que a maioria dos sujeitos, que destacou esse tipo de justificativa, em ambos os intervalos de tempo, tenha sido influenciada pela similaridade das tonalidades afetivas das histórias “fonte” e “alvo”. 


\subsection{6-Justificativa f: "Por causa da minha vivência pessoal”.}

Todos os 6 sujeitos (2,28\%) que apresentaram a justificativa "por causa da minha vivência pessoal” nas sessões consecutivas escolheram outras soluções para os problemas “alvo”, ou seja, escolheram soluções diferentes das soluções serial e convergente. Nas sessões com intervalo de uma semana também encontramos respostas semelhantes, pois dos 5 sujeitos que utilizaram esse tipo de justificativa, todos escolheram outras soluções. Sendo assim, em todos esses casos, não foi verificada transferência. A maioria (4 sujeitos) dos sujeitos, que escolheu esse tipo de justificativa nas sessões consecutivas, destacou a necessidade da realização de uma cirurgia e 2 sujeitos escolheram o uso de medicamentos ou um tratamento com quimioterapia. Nas sessões com intervalo de uma semana, 2 sujeitos também escolheram soluções que envolviam uma cirurgia, 2 sugeriram o uso de medicamentos e um sugeriu uma terapia alternativa.

Serão apresentados abaixo alguns exemplos que ilustram esse tipo de justificativa.

Exemplo 1: Solução: “Esta paciente deve fazer o tratamento de acordo com o ponto de vista do médico, pois se ela não fizer o tratamento pode morrer e se ela fizer um tratamento com radiação vai sofrer alguns danos. Hoje em dia a tecnológica tem avançado muito e tem muitos tratamentos com medicamentos que resolvem mesmo, vale a pena tentar, eu fiz e deu certo”. Justificativa: “Eu fiz um tratamento com quimioterapia e deu certo e acho que pode dar certo com essa paciente”.

Exemplo 2: Solução: “Mesmo que não fosse indicada, eu faria uma cirurgia. No texto fala que a cirurgia não é indicada, porém não diz que é proibida. O tumor maligno precisava ser atingido por uma alta intensidade de raios, pois uma baixa intensidade não conseguiria destruí-lo. E por outro lado, a emissão de raios de alta intensidade poderia piorar o problema, então a solução seria retirar o câncer cirurgicamente”. Justificativa: “Conheço pessoas que se curaram do câncer pela cirurgia”.

Exemplo 3: Solução: “Fazendo uma operação, retirando o rim danificado". Justificativa: "Tive pessoas na família que tiveram esse problema e fizeram uma operação que deu certo". 
Em síntese, no que se refere à justificativa da escolha da solução dos problemas “alvo”, tendo em vista a vivência pessoal, todos os sujeitos que apresentaram esse tipo de justificativa nos dois intervalos de tempo pesquisados escolheram soluções diferentes das soluções serial e convergente, ou seja, não apresentaram transferência. Entretanto, como vimos anteriormente, a maioria dos sujeitos nas sessões consecutivas (21 sujeitos) que escolheu “outras soluções” para os problemas “alvo” justificou sua escolha tendo em vista a eficácia da solução e/ou o fato de a mesma ser menos prejudicial. O mesmo ocorreu nas sessões com intervalo de uma semana, pois a maioria dos sujeitos que escolheu “outras soluções” (17 sujeitos) justificou sua escolha tendo em vista o aspecto pragmático e a eficácia da solução.

8.1.7- Justificativa g: "Para destruir algo nocivo sem danificar o que está em volta, como nas histórias lidas/ para não afetar algo delicado que está no centro de alguma coisa, como foi visto nos textos" (mencionando algumas “coações” das histórias "fonte” e “alvo", sem discriminação de elementos ou termos das histórias).

A menção de uma ou mais “coações” presentes nas histórias “fonte” e "alvo” foi uma justificativa apresentada por alguns sujeitos nos dois intervalos de tempo. “Coações” do tipo "para destruir algo nocivo sem danificar o que está em volta como nas histórias lidas/ para não afetar algo delicado que está no centro de alguma coisa, como foi visto nos textos” foram destacadas como justificativa da escolha da solução do problema “alvo” por apenas 5 sujeitos nas sessões consecutivas, e por apenas 3 sujeitos nas sessões com intervalo de uma semana. Dos 5 sujeitos que mencionaram esse tipo de “coação” nas sessões consecutivas, 3 apresentaram transferência, ao que tudo indica, relacionada à similaridade afetiva das histórias “fonte” e “alvo” e 2 apresentaram transferência não associada à tonalidade afetiva das histórias. Não houve nenhum sujeito que, nesse intervalo de tempo, tenha apresentado transferência parcial ou mesmo outra solução e que tenha utilizado esse tipo de justificativa.

Nas sessões com intervalo de uma semana, por sua vez, dos 3 sujeitos que utilizaram esse tipo de justificativa, todos apresentaram transferência associada à similaridade da tonalidade afetiva das histórias “fonte” e "alvo".

Serão abaixo exemplificadas algumas justificativas que destacam certas similaridades nas “coações” pragmáticas dos problemas “fonte” e “alvo” nas sessões consecutivas. 


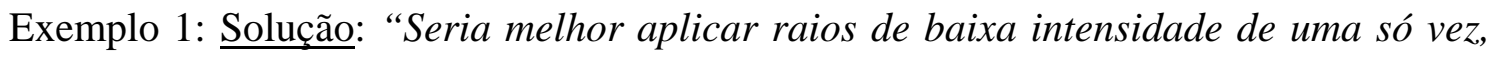
de vários pontos diferentes e todos ao mesmo tempo, assim a força dos raios seria maior”. Justificativa: “Para não solucionar um problema e ocasionar outro, ou seja, para destruir algo nocivo sem danificar o que está em volta como foi visto nas histórias anteriores"

Exemplo 2: Solução: "Eu aplicaria raios de baixa quantidade, em determinados intervalos de tempo, em várias sessões consecutivas, de modo seqüencial”. Justificativa: “Eu escolhi essa solução, pois é uma solução que protege os tecidos e para não afetar algo delicado que está no centro de alguma coisa, como vi nos textos, essa seria uma boa solução".

Exemplo 3: Solução: “O médico poderia utilizar o método de enviar raios de baixa intensidade vindos de varias fontes e que fossem direcionados para o centro do tumor, convergindo os raios de baixa intensidade para que fizessem uma radiação mais forte”. Justificativa: “Escolhi tal resposta, pois as restrições para a solução do problema eram quase as mesmas nas histórias, pois havia a necessidade da proteção de algo frágil e a necessidade de formar uma alta radiação (a partir de varias radiações mais fracas). Pude fazer uma analogia entre as histórias”.

No último exemplo acima, a justificativa apresentada pelo sujeito, além de destacar as principais “coações” pragmáticas dos problemas “fonte” e “alvo" (proteção de algo frágil, suscetível de ser danificado por uma alta radiação e a simultânea necessidade de uma alta radiação para a eficácia do tratamento), destaca o fato de que há semelhança nas “restrições” das histórias (“coações”), bem como utiliza a palavra “analogia”. Observa-se, nesse sujeito, a clara percepção das restrições pragmáticas impostas pelos enunciados dos problemas “fonte” e “alvo" e a percepção de que se tratava da transferência de uma solução que envolvia uma relação analógica.

Como conclusão, podemos argüir que a não explicitação das similaridades das “coações” pragmáticas dos problemas “fonte” e “alvo” nas justificativas dadas pela grande maioria dos sujeitos nas sessões consecutivas e nas sessões com intervalo de uma semana não exclui a possibilidade de ter havido, de modo implícito, a percepção desse tipo de similaridade. Em outros termos, ainda que não tenhamos observado, na maioria 
dos sujeitos, um mapeamento analógico explícito que destacasse as "coações" pragmáticas entre os problemas "fonte” e "alvo", acreditamos que possa ter havido a influência desse tipo de similaridade de modo implícito, não consciente.

Por fim, cabe realçar que uma das “coações” pragmáticas, que foi destacada pela maioria dos sujeitos que escolheu a solução serial ou convergente, ou seja, pelos sujeitos que apresentaram transferência analógica, foi aquela que mencionava a impossibilidade do uso de raios de alta intensidade para a destruição do tumor. Porém esse tipo de “coação” fazia parte dos enunciados de todos os problemas “fonte” e "alvo” e não demandou, assim, a recuperação espontânea por parte dos sujeitos.

\subsection{8- Justificativa h: "Porque tive um insight"/ foi a solução mais criativa”.}

Apenas 2 sujeitos (0,76\%) nas sessões consecutivas mencionaram que escolheram a solução dos problemas "alvo" porque tiveram um insight (um sujeito) ou porque acharam a solução escolhida mais criativa (um sujeito). Nenhum sujeito nas sessões com intervalo de uma semana apresentou esse tipo de justificativa.

Serão apresentados abaixo os exemplos dessas duas justificativas.

Exemplo 1: Solução: “O médico utilizou raios de baixa intensidade vindos de vários pontos e que convergiram para o tumor, de modo que a radiação ficou mais forte $e$ assim, apesar de mais forte, pode destruir o tumor sem afetar os tecidos do corpo ao redor”. Justificativa: “Porque tive um insight a partir da leitura das histórias”.

Exemplo 2: Solução: "Foram emitidos raios de baixa intensidade de direções diferentes, ou melhor, de diferentes pontos para convergir num único ponto no rim”. Justificativa: “Achei essa solução a mais criativa e na vida é preciso ter criatividade para vencer os problemas".

Podemos observar, nos exemplos acima, que as justificativas "porque tive um insight” e "porque foi a solução mais criativa” acompanharam a escolha da solução convergente em ambos os sujeitos. Duncker (1945), em seus estudos com o problema da radiação, já havia destacado a solução convergente como a solução favorecida pelo processo de “insight”. Entretanto, a verificação de um número muito pequeno de sujeitos que utilizou esse tipo de justificativa, nas sessões consecutivas, nos 
impossibilita tecer, em nosso estudo, maiores considerações a respeito de uma associação entre a solução convergente e o processo de insight. Por outro lado, podemos sim observar, como vimos anteriormente, a partir dos resultados encontrados, certa equivalência na escolha das soluções seriais e convergentes nos dois intervalos de tempo estudados. Essa equivalência na escolha desses dois modos de solução em um problema análogo ao da radiação de Duncker, quando há a apresentação de histórias "fonte” que apresentam as duas soluções, parece, inclusive, ir de encontro à idéia de que a solução convergente seria a solução mais “adequada” para esse tipo de problema.

8.1.9- Justificativa i: "Porque a história era desagradável como essa/ era deprimente como essa”.

Em dois sujeitos (0,76\%) nas sessões consecutivas, a conscientização de que havia uma similaridade nas tonalidades afetivas das histórias "fonte” e “alvo" foi explicitada através da justificativa "porque a história era desagradável como essa/ era deprimente como essa”. Em ambos os sujeitos, houve o destaque da similaridade afetiva triste/ desagradável das histórias “fonte” e "alvo”. Por outro lado, não foi verificada nenhuma justificativa que mencionasse a tonalidade afetiva alegre/ agradável das histórias. Nenhum sujeito destacou a similaridade afetiva das histórias nas sessões com intervalo de uma semana.

Os exemplos dessas duas justificativas serão apresentados abaixo.

Exemplo 1: Solução: "Se eu fosse o médico aplicaria baixas dosagens de raios em sessões com certo tempo entre elas para que os raios se acumulassem e fizessem efeito de uma dosagem mais forte”. Justificativa: “A história do tumor é tão deprimente como as histórias anteriores e se a solução para as anteriores foi a utilização de baixas dosagens de raios em quantidade para resolver os problemas, é de se esperar que seja esta a solução para este problema”.

Exemplo 2: Solução: “O médico precisa atingir o tumor com alta intensidade de raios, mas esses raios em alta intensidade poderiam destruir os tecidos corporais. O que ele pode fazer é incidir esses raios de vários pontos, como no caso do mofo do avião, em que para não 'estragar' a proteção do avião precisou atingir vários raios que convergiam em direção a ele". Justificativa: "Escolhi aquela solução, pois achei a 
situação muito parecida ao caso do avião. São duas histórias desagradáveis, onde os sujeitos das histórias se sentem afetado, de modo psicológico e físico. E também no caso do avião, eles deveriam tirar o mofo, sem que quebrassem a proteção e não danificassem ela, mas se incidisse o raio muito forte, ou seja, de alta intensidade, poderia danificar, com isso se chegou a solução de incidir vários raios para se resolver o problema, sem danificar. O mesmo aconteceu com essa história onde o sujeito da história sofria de um tumor, onde precisava incidir alta intensidade de raios, mas se incidisse uma alta intensidade, poderia danificar dos tecidos. Para solucionar esse problema, deve-se incidir vários raios, de várias fontes de raios, para atingir um ponto só, para não danificar o tecido, o mesmo aconteceu com o avião”.

Verificamos que essa última justificativa, além de destacar a semelhança entre a tonalidade afetiva de uma das histórias “fonte” e da história “alvo”, também apresenta elementos da história “fonte” de mesma tonalidade afetiva da história “alvo”, ou seja, apresenta alguns indícios de mapeamento analógico. Sendo assim, essa justificativa poderia também figurar na justificativa d (“porque vi na história do avião/ do navio” (cita tema, título e/ou mais de um elemento presente nas histórias “fonte”). Entretanto, como houve aqui também o destaque da similaridade da tonalidade afetiva de uma das histórias “fonte” e da história “alvo” e, sendo a explicitação dessa similaridade um diferencial importante para a inclusão em uma nova categoria, optamos por dar um destaque especial a essa justificativa. Vale ainda mencionar que ambos os sujeitos que destacaram, em suas justificativas, a semelhança entre as tonalidades afetivas das histórias, apresentaram transferência associada à similaridade de tonalidade afetiva das histórias “fonte” e “alvo”.

Observamos, por um lado, um número bastante restrito de sujeitos que explicitou a importância da similaridade afetiva entre as histórias “fonte” e “alvo” como tendo influenciado a escolha da solução do problema “alvo” e, por outro lado, um número significativo de sujeitos, em ambos os intervalos de tempo pesquisados, especialmente nas sessões consecutivas, que apresentou transferência associada à similaridade de tonalidade afetiva das histórias “fonte” e “alvo”. Em outros termos, a pouca referência à tonalidade afetiva das histórias nas justificativas dos sujeitos parece apontar para o fato de que os efeitos da similaridade afetiva das histórias na transferência analógica se dariam de modo implícito, sem que os sujeitos percebessem, de modo consciente, essa influência. 
Os resultados obtidos nos questionários aplicados após a apresentação da cada história na situação-problema “fonte” (anexo 5) sugerem também que a maioria dos sujeitos nos dois intervalos de tempo pesquisados (cerca de 95,6\% em média) considerou uma das histórias “fonte” triste e a outra alegre. Por outro lado, observamos também, nos questionários, que a maioria dos sujeitos, nos dois intervalos de tempo (75\% em média) não se sentiu afetada pela leitura das histórias “fonte” triste e alegre, apesar de ter considerado essas histórias, respectivamente, triste e alegre. Sendo assim, apesar de ter havido, na maioria quase absoluta de sujeitos, uma avaliação correta de uma história "fonte" como de tonalidade triste e de outra como de tonalidade alegre, relativamente poucos sujeitos disseram ter se sentido afetados por essas histórias.

De modo correlato, como vimos na discussão dos resultados relativos à escolha da solução do problema “alvo” e à variação do humor, foi verificado também que a maioria dos sujeitos nos dois intervalos de tempo pesquisados (80,1\% em média) não sofreu alteração do humor após a leitura das histórias “alvo”.

Podemos concluir que os resultados como um todo sugerem que os efeitos positivos das similaridades afetivas das histórias dos problemas “fonte” e “alvo" se deram de modo implícito, sem que os sujeitos tenham percebido que escolhiam suas respostas pela influência da semelhança da tonalidade afetiva das histórias. De modo complementar, os resultados obtidos também sugerem que esse tipo de influência não parece depender de uma alteração do estado de humor dos indivíduos.

Em suma, os resultados encontrados sugerem que a influência da similaridade afetiva das histórias “fonte” e “alvo” na resolução dos problemas “alvo” estaria associada a um processamento cognitivo implícito, não consciente. E, como observaram autores como Damásio (1994; 2000; 2004), Damásio e colaboradores ( 2001; 2005), Bechara (2003), em estudos sobre a influência das emoções no processo de tomada de decisão, os sinais emocionais não precisam ser conscientes para que tenham influência em uma determinada escolha. Nessa direção, nossos resultados sugerem que possa ter havido uma representação implícita da situação-problema proposta, talvez, devido ao fato de o afeto ser, muitas vezes, representado dessa maneira em nosso sistema cognitivo. De modo complementar, foram verificados poucos indícios de um mapeamento analógico explícito, o que sugere a possibilidade de que possa ter havido um mapeamento implícito de elementos presentes nas histórias "fonte” e “alvo”. A significativa taxa de transferência analógica encontrada nos dois intervalos de tempo pesquisados é sugestiva de que isso possa ter ocorrido. 


\section{$\underline{\text { 9-Conclusão }}$}

Algumas conclusões merecem ser aqui brevemente destacadas. No que se refere à transferência analógica, como já referido, observamos para os dois intervalos de tempo pesquisados, uma transferência significativa, embora tenha havido certo declínio na transferência após o decurso de uma semana. Fatores facilitadores da transferência, especialmente as similaridades das “coações” funcionais dos problemas análogos apresentados, a adequação das soluções serial e convergente aos problemas “alvo”, o uso de questionário para garantir o aprendizado das soluções dos problemas e o fornecimento de dicas de recuperação na situação-problema "alvo”, parecem ter contribuído para a boa taxa de transferência verificada.

Já os resultados relativos à influência das tonalidades afetivas dos problemas "alvo" na escolha do tipo de solução, serial ou convergente, sugerem que essa influência parece dar-se de modo mais imediato, pois não foi verificada após o intervalo de uma semana. A verificação de que esses efeitos ocorreram a curto-prazo, mas não após o decurso de uma semana, sugere que a proximidade temporal das similaridades afetivas das histórias dos problemas “fonte” e “alvo" nas sessões consecutivas pode ter favorecido uma associação entre a tonalidade afetiva triste e a solução serial e uma associação entre a tonalidade afetiva alegre e a solução convergente. Não foi encontrado na literatura, estudos que focalizassem esse tipo de efeito à médio-prazo ou à longo-prazo.

Uma das principais conclusões de nossos estudos diz respeito aos efeitos positivos das similaridades afetivas das histórias dos problemas “fonte” e "alvo” na preferência por um modo de solução do problema “alvo”, isto é, pelo modo de solução que se acha vinculado ao problema "fonte” de mesma tonalidade afetiva do problema "alvo”. Essa preferência foi observada nos dois intervalos de tempo pesquisados, com maior freqüência relativa nas sessões consecutivas. Desse modo, quando há mais de uma solução disponível e funcionalmente adequada para um determinado problema, como ocorre, por exemplo, frequentemente no cotidiano, similaridades de superfície, como as tonalidades afetivas de histórias de problemas, parecem influenciar a preferência por um modo de solução.

Encontramos na literatura, como já referido, estudos que mostram efeitos positivos de similaridades de superfície de diferentes naturezas na transferência analógica. Nossos resultados parecem corroborar esse tipo de evidência ao realçar a importância das similaridades afetivas de superfície na resolução de problemas e na transferência 
analógica. Porém, a focalização de efeitos das similaridades afetivas dos conteúdos de histórias de problemas análogos parece ser pouco privilegiada na literatura da área. Acreditamos, assim, que nossos estudos preenchem um espaço de pesquisa ainda pouco explorado ao trazer contribuições empíricas sobre esse tipo de influência do afeto na cognição.

Quanto ao papel da variação do estado de humor, conjuntamente com os efeitos das similaridades afetivas das histórias dos problemas, verificamos, como foi visto, que somente um número relativamente pequeno de indivíduos apresentou variação de humor após a leitura das histórias dos problemas “alvo”, sendo que a variação de humor exibida por esses indivíduos foi congruente com as tonalidades afetivas dos problemas “alvo”. Podemos, então, supor que as tonalidades afetivas dos problemas “alvo” podem influenciar positivamente a alteração de humor, mas esse efeito, em nosso estudo, foi restrito a um número relativamente pequeno de indivíduos. Parece-nos oportuno o desenvolvimento de pesquisas que procurem esclarecer os fatores subjacentes a essas diferenças individuais. Por outro lado, um número expressivo de indivíduos não apresentou variação de humor após a leitura das histórias “alvo”. Concluímos, então, que os efeitos positivos das similaridades das tonalidades afetivas dos problemas "fonte" e “alvo” na resolução de problemas e na transferência analógica não parecem depender da mediação da variação do humor para ocorrer.

Podemos supor que não só problemas mal-definidos apresentados em situações experimentais e problemas semelhantes do cotidiano poderiam sofrer influência das similaridades afetivas. Problemas de diferentes naturezas com diferentes graus de definição e com maior dependência ou independência de domínio poderiam sofrer a influência, não só dos conteúdos dos enunciados dos problemas e das histórias com um todo, mas também das tonalidades afetivas desses conteúdos.

De modo complementar, diferentes processos cognitivos parecem sofrer a influência do afeto, em especial das emoções e do estado de humor e, de modo correlato, poderiam também sofrer a influência da tonalidade afetiva dos diferentes conteúdos semânticos envolvidos nas tarefas apresentadas. Nessa perspectiva, mostra-se relevante a proposta de novas investigações que enfoquem os efeitos das similaridades afetivas desses conteúdos em diferentes processos cognitivos, com a construção de diferentes histórias e de diferentes problemas com maior ou menor grau de definição.

Mostra-se também relevante a extensão de estudos direcionados para a investigação dos efeitos da similaridade afetiva de problemas na transferência analógica em 
diferentes faixas etárias, com diferentes graus de instrução e diferentes inserções sócioculturais. Acreditamos que o cotejamento de nossos resultados com estudos similares desenvolvidos em diferentes contextos, possa vir a favorecer o desenvolvimento de uma linha base de pesquisas que venha a contribuir para um melhor entendimento da influência do afeto na cognição.

Nossos resultados podem ter particular relevância para os contextos acadêmico e escolar, como um todo, na medida em que as situações-problema vivenciadas pelos alunos podem revestir-se de tonalidades afetivas que favorecem certo tipo de transferência, ainda que os efeitos dessas tonalidades não se dêem, normalmente, de modo consciente e ainda que os mesmos não dependam da mediação do humor para ocorrer. Desse modo, mostra-se relevante a ampliação do conhecimento, por parte dos educadores, de que fatores afetivos de diferentes naturezas, incluindo-se aqui as tonalidades afetivas dos conteúdos escolares, podem ter nítida influência na transferência de aprendizagem.

Acreditamos que os resultados da nossa pesquisa trazem contribuições relevantes para o estudo da relação entre afeto e cognição, em especial, para o estudo da influência do afeto na resolução de problemas e na transferência analógica. E, nesse contexto, a verificação dos efeitos positivos das similaridades afetivas de histórias de problemas parece, não só trazer evidências empíricas sobre esse tipo de influência, mas também sugerir que os efeitos do afeto na cognição poderiam se dar de modo mais implícito e sem a necessidade da mediação da variação do humor.

De modo complementar, como vimos, as justificativas encontradas para a escolha das soluções também sugerem que possa ter havido uma representação implícita da situação-problema proposta, bem como um processo implícito de mapeamento analógico entre os problemas “fonte” e “alvo”. Isso, talvez, tenha ocorrido, em parte, devido ao fato de o afeto ser, muitas vezes, representado dessa maneira em nosso sistema cognitivo.

Em suma, a influência do afeto na cognição poderia ser assim vista como mais abrangente do que a pressuposta na literatura da área, pois mesmo quando os indivíduos não se consideram afetados em seu humor pela leitura de histórias tristes e alegres, eles parecem sofrer a influência das tonalidades afetivas dessas histórias. 


\section{0-Referências Bibliográficas}

Adolphs, R. \& Damasio, A.R. (2001). The interaction of affect and cognition: a neurobiological perspective. In: J.P. Forgas (ed.), Handbook of affect and social cognition (pp.27-49). Mahwah: Lawrence Erlbaum.

Adolphs, R.; Tranel, D. \& Damasio, A.R. (2003). Dissociable neural systems for recognizing emotions. Brain and Cognition, 52(1), 61-69.

Anderson, J.R.(1983). The architecture of cognition. Cambridge: Harvard University Press.

Anderson, J. R. (1987a). Methodologies for studying human knowledge. Behavioral and Brain Sciences, 10(3), 467-477.

Anderson, J.R. (1987b). Skill acquisition: compilation of weak-method problem solutions. Psychological Review, 94(2), 192-210.

Anderson, J.R.; Conrad, F.G. \& Corbett, A.T. (1989). Skill acquisition and the LISP tutor. Cognitive Science, 13(4), 467-505.

Anderson, J.R. \& Fincham, J.M. (1994). Acquisition of procedural skills from examples. Journal of Experimental Psychology: Learning, Memory, and Cognition, 20(6), 1322-1340.

Baddeley, A. D. (1986). Working memory. Oxford: Oxford University Press.

Baddeley, A. D. (1990). Human memory. Theory and practice. Hillsdale: Lawrence Erlbaum.

Barnett, S.M. \& Ceci, S.J. (2002). When and where do we apply what we learn? A taxonomy for far transfer. Psychological Bulletin, 128(4), 612-637.

Bartlett, F.C. (1932) Remembering: a study in experimental and social psychology. Cambridge: Cambridge University Press.

Bassok, M. (1990). Transfer of domain-specific problem-solving procedures. Journal of Experimental Psychology: Learning, Memory and Cognition, 16(3), 522-533.

Bassok, M. (2001). Semantic alignments in mathematical word problems. In: D. Gentner, K.J. Holyoak \& B.N. Kokinov (eds.), The analogical mind: perspectives from cognitive science (pp. 401-433). Cambridge: The MIT Press.

Bassok, M. (2003). Analogical transfer in problem solving. In: J.E. Davidson \& R.J. Sternberg (eds.), The psychology of problem solving (pp. 343-369). Cambridge: Cambridge University Press. 
Bassok, M. \& Holyoak, K.J. (1989). Interdomain transfer between isomorphics topics in algebra and physics. Journal of Experimental Psychology: Learning, Memory and Cognition, 15(1), 153-166.

Bassok, M.; Chase, V.M. \& Martin, S.A. (1998). Adding apples and oranges: alignment of semantic and formal knowledge. Cognitive Psychology, 35(2), 99-134.

Bassok, M.; Wu, L.L \& Olseth, K.L. (1995). Judging a book by its cover: interpretative effects of content in problem-solving transfer. Memory \& Cognition, 23(3), 354-367.

Bechara, A. (2003). O papel positivo da emoção na cognição. In: Arantes, V.A. (org.), Afetividade na escola.Alternativas teóricas e práticas (p.191-214). São Paulo: Summus.

Bechara, A.; Damasio, H.; Tranel, D. \& Damasio, A.R. (2005). The Iowa Gambling Task and the somatic marker hypothesis: some questions and answers. Trends in Cognitive Sciences, 9(4), 159-152.

Berardi-Coletta, B.; Buyer, L.S.; Dominowski, R.L. \& Rellinger, E.R. (1995). Metacognition and problem solving: a process-oriented approach. Journal of Experimental Psychology: Learning, Memory, and Cognition, 21(1), 205-223.

Berg, C. A. \& Calderone, K. S. (1994). The role of problem interpretation in understanding the development of everyday problem solving. In: R.J. Sternberg \& R.K. Wagner (eds.), Mind in context: interactionist perspectives on human intelligence (pp.105-132). New York: Cambridge University Press.

Berntsen, D. \& Rubin, D.C. (2004). Cultural life scripts structure recall from autobiographical memory. Memory \& Cognition, 32(4), 427-442.

Blanchette, I. \& Dunbar, K. (2001). Analogy use in naturalistic settings: the influence of audience, emotion and goals. Memory \& Cognition, 29(5), 730-735.

Blanchette, I. \& Dunbar, K. (2002). Representational change and analogy: how inferences alter target representations. Journal of Experimental Psychology: Learning, Memory and Cognition, 28(4), 672-685.

Blaney, P.H. (1986). Affect and memory: a review. Psychological Bulletin, 99(2), 229246.

Bless, H. (2001). The interplay of affect and cognition: the mediating role of general knowledge structures. In: J.P. Forgas (ed.) Feeling and thinking: the role of affect in social cognition (pp. 201-222). New York: Cambridge University Press.

Bless, H.; Schwarz, N. \& Mackie, D.M.(1992). Moods effects on attitude judgments: independent effects of mood before and after message elaboration. Journal of Personality and Social Psychology, 63(4), 585-595.

Bless, H.; Schwarz, N. \& Wieland, R. (1996). Mood and the impact of category membership and individuating information. European Journal of Social Psychology, 26(6), 935-959. 
Blessing, S.B. \& Ross, B.H. (1996). Content effects in problem categorization and problem-solving. Journal of Experimental Psychology: Learning, Memory and Cognition, 22(3), 792-810.

Bohn, A. \& Berntsen, D. (2007). Pleasantness bias in flashbulb memories: positive and negative flashbulb memories of the fall of the Berlin Wall among east and west germans. Memory \& Cognition, 35(3), 565-577.

Bower, G.H. (1981). Mood and memory. American Psychologist, 36(2), 129-148.

Bower, G.H. (1992). How might emotions affect learning? In: S.A. Christianson (ed.), The handbook of emotion and memory: research and theory (pp.3-32). Hillsdale: Lawrence Erlbaum.

Bower, G. H. \& Cohen, P.R. (1982). Emotional influences in memory and thinking: data and theory. In: M.S. Clark \& T.S. Fiske (eds.), Affect and cognition (pp.291-331). Hillsdale: Lawrence Erlbaum.

Bower, G. H. \& Forgas, J.P. (2001). Mood and social memory. In: J.P. Forgas (ed.), Handbook of affect and social cognition (pp. 95-120). Mahwah: Lawrence Erlbaum.

Bradley, B. \& Mathews, A. (1983). Negative self-schemata in clinical depression. British Journal of Clinical Psychology, 22(3), 173-181.

Brand, S. \& Opwis, K. (2007). Effects of mood and problem solving in dyads on transfer. Swiss Journal of Psychology, 66(1), 51-65.

Brand, S.; Reimer, T. \& Opwis, K. (2007). How do we learn in a negative mood? Effects of a negative mood on transfer and learning. Learning and Instruction, 17(1), p.1-16.

Bruner, J. (1997). Atos de significação. Porto Alegre: Artes Médicas.

Bruner, J.; Goodnow, J.J. \& Austin, G.A. (1956). A study of thinking. New York: John Wiley.

Bussab, V. S. R.; Pedrosa, M. I. \& Carvalho, A. M. A. (2007). Encontros com o outro: empatia e intersubjetividade no primeiro ano de vida. Psicologia USP, 18(2), 99-13.

Butterworth, G. (1993). Context and cognition in models of cognitive growth. In: P. Light \& G. Butterworth (eds.), Context and cognition: ways of learning and knowing (pp.1-13). Hillsdale: Lawrence Erlbaum. (original publicado em 1992)

Buyer, L. S. \& Dominowski, R.L. (1989). Retention of solution: it is better to give than to receive. The American Journal of Psychology, 102(3), 353-363.

Byrne, D. \& Clore, G.L. (1970). A reinforcement model of evaluation responses. Personality: An International Journal, 1, 103-128, 1970. 
Cacioppo, J.T.; Klein, D.J.; Berntson, G.G. \& Hatfield, E. (1993). The psychophysiology of emotion. In: M. Lewis \& J.M. Haviland-Jones (eds.), Handbook of emotions (pp. 119-142). New York: Guilford Press.

Cagnin, S. (2008). Algumas contribuições das Neurociências para o estudo da relação entre o afeto e a cognição. Revista Estudos e Pesquisas em Psicologia, 8(2), 463-492.

Carraher, T.N.; Carraher, D.W. \& Schliemann, A.L.D. (1982). Na vida, dez, na escola, zero: os contextos culturais da educação matemática. Cadernos de Pesquisa, 42, 79-86

Carraher, T.N.; Carraher, D.W. \& Schliemann, A.L.D. (1985). Mathematics in the streets and in schools. British Journal of Developmental Psychology, 3(1), 21-29.

Catrambone, R. (2002). The effects of surface and structural feature matches on access of story analogs. Journal of Experimental Psychology: Learning, Memory, and Cognition, 28 (2), 318-334.

Catrambone, R. \& Holyoak, K.J. (1989). Overcoming contextual limitations on problem-solving transfer. Journal of Experimental Psychology: Learning, Memory and Cognition, 15 (6), 1147-1156.

Chase, W.G. \& Simon., H.A. (1973). Perception in chess. Cognitive Psychology, 4(1), 55-81.

Chen, Z. (1996). Children's analogical problem solving: effects of superficial, structural, and procedural similarity. Journal of Experimental Child Psychology, 62(3), 410-431.

Chen, Z. (2002). Analogical problem solving: a hierarchical analysis of procedural similarity. Journal of Experimental Psychology: Learning, Memory, and Cognition, 28(1), 81-98

Chen, Z. (2004). Have the memory of an elephant: long-term retrieval and the use of analogues in problem solving. Journal of Experimental Psychology: General, 133 (3), 415-433.

Chen, Z. \& Mo, L. (2004). Schema induction in problem solving: a multidimensional analysis. Journal of Experimental Psychology: Learning, Memory, and Cognition, 30(3), 583-600.

Cheng, P. W. \& Holyoak, K.J. (1985). Pragmatic reasoning schemas. Cognitive Psychology, 17(4), 391-416.

Cheng, P.W.; Holyoak, K.J.; Nisbett, R.E. \& Oliver, L.M. (1986)- Pragmatic versus syntactic approaches to training deductive reasoning. Cognitive Psychology, 18(3), 293328.

Chi, M.T.H.; Bassok, M.; Lewis, M.W.; Reimann, P. \& Glaser, R. (1989). Selfexplanations: how students use examples in learning to solve problems. Cognitive Science, 13(2), 145-182. 
Chi, M.T.H. \& Ceci, S.J. (1987). Content knowledge: its role, representation, and restructuring in memory development. Advances in Child Development and Behavioral, 20, 91-142.

Chi, M.T.H.; Feltovich, P. \& Glaser, R. (1981). Categorization and representation of physics problems by experts and novices. Cognitive Science, 5(2), 121-152.

Chi, M.T.H. \& Glaser, R. (1992). A capacidade para a solução de problemas. In: R. J. Sternberg (ed.), As capacidades intelectuais humanas (pp.250-275). Porto Alegre: Artes Médicas.

Cho, S.; Holyoak, K.J. \& Cannon, T.D.(2007). Analogical reasoning in working memory: resources shared among relational integration, interference resolution, and maintenance. Memory \& Cognition, 35(6), 1445-1455.

Christensen, B.T. \& Schunn, C.D. (2007). The relationship of analogical distance to analogical function and preinventive structure: the case of engineering design. Memory \& Cognition, 35(1), 29-38.

Chronicle, E.P.; Ormerod, T.C. \& Mac Gregor, J.N. (2004). What makes an insight problem? The roles of heuristics, goal conception, and solution recoding in knowledgelean problems. Journal of Experimental Psychology: Learning, Memory, and Cognition, 30(1), 14-27.

Clark, D. M. \& Teasdale, J. D. (1985).Constraints on the effects of mood on memory. Journal of Personality and Social Psychology, 48(6), 1595-1608.

Clement, C.A.; Mawby, R. \& Giles, D.E. (1994). The effects of manifest relational similarity on analog retrieval. Journal of Memory and Language, 33(3), 396-420.

Clore, G.L.; Gasper, U.C. \& Garvin, E. (2001). Affect as information. In: J.P. Forgas (ed.), Handbook of affect and social cognition (pp.121-144). Mahwah: Lawrence Erlbaum.

Clore, G.L; Schwarz, N. \& Conway, M. (1994). Affective causes and consequences of social information processing. In: R.S. Wyer \& T.K. Srull (eds.), Handbook of social cognition ( $2^{\text {a }}$ ed., vol. 1, pp.323-418). Hillsdale: Lawrence Erlbaum.

Clore, G.L. \& Huntsinger, J.R. (2007). How emotions inform judgment and regulate thought. Trends in Cognitive Sciences, 11(9): 393-399.

Cohen, N.J. \& Squire, L.(1980). Preserved learning and retention of pattern-analysing skill in amnesia: dissociation of knowing how and knowing that. Science, 210 (4466), 201-210.

Cole, M. (1996). Cultural psychology: a once and future discipline. Cambridge: Harvard University Press. 
Collins, K. A.; Pillemer, D.B.; Z. Ivcevic, Z. \& Gooze, R.A. (2007). Cultural scripts guide recall of intensely positive life events. Memory \& Cognition, 35(4), 651-659.

Coricelli, G.; Dolan, R.J. \& Sirigu, A. (2007). Brain, emotion and decision making: the paradigmatic example of the regret. Trends in Cognitive Sciences, 11(6), 258-265.

Cosmides, L (1989). The logic of social exchange: has natural selection shaped how humans reason? Studies with the Wason selection task. Cognition, 31(3), 187-276.

Cosmides, L. \& Tooby, J. (2000). Evolutionary psychology and the emotions. In: M. Lewis \& J. M. Haviland-Jones (eds.), Handbook of emotions ( ${ }^{\mathrm{a}} \mathrm{ed}$. pp.91-115). New York: Guilford.

Craik, F.I.M. \& Tulving, E. (1975). Depth of processing and the retention of words in episodic memory. Journal of Experimental Psychology: General, 104(3), 268-294.

Cummins, D.D. (1992). Role of analogical reasoning in the induction of problem categories. Journal of Experimental Psychology: Learning, Memory, and Cognition, 18(5), 1103-1124.

Curran, L.H. (2007). The quest for mood dependent memory continues: mood congruence facilitates recall of autobiographical memories. A Thesis submitted to the Department of Psychology in partial fulfillment of the requirements for Honors in the Major. The Florida State University College of Arts \& Sciences, Florida.

Custers, R. \& Aarts, R. (2005). Positive affect as implicit motivation on the non conscious operation of behavioral goals. Journal of Personality and Social Psychology, 89(2), 129-142.

Dai, D.Y. \& Sternberg, R.J. (2004). Beyond cognitivism: toward an integrated understanding of intellectual functioning and development. In: D.Y. Dai \& R.J. Sternberg (eds.), Motivation, emotion, and cognition. Integrative perspectives on intellectual functioning and development (pp. 3-38). Mahwah: Lawrence Erlbaum.

Damásio, A. R. (1994).O erro de Descartes. Emoção, razão e cérebro humano. São Paulo: Cia das Letras.

Damásio, A. R. (1996). The somatic marker hypothesis and the possible functions and the prefrontal cortex. Philosophical Transactions of the Royal Society of London, 35, 1413-1420.

Damásio, A. R. (2000). O mistério da consciência. São Paulo: Cia das Letras.

Damásio, A. R. (2004). Em busca de Espinosa. Prazer e dor nas ciências dos sentimentos. São Paulo: Cia das Letras.

D’Andrade, R.G. (1991). Cultural cognition. In: M.I. Posner (ed.), Foundations of cognitive science ( $3^{\mathrm{a}}$ ed. pp.795-830). Cambridge: MIT Press. 
Day, S.B. \& Gentner, D. (2007). Nonintencional analogical inference in text comprehension. Memory \& Cognition, 35 (1), 39-49.

De Groot, A.D. (1966). Perception and memory versus thought: some old ideas and recent findings. In: B. Kleinmuntz (ed.), Problem solving: research, method and theory (pp.19-50). New York: John Wiley.

Dellarosa, D. (1991). A history of thinking. In: R.J. Sternberg \& E.E. Smith (eds.), The psychology of human thought ( $3^{\mathrm{a} e d .}$. pp.1-18). Cambridge: Cambridge University Press.

Dreisbach, G. \& Goschke, T. (2004). How positive affect modulates cognitive control: reduced perseveration at the cost of increased distractibility. Journal of Experimental Psychology: Learning, Memory, and Cognition, 30 (2), 343-353.

Dias, M.G.B.B. (1988). A compreensão de silogismos em crianças. Psicologia: Teoria e Pesquisa, 4(2), 156-169.

Dias, M.G.B.B. (2000). Raciocínio lógico, experiência escolar e leitura com compreensão. Psicologia: Teoria e Pesquisa, 16(1), 55-62.

Dias, M.G.B.B. \& Harris, P.L. (1996). Imaginando e raciocinando dedutivamente: um estudo entre crianças. Arquivos Brasileiros de Psicologia, 48(1), 82-98.

Dias, M.G.B.B.; Roazzi, A. \& Harris, P.L. (2005). Reasoning from unfamiliar premises: a study with unschooled adults. Psychological Science, 16 (7), 550-554.

Dinsmore, J. (1992). Thunder the gap. In: J. Dinsmore (ed.), The symbolic and connectionist paradigms: closing the gap (pp.1-23). Hillsdale: Lawrence Erlbaum.

Dominowski, R.L. (1990). Problem solving and metacognition. In: K.J. Gilhooly, M.T.G. Keane, R.H. Logie \& G. Erdos, (eds.), Lines of thinking: reflections on the psychology of thought.Vol2: skills, emotion, creative processes, individual difference and teaching thinking (pp.313-328). Chichester: John Wiley.

Dominowski, R.L. \& Dallob, P. (1996). Insight and problem solving. In: R.J. Sternberg \& J. E. Davidson (eds.), The nature of insight (pp.33-62). Cambridge: MIT Press.

Dunbar, G.C. \& Lishman, W.A. (1984). Depression, recognition -memory and hedonic tone: a signal detection analysis. British Journal of Psychiatry, 144(4), 376-382.

Dunbar, K. (2001). The analogical paradox: why analogy is so easy in naturalistic settings yet so difficult in the psychological laboratory. In: D. Gentner; K.J. Holyoak \& B.N.Kokinov (eds.), The analogical mind: perspectives from cognitive science (pp.313334). Cambridge: The MIT Press.

Dunbar, K. \& Blanchette, I. (2001). The in vivo/in vitro approach to cognition: the case of analogy. Trends in Cognitive Sciences, 5(8), 334-339.

Duncker, K. (1945). On problem solving. Psychological monographs, 58 (5, whole $\mathrm{n}^{\circ}$ 270) (original publicado em 1935). 
Dunn, J.R. \& Schweitzer, M.E. (2005). Feeling and believing: the influence of emotion on trust. Journal of Personality and Social Psychology, 88(5), 736-748.

Eich; J.E. (1980). The cue-dependent nature of state-dependent retrieval. Memory \& Cognition, 8(2), 157-173.

Eich, E. \& Macaulay, D. (2001). Fundamental factors in mood-dependent memory. In: J.P. Forgas (ed.), Feeling and thinking: the role of affect in social cognition (pp.109130). New York : Cambridge University Press.

Escarabajal, M. C. \& Richard, J. F. (1986). Le transfert analogique de procédures dans l'interprétation et la resolution d'un problème d'inclusion de classes chez des adultes. Archives de Psychologie, 54, 39-64.

Evans, J. St. B.T. (1989). Bias in human reasoning: causes and consequences. Hillsdale: Lawrence Erlbaum.

Eysenck, M.W. (1979). Depth, elaboration, and distinctiveness. In: L.S. Cermak \& F.I.M. Craik (eds.), Levels of processing in human memory (pp.89-118). Hillsdale: Lawrence Erlbaum.

Fazio, R.H.; Sanbonmatsu, D.M.; Powell, M.C. \& Kardes, F.R. (1986). On the automatic activation of attitudes. Journal of Personality and Social Psychology, 50(2), 229-238.

Ferreira, A.B.H. (1999). Novo Aurélio século XXI: o dicionário da língua portuguesa. (3a ed. rev. e ampl.). Rio de Janeiro: Nova Fronteira.

Feshbach, S. \& Singer, R.D. (1957). The effects of fear arousal and suppression of fear upon social perception. Journal of Abnormal and Social Psychology, 55, 283-288.

Fiddick, C.; Cosmides, L. \& Tooby, J. (2000). No interpretation without representation: the role of domain-specific representations and inferences in the Wason selection task. Cognition, 77(1), 1-79.

Fodor, J.A. \& Pylyshyn, Z. (1988). Connectionism and cognitive architecture: a critical analysis. Cognition, 28(1-2), 3-71.

Fong, G.T. \& Nisbett, R.E. (1991). Immediate and delayed transfer of training effects in statistical reasoning. Journal of Experimental Psychology: General, 120(1), 34-45.

Forbus, K. D.; Gentner, D. \& Law, K. (1995). MAC/FAC: a model of similarity-based retrieval. Cognitive Science, 19(2), 141-205.

Forgas, J.P. (1995). Mood and Judgment: the affect infusion model (AIM). Psychological Bulletin, 117(1), 39-66.

Forgas, J.P. (1998). On feeling good and getting way: mood on negotiator cognition and bargaining strategies. Journal of Personality and Social Psychology, 74(3), 565-577. 
Forgas, J.P. (2001a). Introduction: the role of affect in social cognition. In: J.P. Forgas (ed.), Feeling and thinking: the role of affect in social cognition (pp.1-28). New York: Cambridge University Press.

Forgas, J.P. (2001 b). Feeling and thinking: Summary and integration. In: J.P. Forgas (ed.), Feeling and thinking: the role of affect in social cognition (pp. 387-406). New York: Cambridge University Press.

Forgas, J.P. (2001c). Affect and information processing strategies: an interactive relationship. In: J.P. Forgas (ed.), Feeling and thinking: the role of affect in social cognition (pp. 253-280). New York: Cambridge University Press.

Forgas, J.P. (2001d). Introduction: affect and social cognition. In: J.P. Forgas (ed.), Handbook of affect and social cognition (pp.1-24). Mahwah: Lawrence Erlbaum.

Forgas, J.P. (2001e). Affect, cognition, and interpersonal behavior: the mediating role of processing strategies. In: J.P. Forgas (ed.), Handbook of affect and social cognition (pp. 293-318). Mahwah: Lawrence Erlbaum.

Forgas, J.P. \& Bower, G.H. (1987). Moods effects on person-perception judgments. Journal of Personality and Social Psychology, 53 (1), 53-60.

Forgas, J.P.; Bower, G. H. \& Krantz, S. (1984). The influence of mood on perception of social interactions. Journal of Experimental Social Psychology, 20(6), 497-513.

Fredrickson, B.L. (2001). The role of positive emotions in positive psychology: the broaden-and-build theory of positive emotions. American Psychologist, 56(3), 218-226.

Fredrickson, B.L. \& Losada, M.F. (2005). Positive affect and the complex dynamics of human flourishing. American Psychologist, 60 (7), 678-686.

Friedman, R.S. \& Foster, J. (2000). The effects of approach and avoidance motor actions on the elements of creative insight. Journal of Personality and Social Psychology, 79(4), 477-492.

Gentner, D. \& Gentner, D.R. (1983). Flowing waters or teeming crowds: mental models of electricity. In: D. Gentner, \& A.L. Stevens (eds.), Mental models (pp. 99-129). Hillsdale: Lawrence Erlbaum.

Gentner, D. \& Markmann, A.B. (1997). Structure mapping in analogy and similarity. American Psychologist, 52 (1), 45-56.

Gentner, D.; Ratterman, M. J. \& Forbus, K.D. (1993). The roles of similarity in transfer: separating retrievability from inferential soundness. Cognitive Psychology, 25(4), 524-575.

Gentner, D. \& Toupin, C. (1986). Systemacity and surface similarity in the development of analogy. Cognitive Science, 10(3), 277-300. 
Gerrards-Hesse, A.; Spies, K. \& Hesse, F.W. (1994). Experimental inductions of emotional states and their effectiveness: a review. British, Journal of Psychology, 85(1), 55-78.

Gick, M.L. (1985). The effect of a diagram retrieval cue on spontaneous transfer analogical transfer. Canadian Journal f Experimental Psychology, 39 (3), 460-466.

Gick, M.L. (1990). Transfer in insight problems: the effects of different types of similarity. In: J.J. Gilhooly; M.T.G. Keane; R.H. Logie \& G.Erdos (eds.), Lines of thinking: reflections on the psychology of thought. Vol. 1: representation, reasoning, analogy and decision making (pp. 251-265). Chichester: John Wiley.

Gick, M.L. (1992). Inducing analogous solution failures to a source problem produces later successes in analogical transfer. Journal of Experimental Psychology: Learning, Memory, and Cognition, 18 (3), 623-639.

Gick, M.L. \& Holyoak, K.J. (1980). Analogical problem solving transfer. Cognitive Psychology, 12(3), 306-355.

Gick, M.L. \& Holyoak, K.J. (1983). Schema induction and analogical transfer. Cognitive Psychology, 15(1), 1-38.

Girotto, V. \& Light, P. (1993). The pragmatic bases of children's reasoning. In: P. Light \& G. Butterworth (eds.), Context and cognition: ways of learning and knowing (pp. 134-156). Hillsdale: Lawrence Erlbaum. (original publicado em 1992).

Goodnow, J.F. \& Warton, P. (1993). Contexts and cognitions: Taking a plurarist view. In: P. Light \& G. Butterworth (eds.), Context and cognition: ways of learning and knowing (pp.157-177). Hillsdale: Lawrence Erlbaum. (original publicado em 1992).

Goldstone, R.L. \& Son, J.Y. (2005). Similarity. In: K.J. Holyoak \& R.G. Morrison (eds.), The Cambridge handbook of thinking and reasoning (pp. 13-36). Cambridge: Cambridge University Press.

Goswami, U. (1995). Transitive relational mappings in 3-and 4-years-olds: the analogy of Goldilocks and the Three Bears. Child Development, 66(3), 877-892.

Goswami, U. (2001). Analogical reason in children. In: D. Gentner; K.J. Holyoak \& B.N.Kokinov (eds.), The analogical mind: perspectives from cognitive sciences (pp. 437-470). Cambridge: The MIT Press.

Gouaux, C. (1971). Induced affective states and interpersonal attraction. Journal of Personality and Social Psychology, 20(1), 37-43.

Grant, E.R. \& Spivey, M.J. (2003). Eye movements and problem solving. Psychological Science, 11 (4), 462-466.

Greeno, J.G. (1974). Hobbits and orcs: acquisition of a sequential concept. Cognitive Psychology, 6(2), 270-292. 
Griffitt, W. (1970). Environmental effects on interpersonal behavior: ambient effective temperature and attraction. Journal of Personality and Social Psychology, 15(3), 240244.

Hadley, C.B. \& Mackay, D.G. (2006). Does emotion help or hinder immediate memory? Arousal versus priority-binding mechanisms. Journal of Experimental Psychology: Learning, Memory, and Cognition, 32 (1), 79-88.

Halberstadt, J.B \& Niedenthal, P.M. (1997). Emotional state and the use of stimulus dimensions in judgment. Journal of Personality and Social Psychology, 72(5), 10171033.

Hamman, S. (2001). Cognitive and neural mechanisms of emotional memory. Trends in Cognitive Sciences, 5(9), 394-400.

Helfenstein, S. \& Saariluoma, P. (2006). Mental contents in transfer. Psychological Research, 70(4), 293-303.

Hesse, F.W.; Kauer, G. \& Spies, K. (1997). Effects of emotion-related surface similarity in analogical problem solving. American Journal of Psychology, 110(3), 357383.

Hesse, F.W. \& Klecha, D. (1990). Use of analogies in problem solving. Computers in Human Behavior, 6(1), 115-129.

Heydenbluth, C. \& Hesse, F.W. (1996). Impact of superficial similarities in the application phase of analogical problem solving. American Journal of Psychology, 109(1), 37-57.

Holyoak, K.J. (1990). Problem solving. In: D.N. Osherson \& E.E. Smith, (eds.), An invitation to cognitive science: thinking (vol. 3, pp. 116-146). Cambridge: MIT Press.

Holyoak, K.J. (2005). Analogy. In: K.J. Holyoak \& R.G. Morrison (eds.), The Cambridge handbook of thinking and reasoning (pp.117-142). Cambridge: Cambridge University Press.

Holyoak, K.J. \& Hummel, J.E. (2001). Toward an understanding of analogy within a biological system. In: D. Gentner; K.J. Holyoak \& B.N. Kokinov (eds.), The analogical mind: perspectives from cognitive sciences (pp.161-195). Cambridge: The MIT Press.

Holyoak, K.J. \& Koh, K. (1987). Surface and structural similarity in analogical transfer. Memory \& Cognition, 15(4), 332-340.

Holyoak, K.J. \& Thagard, P. (1989). Analogical mapping by constraint satisfaction. Cognitive Science, 13(3), 295-355.

Holyoak, K.J. \& Thagard, P. (1997). The analogical mind. American Psychologist, 52 (1), 35-44. 
Houaiss, A. \& Villar, M.S. (2001). Dicionário Houaiss da língua portuguesa. Rio de Janeiro: Objetiva.

Hummel, J.E. \& Holyoak, K.J. (1997). Distributed representations of structure: a theory of analogical access and mapping. Psychological Review, 104(3), 427-466.

Hummel, J.E. \& Holyoak, K.J. (2003).A symbolic-connectionist theory of relational inference and generalization. Psychological Review, 110(2), 220-264.

Innes-Ker, A. \& Niedenthal, P.M. (2002). Emotion concepts and emotional states in social judgment and categorization. Journal of Personality and Social Psychology, 83(4), 804-816.

Isen, A.M. \& Daubman, K.A. (1984). The influence of affect in categorization. Journal of Personality and Social Psychology, 47 (6), 1206-1217.

Isen, A. M.; Daubman, K. A. \& Nowicki, G.P. (1987). Positive affect facilitates creative problem solving. Journal of Personality and Social Psychology, 52(6), 1122-1131.

Isen, A.M.; Shalker, T.E.; Clark, M. \& Karp, L. (1978). Affect, accessibility of material in memory, and behavior: a cognitive loop? Journal of Personality and Social Psychology, 36(1), 1-12.

Ito, T. A. \& Cacioppo, J.T. (2001). Affect and attitudes: a social neuroscience approach. In: J.P. Forgas (ed.), Handbook of affect and social cognition (pp. 50-74). Mahwah: Lawrence Erlbaum.

Izard, C.E. (1964). The effect of role-played emotion on affective reactions, intellectual functioning and evaluative ratings of the actress. Journal of Clinical Psychology, 20, 444-446.

Jacoby, J. L. \& Craik, F.I.M. (1979).Effects of processing at encoding and retrieval: trace distinctiveness and recovery of initial context. In: L. S. Cermak \& F.I.M. Craik (eds.), Levels of processing in human memory (pp.1-21). Hillsdale: Lawrence Erlbaum.

Jeffries, R.; Polson, P.G.; Razran, L. \& Atwood, M.E. (1977). A process model for missionaries-cannibals and others river-crossing problems. Cognitive Psychology, 9(4), 412-440.

Jonhson, E.J. \& Tversky, A. (1983). Affect, generalization, and perception of risk. Journal of Personality and Social Psychology, 45(1), 20-31.

Johnson-Laird, P. N. (1991). Mental models. In: M.I. Posner (ed.), Foundations of cognitive science ( $3^{\mathrm{a}}$ ed., pp.469-499). Cambridge: The MIT Press.

Kahneman, D. \& Tversky, A. (1972). Subjective probability: a judgment of representativeness. Cognitive Psychology, 3(3), 430-454.

Keane, M.T.; Ledgeway, T. \& Duff, S. (1994). Constraints on analogical mapping: a comparison of three models. Cognitive Science, 18(3), 387-438. 
Kenworthy, J.B.; Canales, C.J.; Weaver, K.D. \& Miller, N. (2003). Negative incidental affect and mood congruency in crossed categorization. Journal of Experimental and Social Psychology, 39 (3), 195-219.

King, L.A.; Hicks, J.A.; Krull, J.L. \& Del Gaiso, A. (2006). Positive affect and the experience of meaning in life. Journal of Personality and Social Psychology, 90(1), 179-196.

Kintsch, W. \& Van Dijk, T.A. (1978). Toward a model of text comprehension and production. Psychological Review, 85(5), 363-394.

Koechlin, E. \& Summerfield, C. (2007). An information theoretical approach to prefrontal executive functions. Trends in Cognitive Sciences, 11 (6), 229-235.

Kokinov, B.N. \& Petrov, A.A. (2001). Integrating memory and reasoning in analogymaking: the AMBR model. In: D. Gentner; K.J. Holyoak \& B.N. Kokinov (eds.), The analogical mind: perspectives from cognitive sciences (pp.59-124). Cambridge: The MIT Press.

Kotovsky, K.; Hayes, J. R. \& Simon, H. A. (1985). Why are some problems hard? Evidence from the tower of Hanoi. Cognitive Psychology, 17(2), 248-294.

Kotovsky, K. \& Simon, H.A. (1990). What makes some problems really hard? Explorations in the problem space of difficulty. Cognitive Psychology, 22(2), 143-183.

Kulkarni, D. \& Simon, H.A. (1988). The processes of cientific discovery: The strategy of experimentation. Cognitive Science, 12(2), 139-175.

Kunda, Z. (1990). The case for motivated reasoning. Psychological Bulletin, 108(3), 480-498.

Kurtz, K.J. \& Loewenstein, J. (2007). Converging on a new role for analogy in problem solving retrieval: when two problems are better than one. Memory \& Cognition, 35(2), 334-341.

Lange, T. E. (1992). Hybrid connectionist models: temporary bridges over the gap between the symbolic and the subsymbolic. In: J. Dinsmore (ed.), The symbolic and connectionist paradigms: closing the gap (pp.237-289). Hillsdale: Lawrence Erlbaum.

LeDoux, J. E. (1992). Emotion as memory: anatomical systems underlying indelible neural traces. In: S.A. Christianson (ed.), The handbook of emotion and memory: research and theory (pp..269-288). Hillsdale: Lawrence Erlbaum.

LeDoux, J. E. (1998). O cérebro emocional. Os misteriosos alicerces da vida emocional. São Paulo: Objetiva. (original publicado em 1996)

Leme, M. I. S. (2001). Revisitando a crítica de Bruner: O desvio da proposta cognitivista nos estudos de solução de problemas. Psicologia: Reflexão e Crítica, 14 (3), 521-536. 
Lesgold, A. M. (1991). Problem solving. In: R.J. Sternberg \& E. Smith (eds.), The psychology of human thought ( $3^{\mathrm{a} e d .}$. pp.188-213). Cambridge: Cambridge University Press.

Lesgold, A. \& Lajoie, S. (1991). Complex problem solving in electronics. In: R.J. Stenberg \& P.A. Frensch(eds.), Complex problem solving: principles and mechanisms (pp.287-316). Hillsdale: Lawrence Erlbaum.

Lewinsohn, P.M. \& Rosenbaum, M. (1987). Recall of parental behavior by acute depressives, remitted depressives, and nondepresssives. Journal of Personality and Social Psychology, 52 (3), 611-619.

Light, P.; Blaye, A.; Gilly, M. \& Girotto, V. (1989). Pragmatic schemas and logical reasoning in 6-to 8-year-old children. Cognitive Development, 4(1), 49-64,

Light, P.; Girotto, V.; \& Legrenzi, P. (1990). Children's reasoning on conditional promises and permissions. Cognitive Development, 5(4), 369-383.

Linnenbrink, E.A. \& Pintrich, P.R. (2004). Role of affect in cognitive processing in academic contexts. In: D.Y. Dai \& R.J. Sternberg (eds.), Motivation, emotion, and cognition: integrative perspectives on intellectual functioning and development (pp. 5787). Mahwah: Lawrence Erlbaum.

Lockhart, R.S. (1979). Remembering events: discussion of papers of Jacoby and Craik, Battig, and Nelson. In: L.S. Cermak \& F.I.M. Craik (eds), Levels of processing in human memory (pp.77-85). Hillsdale: Lawrence Erlbaum.

Loftus, E.F. (2003). Make-believe memories. American Psychologist, 58(11), 867-873.

Loftus, E.F. \& Hoffman, H. G. (1989). Misinformation and memory: The creation of memory. Journal of Experimental Psychology: General, 118(1), 100-104.

Luce, M.; Bettman, J. \& Payne, J.W. (1997). Choice processing in emotionally difficult decisions. Journal of Experimental Psychology: Learning, Memory and Cognition, 23 (2), 384-405.

Luchins, A. S. (1942). Mechanization in problem solving. Psychological Monographs, 54 (6, Serial No. 95).

Mac Lean, P.D. (1973). A triune concept of the brain and behavior. Toronto: University of Toronto Press.

Mac Lean, P.D. (1993). Cerebral evolution of the emotion. In: M. Lewis \& J.M Haviland-Jones (eds.), Handbook of emotions (pp.67-83). New York: Guilford Press.

Mackie, D.M. \& Worth, L.T. (1989). Cognitive deficits and the mediation of positive affect in persuasion. Journal of Personality and Social Psychology, 57(1), 27-40. 
Maia, T.V. \& Mc Clelland, J.L. (2005). The somatic hypothesis: Still many questions but no answers. Trends in Cognitive Sciences, 9 (4), 162-164.

Maier, N. (1931). Reasoning in humans II: The solution of a problem and its appearance in consciousness. Journal of Comparative Psychology, 12(2), 181-194.

Mandler, G. (1989). Memory: Conscious and unconscious. In: P.R. Solomon; G.R. Goethals; C.M. Kelley \& B.R. Stephens (eds.), Memory: interdisciplinary approaches (pp.84-106). New York: Springer-Verlag.

Mandler, G. (1992). Memory, arousal, and mood: A theoretical integration. In: S.A. Christianson (ed.), The handbook of emotion and memory: research and theory. (pp.93110). Hillsdale: Lawrence Erlbaum

Marino, R. (1975). Fisiologia das emoções. São Paulo: Sarvier,

Markmann, A.B. (1997). Constraints on analogical inference. Cognitive Science, 21(4), 373-428.

Marr, D. \& Poggio, T. (1977). From understanding computation to understanding neural circuitry. Neurosciences Res. Prog. Bull., 15, 470-488.

Martin, L.L. (2001). Moods do not convey information: moods in context do. In: J.P. Forgas (ed.), Feeling and thinking: the role of affect in social cognition (pp.153-177). New York: Cambridge University Press.

Martin, L.L.; Abend, T.; Sedikides, C. \& Green, J.D. (1997). How would I feel if...? Mood as input to a role fulfillment evaluation process. Journal of Personality and Social Psychology, 73 (20), 242-253.

Martin, S.A. \& Bassok, M. (2005). Effects of semantic cues on mathematical modeling: Evidence from word-problem solving and equation construction tasks. Memory \& Cognition, 33 (3), 471-478.

Mayer, R. E. (1996). The search for insight: Grappling with gestalt psychology's unanswered questions. In: R.J. Sternberg \& J.E. Davidson (eds.), The nature of insight (pp.3-62). Cambridge: MIT Press .

Mazzoni, G.A. L.; Loftus, E. F. \& Kirsch, I. (2001). Changing beliefs about implausible autobiographical events: A little plausibility goes a long way. Journal of Experimental Psychology: Applied, 7(1), 51-59.

McClelland, J.L. \& Rumelhart, D.E. (1981). An interactive activation model of context effects in letter perception: Part 1. An account of basic findings. Psychological Review, 88(5), 375-407.

Mitchell, R.L.C. \& Phillips, L.H. (2007). The psychological, neurochemical and functional neuroanatomical mediators of the effects of positive and negative mood on executive functions. Neuropsychologia, 45(4), 617-629. 
Mithen, S. (2002). A pré-história da mente: uma busca das origens da arte, da religião e da ciência. São Paulo: Editora da UNESP. (original publicado em 1996)

Moll, J. \& Oliveira-Souza, R. (2007). Moral judgments, emotions and the utilitarian brain. Trends in Cognitive Sciences, 11(8), 319-321.

Murray, H.A. (1933). The effects of fear upon estimates of the maliciousness of other personalities. Journal of Social Psychology, 4, 310-329.

Neisser, U. (1976). Psicología cognoscitiva. México: Trillas.

Nelson, D.L.; Goodmon, L.B. \& Ceo, D. (2007). How does delayed testing reduce effects of implicit memory: Context infusion or cuing with context? Memory \& Cognition, 35 (5), 1014-1023.

Newell, A.; Shaw, J. C. \& Simon, H. A. (1958). Elements of a theory of human problem solving, Psychological Review, 65(3), 151- 166.

Newell, A. \& Simon, H. A. (1972). Human problem solving. Englewood: Prentice-Hall.

Niedenthal, P. M. \& Halberstadt, J.H. (2001). Grounding categories in emotional response. In: J.P. Forgas (ed.), Feeling and thinking: the role of affect in social cognition (pp.357-386). New York: Cambridge University Press.

Nisbett, R.E. \& Wilson, T.D. (1977). Telling more than we can know: verbal reports on mental processes. Psychological Review, 84(3), 231-259.

Norman, G.; Dore, K.; Krebs, J. \& Neville, A.J. (2007). The power of plural: Effect of conceptual analogies on successful transfer. Academic Medicine, 82 (10), 16-18.

Novick, L.R. (1988). Analogical transfer, problem similarity and expertise. Journal of Experimental Psychology: Learning, Memory and Cognition, 14(3), 510-520.

Novick, L.R. \& Bassok, M. (2005). Problem solving. In: K.J. Holyoak \& R.G. Morrison (eds.), The Cambridge handbook of thinking and reasoning (pp.321-348). Cambridge: Cambridge University Press.

Novick, L. R. \& Hmelo, C.E. (1994). Transferring symbolic representations across nonisomorphic problems. Journal of Experimental Psychology. Learning, Memory and Cognition, 20 (6), 1296-1321.

Novick, L.R. \& Holyoak, K.J. (1991). Mathematical problem solving by analogy. Journal of Experimental Psychology: Learning, Memory and Cognition, 17 (3), 398415..

Ochsner, K.N. \& Phelps, E. (2007). Emerging perspectives on emotion-cognition interactions. Trends in Cognitive Sciences, 11(8), 317-318.

Oden, D.L.; Thompson, R.K.R. \& Premack, D. (2001). Can a ape reason analogically? Comprehension and production of analogical problems by Sarah, a chimpanzee (Pan 
troglodytes). In: D. Gentner; K.J. Holyoak \& B.N. Kokinov (eds.). The analogical mind: perspectives from cognitive science (pp.471-497). Cambridge: The MIT Press.

Oliva, A.D.; Otta, E.; Ribeiro, F.L.; Bussab, V.S.R.; Lopes, F.A. et al. (2006). Razão, emoção e ação em cena: A mente humana sob um olhar evolucionista. Psicologia: Teoria e Pesquisa, 22(1), 53-62.

Ormerod, T.C.; Chronicle, E.P. \& Mac Gregor, J.N. (2002). Dynamics and constraints in insight problem solving. Journal of Experimental Psychology: Learning, Memory, and Cognition, 28 (4), 791-799.

Ornstein, R. (1991). A evolução da consciência. De Darwin a Freud, a origem e os fundamentos da mente. São Paulo: Best Seller.

Osgood, C.E. (1952). The nature of measurement of meaning. Psychological Bulletin, 49(3), 197-237.

Osgood, C.E. (1955). Factor analysis of meaning. Journal of Experimental Psychology: General, 50(5), 325-338.

Otta, E. (1994). O sorriso e seus significados. Petrópolis, Vozes.

Parrot, W.G. \& Sabini, J. (1990). Mood and memory under natural conditions: Evidence for mood and incongruent recall. Journal of Personality and Social Psychology, 59(2), 321-336.

Pierce, K.A.; Crain, R.M.; Gholson, B.; Smither, D. \& Rabinowitz, F.M. (1996).The sources of errors during nonisomorphic analogical transfer: Script theory and structure mapping theory. Journal of Experimental Child Psychology, 62(1): 102-130.

Pierce, K.A. \& Gholson, B. (1994). Surface similarity and relational similarity in the development of analogical problem solving: Isomorphic and nonisomorphic transfer. Developmental Psychology, 30 (5), 724-737.

Pretz, J. E.; Naples, A. J. \& Sternberg, R. J. (2003). Recognizing, defining and representing problems. In: J. E. Davidson \& R. J. Sternberg (eds.), The psychology of problem solving (pp. 3-30). Cambridge: Cambridge University Press.

Pylyshyn, Z. (2001). Why the mind is (still) not a network. Trends in Cognitive Science, 5 (11), 499.

Ratcliff, R. (1990). Connectionist models of recognition memory: Constraints imposed by learning and forgetting functions. Psychological Review, 97 (2), 285-308.

Reed, S.K.; Dempster, A. \& Ettinger, M. (1985). Usefulness of analogous solutions for solving algebra word problems. Journal of Experimental Psychology: Learning, Memory, and Cognition, 11(1), 106-125.

Reed, S. K., Ernst, G.W. \& Banerji, R. (1974). The role of analogy in transfer between similar problem states. Cognitive Psychology, 6(3), 436-450. 
Ripoll, T.; Brude, T. \& Coulon, D. (2003). Does analogical transfer involve a term-toterm alignment? Memory and Cognition, 31(2), 221-230.

Robertson, S.I. (2001). Problem solving. East Sussex, Psychology Press.

Rorie, A. E. \& Newsome, W.T. (2005). A general mechanism for decision-making in the human brain? Trends in Cognitive Science, 9 (2), 41-43.

Ross, B. R. (1987). This is like that: The use of earlier problems and the separation of similarity effects. Journal of Experimental Psychology: Learning, Memory and Cognition, 13 (4), 629-639.

Ross, B.H. (1989). Distinguishing types of superficial similarities: Different effects on the access and use of earlier problems. Journal of Experimental Psychology: Learning, Memory and Cognition, 15(3), 456-468.

Ross, B. H. \& Kennedy, P.T. (1990). Generalizing from the use of earlier examples in problem solving. Journal of Experimental Psychology: Learning, Memory and Cognition, 16(1), 42-55.

Ross, B.H. \& Warren, J.L. (2002). Learning abstract relations from using categories. Memory and Cognition, 30(5), 657-665.

Rumelhart, D. (1991). The architecture of mind: A connectionist approach. In: M.I.Posner (ed.), Foundations of cognitive science ( $\left.3^{\mathrm{a}} \mathrm{ed} ., \mathrm{pp} .133-157\right)$. Cambridge: The MIT Press.

Rusting, C.L. (2001). Personality as a moderator of affective influences on cognition. In: J.P. Forgas (ed.), Handbook of affect and social cognition (pp. 371-391). Mahwah: Lawrence Erlbaum.

Salovey, P.; Detweiler, J.B.; Steward, W.T. \& Bedell, B.T (2001). Affect an healthrelevant cognition. In: J.P. Forgas (ed.), Handbook of affect and social cognition (pp.344-368). Mahwah: Lawrence Erlbaum.

Schacter, D.L. (1986). Effects of elaborative processing on implicit and explicit memory for new associations. Journal of Experimental Psychology: Learning, Memory and Cognition, 12 (3), 432-444.

Schacter, D.L. (1991). Memory: In: M.I. Posner (ed.), Foundations of cognitive science ( $3^{\mathrm{a}} \mathrm{d} .$, p.p. 683-725). Cambridge: The MIT Press.

Schacter, D.L.; Cooper, L. A. \& Delaney, S. (1990). Implicit memory for unfamiliar objects depends on access to structural descriptions. Journal of Experimental Psychology: General, 119 (1), 5-24.

Schank, R.C. \& Abelson, R.P. (1977). Scripts, plans, goals and understanding. Hillsdale: Lawrence Erlbaum. 
Scheerer, M. (1963). Problem-solving, Scientific American, 208 (4), 118-128.

Schliemann, A.L.D. \& Carraher, D. (1993). Proportional reasoning in and out school. In: P. Light \& G. Butterworth (eds.), Context and cognition: ways of learning and knowing (pp. 47-73), Hillsdale, Lawrence Erlbaum. (original publicado em 1992)

Schmidt, S.R. (2004). Autobiographical memories for the September 11 th. attacks: Reconstructive errors and emotional impairment of memory. Memory \& Cognition, 32 (3), 443-454.

Schoenfeld, A.Y. \& Hermann, D.J. (1982). Problem perception and knowledge structure in expert and novice mathematical problem solvers. Journal of Experimental Psychology: Learning, Memory and Cognition, 8(5), 484-494.

Schunn, C.D. \& Dunbar, K. (1996). Priming, analogy and awareness in complex reasoning. Memory \& Cognition, 24(3), 271-284.

Schwarz, N. \& Clore, G.L. (1983). Mood, misattribution, and judgments of wellbeing: Informative and directive functions of affective states. Journal of Personality and Social Psychology, 45(3), 513-523.

Schwarz, N. \& Skurnik, I. (2003). Feeling and thinking: Implications for problem solving. In: J. E. Davidson \& R. J. Sternberg (eds.), The psychology of problem solving (pp. 263-290). Cambridge: Cambridge University Press.

Scoville, W.B. \& Milner, B.G. (1957). Loss of recent memory after bilateral hippocampal lesions. Journal of Neurology, Neurosurgery, and Psychiatry, 20, 11-21.

Seidl de Moura, M.L. (2005). Dentro e fora da caixa preta: A mente sob um olhar evolucionista. Psicologia: Teoria e Pesquisa: 21(2), 141-147.

Searle, J. (1987). Mente, cérebro e ciência. Lisboa: Edições 70.

Simon, H.A. (1967). Motivational and emotional controls of cognition. Psychological Review, 74(1), p.29-39.

Simon, H. A \& Hayes, J.R. (1976). The understanding process: Problem isomorphs. Cognitive Psychology, 8(2), 165-190.

Simon, H.A. \& Kaplan, C.A. (1991). Foundations of cognitive science. In: M.I. Posner (ed.), Foundations of cognitive science ( $3^{\mathrm{a}}$ ed., pp.1-47). Cambridge: The MIT Press.

Smith, E.R. (1998). Mental representation and memory. In: D.T.Gilbert; S.T.Fiske \& G. Lindzey (eds.), The handbook of social psychology (vol. 1, 4 ed., pp. 391-445). Boston: Mac Graw Hill.

Smith, C.A. \& Kirby, L.D. (2001). Process model of emotion elicitation. In: J.P.Forgas (ed.), Feeling and Thinking: the role of affect in social cognition (pp.83-106). Cambridge: Cambridge University Press. 
Snyder, M. \& White, P. (1982). Moods and memory: Elation, depression and the remembering of the events of one' s life. Journal of Personality, 50(2), 149-167.

Spellman, B. A. \& Holyoak, K.J. (1996). Pragmatics in analogical mapping. Cognitive Psychology, 31(3), 307-346.

Spencer, R.M. \& Weisberg; R. W. (1986). Context-dependent effects on analogical transfer. Memory \& Cognition, 14(5), 442-449.

Sperber, D. \& Girotto, V. (2002). Use or misuse of the selection task? Rejoinder to Fiddick, Cosmides, and Tooby. Cognition, 85 (3), 277-290.

Stenning, K. \& Van Lambalgen, M. (2004). A little logic goes a long way: Basing experiment on semantic theory of cognitive science of conditional reasoning. Cognitive Science, 28(4), 481-529.

Sternberg, R.J. (2000). Psicologia cognitiva. Porto Alegre: Artes Médicas.

Stevenson, R. J. (1993). Language, thought and representation. Chichester: John Wiley.

Suls, J. (2001). Affect, stress, and personality. In: J.P. Forgas (ed.), Handbook of affect and social cognition (pp. 392-409). Mahwah: Lawrence Erlbaum.

Teasdale, J.D. \& Fogarty, S.J. (1979). Differential effects on induced mood on the retrieval of pleasant and unpleasant events from episodic memory. Journal of Abnormal Psychology, 88(3), 248-257.

Tiedens, L.Z. \& Linton, S. (2001). Judgment under emotional certainly and uncertainly: The effects of specifics emotions on information processing. Journal of Personality and Social Psychology, 81 (6), 973-988.

Tobias, B.A.; Kihlstrom, J.F. \& Schacter, D.L. (1992). Emotion and implicit memory. In: S.A. Christianson (ed.), The handbook of emotion and memory: research and theory (pp.67-92). Hillsdale: Lawrence Erlbaum.

Tranel, D. \& Damasio, A. R. (1988). Non-conscious face recognition in patients with face agnosia. Behavioural Brain Research, 30 (3), 235-249.

Tulving, E. (1979). Relation between encoding specificity and levels of processing. In: L.S.Cermak \& F.I.M. Craik (eds.), Levels of processing in human memory (pp. 405428). Hillsdale: Lawrence Erlbaum.

Tulving, E. \& Thomson, D.M. (1973). Encoding specificity and retrieval processes in episodic memory. Psychological Review, 80 (5), 352-373.

Tversky, A. (1977). Features of similarity. Psychological Review, 84 (4), 327-352.

Tversky, A. \& Kahneman, D. (1983). Extensional versus intuitive reasoning: The conjunction fallacy in probability judgment. Psychological Review, 90(4), 293-315. 
Urada, D.I. \& Miller, N. (2000). The impact of positive mood and category importance on crossed categorization. Journal of Personality and Social Psychology, 78(3), 417433.

Verleur, R.; Verhagen, P.W. \& Heuvelman, A. (2007). Can mood-inducing videos affect problem-solving in a web-based enviroment? British Journal of Educational Techology, 38(6), 1010-1019.

Zajonc, R.B. (1980). Feeling and thinking: preferences need no inferences. American Psychologist, 35(2), 151-175.

Zajonc, R. B. (2001). Feeling and thinking: Closing the debate over the independence of affect. In: J.P. Forgas (ed.), Feeling and thinking: the role of affect in social cognition (pp.31-58). Cambridge: Cambridge University Press.

Wagner-Egger, P. W. (2001). Costs ands benefits in Wason's selection task 1: The social conditional model. Swiss Journal of Psychology, 60 (3), 117-135.

Watkins, T.; Mathews, A.M.; Williamson, D.A. \& Fuller, R. (1992). Mood congruent memory in depression: Emotional priming and elaboration. Journal of Abnormal Psychology, 101(3), 581-586.

Wharton, C. M.; Holyoak, K. J.; Downing, P.E.; Lange, T.E.; Wickens, T.D. et al. (1994). Below the surface: Analogical similarity and retrieval competition in reminding. Cognitive Psychology, 26(1), 64-101.

Whertheimer, M. (1959). Productive thinking. Chicago: University of Chicago Press.

Wiley J. (1998). Expertise as mental set: The effects of domain knowledge in creative problem solving. Memory \& Cognition, 26(4), 716-730. 


\section{ANEXO 1: HISTÓRIAS DOS PROBLEMAS}

Cabe observar que serão aqui apresentadas: 4 histórias “fonte”, 2 histórias distrativas e 2 histórias "alvo”, revestidas com tonalidade afetiva triste ou alegre. Também serão apresentadas as histórias neutras utilizadas no estudo piloto 2 (2 histórias “fonte” neutras, 2 histórias distrativas neutras e sua respectiva história “alvo” também neutra). Sendo assim o total de 13 histórias serão apresentadas a seguir.

\section{1-PROBLEMAS “FONTE”:}

\section{1- PROBLEMA “FONTE” TRISTE 1 (modo de solução serial)}

\section{ATERRISSAGEM FORCADA}

Há pouco tempo aconteceu um episódio que deixou marcas profundas em mim e nunca mais fui o mesmo depois do que me aconteceu.

Eu estava em um momento de vida particularmente difícil, pois tinha perdido recentemente meus pais em um desastre de carro e ia morar com meus tios em uma cidade muito distante de onde tinha passado toda a minha vida. Ia deixar para trás meus amigos e a faculdade em que acabara de entrar e isso me deixava ainda mais triste.

Como estava sem dinheiro e sem emprego e meus tios eram muito pobres para me ajudar na viagem, consegui uma carona em um avião de carga em troca de trabalhar durante um mês para o dono do avião.

Quando a viagem de avião começou, eu estava exausto e sem disposição após semanas trabalhando, sem descansar, em péssimas condições. Em um determinado momento da viagem, quando estávamos sobrevoando muito alto, o avião começou a tremer todo e a fazer um barulho ensurdecedor o que deixou em pânico todas as pessoas que nele viajavam. Pensei que íamos todos morrer e uma súbita angustia se apoderou de mim e comecei a chorar compulsivamente. Estávamos em um inverno rigoroso e lá fora tudo era cinza e desolado. Uma grande tempestade estava em curso e os raios e trovões só faziam aumentar o meu pavor e sacudiam ainda mais o velho avião.

O piloto resolveu aterrissar para pedir ajuda e, após muita dificuldade, conseguiu fazê-lo em um local que parecia uma base militar e, confirmando minhas suspeitas, logo que chegou ao solo, o avião foi cercado por soldados que nos encararam com pesadas 
armas apontadas em nossa direção. Pensei: Meu Deus! Acho que agora não vou conseguir sair dessa situação, estou em um beco sem saída. Aqueles homens, com o rosto parcialmente coberto, pareciam terroristas e não tinham nada a perder se nos matassem. Tive muito medo do que poderia nos acontecer e fiquei paralisado, sem me mexer na minha poltrona.

O piloto, após uns minutos de hesitação, desceu do avião e foi pedir ajuda àqueles soldados. Após ter sido revistado e humilhado pelo chefe daquele exército, o piloto nos disse que eles até poderiam nos ajudar a consertar o avião, mas que só fariam isso se o avião levasse, em troca, um carregamento de metralhadoras para um grupo de soldados que estava em uma base militar de um país vizinho. Como não tinha outra escolha, o piloto concordou com isso.

Enquanto nós esperávamos o avião ser levado para um local que parecia uma grande oficina, vários soldados continuaram a apontar seus fuzis para as nossas cabeças. O piloto nos contou que, enfim, descobriram qual o problema do avião: tratava-se de um problema no sistema de controle da altitude do avião.

Após procurar bastante a causa do problema, os técnicos da oficina verificaram, através de um visor, que um dos transistores do sistema de controle da altitude estava recoberto de mofo. Como este transistor estava situado no centro de um compartimento lacrado, não poderia haver uma manipulação direta do mesmo, ou seja, o compartimento não poderia ser aberto para a limpeza do mofo.

Os técnicos resolveram, então, utilizar o calor emitido por raios infravermelhos para a eliminação do mofo no transistor, porém para que o mofo fosse totalmente eliminado, havia a necessidade de uma alta intensidade de radiação. Mas havia um problema com o qual os técnicos se depararam: como as paredes do compartimento, onde se situava este transistor, eram recobertas internamente por uma frágil película, uma alta intensidade de radiação incidida sobre ela poderia danificá-la, o que deveria ser evitado.

Após se perguntar como conseguiriam aumentar a intensidade da radiação infravermelha sobre o transistor, sem danificar a película, os técnicos chegaram a uma solução.

A solução encontrada foi a de lançar feixes de raios infravermelhos, de baixa intensidade, emitidos uns após os outros, em série, que foram focalizados e incididos na parte mofada do transistor, a intervalos de tempo que permitiam a absorção e o acúmulo de calor no transistor, eliminando assim o mofo de modo gradual e continuo, sem que a película fosse danificada. 
Essa solução se mostrou eficaz e logo que o conserto ficou pronto, os soldados nos empurraram para dentro do avião e três deles entraram conosco para nos vigiar e, com as armas apontadas para as nossas cabeças, pretendo matar-nos, caso não cumpríssemos o acordo, forçaram-nos a levá-los, junto com o armamento.

Quando chegamos na base militar para onde nos forçaram a ir, fomos presos e ficamos semanas em um campo de prisioneiros, onde passamos todo o tipo de privação. Sentimos frio, fome e fomos maltratados. Sofremos horrores que gostaríamos de esquecer.

Quando me lembro de tudo que passei não sei como consegui sobreviver. Com freqüência acordo durante a noite suando frio e com terríveis pesadelos. Até hoje ainda guardo as cicatrizes físicas e psicológicas desta experiência tão angustiante.

\section{2- PROBLEMA “FONTE” TRISTE 2 (modo de solução convergente)}

\section{ATERRISSAGEM FORCADA}

Há pouco tempo aconteceu um episódio que deixou marcas profundas em mim e nunca mais fui o mesmo depois do que me aconteceu.

Eu estava em um momento de vida particularmente difícil, pois tinha perdido recentemente meus pais em um desastre de carro e ia morar com meus tios em uma cidade muito distante de onde tinha passado toda a minha vida. Ia deixar para trás meus amigos e a faculdade em que acabara de entrar e isso me deixava ainda mais triste.

Como estava sem dinheiro e sem emprego e meus tios eram muito pobres para me ajudar na viagem, consegui uma carona em um avião de carga em troca de trabalhar durante um mês para o dono do avião.

Quando a viagem de avião começou, eu estava exausto e sem disposição após semanas trabalhando, sem descansar, em péssimas condições. Em um determinado momento da viagem, quando estávamos sobrevoando muito alto, o avião começou a tremer todo e a fazer um barulho ensurdecedor o que deixou em pânico todas as pessoas que nele viajavam. Pensei que íamos todos morrer e uma súbita angustia se apoderou de mim e comecei a chorar compulsivamente. Estávamos em um inverno rigoroso e lá fora tudo era cinza e desolado. Uma grande tempestade estava em curso e os raios e trovões só faziam aumentar o meu pavor e sacudiam ainda mais o velho avião. 
O piloto resolveu aterrissar para pedir ajuda e, após muita dificuldade, conseguiu fazê-lo em um local que parecia uma base militar e, confirmando minhas suspeitas, logo que chegou ao solo, o avião foi cercado por soldados que nos encararam com pesadas armas apontadas em nossa direção. Pensei: Meu Deus! Acho que agora não vou conseguir sair dessa situação, estou em um beco sem saída. Aqueles homens, com o rosto parcialmente coberto, pareciam terroristas e não tinham nada a perder se nos matassem. Tive muito medo do que poderia nos acontecer e fiquei paralisado, sem me mexer na minha poltrona.

O piloto, após uns minutos de hesitação, desceu do avião e foi pedir ajuda àqueles soldados. Após ter sido revistado e humilhado pelo chefe daquele exército, o piloto nos disse que eles até poderiam nos ajudar a consertar o avião, mas que só fariam isso se o avião levasse, em troca, um carregamento de metralhadoras para um grupo de soldados que estava em uma base militar de um país vizinho. Como não tinha outra escolha, o piloto concordou com isso.

Enquanto nós esperávamos o avião ser levado para um local que parecia uma grande oficina, vários soldados continuaram a apontar seus fuzis para as nossas cabeças. O piloto nos contou que, enfim, descobriram qual o problema do avião: tratava-se de um problema no sistema de controle da altitude do avião.

Após procurar bastante a causa do problema, os técnicos da oficina verificaram, através de um visor, que um dos transistores do sistema de controle da altitude estava recoberto de mofo. Como este transistor estava situado no centro de um compartimento lacrado, não poderia haver uma manipulação direta do mesmo, ou seja, o compartimento não poderia ser aberto para a limpeza do mofo.

Os técnicos resolveram então utilizar o calor emitido por raios infravermelhos para a eliminação do mofo no transistor, porém para que o mofo fosse totalmente eliminado, havia a necessidade de uma alta intensidade de radiação. Mas havia um problema com o qual os técnicos se depararam: como as paredes do compartimento, onde se situava este transistor, eram recobertas internamente por uma frágil película, uma alta intensidade de radiação incidida sobre ela poderia danificá-la, o que deveria ser evitado.

Após se perguntar como conseguiriam aumentar a intensidade da radiação infravermelha sobre o transistor, sem danificar a película, os técnicos chegaram a uma solução.

A solução encontrada foi a de lançar feixes de raios infravermelhos, de baixa intensidade, emitidos de diferentes fontes de emissão, cada uma delas situada em um 
ponto diferente, e que foram focalizadas para convergir, todas ao mesmo tempo, sobre o transistor mofado, de modo que pelo somatório de sua radiação, pudessem eliminar o mofo, sem que a película fosse danificada.

Essa solução se mostrou eficaz e logo que o conserto ficou pronto, os soldados nos empurraram para dentro do avião e três deles entraram conosco para nos vigiar e, com as armas apontadas para as nossas cabeças, pretendo matar-nos, caso não cumpríssemos o acordo, forçaram-nos a levá-los junto com o armamento

Quando chegamos na base militar para onde nos forçaram a ir, fomos presos e ficamos semanas em um campo de prisioneiros, onde passamos todo o tipo de privação. Sentimos frio, fome e fomos maltratados. Sofremos horrores que gostaríamos de esquecer.

Quando me lembro de tudo que passei não sei como consegui sobreviver. Com freqüência acordo durante a noite suando frio e com terríveis pesadelos.Até hoje ainda guardo as cicatrizes físicas e psicológicas desta experiência tão angustiante.

\section{3- PROBLEMA “FONTE” ALEGRE 1 (modo de solução serial)}

\section{CRUZEIRO DE SONHO}

Ontem eu estava conversando com uns amigos numa festa e lembrávamos de coisas alegres e engraçadas que nos acontecem na vida. Rimos muito de tudo e recordamos de tudo de bom que nos tinha acontecido nos últimos tempos.

Estava contando a todo mundo uma magnífica viagem de navio que eu tinha feito no ano passado. Era um navio muito luxuoso, com todo tipo de lazer que alguém possa imaginar. Os dias estavam lindos e ensolarados e pudemos tomar muitos banhos de piscina e praticar várias modalidades de esporte. Fomos a boates, a cinemas, a restaurantes com comidas deliciosas e tivemos muita animação dia e noite.

Eu fiz esse cruzeiro marítimo com uma turma de amigos. Como eu havia passado no vestibular muito bem colocado, meus pais, que têm uma boa situação financeira, me deram essa viagem de presente. Aliás, meus pais me apóiam sempre em tudo que faço e formam um casal muito feliz e dinâmico. Eu estava também satisfeito porque tinha um estágio em vista em uma empresa conceituada e isso significava uma chance real de um bom emprego quando terminasse meu curso. 
Fomos todos, meus amigos e eu, comemorar juntos o fato de termos passado no vestibular nesse cruzeiro de sonho. Foi tudo tão perfeito que até nas fotos da viagem fica bem visível nossa alegria.

Durante o dia, a diversão maior era na piscina, onde participávamos de torneios e jogos dentro e fora da água. Inclusive, ganhei uma linda taça em um difícil torneio de frescobol e fui muito aplaudido pelo meu desempenho. No fim da tarde, costumávamos assistir a um filme e depois circulávamos pelo grande shopping do navio, onde costumávamos fazer compras e conversávamos com pessoas diferentes que por ali passeavam. Fizemos assim um monte de novos amigos, que se juntaram ao nosso grupo e nos acompanharam em muitas atividades.

Toda noite a gente ia jantar em um restaurante sofisticado e eu conheci vários tipos de comidas saborosas que nem imaginava existirem. Fiquei muito amigo do famoso cozinheiro do restaurante e ele acabou me dando várias receitas e me contando como preparava os alimentos e como os mesmos eram conservados no navio. Inclusive me contou que tinha havido recentemente um problema em um dos setores de conservação de alimentos, mas que, felizmente, os técnicos do setor tinham conseguido resolver.

Fiquei curioso e perguntei o que havia acontecido. Ele me disse que um contêiner que guardava alimentos muito caros tinha tido um problema em sua refrigeração e que requisitava um conserto rápido para que não houvesse um grande prejuízo com a perda da carga. Após uma avaliação inicial do que estava acontecendo, os técnicos do setor constataram, através de uma janela de vidro, que a temperatura de um dos contêineres de alimentos estava subindo, pois um filamento, que estava dentro do container e que fazia parte do seu sistema de refrigeração, estava coberto de fungo, o que ocasionava o mau funcionamento deste sistema. Havia assim a necessidade de um rápido conserto para que não houvesse a deterioração desses alimentos.

Enfim, após pensar muito, chegaram à melhor solução para este problema. A solução proposta foi o uso de raios ultravioletas (UV) para a esterilização do filamento com fungo. Os técnicos sabiam que não poderiam abrir o contêiner para manusear diretamente o filamento, pois os alimentos não poderiam ter contato com o ar. Também sabiam que havia a exigência de uma alta intensidade de raios para que essa esterilização fosse eficaz. Entretanto, sabiam que não poderiam emitir toda a radiação necessária através de uma única emissão de raios de alta intensidade, pois a alta intensidade, emitida de uma só vez, poderia danificar as paredes internas do contêiner que eram feitas de um gel protetor. 
A solução encontrada foi a de emitir raios ultravioletas, de baixa intensidade, emitidos uns após os outros, em série, que foram focalizados e incididos sobre o fungo do filamento, a intervalos de tempo que permitiam a absorção e o acúmulo de radiação neste filamento, esterilizando-o de modo gradual e continuo, sem que o gel protetor fosse danificado. Os alimentos foram assim preservados, pois o sistema de refrigeração do contêiner voltou a funcionar normalmente após este conserto.

Fiquei feliz em saber que havia tanto cuidado na conservação e no preparo dos alimentos e até me motivei em estudar um pouco esse assunto. Adoro comer comidas diferentes, especialmente com meus amigos e namorada. É claro que com ela prefiro uns jantares mais românticos e com meus amigos prefiro fazer uma farra, como essa que a gente fez no navio.

Foi uma viagem inesquecível e quero voltar a viajar sempre para ter muitas histórias para contar para meus filhos e netos. É tão bom quando a gente tem experiências alegres que nos enriquecem de imagens e de vivências tão positivas. Já marquei uma nova viagem com meus amigos de sempre. Gosto de viajar de preferência com pessoas que compartilham dos meus interesses e que gostem muito de uma boa diversão e de rir bastante.

\section{4-PROBLEMA “FONTE” ALEGRE 2 (modo de solução convergente)}

\section{CRUZEIRO DE SONHO}

Ontem eu estava conversando com uns amigos numa festa e lembrávamos de coisas alegres e engraçadas que nos acontecem na vida. Rimos muito de tudo e recordamos de tudo de bom que nos tinha acontecido nos últimos tempos.

Estava contando a todo mundo uma magnífica viagem de navio que eu tinha feito no ano passado. Era um navio muito luxuoso, com todo tipo de lazer que alguém possa imaginar. Os dias estavam lindos e ensolarados e pudemos tomar muitos banhos de piscina e praticar várias modalidades de esporte. Fomos a boates, a cinemas, a restaurantes com comidas deliciosas e tivemos muita animação dia e noite.

Eu fiz esse cruzeiro marítimo com uma turma de amigos. Como eu havia passado no vestibular muito bem colocado, meus pais, que têm uma boa situação financeira, me deram essa viagem de presente. Aliás, meus pais me apóiam sempre em tudo que faço e formam um casal muito feliz e dinâmico. Eu estava também satisfeito porque tinha um 
estágio em vista em uma empresa conceituada e isso significava uma chance real de um bom emprego quando terminasse meu curso.

Fomos todos, meus amigos e eu, comemorar juntos o fato de termos passado no vestibular nesse cruzeiro de sonho. Foi tudo tão perfeito que até nas fotos da viagem fica bem visível nossa alegria.

Durante o dia, a diversão maior era na piscina, onde participávamos de torneios e jogos dentro e fora da água. Inclusive, ganhei uma linda taça em um difícil torneio de frescobol e fui muito aplaudido pelo meu desempenho. No fim da tarde, costumávamos assistir a um filme e depois circulávamos pelo grande shopping do navio, onde costumávamos fazer compras e conversávamos com pessoas diferentes que por ali passeavam. Fizemos assim um monte de novos amigos, que se juntaram ao nosso grupo e nos acompanharam em muitas atividades.

Toda noite a gente ia jantar em um restaurante sofisticado e eu conheci vários tipos de comidas saborosas que nem imaginava existirem. Fiquei muito amigo do famoso cozinheiro do restaurante e ele acabou me dando várias receitas e me contando como preparava os alimentos e como os mesmos eram conservados no navio. Inclusive me contou que tinha havido recentemente um problema em um dos setores de conservação de alimentos, mas que, felizmente, os técnicos do setor tinham conseguido resolver.

Fiquei curioso e perguntei o que havia acontecido. Ele me disse que um contêiner que guardava alimentos muito caros tinha tido um problema em sua refrigeração e que requisitava um conserto rápido para que não houvesse um grande prejuízo com a perda da carga. Após uma avaliação inicial do que estava acontecendo, os técnicos do setor constataram, através de uma janela de vidro, que a temperatura de um dos contêineres de alimentos estava subindo, pois um filamento, que estava dentro do contêiner e que fazia parte do seu sistema de refrigeração, estava coberto de fungo, o que ocasionava o mau funcionamento deste sistema. Havia assim a necessidade de um rápido conserto para que não houvesse a deterioração desses alimentos.

Enfim, após pensar muito, chegaram à melhor solução para este problema. A solução proposta foi o uso de raios ultravioletas (UV) para a esterilização do filamento com fungo. Os técnicos sabiam que não poderiam abrir o contêiner para manusear diretamente o filamento, pois os alimentos não poderiam ter contato com o ar. Também sabiam que havia a exigência de uma alta intensidade de raios para que essa esterilização fosse eficaz. Entretanto, sabiam que não poderiam emitir toda a radiação necessária através de uma única emissão de raios de alta intensidade, pois a alta 
intensidade, emitida de uma só vez, poderia danificar as paredes internas do contêiner que eram feitas de um gel protetor.

A solução encontrada foi a de emitir raios ultravioletas, de baixa intensidade, emitidos de diferentes fontes de emissão, cada uma delas situada em um ponto diferente, e que foram focalizadas para convergir todas ao mesmo tempo, para o filamento com fungo, de modo que, pelo somatório de sua radiação, pudessem chegar a uma forte radiação e assim pudessem esterilizar o filamento, sem que fossem danificadas as paredes do contêiner. Os alimentos foram assim preservados, pois o sistema de refrigeração do contêiner voltou a funcionar normalmente após este conserto.

Fiquei feliz em saber que havia tanto cuidado na conservação e no preparo dos alimentos e até me motivei em estudar um pouco esse assunto. Adoro comer comidas diferentes, especialmente com meus amigos e namorada. É claro que com ela prefiro uns jantares mais românticos e com meus amigos prefiro fazer uma farra, como essa que a gente fez no navio.

Foi uma viagem inesquecível e quero voltar a viajar sempre para ter muitas histórias para contar para meus filhos e netos. É tão bom quando a gente tem experiências alegres que nos enriquecem de imagens e de vivências tão positivas. Já marquei uma nova viagem com meus amigos de sempre. Gosto de viajar, de preferência com pessoas que compartilham dos meus interesses e que gostem muito de uma boa diversão e de rir bastante.

\section{5-PROBLEMA “FONTE” NEUTRO 1 A (modo de solução serial)}

\section{UMA VIAGEM COM ESCALAS}

Em um aeroporto, uma equipe técnica foi chamada para resolver um problema que estava, há horas, impossibilitando um avião de decolar.

Era um avião de carga que tinha saído do México e que estava voando em direção ao Brasil, fazendo escalas em vários países da América do Sul para se abastecer de novos carregamentos em cada país em que aterrissava. Na sua escala no Chile, para se abastecer de um carregamento de vinhos, o avião não conseguiu sair do chão e por isso uma equipe especializada em conserto de aeronaves foi chamada. 
Após procurar bastante a causa do problema, os técnicos verificaram, através de um visor, que um dos transistores do sistema de controle da altitude estava recoberto de mofo. Como este transistor estava situado no centro de um compartimento lacrado, não poderia haver uma manipulação direta do mesmo ou seja, o compartimento não poderia ser aberto para a limpeza do mofo.

Os técnicos resolveram utilizar o calor emitido por raios infravermelhos para a eliminação do mofo no transistor, porém para que o mofo fosse totalmente eliminado, havia a necessidade de uma alta intensidade de radiação. Mas havia um problema com o qual os técnicos se depararam: como as paredes do compartimento onde se situava o transistor mofado eram recobertas internamente por uma frágil película, uma alta intensidade de radiação incidida sobre ela poderia danificá-la, o que deveria ser evitado.

Após se perguntar como conseguiriam aumentar a intensidade da radiação infravermelha sobre o transistor sem danificar a película, os técnicos chegaram a uma solução.

A solução encontrada foi a de lançar feixes de raios infravermelhos, de baixa intensidade, emitidos uns após os outros, em série, que foram focalizados e incididos na parte mofada do transistor, a intervalos de tempo que permitiam a absorção e o acúmulo de calor no transistor, eliminando assim o mofo de modo gradual e continuo, sem que a película fosse danificada. Esta solução se mostrou eficaz e o avião pôde assim seguir viagem sem mais problemas.

\section{6-PROBLEMA “FONTE” NEUTRO 1 B (modo de solução convergente)}

\section{UMA VIAGEM COM ESCALAS}

Em um aeroporto, uma equipe técnica foi chamada para resolver um problema que estava, há horas, impossibilitando um avião de decolar.

Era um avião de carga que tinha saído do México e que estava voando em direção ao Brasil, fazendo escalas em vários países da América do Sul para se abastecer de novos carregamentos em cada país em que aterrissava. Na sua escala no Chile, para se abastecer de um carregamento de vinhos, o avião não conseguiu sair do chão e por isso uma equipe especializada em conserto de aeronaves foi chamada.

Após procurar bastante a causa do problema, os técnicos verificaram, através de um visor, que um dos transistores do sistema de controle da altitude estava recoberto de 
mofo. Como este transistor estava situado no centro de um compartimento lacrado, não poderia haver uma manipulação direta do mesmo ou seja, o compartimento não poderia ser aberto para a limpeza do mofo.

Os técnicos resolveram utilizar o calor emitido por raios infravermelhos para a eliminação do mofo no transistor, porém para que o mofo fosse totalmente eliminado, havia a necessidade de uma alta intensidade de radiação. Mas havia um problema com o qual os técnicos se depararam: como as paredes do compartimento onde se situava o transistor mofado eram recobertas internamente por uma frágil película, uma alta intensidade de radiação incidida sobre ela poderia danificá-la, o que deveria ser evitado.

Após se perguntar como conseguiriam aumentar a intensidade da radiação infravermelha sobre o transistor sem danificar a película, os técnicos chegaram a uma solução.

A solução encontrada foi a de lançar feixes de raios infravermelhos, de baixa intensidade, emitidos de diferentes fontes de emissão, cada uma delas situada em um ponto diferente, e que foram focalizadas para convergir, todas ao mesmo tempo, sobre o transistor mofado, de modo que pelo somatório de sua radiação, pudessem eliminar o mofo, sem que a película fosse danificada. Esta solução se mostrou eficaz e o avião pôde assim seguir viagem sem mais problemas.

\section{7- PROBLEMA “FONTE” NEUTRO 2 A (modo de solução serial)}

\section{VIAGEM DE NAVIO}

Em um navio de passageiros os encarregados do setor de cargas foram convocados pelo capitão para resolverem um problema que estava ocorrendo em um contêiner que carregava alimentos.

Era um grande navio de transporte de passageiros, mas que também possuía compartimentos no porão, onde eram transportados vários contêineres que armazenavam diferentes tipos de mercadorias, inclusive alimentos perecíveis e bebidas.

Após uma avaliação inicial do que estava acontecendo, os técnicos do setor de conservação e manutenção de cargas constataram, através de uma janela de vidro, que a temperatura de um dos contêineres de alimentos estava subindo, pois um filamento que estava dentro do contêiner e que fazia parte do seu sistema de refrigeração estava 
coberto de fungo, o que ocasionava o mau funcionamento deste sistema. Havia assim a necessidade de um rápido conserto para que não houvesse a deterioração desses alimentos.

Após pensar muito, eles chegaram à melhor solução para este problema. A solução proposta foi o uso de raios ultravioletas (UV) para a esterilização do filamento com fungo. Os técnicos sabiam que não poderiam abrir o contêiner para manusear diretamente o filamento, pois os alimentos não poderiam ter contato com o ar. Também sabiam que havia a exigência de uma alta intensidade de raios para que esta esterilização fosse eficaz. Entretanto, sabiam também que não poderiam emitir toda e radiação necessária através de uma única emissão de raios da alta intensidade, pois a alta intensidade emitida de uma só vez poderia danificar as paredes internas do contêiner que eram feitas de um gel protetor.

A solução encontrada foi a de lançar feixes de raios ultravioletas, de baixa intensidade, emitidos uns após os outros, em série, que foram focalizados e incididos sobre o fungo do filamento, a intervalos de tempo que permitiam a absorção e o acúmulo de radiação no transistor, esterilizando assim o filamento de modo gradual e continuo, sem que o gel protetor fosse danificado. Os alimentos foram assim preservados, pois o sistema de refrigeração do contêiner voltou a funcionar normalmente após este conserto.

\section{8-PROBLEMA “FONTE” NEUTRO 2 B ( modo de solução convergente)}

\section{VIAGEM DE NAVIO}

Em um navio de passageiros os encarregados do setor de cargas foram convocados pelo capitão para resolverem um problema que estava ocorrendo em um contêiner que carregava alimentos.

Era um grande navio de transporte de passageiros, mas que também possuía compartimentos no porão, onde eram transportados vários contêineres que armazenavam diferentes tipos de mercadorias, inclusive alimentos perecíveis e bebidas.

Após uma avaliação inicial do que estava acontecendo, os técnicos do setor de conservação e manutenção de cargas constataram, através de uma janela de vidro, que a temperatura de um dos contêineres de alimentos estava subindo, pois um filamento que estava dentro do contêiner e que fazia parte do seu sistema de refrigeração estava 
coberto de fungo, o que ocasionava o mau funcionamento deste sistema. Havia assim a necessidade de um rápido conserto para que não houvesse a deterioração desses alimentos.

Após pensar muito, eles chegaram à melhor solução para este problema. A solução proposta foi o uso de raios ultravioletas (UV) para a esterilização do filamento com fungo. Os técnicos sabiam que não poderiam abrir o contêiner para manusear diretamente o filamento, pois os alimentos não poderiam ter contato com o ar. Também sabiam que havia a exigência de uma alta intensidade de raios para que esta esterilização fosse eficaz. Entretanto, sabiam também que não poderiam emitir toda e radiação necessária através de uma única emissão de raios da alta intensidade, pois a alta intensidade emitida de uma só vez poderia danificar as paredes internas do contêiner que eram feitas de um gel protetor.

A solução que se mostrou eficaz foi a de emitir raios ultravioletas de baixa intensidade, emitidos de diferentes fontes de emissão, cada uma delas posicionada em um ponto diferente, e que foram focalizadas para convergir, todas ao mesmo tempo, sobre o fungo do filamento, de modo que, pelo somatório de sua radiação, pudessem chegar a uma forte radiação e assim pudessem esterilizar o filamento, sem que fossem danificadas as paredes do contêiner. Os alimentos foram assim preservados, pois o sistema de refrigeração do contêiner voltou a funcionar normalmente após este conserto.

\section{2-PROBLEMAS “ALVO”}

\section{1-PROBLEMA “ALVO” TRISTE}

\section{TRISTES LEMBRANCAS}

Aquele ano de 1995 foi um ano muito difícil. Lembro-me como se fosse hoje. Logo no início do ano eu perdi meu emprego e fiquei desempregado quase o ano todo. Nossas economias foram todas gastas e os acontecimentos que vieram a seguir nos pegaram desprevenidos.

Minha mulher tinha acabado de perder nosso primeiro filho e precisou fazer um tratamento com medicamentos muito caros. Eu comecei a fazer biscates entregando jornais de bicicleta. Andava muitos quilômetros por dia e chegava em casa todo doído e bastante cansado. Eu e minha mulher estávamos muito deprimidos com a perda do 
nosso bebê e com a falta de dinheiro. Além disso, tivemos que abandonar nossa casa, pois não podíamos mais pagar o aluguel. Tivemos que vender nossos móveis e objetos e fomos morar em um quarto alugado em uma pensão bem velha e suja, mas era o que podíamos pagar. O quarto tinha as paredes imundas, uma velha e feia cama quebrada e tudo tinha um cheiro muito desagradável. Mas o pior ainda estava por vir.

Em meados de julho, minha mulher começou a sentir muitas dores nas costas e dificuldade para urinar. Vinha emagrecendo muito rapidamente, pois rejeitava a ingestão de alimentos e não tinha ânimo para nada. Levei-a então a um hospital onde tivemos que enfrentar uma enorme fila de espera e, só depois de quase um dia inteiro, fomos atendidos e conseguimos marcar uma consulta para daí a dois meses.

Neste período ela foi piorando e foi preciso um atendimento de urgência. No pronto socorro onde foi atendida, havia muita gente sendo atendida ao mesmo tempo em uma sala de paredes descascadas e cheias de infiltração, onde estavam diversas mulheres. Quando chegou a vez da minha mulher, o antipático médico que a examinou mostrou-se muito preocupado e fez um encaminhamento para internação imediata em uma enfermaria onde havia vários leitos e onde ela foi recebida por uma enfermeira agressiva.

Os exames constataram um tumor cancerígeno, de alta malignidade com uma real possibilidade de metástase, no rim esquerdo. Este rim já não estava funcionando direito, por isso minha mulher sentia tantas dores e estava tão debilitada. Um episódio muito preocupante ocorreu depois disso. O médico receitou alguns medicamentos para dor e disse à minha mulher para tomá-los com precaução e que tomasse apenas um, antes da próxima consulta. Porém, minha mulher não entendeu bem a sua recomendação e tomou vários medicamentos diferentes de uma só vez antes da consulta, o que a levou a uma grave intoxicação com conseqüente piora do seu estado de saúde. Vê-la desmaiada e passando tão mal deixou todos no hospital preocupados e eu fiquei tão aflito que não sabia o que fazer.

O médico resolveu então atacar o tumor diretamente e recomendou um tratamento a base de radiação, pois a cirurgia não era indicada neste caso.

Havia, porém, um problema com o qual o médico se deparou: o tumor necessitava ser atingido por uma alta intensidade de raios, pois uma baixa intensidade não conseguiria destruí-lo. Mas, por outro lado, a emissão de raios de alta intensidade poderia atingir os tecidos corporais sadios que envolviam o tumor e poderia danificar 
estes tecidos, o que deveria ser evitado, pois poderia piorar ainda mais o grave estado de saúde da paciente.

A seguir será pedido ao participante para responder à seguinte questão: Como você acha que o médico resolveu este problema da emissão de raios para destruir o tumor, sem danificar os tecidos corporais sadios que o envolviam? (vide o anexo $7 \mathrm{com}$ as folhas de instrução/respostas)

Lembre-se das histórias que você leu anteriormente, elas podem dar uma dica para a solução desse problema. Mas, lembre-se também que você deve escolher uma única solução para este problema, ou seja, aquela solução que vier primeiro à sua cabeça. Mas, somente após a escolha da solução por escrito, leia a pergunta da página seguinte.

Na página seguinte será pedido ao participante que justifique a sua escolha, através da seguinte instrução: “Justifique, com suas palavras, porque escolheu esta solução”.

\section{2-PROBLEMA “ALVO” ALEGRE}

\section{ALEGRES LEMBRANCAS}

O ano de 1995 foi um ano muito bom. Lembro-me como se fosse hoje. Logo no início do ano, consegui um emprego novo onde estou até hoje e com o bom salário que venho recebendo, consegui juntar dinheiro, fazer uma grande poupança e tenho estado prevenido para qualquer eventualidade que venha ocorrer.

Minha mulher tinha acabado de ganhar nosso primeiro filho e tudo correu tão bem no parto que ela nem precisou de nenhum remédio para sua recuperação. Meu patrão me deu umas semanas de folga, assim eu pude descansar um pouco e pude curtir bastante meu filho. Eu e minha mulher estávamos tão felizes com o nascimento do bebê que resolvemos morar em uma casa nova, maior e mais bonita, para que ele tivesse um ambiente bem confortável e amplo para crescer. Como tinha um bom emprego, pude comprar uma bela casa e muitos presentes para meu filho. $\mathrm{O}$ quarto do bebê tinha lindas paredes decoradas, um berço novo e bonito e tudo era bem cheiroso e limpinho. Novos acontecimentos, entretanto, ainda estavam por vir.

Em meados de julho, minha mulher foi fazer um exame médico de rotina, apesar de se sentir bem animada, com bom apetite e sem sentir nenhum tipo de dor ou queixa. Ela que sempre gozou de ótima saúde, tinha, inclusive, muito leite para o bebê e sentia-se bem disposta em suas atividades diárias. Levei-a então a um consultório médico onde 
fomos logo atendidos, pois conseguimos marcar a consulta, sem dificuldade, para o mesmo dia.

Enquanto fazia os exames de rotina, minha mulher teve à sua disposição uma sala de espera muito limpa e agradável. Era uma sala individualizada onde dispúnhamos de todo conforto possível e nem parecia que estávamos em uma situação de atendimento médico. Quando minha mulher foi atendida, o simpático médico que a examinou pediu que ela fosse encaminhada para uma sala anexa onde ela teve um atendimento individualizado e foi recebida por uma enfermeira carinhosa.

Os exames constataram um tumor benigno no rim esquerdo. Porém, os rins estavam funcionando perfeitamente, por isso minha mulher não sentia nenhum incômodo ou dor. Um episódio muito engraçado ocorreu depois disso. O médico tinha recomendado que minha mulher bebesse muito líquido, inclusive permitiu que ela bebesse uma cervejinha de vez em quando, caso ela gostasse. Disse também que quando voltasse, na próxima consulta, deveria beber muito líquido antes. Mas minha mulher entendeu errado seu conselho e achou que era para tomar muita cerveja antes da consulta. Dito e feito: bebeu tanta cerveja que acabou ficando um pouco tonta e falando bobagem durante a consulta. Todo mundo riu dela, inclusive ela mesma depois que se recuperou do episódio.

O médico, apesar de ter dito que o seu caso não tinha gravidade, sugeriu um tratamento à base de radiação para que o tumor benigno, cujo crescimento poderia vir a comprimir estruturas adjacentes, fosse destruído.

Havia, porém, um problema com o qual o médico se deparou: o tumor benigno precisava ser atingido por uma alta intensidade de raios, pois uma baixa intensidade não conseguiria destruí-lo. Mas, por outro lado, a emissão de raios de alta intensidade poderia atingir os tecidos corporais sadios que envolviam o tumor e isso poderia danificar estes tecidos, o que deveria ser evitado.

A seguir será pedido ao participante para responder à seguinte questão: Como você acha que o médico resolveu este problema da emissão de raios para destruir o tumor, sem danificar os tecidos corporais sadios que o envolviam? (vide o anexo $7 \mathrm{com}$ as folhas de instrução/respostas)

Lembre-se das histórias que você leu anteriormente, elas podem dar uma dica para a solução deste problema. Mas, lembre-se também que você deve escolher uma única solução para este problema, ou seja, aquela solução que vier primeiro à sua cabeça. Mas, somente após a escolha da solução por escrito, leia a pergunta da página seguinte. 
Na página seguinte será pedido ao participante que justifique a sua escolha, através da seguinte instrução: “Justifique, com suas palavras, porque escolheu esta solução”.

\section{3-PROBLEMA “ALVO” NEUTRO}

\section{LEMBRANCAS DO LABORATÓRIO}

Lembro-me bem daquele ano de 1995, quando trabalhava no laboratório de pesquisa de Biologia Médica da Faculdade de Biologia. Nosso laboratório era bem equipado para testar procedimentos no tratamento de diferentes doenças e, em particular, vínhamos desenvolvendo uma série de abordagens experimentais com culturas de microorganismos.

Neste ano, nos foi trazido por um professor do Centro de Agropecuária, que conhecia nosso laboratório, uma cobaia com um tumor de difícil acesso cirúrgico. Esta cobaia despertou nosso interesse científico de imediato. De fato, acabou incentivando o início de uma nova linha de pesquisa.

Como, neste caso, havia a impossibilidade de uma intervenção cirúrgica, resolvemos optar por um procedimento de aplicação de radiação.

Porém havia um problema com o qual nós cientistas nos deparamos: o tumor precisava ser destruído por uma alta intensidade de radiação, pois uma baixa intensidade não conseguiria destruí-lo. Mas, por outro lado, a emissão de raios de alta intensidade poderia afetar os tecidos corporais sadios que estavam ao redor do tumor, o que não poderia acontecer.

A seguir será pedido ao participante para responder à seguinte questão, através da seguinte instrução: Como você acha que foi resolvido este problema da emissão de raios para destruir o tumor, sem que fossem danificados os tecidos corporais sadios que o envolviam? (vide o anexo 3 com as folhas de instrução/respostas do estudo piloto 2).

Lembre-se das histórias que você leu anteriormente, elas podem dar uma dica para a solução desse problema. Mas, lembre-se também que você deve escolher uma única solução para este problema, ou seja, aquela solução que vier primeiro à sua cabeça. Mas, somente após a escolha da solução por escrito, leia a pergunta da página seguinte.

Na página seguinte será pedido ao participante que justifique a sua escolha com a seguinte instrução”: “Justifique, com suas palavras, porque escolheu esta solução”. 


\section{3-PROBLEMAS “DISTRATIVOS”}

\section{1-PROBLEMA “DISTRATIVO” TRISTE}

\section{NO SERTÃO}

Atravessar, de ônibus, aquela região do interior é muito penoso. A paisagem é desoladora, semi-árida, quase não há vegetação e, quando há alguma, ela é espinhosa e retorcida. E tudo parece coberto por uma poeira vermelha, sufocante. De vez em quando se avista um casebre, feito de estuque e com cobertura de sapê, muito pequeno e pobre. Quando existe alguma plantação à volta dos casebres, ela é em pequena escala e as plantas, quase sempre pés de mandioca, parecem não se ter desenvolvido bem.

A água é precária na região e chove muito pouco. Grandes períodos de seca parecem predominar e tornar a vida ainda mais difícil. Não existe nenhum açude na região e há uma grande dificuldade para se encontrar um poço que tenha água suficiente. Muitas vezes o percurso para se chegar a um desses poços é extenso e as pessoas têm que carregar as latas de água na cabeça.

A estrada de terra batida é estreita e cheia de buracos. O calor durante o dia é intenso. Além disso, os ônibus são apinhados de gente. São velhos e mal conservados e dão muito defeito, levando a paradas que podem durar horas, sob o sol a pino neste calor opressor. Mas é a única condução coletiva disponível para transporte a distâncias maiores.

Nesta mesma semana, o ponteiro do marcador de gasolina de um ônibus começou a baixar rapidamente e um forte cheiro de gasolina se espalhou. O motorista abriu a tampa do capô e verificou que havia um furo no tubo que levava a gasolina para o motor. E não existia um tubo sobressalente. Após bastante tempo sob o sol escaldante, lembrou que tinha um rolo de fita isolante no porta-luvas, então pegou a fita e enrolou-a bem apertada no tubo, na região do furo.

A viagem prosseguiu tensa, pois não havia certeza de que a gasolina seria suficiente para a chegada ao destino. Aliás, a tensão e a incerteza parecem dominar o panorama dessa região tão árida. 


\section{2)PROBLEMA “DISTRATIVO” ALEGRE}

\section{NO PARQUE FLORESTAL}

Cada vez tem sido mais freqüente a presença pessoas que exploram os caminhos mais tortuosos de enorme parque florestal. Ao andar por estes caminhos, pode-se ver uma vegetação exuberante. Muitas árvores nativas, como o pau-brasil, estão lá representadas. Há também muitos córregos e riachos cortando o parque e, não raro, se vê cachoeiras inesperadas. No verão, freqüentemente, há pessoas refrescando-se nelas. A paz é intensa e pode-se se sentir uma grande comunicação com a natureza.

Há também muitos animais no parque. Lindos pássaros e vários mamíferos, inclusive alguns exemplares raros, como o mico-leão dourado. Eles parecem não ter medo e se aproximam bastante.

O parque é muito bem cuidado. Há placas orientando os visitantes, solicitando que não se acendam fogueiras ou se deixe lixo no chão. Parece que os freqüentadores do parque têm prazer em contribuir na preservação, pois não há vestígios de lixo ou de destruição.

A área destinada ao acampamento fica em um platô de onde se tem uma vista de tirar o fôlego de tão bela. Há também uma área coberta com banheiros e um centro de apoio ao eco-turismo local.

Os celulares não funcionam no parque e deste modo o rádio transmissor é um recurso importante para qualquer eventualidade. No último fim de semana houve um pequeno problema com o rádio transmissor e o guarda florestal de plantão procurou consertá-lo. Abriu sua tampa e logo localizou o defeito que era apenas um parafuso frouxo. Ele procurou a chave de fenda para apertá-lo, mas, como não a encontrou, usou uma faca de ponta arredondada. Com movimentos rotativos cuidadosos conseguiu apertar o parafuso.

Porém neste parque acontecimentos que perturbam sua rotina são raros. Parece que seus freqüentadores o tratam como um santuário, um local privilegiado de paz e harmonia. 


\section{3-PROBLEMA “DISTRATIVO” NEUTRO 1}

\section{ESTUDO DO SOLO}

Um grupo de geógrafos estava viajando por uma região situada no interior do Brasil para fazer uma avaliação dos diferentes tipos de solo que esta região apresentava, pois havia aí uma diversidade geográfica que se expressava através de diferentes relevos e das diferenças encontradas na coloração da terra.

O objetivo principal desse grupo era o de implementar um projeto governamental que visava estudar o impacto do plantio de determinados legumes e frutas na região.

O trabalho de avaliação do solo era muito meticuloso e demandava o uso de recursos tecnológicos tais como aparelhos de medição e de coleta de terra em diferentes pontos da região. Para isso, havia a demanda de muitos dias de trabalho para que todo o material necessário fosse coletado, etiquetado e armazenado para posterior análise.

Como a região era distante e remota, a comunicação era feita através de um radio transmissor que o grupo transportava, pois os telefones celulares não funcionavam no local.

Entretanto, no último fim de semana houve um pequeno problema com o rádio transmissor e o geógrafo mais experiente do grupo foi chamado para consertá-lo. Ele abriu a sua tampa e logo localizou o defeito que era apenas um parafuso frouxo. Como não encontrou a chave de fenda para apertar o parafuso, usou uma faca de ponta arredondada para este fim e, com movimentos rotativos cuidadosos, conseguiu apertar o parafuso.

Após o conserto do rádio, os geógrafos continuaram seu trabalho minucioso de coleta e armazenamento de material e quando voltaram para as suas cidades, carregavam uma boa quantidade de dados para análise.

\section{4- PROBLEMA “DISTRATIVO” NEUTRO 2}

\section{TESTANDO O MATERIAL}

Quatro alpinistas profissionais viajavam de jipe por uma área montanhosa, onde pretendiam escalar a maior pedra que se destacava na região. Pretendiam ir de jipe até 
uma localidade que se situava na base da cadeia de montanhas e começar a partir daí sua escalada.

O grupo levava os equipamentos necessários para e empreitada, bem como portava mochilas com alimentos não perecíveis, medicamentos, sacos de dormir e roupas apropriadas.

Estes alpinistas tinham sido contratados por uma firma de equipamentos de montanhismo para testar um novo tipo de material a base de fibra de nylon que recobria as mochilas, com o intuito de verificar se este material era bastante resistente à chuva e ao peso da carga das mochilas.

Como era uma firma bem conhecida e respeitada no ramo, ela não queria colocar à venda um produto que não tivesse sido bem testado nas condições de uso para as quais foi desenvolvido. Para isso resolveu contratar profissionais experientes que pudessem avaliar a resistência do material para compará-lo com outros materiais existentes no mercado.

Na sua viagem de regresso, após alguns dias escalando, ao pegar o jipe no local onde o deixaram, os alpinistas verificaram que, ao ligarem o carro, o ponteiro do marcador de gasolina começou a baixar rapidamente. Eles abriram a tampa do capô e verificaram que havia um furo no tubo que levava a gasolina para o motor. Porém não havia um tubo sobressalente. Mas um dos alpinistas se lembrou que havia um rolo de fita isolante no porta-luvas do jipe, pegou então a fita e enrolou-a bem apertada no tubo, na região do furo.

A viagem então pode prosseguir sem mais problemas e os alpinistas quando retornaram, apresentaram um relatório detalhado da viagem, onde foi avaliado o grau de resistência do material da nova mochila a ser colocada à venda no mercado. 


\section{ANEXO 2: ESTUDO PILOTO 1 (AVALIACÃO DA TONALIDADE AFETIVA DAS HISTÓRIAS )}

Esse estudo foi realizado com o objetivo de avaliar as tonalidades afetivas das histórias dos problemas ("alvo”, “fonte” e distrativos) utilizados em nossa pesquisa sobre a influência das tonalidades afetivas dos problemas na transferência analógica.

As histórias avaliadas foram:

1-“Tristes Lembranças” e “Alegres Lembranças”, associadas aos dois problemas “alvo”. 2-“Aterrissagem Forçada” e “Cruzeiro de Sonho”, associadas aos dois problemas "fonte".

3-“No Sertão” e "No Parque Florestal”, associadas aos dois problemas distrativos.

As histórias associadas a cada um desses tipos de problemas foram construídas com tonalidades afetivas opostas (triste/ alegre). Elas acham-se descritas, na íntegra, nas folhas de instrução entregues aos alunos, cujo modelo encontra-se ao final desse anexo.

Espera-se que as histórias sejam avaliadas como apresentando conotações afetivas opostas, porém com equivalentes graus de intensidade.

\section{Método}

$\underline{\text { Sujeitos }}$

Houve a participação de 20 estudantes universitários, 18 mulheres e 2 homens, que cursavam o terceiro e o quarto períodos do curso de psicologia da Universidade do Estado do Rio de Janeiro, com média de idade de 23,8 anos.

\section{$\underline{\text { Instrumentos }}$}

O instrumento utilizado foi baseado nas escalas de diferencial semântico de Osgood (1952), como adaptada por Hesse e colaboradores (1997) para avaliar a equivalência de tonalidades afetivas de histórias.

As escalas de Osgood (1952) foram utilizadas, originalmente, para determinar o significado conativo de conceitos simples em sentenças e abordam o diferencial semântico entre os conceitos, através da contraposição de adjetivos bipolares, como, por exemplo: agradável/ desagradável; triste/ alegre, etc. 
Nessas escalas, há sete intervalos que variam de -3 a +3 , sendo o ponto zero um ponto neutro.

Por exemplo, no caso da contraposição agradável/ desagradável:

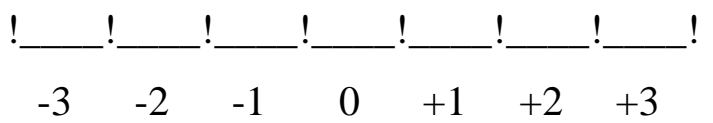

Os intervalos acima significam:

-3 = muito intimamente relacionado ao desagradável.

-2 = intimamente relacionado ao desagradável

-1 = apenas ligeiramente relacionado ao desagradável

0 = igualmente relacionado ao desagradável e ao agradável, ou seja, é completamente neutro e irrelevante.

+1 = ligeiramente relacionado ao agradável.

+2 = intimamente relacionado ao agradável.

+3 = muito intimamente relacionado ao agradável.

As escalas utilizadas em nosso estudo variam em 3 dimensões principais, de acordo com as dimensões de diferencial semântico de Osgood (1952): valência, atividade e potência. Foram utilizadas seis escalas consideradas mais apropriadas para avaliar as três dimensões do diferencial semântico de Osgood:

-Triste/ alegre e desagradável/ agradável (para a dimensão valência)

- Lenta/ rápida e desanimada/ animada (para a dimensão atividade)

- Fraca/ forte e pequena/ grande (para a dimensão potência)

A dimensão "valência” afetiva é a dimensão realmente importante para nossa investigação, tendo em vista que a principal razão para a recuperação de um dado problema “fonte”, nas condições de nossa pesquisa, seria a correspondência entre sua tonalidade afetiva e a tonalidade afetiva do problema "alvo".

As dimensões "potência” e “atividade” são usadas, principalmente, como dimensões complementares. As diferenças observadas nas avaliações das histórias nessas duas dimensões não devem ser consideradas significativas para nossos objetivos. 


\section{$\underline{\text { Procedimento }}$}

Os procedimentos para esse estudo piloto foram aperfeiçoados a partir de um estudo anterior feito com 30 estudantes universitários de duas turmas do curso de Comunicação Social do Centro Universitário São Camilo (ES), estudo esse não relatado.

A participação na pesquisa foi voluntária e a testagem agendada com antecedência com os professoras das disciplinas e com os participantes. Na primeira sessão, houve, inicialmente, a apresentação da pesquisadora pelas professoras da disciplina. Em seguida, foram feitos esclarecimentos sobre a natureza da pesquisa, a participação voluntária dos alunos e os termos do compromisso ético assumido pela pesquisadora.

Os participantes realizaram a tarefa individualmente. Cada participante recebeu, para avaliar, as duas histórias associadas aos problemas “fonte”, as duas histórias relativas aos dois problemas distrativos e apenas uma das histórias associada aos problemas “alvo”. Desse modo, 50\% dos participantes leram a história do problema "alvo” de tonalidade triste e os outros 50\% leram a história do problema "alvo" de tonalidade alegre. A distribuição dos participantes foi feita de modo aleatório.

Esse procedimento teve os seguintes objetivos:

a)Evitar que a avaliação da tonalidade afetiva das duas histórias dos problemas “alvo”, histórias essas semelhantes em termos de seus personagens, argumentos, etc., fosse influenciada pela apresentação das mesmas, uma após a outra.

b)Apresentar as histórias dos problemas “alvo", mantendo o mesmo procedimento proposto para o teste propriamente dito, ou seja, 50\% dos participantes lendo a história do problema “alvo” triste e os outros 50\%, a história do problema “alvo” alegre.

As instruções fornecidas aos participantes encontram-se ao final desse anexo.

\section{$\underline{\text { Resultado e discussão }}$}

Foi utilizado o teste paramétrico t de Student para amostras independentes (problemas “alvo”) e para amostras emparelhadas (problemas “fonte” e distrativos).

O nível de significância (ou probabilidade de significância) mínimo adotado foi de 5\%. Os resultados relativos às avaliações baseadas nas escalas descritas encontram-se discriminados na tabela 14 e 15 (relativa às escalas) e 16 e 17 (relativa às dimensões) que serão a seguir apresentadas. Abaixo a tabela 14 mostra os resultados das escalas de avaliação das histórias vinculadas aos problemas “alvo”. 
TABELA 14 - ESCALAS DE AVALIAÇÃO DAS HISTÓRIAS VINCULADAS AO PROBLEMAS ALVO

\begin{tabular}{|c|c|c|c|c|c|c|c|}
\hline \multirow{3}{*}{ ESCALAS } & \multicolumn{7}{|c|}{ HISTÓRIAS ALVO } \\
\hline & \multicolumn{2}{|c|}{$\begin{array}{c}\text { TRISTES } \\
\text { LEMBRANÇAS }\end{array}$} & \multicolumn{2}{|c|}{$\begin{array}{c}\text { ALEGRES } \\
\text { LEMBRANÇAS }\end{array}$} & \multirow{2}{*}{$\begin{array}{l}\text { t } \\
\text { try } \\
\text { ⿹ } \\
\text { 돕 }\end{array}$} & \multirow{2}{*}{ 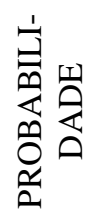 } & \multirow{2}{*}{ 忘 } \\
\hline & MÉDIA & DP & MÉDIA & $\mathrm{DP}$ & & & \\
\hline
\end{tabular}

DIMENSÃO

VALÊNCIA

$\begin{array}{lccccccc}\begin{array}{l}\text { DESAGRADÁVEL/ } \\ \text { AGRADÁVEL }\end{array} & -1,5 & 1,08 & 1,3 & 0,82 & -6,52 & * & \mathrm{~S} \\ \text { TRISTE/ALEGRE } & -1,9 & 1,1 & 1,7 & 1,05 & -7,45 & * & \mathrm{~S}\end{array}$

DIMENSÃO

ATIVIDADE

\begin{tabular}{lccccccc} 
LENTA/RÁPIDA & 0,2 & 1,54 & 0,7 & 1,33 & $-0,77$ & $* * *$ & NS \\
$\begin{array}{l}\text { DESANIMADA/ } \\
\text { ANIMADA }\end{array}$ & $-0,6$ & 1,5 & 0,6 & 0,96 & $-2,12$ & $* *$ & $\mathrm{~S}$ \\
$\begin{array}{l}\text { DIMENSÃo } \\
\text { POTÊNCIA }\end{array}$ & & & & & & & \\
$\begin{array}{l}\text { FRACA/FORTE } \\
\begin{array}{l}\text { PEQUENA/ } \\
\text { GRANDE }\end{array}\end{array}$ & 1,3 & 1,56 & $-0,3$ & 1,7 & 0,68 & $* * *$ & $\mathrm{~S}$ \\
\hline
\end{tabular}

$*<0,001 ; * *<0,05 ; * * *>0,05$

A tabela 15 apresenta abaixo os resultados das escalas de avaliação das histórias vinculadas aos problemas "fonte" e distrativos. 
TABELA 15 - ESCALAS DE AVALIAÇÃO DAS HISTÓRIAS VINCULADAS AOS PROBLEMAS FONTE E DISTRATIVOS

\begin{tabular}{|c|c|c|c|c|c|c|c|c|c|c|c|c|c|c|}
\hline \multirow{3}{*}{ ESCALAS } & \multicolumn{7}{|c|}{ HISTÓRIAS FONTE } & \multicolumn{7}{|c|}{ HISTÓRIAS DISTRATIVAS } \\
\hline & \multicolumn{2}{|c|}{$\begin{array}{l}\text { ATERRIS- } \\
\text { SAGEM } \\
\text { FORÇADA }\end{array}$} & \multicolumn{2}{|c|}{$\begin{array}{c}\text { CRUZEIRO } \\
\text { DE } \\
\text { SONHO }\end{array}$} & \multirow{2}{*}{ 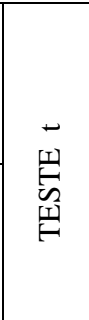 } & \multirow{2}{*}{ 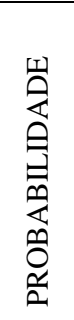 } & \multirow{2}{*}{ 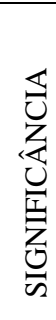 } & \multicolumn{2}{|c|}{$\begin{array}{l}\mathrm{NO} \\
\text { SERTÃO }\end{array}$} & \multicolumn{2}{|c|}{$\begin{array}{c}\text { NO } \\
\text { PARQUE } \\
\text { FLORES- } \\
\text { TAL }\end{array}$} & \multirow{2}{*}{ 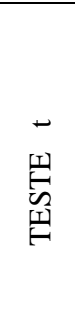 } & \multirow{2}{*}{ 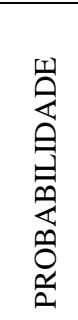 } & \multirow{2}{*}{ 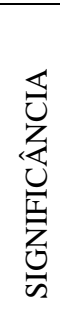 } \\
\hline & 氙 & DP & 匍 & DP & & & & 空 & DP & 兒 & DP & & & \\
\hline \multicolumn{15}{|l|}{$\begin{array}{l}\text { DIMENSÃO } \\
\text { VALÊNCIA }\end{array}$} \\
\hline $\begin{array}{l}\text { DESAGRADÁVEL/ } \\
\text { AGRADÁVEL }\end{array}$ & $-2,05$ & 0,88 & 1,9 & 0,71 & $-15,4$ & * & $\mathrm{S}$ & $-1,05$ & 1,39 & 1,7 & 0,97 & $-7,3$ & $*$ & $\mathrm{~S}$ \\
\hline TRISTE/ALEGRE & $-1,95$ & 1,09 & 1,9 & 0,96 & $-9,48$ & $*$ & $\mathrm{~S}$ & 0,7 & 1,17 & 0,8 & 1,28 & $-4,4$ & * & S \\
\hline \multicolumn{15}{|l|}{$\begin{array}{l}\text { DIMENSÃO } \\
\text { ATIVIDADE }\end{array}$} \\
\hline LENTA/RÁPIDA & $-0,7$ & 2,02 & 0,25 & 1,51 & 2,54 & $* *$ & $\mathrm{~S}$ & 0,6 & 1,69 & 1,3 & 1,26 & $-2,4$ & $* *$ & S \\
\hline $\begin{array}{l}\text { DESANIMADA/ } \\
\text { ANIMADA }\end{array}$ & $-0,7$ & 1,8 & 1,75 & 1,16 & $-5,18$ & $*$ & $\mathrm{~S}$ & $-1,05$ & 1,6 & 0,65 & 0,74 & $-4,6$ & * & $\mathrm{S}$ \\
\hline \multicolumn{15}{|l|}{$\begin{array}{l}\text { DIMENSÃO } \\
\text { POTÊNCIA }\end{array}$} \\
\hline FRACA/FORTE & 1,15 & 1,59 & $-0,5$ & 1,19 & 3,54 & $* *$ & $\mathrm{~S}$ & 0,0 & 1,16 & 0,1 & 0,64 & $-0,4$ & $* * *$ & NS \\
\hline $\begin{array}{l}\text { PEQUENA/ } \\
\text { GRANDE }\end{array}$ & 1,25 & 1,25 & 0,6 & 0,99 & 2,79 & $* *$ & $\mathrm{~S}$ & $-1,8$ & 1,57 & $-1,7$ & 1,12 & $-0,4$ & $* * *$ & NS \\
\hline
\end{tabular}

$*<0,001 ; * *<0,05 ; * * *>0,05$

Será apresentada, a seguir, a tabela 16 que mostra os resultados relativos às dimensões de avaliação das histórias vinculadas aos problemas “alvo”. 
TABELA 16-DIMENSÕES DE AVALIAÇÃO DAS HISTÓRIAS VINCULADAS AOS PROBLEMAS ALVO

\begin{tabular}{|c|c|c|c|c|c|c|c|}
\hline \multirow{3}{*}{ DIMENSÕES } & \multicolumn{7}{|c|}{ HISTÓRIAS ALVO } \\
\hline & \multicolumn{2}{|c|}{$\begin{array}{c}\text { TRISTES } \\
\text { LEMBRANÇAS }\end{array}$} & \multicolumn{2}{|c|}{$\begin{array}{c}\text { ALEGRES } \\
\text { LEMBRANÇAS }\end{array}$} & \multirow{2}{*}{ 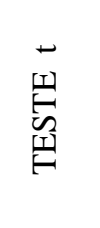 } & \multirow{2}{*}{ 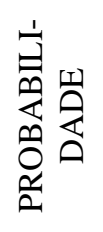 } & \multirow{2}{*}{ 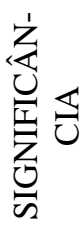 } \\
\hline & MÉDIA & DP & MÉDIA & DP & & & \\
\hline VALÊNCIA & $-1,7$ & 0,97 & 1,5 & 0,74 & $-8,23$ & * & S \\
\hline ATIVIDADE & $-0,2$ & 1,08 & 0,65 & 0,85 & $-1,94$ & $* * *$ & NS \\
\hline POTÊNCIA & $-0,75$ & 0,85 & $-0,3$ & 1,18 & 2,27 & $* *$ & S \\
\hline
\end{tabular}

Por último, será apresentada abaixo a tabela 17 que mostra os resultados relativos às dimensões de avaliação das histórias vinculadas aos problemas “fonte” e distrativos. 
TABELA 17 - DIMENSÕES DE AVALIAÇÃO DAS HISTÓRIAS VINCULADAS AOS PROBLEMAS FONTE E DISTRATIVOS

\begin{tabular}{|c|c|c|c|c|c|c|c|c|c|c|c|c|c|c|}
\hline \multirow{3}{*}{ DIMENSÕES } & \multicolumn{7}{|c|}{ HISTÓRIAS FONTE } & \multicolumn{7}{|c|}{ HISTÓRIAS DISTRATIVAS } \\
\hline & \multicolumn{2}{|c|}{$\begin{array}{l}\text { ATERRIS- } \\
\text { SAGEM } \\
\text { FORÇADA }\end{array}$} & \multicolumn{2}{|c|}{$\begin{array}{c}\text { CRUZEIRO } \\
\text { DE } \\
\text { SONHO }\end{array}$} & \multirow{2}{*}{ 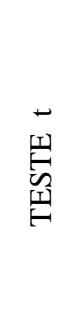 } & \multirow{2}{*}{ 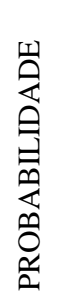 } & \multirow{2}{*}{ 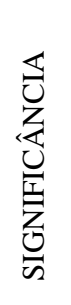 } & \multicolumn{2}{|c|}{$\begin{array}{c}\text { NO } \\
\text { SERTÃO }\end{array}$} & \multicolumn{2}{|c|}{$\begin{array}{c}\text { NO } \\
\text { PARQUE } \\
\text { FLORESTAL }\end{array}$} & \multirow{2}{*}{ 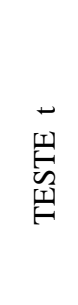 } & \multirow{2}{*}{ 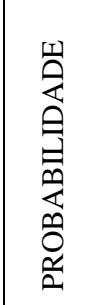 } & \multirow{2}{*}{ 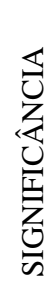 } \\
\hline & 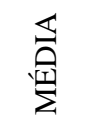 & DP & 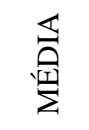 & $\mathrm{DP}$ & & & & 品 & DP & 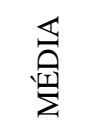 & DP & & & \\
\hline VALÊNCIA & -2 & 0,82 & 1,9 & 0,69 & $-14,4$ & $*$ & S & $-0,87$ & 1,16 & 1,25 & 0,93 & $-7,4$ & $*$ & S \\
\hline ATIVIDADE & $-0,72$ & 1,58 & 1,12 & 1,04 & $-5,77$ & $*$ & S & $-0,22$ & 1,33 & 0,97 & 0,63 & $-4,2$ & $*$ & S \\
\hline POTÊNCIA & 1,2 & 0,97 & 0,05 & 0,85 & 4,02 & * & $\mathrm{S}$ & $-0,85$ & 1,26 & $-0,8$ & 0,75 & $-0,2$ & $* * *$ & NS \\
\hline
\end{tabular}

$*<0,001 ; * *<0,05 ; * * *>0,05$

No que se refere aos problemas "alvo", como podemos observar, a história "alvo" “Alegres Lembranças” pode ser considerada significativamente mais alegre e mais agradável do que a história “Tristes Lembranças”. E, de modo complementar, a história “alvo" “Tristes Lembranças” pode ser considerada consideravelmente mais triste e desagradável do que a história “alvo” “Alegres Lembranças”.

As diferenças entre as histórias “alvo”, quanto às médias nas escalas desanimada/ animada e fraca/ forte, também foram significativas. Já as diferenças entre as histórias “alvo”, quanto às médias nas escalas lenta/ rápida e pequena/ grande, não foram significativas.

No que se refere aos problemas "fonte", podemos ver que as diferenças entre as médias das histórias “Aterrissagem Forçada” e "Cruzeiro de Sonho”, relativas a todas as escalas utilizadas, foram significativas. A história “Aterrissagem Forçada” foi, então, significativamente mais triste e desagradável do que a história "Cruzeiro de Sonho" e vice-versa. 
As histórias distrativas “No Sertão” e "No Parque Florestal” apresentaram diferenças significativas entre as médias nas escalas desagradável/ agradável, triste/ alegre, lenta/ rápida e desanimada/ animada e diferenças não significativas nas escalas fraca/ forte e pequena/ grande.

Em suma, podemos observar que as diferenças entre as escalas desagradável/ agradável e triste/ alegre foram significativas para todas as histórias construídas (“alvo”, "fonte” e distrativas). Em consonância, a dimensão valência, a mais importante para a caracterização da tonalidade afetiva de uma dada história, também apresentou diferenças significativas entre cada par de histórias de tonalidades opostas.

Ainda no que diz respeito à dimensão "valência”, podemos ver que as médias das avaliações das histórias “alvo", “fonte” e distrativas, nas escalas triste/ alegre e desagradável/ agradável, parecem bem próximas, em números absolutos, o que sugere uma boa equivalência entre o grau de tristeza e o grau de alegria percebidos. 


\section{Instruções do estudo piloto 1}

Nas páginas seguintes serão apresentadas cinco histórias para você avaliar cada uma delas como um todo. Serão utilizados seis pares de adjetivos opostos separados por sete linhas segmentadas, abaixo das quais haverá uma escala de $-3 \mathrm{a}+3$. Marque com um $\mathrm{X}$ a linha acima do grau (número) da escala que você considera ser mais adequado para descrever a história como um todo.

Por exemplo, se o par de adjetivos fosse "pobre e rica":

$$
\text { Pobre } \frac{}{-3} ! \frac{!}{-2} ! \frac{1}{-1} ! \frac{1}{0} ! \frac{1}{+1} ! \frac{1}{+2} ! \frac{1}{+3} \text { Rica }
$$

Neste exemplo, se você marcasse um X em cima do:

-3 : significa que você considerou a história muito pobre;

-2 : significa que você considerou a história pobre;

-1 : significa que você considerou a história um pouco pobre;

0 : significa que você considerou a história neutra, nem pobre, nem rica

+1: significa que você considerou a história um pouco rica;

+2 :significa que você considerou a história rica;

+3 :significa que você considerou a história muito rica.

Sendo assim, quanto mais perto de um desses adjetivos opostos você marcar o X, significa que você considera aquele adjetivo mais adequado para qualificar a história como um todo. Já a marcação da linha segmentada central, cujo número zero fica logo abaixo da mesma, significa que você considera a história neutra em relação ao par de adjetivos que está sendo avaliado. 
História I A:

TRISTES LEMBRANCAS

Aquele ano de 1995 foi um ano muito difícil. Lembro-me como se fosse hoje. Logo no início do ano eu perdi meu emprego e fiquei desempregado quase o ano todo. Nossas economias foram todas gastas e os acontecimentos que vieram a seguir nos pegaram desprevenidos.

Minha mulher tinha acabado de perder nosso primeiro filho e precisou fazer um tratamento com medicamentos muito caros. Eu comecei a fazer biscates entregando jornais de bicicleta. Andava muitos quilômetros por dia e chegava em casa todo doído e bastante cansado. Eu e minha mulher estávamos muito deprimidos com a perda do nosso bebê e com a falta de dinheiro. Além disso, tivemos que abandonar nossa casa, pois não podíamos mais pagar o aluguel. Tivemos que vender nossos móveis e objetos e fomos morar em um quarto alugado em uma pensão bem velha e suja, mas era o que podíamos pagar. O quarto tinha as paredes imundas, uma velha e feia cama quebrada e tudo tinha um cheiro muito desagradável. Mas o pior ainda estava por vir.

Em meados de julho, minha mulher começou a sentir muitas dores nas costas e dificuldade para urinar. Vinha emagrecendo muito rapidamente, pois rejeitava a ingestão de alimentos e não tinha ânimo para nada. Levei-a então a um hospital onde tivemos que enfrentar uma enorme fila de espera e, só depois de quase um dia inteiro, fomos atendidos e conseguimos marcar uma consulta para daí a dois meses.

Neste período ela foi piorando e foi preciso um atendimento de urgência. No pronto socorro onde foi atendida, havia muita gente sendo atendida ao mesmo tempo em uma sala de paredes descascadas e cheias de infiltração, onde estavam diversas mulheres. Quando chegou a vez da minha mulher, o antipático médico que a examinou mostrou-se muito preocupado e fez um encaminhamento para internação imediata em uma enfermaria onde havia vários leitos e onde ela foi recebida por uma enfermeira agressiva.

Os exames constataram um tumor cancerígeno, de alta malignidade com real possibilidade de metástase, no rim esquerdo. Este rim já não estava funcionando direito, por isso minha mulher sentia tantas dores e estava tão debilitada. Um episódio muito preocupante ocorreu depois disso. O médico receitou alguns medicamentos para dor e disse à minha mulher para tomá-los com precaução e que tomasse apenas um, antes da próxima consulta. Porém, minha mulher não entendeu bem a sua recomendação e tomou vários medicamentos diferentes de uma só vez antes da consulta, o que a levou a uma 
grave intoxicação com conseqüente piora do seu estado de saúde. Vê-la desmaiada e passando tal mal deixou todos nos hospital preocupados e eu fiquei tão aflito que não sabia o que fazer.

O médico resolveu então atacar o tumor diretamente e recomendou um tratamento a base de radiação, pois a cirurgia não era indicada neste caso.

Havia, porém, um problema com o qual o médico se deparou: o tumor necessitava ser atingido por uma alta intensidade de radiação, pois uma baixa intensidade não conseguiria destruí-lo. Mas, por outro lado, a emissão de raios de alta intensidade poderia atingir os tecidos corporais sadios que envolviam o tumor e poderia danificar estes tecidos, o que deveria ser evitado, pois poderia piorar ainda mais o grave estado de saúde da paciente.

Mas, apesar das dificuldades encontradas, o médico enfim encontrou uma solução para a forma de emissão de raios laser exigida neste caso.

Após a leitura da primeira história “Tristes Lembranças”, marque um X sobre o número que você considera mais adequado para qualificar a história como um todo.

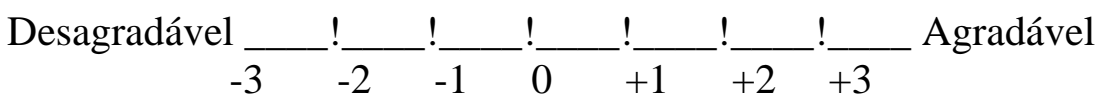

$$
\begin{aligned}
& \text { Triste } \frac{}{-3} ! \frac{1}{-2} ! \frac{1}{-1} ! \frac{1}{0} ! \frac{1}{+1} ! \frac{1}{+2} ! \frac{1}{+3} \text { Alegre } \\
& \text { Lenta } \frac{}{-3} ! \frac{1}{-2} ! \frac{1}{-1} ! \frac{1}{0} ! \frac{1}{+1} ! \frac{1}{+2} ! \frac{1}{+3} \text { Rápida }
\end{aligned}
$$$$
\text { Desanimada } \frac{}{-3} ! \frac{}{-2} \cdot \frac{!}{-1} \cdot \frac{!}{0} \cdot \frac{1}{+1}+\frac{!}{+2}+\ldots \text { Animada }
$$$$
\text { Fraca } \frac{}{-3} ! \frac{}{-2} ! \frac{1}{-1} ! \frac{1}{0} ! \frac{1}{+1} \cdot \frac{}{+2} \cdot \frac{\text { Forte }}{+3}
$$$$
\text { Pequena } \frac{}{-3} ! \frac{}{-2} ! \frac{1}{-1} \cdot \frac{1}{0} \cdot \frac{1}{+1} \cdot \frac{1}{+2} \cdot \frac{\square}{+3} \text { Grande }
$$ 
História I B:

ALEGRES LEMBRANCAS

O ano de 1995 foi um ano muito bom. Lembro-me como se fosse hoje. Logo no início do ano, consegui um emprego novo onde estou até hoje e com o bom salário que venho recebendo, consegui juntar dinheiro, fazer uma grande poupança e tenho estado prevenido para qualquer eventualidade que venha ocorrer.

Minha mulher tinha acabado de ganhar nosso primeiro filho e tudo correu tão bem no parto que ela nem precisou de nenhum remédio para sua recuperação. Meu patrão me deu umas semanas de folga, assim eu pude descansar um pouco e pude curtir bastante meu filho. Eu e minha mulher estávamos tão felizes com o nascimento do bebê que resolvemos morar em uma casa nova, maior e mais bonita, para que ele tivesse um ambiente bem confortável e amplo para crescer. Como tinha um bom emprego pude comprar uma bela casa e muitos presentes para meu filho. O quarto do bebê tinha lindas paredes decoradas, um berço novo e bonito e tudo era bem cheiroso e limpinho. Novos acontecimentos, entretanto, ainda estavam por vir.

Em meados de julho, minha mulher foi fazer um exame médico de rotina, apesar de se sentir bem animada, com bom apetite e sem sentir nenhum tipo de dor ou queixa. Ela que sempre gozou de ótima saúde, tinha, inclusive, muito leite para o bebê e sentia-se bem disposta em suas atividades diárias. Levei-a a um consultório médico onde fomos logo atendidos, pois conseguimos marcar a consulta sem dificuldade para o mesmo dia.

Enquanto fazia os exames de rotina, minha mulher teve à sua disposição uma sala de espera muito limpa e agradável. Era uma sala individualizada onde dispúnhamos de todo conforto possível e nem parecia que estávamos em uma situação de atendimento médico. Quando minha mulher foi atendida, o simpático médico, que a examinou, pediu que ela fosse encaminhada para uma sala anexa onde ela teve um atendimento individualizado e foi recebida por uma enfermeira carinhosa.

Os exames constataram um tumor benigno no rim esquerdo. Porém, os rins estavam funcionando perfeitamente, por isso minha mulher não sentia nenhum incômodo ou dor. Um episódio muito engraçado ocorreu depois disso. O médico tinha recomendado que minha mulher bebesse muito líquido, inclusive permitiu que ela bebesse uma cervejinha de vez em quando, caso ela gostasse. Disse também que quando voltasse, na próxima consulta, deveria beber muito líquido antes. Mas minha mulher entendeu errado seu conselho e achou que era para tomar muita cerveja antes da consulta. Dito e feito: bebeu 
tanta cerveja que acabou ficando um pouco tonta e falando bobagem durante a consulta. Todo mundo riu dela, inclusive ela mesma depois que se recuperou do episódio.

O médico, apesar de ter dito que o seu caso não tinha gravidade, sugeriu um tratamento à base de radiação a laser para que o tumor benigno, cujo crescimento poderia vir a comprimir estruturas adjacentes, fosse destruído.

Havia, porém, um problema com o qual o médico se deparou: o tumor benigno precisava ser atingido por uma alta intensidade de radiação, pois uma baixa intensidade não conseguiria destruí-lo. Mas, por outro lado, a emissão de raios de alta intensidade poderia atingir os tecidos corporais sadios que envolviam o tumor e poderia danificar estes tecidos, o que deveria ser evitado, apesar do ótimo estado de saúde da paciente.

Mas, apesar das dificuldades encontradas, o médico, enfim, encontrou uma boa solução para a forma de emissão de raios laser exigida neste caso.

Após a leitura da primeira história “Alegres Lembranças”, marque um X sobre o número que você considera mais adequado para qualificar a história como um todo.

$$
\begin{aligned}
& \text { Desagradável } \frac{}{-3} ! \frac{1}{-2} ! \frac{1}{-1} \cdot \frac{1}{0} \cdot \frac{1}{+1} \cdot \frac{1}{+2} ! \frac{}{+3} \text { Agradável } \\
& \text { Triste } \frac{}{-3} ! \frac{1}{-2} ! \frac{1}{-1} ! \frac{1}{0} ! \frac{1}{+1} \cdot \frac{1}{+2} ! \frac{}{+3} \text { Alegre }
\end{aligned}
$$

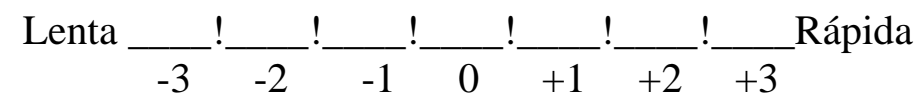$$
\text { Desanimada } \frac{}{-3} ! \frac{1}{-2} ! \frac{1}{-1} ! \frac{1}{0} ! \frac{1}{+1} \cdot \frac{1}{+2} ! \frac{}{+3} \text { Animada }
$$$$
\text { Fraca } \frac{}{-3} ! \frac{1}{-2} ! \frac{1}{-1} ! \frac{1}{0} ! \frac{1}{+1} ! \frac{1}{+2} ! \frac{\text { Forte }}{+3} \text { F }
$$$$
\text { Pequena } \frac{}{-3} ! \frac{1}{-2} ! \frac{1}{-1} ! \frac{1}{0} ! \frac{1}{+1} \cdot \frac{1}{+2} ! \frac{}{+3} \text { Grande }
$$ 


\section{História II:}

\section{ATERRISSAGEM FORCADA}

Há pouco tempo aconteceu um episódio que deixou marcas profundas em mim e nunca mais fui o mesmo depois do que me aconteceu.

Eu estava em um momento de vida particularmente difícil, pois tinha perdido recentemente meus pais em um desastre de carro e ia morar com meus tios em uma cidade muito distante de onde tinha passado toda a minha vida. Ia deixar para trás meus amigos e a faculdade em que acabara de entrar e isso me deixava ainda mais triste.

Como estava sem dinheiro e sem emprego e meus tios eram muito pobres para me ajudar na viagem, consegui uma carona em um avião de carga em troca de trabalhar durante um mês para o dono do avião.

Quando a viagem de avião começou, eu estava exausto e sem disposição após semanas trabalhando, sem descansar, em péssimas condições. Em um determinado momento da viagem, quando estávamos sobrevoando muito alto, o avião começou a tremer todo e a fazer um barulho ensurdecedor o que deixou em pânico todas as pessoas que nele viajavam. Pensei que íamos todos morrer e uma súbita angustia se apoderou de mim e comecei a chorar compulsivamente. Estávamos em um inverno rigoroso e lá fora tudo era cinza e desolado. Uma grande tempestade estava em curso e os raios e trovões só faziam aumentar o meu pavor e sacudiam ainda mais o velho avião.

O piloto resolveu aterrissar para pedir ajuda e, após muita dificuldade, conseguiu faz-lo em um local que parecia uma base militar e, confirmando minhas suspeitas, logo que chegou ao solo, o avião foi cercado por soldados que nos encararam com pesadas armas apontadas em nossa direção. Pensei: Meu Deus! Acho que agora não vou conseguir sair dessa situação, estou em um beco sem saída. Aqueles homens, com o rosto parcialmente coberto, pareciam terroristas e não tinham nada a perder se nos matassem. Tive muito medo do que poderia nos acontecer e fiquei paralisado, sem me mexer na minha poltrona.

O piloto, após uns minutos de hesitação, desceu do avião e foi pedir ajuda àqueles soldados. Após ter sido revistado e humilhado pelo chefe daquele exército, o piloto nos disse que eles até poderiam nos ajudar a consertar o avião, mas que só fariam isso se o avião levasse, em troca, um carregamento de metralhadoras para um grupo de soldados que estava em uma base militar de um país vizinho. Como não tinha outra escolha, o piloto concordou com isso. 
Enquanto nós esperávamos o avião ser levado para um local que parecia uma grande oficina, vários soldados continuaram a apontar seus fuzis para as nossas cabeças. O piloto nos contou que, enfim, descobriram qual o problema do avião: tratava-se de um problema no sistema de controle da altitude do avião.

Após procurar bastante a causa do problema, os técnicos da oficina verificaram, através de um visor, que um dos transistores do sistema de controle da altitude estava recoberto de mofo. Como este transistor estava situado no centro de um compartimento lacrado, não poderia haver uma manipulação direta do mesmo, ou seja, o compartimento não poderia ser aberto para a limpeza do mofo.

Os técnicos resolveram, então, utilizar o calor emitido por raios infravermelhos para a eliminação do mofo no transistor, porém para que o mofo fosse totalmente eliminado, havia a necessidade de uma alta intensidade de radiação. Mas havia um problema com o qual os técnicos se depararam: como as paredes do compartimento onde se situava este transistor eram recobertas internamente por uma frágil película, uma alta intensidade de radiação incidida sobre ela poderia danificá-la, o que deveria ser evitado.

Após se perguntar como conseguiriam aumentar a intensidade da radiação infravermelha sobre o transistor, sem danificar a película, os técnicos chegaram a uma solução.

A solução encontrada foi a de lançar feixes de raios infravermelhos, de baixa intensidade, emitidos uns após os outros, em série, que foram focalizados e incididos na parte mofada do transistor a intervalos de tempo que permitiam a absorção e o acúmulo de calor no transistor, eliminando assim o mofo de modo gradual e contínuo, sem que a película fosse danificada.

Essa solução mostrou-se eficaz e logo que o conserto ficou pronto, os soldados nos empurraram para dentro do avião e três deles entraram conosco para nos vigiar e, com as armas apontadas para as nossas cabeças, pretendo matar-nos, caso não cumpríssemos o acordo, forçaram a levá-los, junto com o armamento.

Quando chegamos na base militar para onde nos forçaram a ir, fomos presos e ficamos semanas em um campo de prisioneiros, onde passamos todo o tipo de privação. Sentimos frio, fome e fomos maltratados. Sofremos horrores que gostaríamos de esquecer.

Quando me lembro de tudo que passei não sei como consegui sobreviver. Com freqüência acordo durante a noite suando frio e com terríveis pesadelos. Até hoje ainda guardo as cicatrizes físicas e psicológicas desta experiência tão angustiante. 
Após a leitura da segunda história “Aterrissagem Forçada”, marque com um X sobre o intervalo que você considera mais adequado para qualificar a história como um todo.

Desagradável $\frac{}{-3} ! \frac{}{-2} ! \frac{}{-1} \cdot \frac{1}{0} ! \frac{1}{+1} ! \frac{1}{+2} \cdot \frac{}{+3}$ Agradável

\begin{tabular}{|c|c|c|c|c|c|c|c|c|c|}
\hline \multirow{2}{*}{ Triste } & \multicolumn{2}{|c|}{ ! } & $!$ & $!$ & \multicolumn{2}{|l|}{$!$} & $!$ & 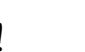 & \multirow{2}{*}{ Alegre } \\
\hline & -3 & -2 & -1 & c & & +1 & +2 & +3 & \\
\hline \multirow[t]{2}{*}{ Lenta } & & & $!$ & $!$ & $!$ & & & _ & \multirow[t]{2}{*}{ Rápida } \\
\hline & -3 & -2 & -1 & c & & +1 & +2 & +3 & \\
\hline \multirow[t]{2}{*}{ Desanimad } & & $!$ & $!$ & $!$ & & $!$ & _! & _! & \multirow[t]{2}{*}{ _ Animada } \\
\hline & -3 & -2 & -1 & 0 & & +1 & +2 & +3 & \\
\hline
\end{tabular}

Fraca $\frac{}{-3} \cdot \frac{1}{-2} \cdot \frac{1}{-1} \cdot \frac{1}{0} \cdot \frac{1}{+1} \cdot \frac{1}{+2} \cdot \frac{}{+3}$ Forte

Pequena $\frac{}{-3} ! \frac{}{-2} ! \frac{}{-1} ! \frac{1}{0} ! \frac{1}{+1} \cdot \frac{1}{+2} \cdot \frac{}{+3}$ Grande

História III:

\section{CRUZEIRO DE SONHO}

Ontem eu estava conversando com uns amigos numa festa e lembrávamos de umas coisas alegres e engraçadas que nos acontecem na vida. Rimos muito de tudo e recordamos de tudo de bom que nos tinha acontecido nos últimos tempos.

Estava contando a todo mundo uma magnífica viagem de navio que eu tinha feito no ano passado. Era um navio muito luxuoso, com todo tipo de lazer que alguém possa imaginar. Os dias estavam lindos e ensolarados e pudemos tomar muitos banhos de piscina e praticar várias modalidades de esporte. Fomos a boates, a cinemas, a restaurantes com comidas deliciosas e tivemos muita animação dia e noite.

Eu fiz esse cruzeiro marítimo com uma turma de amigos. Como eu havia passado no vestibular muito bem colocado, meus pais, que têm uma boa situação financeira, me deram essa viagem de presente. Aliás, meus pais me apóiam em tudo que faço e formam um casal muito feliz e dinâmico. Eu estava também satisfeito porque tinha um estágio 
em vista em uma empresa conceituada e isso significava uma chance real de um bom emprego quando terminasse meu curso.

Fomos todos, meus amigos e eu, comemorar juntos o fato de termos passado no vestibular nesse cruzeiro de sonho. Foi tudo tão perfeito que até nas fotos da viagem fica bem visível nossa alegria.

Durante o dia, a diversão maior era na piscina, onde participávamos de torneios e jogos dentro e fora da água. Inclusive, ganhei uma linda taça em um difícil torneio de frescobol e fui muito aplaudido pelo meu desempenho. No fim da tarde, costumávamos assistir a um filme e depois circulávamos pelo grande shopping do navio, onde costumávamos fazer compras e conversávamos com pessoas diferentes que por ali passeavam. Fizemos assim um monte de novos amigos, que se juntaram ao nosso grupo e nos acompanharam em muitas atividades.

Todo dia a gente ia jantar em um restaurante sofisticado e eu conheci vários tipos de comidas saborosas que nem imaginava existirem. Fiquei muito amigo do famoso cozinheiro do restaurante e ele acabou me dando várias receitas e me contando como preparava os alimentos e como os mesmos eram conservados no navio. Inclusive me contou que tinha havido recentemente um problema em um dos setores de conservação de alimentos, mas que, felizmente, os encarregados do setor tinham conseguido resolver.

Fiquei curioso e perguntei o que havia acontecido. Ele me disse que um contêiner que guardava alimentos muito caros tinha tido um problema em sua refrigeração e que requisitava um conserto rápido para que não houvesse um grande prejuízo com a perda da carga. Após uma avaliação inicial do que estava acontecendo, os técnicos do setor constataram, através de uma janela de vidro, que a temperatura de um dos contêineres de alimentos estava subindo, pois um filamento, que estava dentro do contêiner e que fazia parte do seu sistema de refrigeração, estava coberto de fungo, o que ocasionava o mau funcionamento deste sistema. Havia assim a necessidade de um rápido conserto para que não houvesse a deterioração desses alimentos.

Enfim, após pensar muito, chegaram à melhor solução para este problema. A solução proposta foi o uso de raios ultravioletas (UV) para a esterilização do filamento com fungo. Os técnicos também sabiam que não poderiam abrir o contêiner para manusear diretamente o filamento, pois os alimentos não poderiam ter contato com o ar. Também sabiam que havia a exigência de uma alta intensidade de raios para que essa esterilização fosse eficaz. Entretanto, sabiam que não poderiam emitir toda a radiação necessária através de uma única emissão de raios de alta intensidade, pois a alta 
intensidade, emitida de uma só vez, poderia danificar as paredes internas do contêiner que eram feitas de um gel protetor.

A solução encontrada foi a de emitir raios ultravioletas de baixa intensidade, emitidos de diferentes fontes de emissão, cada uma delas posicionada em um ponto diferente, e que foram focalizadas para convergir todas ao mesmo tempo para o filamento com fungo, de modo que pelo somatório de sua radiação, pudessem chegar a uma forte radiação e assim pudessem esterilizar o filamento, sem que fossem danificadas as paredes do contêiner. Os alimentos foram assim preservados, pois o sistema de refrigeração do contêiner voltou a funcionar normalmente após este conserto.

Fiquei feliz em saber que havia tanto cuidado na conservação e no preparo dos alimentos e até me motivei em estudar um pouco esse assunto. Adoro comer comidas diferentes, especialmente com meus amigos e namorada. É claro que com ela prefiro uns jantares mais românticos e com meus amigos prefiro fazer uma farra, como essa que a gente fez no navio.

Foi uma viagem inesquecível e quero voltar a viajar sempre para ter muitas histórias para contar para meus filhos e netos. É tão bom quando a gente tem experiências alegres que nos enriquecem de imagens e de vivências tão positivas. Já marquei uma nova viagem com meus amigos de sempre. Gosto de viajar, de preferência com pessoas que compartilham dos meus interesses e que gostem muito de uma boa diversão e de rir bastante.

Após a leitura da terceira história "Cruzeiro de Sonho", marque um X sobre o intervalo que você considera mais adequado para qualificar a história como um todo.

$$
\begin{aligned}
& \text { Desagradável } \frac{}{-3} ! \frac{1}{-2} ! \frac{}{-1} ! \frac{1}{0} ! \frac{1}{+1} ! \frac{1}{+2} ! \frac{\ldots}{+3} \text { Agradável } \\
& \text { Triste } \frac{}{-3} ! \frac{}{-2} ! \frac{}{-1} ! \frac{1}{0} ! \frac{1}{+1} ! \frac{1}{+2} ! \frac{1}{+3} \text { Alegre } \\
& \text { Lenta } \frac{}{-3} ! \frac{}{-2} ! \frac{1}{-1} ! \frac{1}{0} ! \frac{1}{+1} ! \frac{1}{+2} ! \frac{1}{+3} \text { Rápida }
\end{aligned}
$$$$
\text { Desanimada } \left.\frac{}{-3} ! \frac{1}{-2} ! \frac{1}{-1} ! \frac{1}{0} ! \frac{1}{+1} ! \frac{1}{+2} !\right]_{+3} \text { Animada }
$$ 


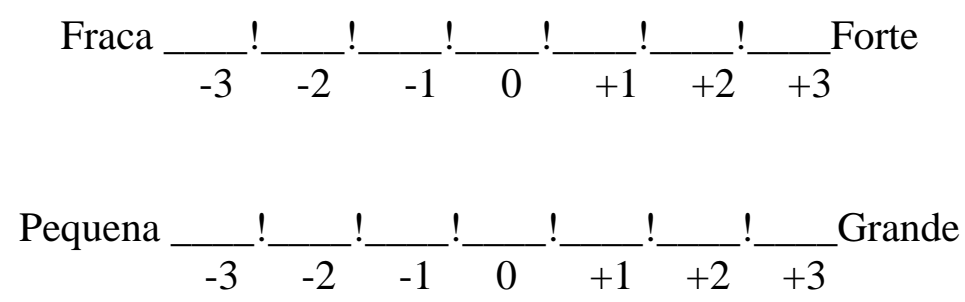

HISTÓRIA IV: NO SERTÃO

Atravessar, de ônibus, aquela região do interior é muito penoso. A paisagem é desoladora, semi-árida, quase não há vegetação e quando há alguma ela é espinhosa e retorcida. E tudo parece coberto por uma poeira vermelha, sufocante. De vez em quando se avista um casebre, feito de estuque e com cobertura de sapê, muito pequeno e pobre. Quando existe alguma plantação à volta dos casebres, ela é em pequena escala e as plantas, quase sempre pés de mandioca, parecem não ter se desenvolvido bem.

A água é precária na região e chove muito pouco. Grandes períodos de seca parecem predominar e tornar a vida ainda mais difícil. Não existe nenhum açude na região e há uma grande dificuldade para encontrar um poço que tenha água suficiente. Muitas vezes o percurso para se chegar a um desses poços é extenso e as pessoas têm que carregar as latas de água na cabeça.

A estrada de terra batida é estreita e cheia de buracos. O calor durante o dia é intenso. Além disso, os ônibus são apinhados de gente. São velhos e mal conservados e dão muito defeito, levando a paradas que podem durar horas, sob o sol a pino neste calor opressor. Mas é a única condução coletiva disponível para transporte a distâncias maiores.

Nesta mesma semana, o ponteiro do marcador de gasolina de um ônibus começou a baixar rapidamente e um forte cheiro de gasolina se espalhou. O motorista abriu a tampa do capô e verificou que havia um furo no tubo que levava a gasolina para o motor. E não havia um tubo sobressalente. Após bastante tempo sob o sol escaldante, ele lembrou que tinha um rolo de fita isolante no porta-luvas, então pegou a fita isolante e enrolou-a bem apertada no tubo, na região do furo. 
A viagem prosseguiu tensa, pois não havia certeza de que a gasolina seria suficiente para a chegada ao destino. Aliás, a tensão e a incerteza parecem dominar o panorama dessa região tão árida.

Após a leitura da quarta história "No Sertão", marque um X sobre o intervalo que você considera mais adequado para qualificar a história como um todo.
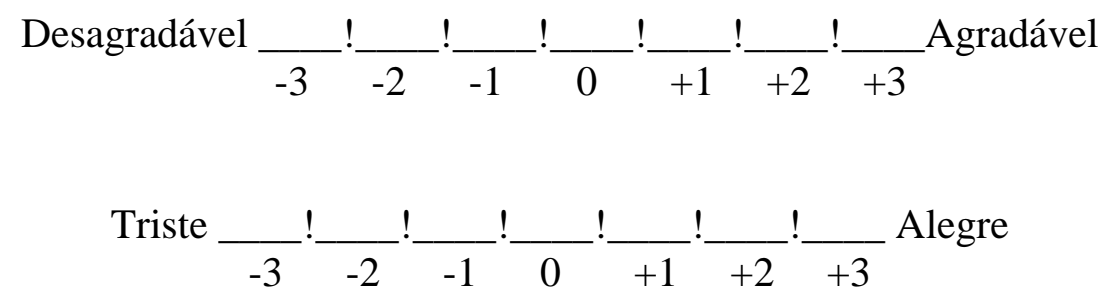

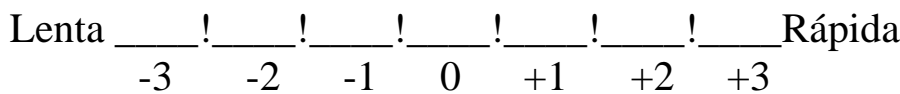
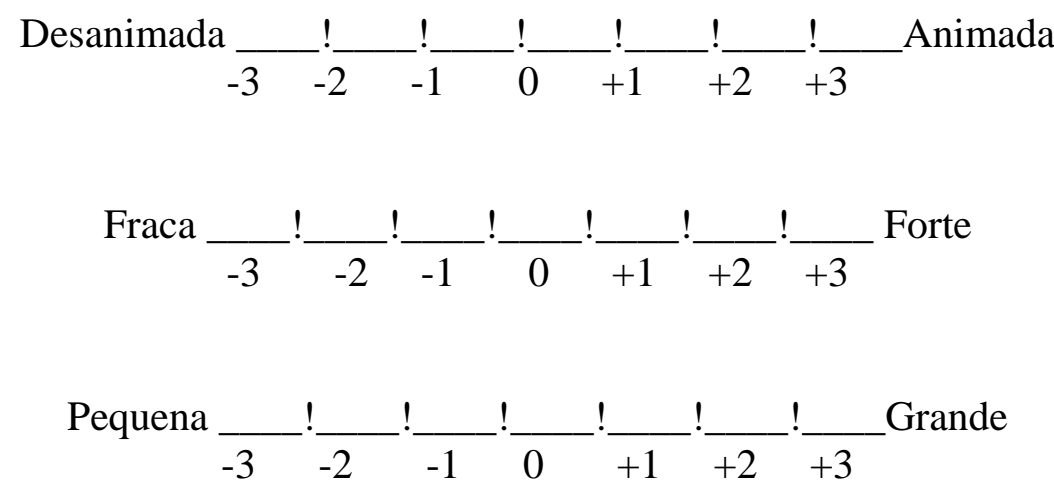

\section{HISTÓRIA V:}

\section{NO PARQUE FLORESTAL}

Cada vez tem sido mais freqüente a presença pessoas que exploram os caminhos mais sinuosos de enorme parque florestal. Ao andar por estes caminhos, pode-se ver uma vegetação exuberante. Muitas árvores nativas, como o pau-brasil, estão lá representadas. Há também muitos córregos e riachos cortando o parque e não raro se vê cachoeiras inesperadas. No verão, freqüentemente, há pessoas refrescando-se nelas. A paz é intensa e pode-se se sentir uma grande comunicação com a natureza. 
Há também muitos animais no parque. Lindos pássaros e vários mamíferos, inclusive alguns exemplares raros, como o mico-leão dourado. Eles parecem não ter medo e se aproximam bastante.

O parque é muito bem cuidado. Há placas orientando os visitantes solicitando que não se acendam fogueiras ou se deixe lixo no chão. Parece que os freqüentadores do parque têm prazer em contribuir na preservação, pois não há vestígios de lixo ou de destruição.

A área destinada ao acampamento fica em um platô de onde se tem uma vista de tirar o fôlego de tão bela. Há também uma área coberta com banheiros e um centro de apoio ao eco-turismo local.

Os celulares não funcionam no parque e deste modo o rádio transmissor é um recurso importante para qualquer eventualidade. No último fim de semana houve um pequeno problema com o rádio transmissor e o guarda florestal de plantão procurou conserta-lo. Abriu sua tampa e logo localizou o defeito que era apenas um parafuso frouxo. Ele procurou a chave de fenda para apertá-lo, mas, como não a encontrou, usou uma faca de ponta arredondada. Com movimentos rotativos cuidadosos conseguiu apertar o parafuso.

Porém neste parque acontecimentos que perturbam sua rotina são raros. Parece que seus freqüentadores o tratam como um santuário, um local privilegiado de paz e harmonia.

Após a leitura da quinta história "No Parque Florestal”, marque um X sobre o intervalo que você considera mais adequado para qualificar a história como um todo.

Desagradável $\frac{}{-3} ! \frac{1}{-2} ! \frac{1}{-1} ! \frac{1}{0} ! \frac{1}{+1} ! \frac{1}{+2} ! \frac{\ldots}{+3}$ Agradável

Triste $\frac{}{-3} ! \frac{}{-2} ! \frac{1}{-1} ! \frac{1}{0} ! \frac{1}{+1} ! \frac{1}{+2} ! \frac{1}{+3}$ Alegre

Lenta $\left.\frac{}{-3} ! \frac{1}{-2} ! \frac{1}{-1} ! \frac{}{0} ! \frac{1}{+1} ! \frac{1}{+2} !\right]_{+3}$ Rápida 


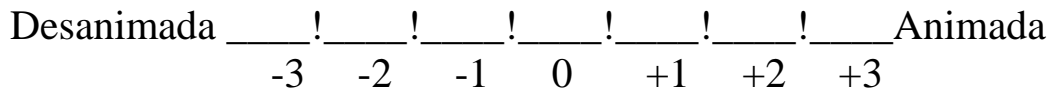

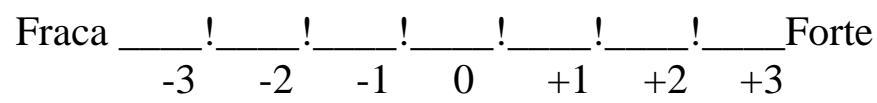

Pequena $\frac{}{-3} ! \frac{}{-2} ! \frac{1}{-1} ! \frac{1}{0} ! \frac{1}{+1} ! \frac{1}{+2} ! \frac{1}{+3}$ Grande

Cabe destacar que a sua colaboração está sendo muito importante, pois está contribuindo com informações que nos ajudarão a aprimorar a metodologia da nossa pesquisa. Agradeço a sua disponibilidade em participar da mesma.

Para finalizar, por favor, forneça as seguintes informações a seu respeito:

SEXO: ( )masculino ( )feminino

IDADE:

CURSO:

PERÍODO: 


\section{ANEXO 3 - ESTUDO PILOTO 2 (COM PROBLEMAS NEUTROS)}

O objetivo desse estudo piloto foi a investigação da preferência dos indivíduos dos modos de solução serial ou convergente, frente a um problema análogo ao da radiação de Duncker (1945).

O resultado esperado seria a inexistência de diferença significativa na preferência pelos dois modos de solução do problema “alvo".

\section{Método}

\section{a)Sujeitos}

Houve a participação de 22 estudantes universitários do curso de psicologia, 17 mulheres e 5 homens, com média de idade de 20,23 anos, cursando o terceiro período da Universidade Federal do Espírito Santo (UFES), situada em Vitória (ES).

\section{b)Instrumentos}

\section{-Problemas utilizados}

Foram utilizados dois problemas “fonte", dois problemas distrativos e um problema “alvo”, construídos sem qualquer conotação afetiva, isto é, neutros.

As histórias dos problemas “fonte” apresentados foram: "Uma Viagem com Escalas” e "Viagem de Navio". Esses problemas, análogos ao da radiação de Duncker, continham, cada um, uma solução serial ou convergente.

A história do problema “alvo”, intitulada "No laboratório”, foi construída de modo a que seu problema pudesse ser solucionado, adequadamente, pela solução serial ou convergente.

As histórias dos problemas distrativos apresentadas foram intituladas "Estudo do Solo” e Testando o Material” .

A descrição desses problemas encontra-se, na íntegra, nas folhas de instruções/ respostas, ao final desse anexo. 


\section{-Questionários}

Foram utilizados quatro questionários de múltipla escolha relativos aos problemas "fonte" e distrativos, sendo que os dois questionários relativos às histórias dos problemas “fonte” apresentaram quatro questões cada e os dois questionários relativos às histórias dos problemas distrativos apresentaram, por sua vez, três questões cada.

Esses questionários tiveram, como principal objetivo, auxiliar a compreensão e o aprendizado dos problemas (“fonte” e distrativos) no que diz respeito às suas principais características, incluindo-se aqui a opinião dos sujeitos sobre a tonalidade afetiva das histórias, bem como sobre o modo de solução dado para cada problema contido nas histórias. Esses questionários encontram-se nas folhas de instrução/ respostas apresentadas no final desse anexo.

\section{c)Procedimento}

A participação na pesquisa foi voluntária e a testagem agendada com antecedência com a professora de disciplina e com os participantes. Na primeira sessão, inicialmente, houve a apresentação da pesquisadora pela professora da disciplina. Em seguida, foi dado um esclarecimento sobre a natureza da pesquisa, sobre a participação voluntária dos alunos e sobre os termos do compromisso ético assumido pela pesquisadora.

Nessa sessão, os sujeitos foram testados em grupo, em sessões consecutivas, mas foram apresentados aos problemas individualmente, ou seja, cada sujeito recebeu folhas de instrução/ respostas de modo individual. No sentido de controlar possíveis efeitos de ordem de apresentação das histórias provenientes de uma vinculação exclusiva de cada solução a um só problema, bem como os possíveis efeitos de primazia ou de proximidade temporal das histórias, os sujeitos foram distribuídos aleatoriamente em quatro subgrupos:

Grupo A (6 sujeitos): em primeiro lugar, houve a apresentação do problema da história “Uma Viagem com Escalas” com solução serial e, em segundo lugar, a apresentação do problema da história "Viagem de Navio” com solução convergente.

Grupo B (6 sujeitos): em primeiro lugar, houve a apresentação do problema da história “Uma Viagem com Escalas” com solução convergente e, em segundo lugar, a apresentação do problema da história “Viagem de Navio” com solução serial. 
Grupo C (5 sujeitos): em primeiro lugar, houve a apresentação do problema da história "Viagem de Navio" com solução serial e, em segundo lugar, a apresentação do problema da história “Uma Viagem com Escalas” com solução convergente.

Grupo D (5 sujeitos): em primeiro lugar, houve a apresentação do problema da história "Viagem de Navio" com solução convergente e, em segundo lugar, a apresentação do problema da história “Uma Viagem com Escalas” com solução serial.

A identificação dos sujeitos que, pertenceram a cada um desses quatro subgrupos, foi feita através da combinação de uma letra e um número coloridos nas folhas de rosto da primeira e da segunda sessões. Dessa maneira, cada participante pôde ser identificado pela combinatória de letra e número que recebeu. Esse procedimento pretendeu, por um lado, preservar o anonimato dos participantes e, por outro, permitir que houvesse uma correspondência entre as folhas das histórias e dos questionários da primeira sessão com as folhas dos problemas “alvo” da segunda sessão.

Ao final da apresentação de cada problema, houve a apresentação do questionário já referido que teve, como principal objetivo, reforçar o aprendizado das soluções vinculadas aos problemas da primeira sessão.

Na medida em que os sujeitos completaram a tarefa da primeira sessão, foi distribuída a folha de resposta onde constava o problema “alvo” a ser solucionado. Nessa sessão consecutiva à primeira, foram instruídos a escolher, apenas um modo de solução, aquele que achassem o mais adequado para o problema “alvo”. Ao final, houve a solicitação para que justificassem a escolha. O tempo de duração das duas sessões foi de, aproximadamente, 40 minutos.

Ao final da sessão, foi feito um agradecimento pela participação dos estudantes e foi assumido o compromisso, por parte da pesquisadora, de dar um feedback dos resultados da pesquisa aos participantes.

\section{d)Resultados e Discussão}

Utilizou-se, como teste de significância, o teste não-paramétrico “qui-quadrado”. O nível de significância mínimo adotado foi de 5\%.

A grande maioria dos sujeitos transferiu, para o problema "alvo", os modos de solução dos problemas “fonte” (20; 90,9\%). Apenas dois sujeitos escolheram outros modos de solução, sendo que um deles escolheu a solução de um dos problemas 
distrativos e o outro apresentou uma transferência "parcial”, pois sua resposta continha elementos da solução serial e convergente.

No que se refere à freqüência entre os modos de solução serial e convergente, objeto principal de nossa investigação, verificou-se que a freqüência da preferência pelo modo de solução serial foi um pouco maior $(11 ; 55 \%)$ do que a preferência pela solução convergente ( $9 ; 45 \%)$.

A diferença observada na preferência pelos modos de solução serial e convergente não foi significativa. $X^{2}(1)=0,2, p>0,05$.

Não se observaram efeitos de ordem de apresentação das histórias na escolha do modo de solução.

A maioria dos participantes considerou as histórias dos problemas "fonte", distrativos e "alvo" com de tonalidade afetiva neutra.

Consideramos que nossos resultados sejam sugestivos de que os dois modos de solução, serial e convergente, não apresentem discrepâncias nas preferências dos indivíduos, havendo possibilidade de que sejam escolhidos com probabilidades similares, quando estiverem igualmente disponíveis, como nessa investigação. 


\section{Instrucões do estudo piloto 2}

Abaixo será apresentada uma das quatro versões das folhas de instrução/ respostas.

\section{(Folhas de instrução/ respostas)}

Nas páginas seguintes serão apresentadas quatro histórias que contém uma situaçãoproblema e sua respectiva solução. Leia as histórias com atenção, na ordem em que serão apresentadas e logo após a leitura de cada história, responda a um pequeno questionário de múltipla escolha. Em outras palavras, mantenha a ordem na execução da tarefa: comece primeiro lendo a primeira história e responda ao questionário relativo à mesma, depois leia a segunda história e responda ao questionário relativo à segunda história e, assim por diante, até a última história. O tempo disponível será de cerca de 40 minutos.

Cabe destacar que sua colaboração está sendo muito importante, pois está contribuindo com informações que nos ajudarão a aprimorar a metodologia da pesquisa. Agradeço a sua disponibilidade em participar da mesma.

Mas, antes de começar a leitura das histórias, por favor, forneça as seguintes informações a seu respeito:

IDADE:

SEXO: ( ) masculino ( ) feminino

CURSO:

PERÍODO: 
História I:

ESTUDO DO SOLO

Um grupo de geógrafos estava viajando por uma região, situada no interior do Brasil, para fazer uma avaliação dos diferentes tipos de solo que esta região apresentava, pois havia aí uma diversidade geográfica que se expressava através de diferentes relevos e das diferenças encontradas na coloração da terra.

O objetivo principal desse grupo era o de implementar um projeto governamental que visava a estudar o impacto do plantio de determinados legumes e frutas na região.

O trabalho de avaliação do solo era muito meticuloso e demandava o uso de recursos tecnológicos, tais como aparelhos de medição e de coleta de terra em diferentes pontos da região. Para isso, havia a demanda de muitos dias de trabalho para que todo o material necessário fosse coletado, etiquetado e armazenado para posterior análise.

Como a região era distante e remota, a comunicação era feita através de um radio transmissor que o grupo transportava, pois os telefones celulares não funcionavam no local.

Entretanto, no último fim de semana houve um pequeno problema com o rádio transmissor e o geógrafo mais experiente do grupo foi chamado para consertá-lo. Ele abriu a tampa e logo localizou o defeito que era apenas um parafuso frouxo. Como não encontrou a chave de fenda para apertar o parafuso, usou uma faca de ponta arredondada para este fim e, com movimentos rotativos cuidadosos, conseguiu apertar o parafuso.

Após o conserto do rádio, os geógrafos continuaram seu trabalho minucioso de coleta e armazenamento de material e quando voltaram para as suas cidades, carregavam uma boa quantidade de dados para análise.

A partir da leitura da história “Estudo do Solo” , marque uma única resposta em cada questão.

1)Na sua opinião, a história "Estudo do Solo" pode ser considerada:

a)Uma história que relata um episódio alegre e agradável.

b)Uma história que relata um episódio triste e desagradável.

c)Uma história que relata um episódio neutro, nem agradável/alegre, nem desagradável/triste. 
2)Na história "Estudo do solo", qual foi o principal objetivo dos geógrafos:

a)Coletar amostras do solo para a construção de uma barragem na região.

b)Mapear os terrenos da região para a construção de um condomínio de casas.

c)Implementar um projeto do governo que visava a analisar as condições do solo para o plantio de frutas e de legumes na região.

e)Nenhuma das respostas acima.

3)Na história "Estudo do solo", qual foi a solução dada ao problema que surgiu no radio transmissor:

a)Um dos geógrafos abriu a tampa e apertou um parafuso frouxo em seu interior com uma faca de ponta arredondada.

b)Um dos geógrafos abriu a tampa e retirou uma placa enferrujada de seu interior.

c)Os quatro geógrafos juntos amarraram a tampa do rádio com um barbante e apertaram bastante o nó que fizeram.

d)Os geógrafos preferiram comunicar-se com um telefone celular, ao invés de consertar o radio transmissor.

\section{História II: $\quad$ UMA VIAGEM COM ESCALAS (modo de solução serial)}

Em um aeroporto, uma equipe técnica foi chamada para resolver um problema que estava, há horas, impossibilitando um avião de decolar.

Era um avião de carga que tinha saído do México e que estava voando em direção ao Brasil, fazendo escalas em vários países da América do Sul para se abastecer de novos carregamentos em cada país em que aterrissava. Na sua escala no Chile, para se abastecer de um carregamento de vinhos, o avião não conseguiu sair do chão e por isso uma equipe especializada em conserto de aeronaves foi chamada.

Após procurar bastante a causa do problema, os técnicos verificaram, através de um visor, que um dos transistores do sistema de controle da altitude estava recoberto de mofo. Como este transistor estava situado no centro de um compartimento lacrado, não poderia haver uma manipulação direta do mesmo ou seja, o compartimento não poderia ser aberto para a limpeza do mofo.

Os técnicos resolveram utilizar o calor emitido por raios infravermelhos para a eliminação do mofo no transistor, já que o transistor era feito de um material resistente à radiação. Porém, para que o mofo fosse totalmente eliminado, havia a necessidade de 
uma alta intensidade de radiação. Mas havia um problema com o qual os técnicos se depararam: como as paredes do compartimento, onde se situava o transistor mofado eram recobertas internamente por uma frágil película, uma alta intensidade de radiação incidida sobre ela poderia danificá-la, o que deveria ser evitado.

Após se perguntar como conseguiriam aumentar a intensidade da radiação infravermelha sobre o transistor, sem danificar a película, os técnicos chegaram a uma solução.

A solução encontrada foi a de lançar feixes de raios infravermelhos, de baixa intensidade, emitidos uns após os outros, em série, que foram focalizados e incididos na parte mofada do transistor, a intervalos de tempo que permitiam a absorção e o acúmulo de calor no transistor, eliminando assim o mofo de modo gradual e continuo, sem que a película fosse danificada. Esta solução se mostrou eficaz e o avião pôde assim seguir viagem sem mais problemas.

A partir da leitura da história “Uma Viagem com Escalas”, marque uma única resposta em cada questão.

1)Na sua opinião, a história “Uma Viagem com Escalas” pode ser considerada:

a)Uma história que relata um episódio alegre e agradável.

b)Uma história que relata um episódio triste e desagradável.

c)Uma história que relata um episódio neutro: nem agradável/alegre, nem desagradável/triste.

2)Na história “Uma Viagem com Escalas", como poderia ser caracterizado o avião relatado na história:

a)Era um avião de carga que fazia escalas em vários paises da América do Sul para se abastecer de carregamentos em cada país que aterrissava.

b)Era um avião de passageiros que fazia escalas em várias cidades do Brasil.

c)Era um hidroavião que fazia escalas em diferentes rios da Amazônia.

d)Nenhuma das respostas acima.

3)Na história “Uma Viagem com Escalas”, quais foram os países que faziam parte da rota do avião, citados pelo narrador:

a)França, Bolívia e Venezuela. 
b)México, Chile e Brasil.

c)Argentina, Turquia e Brasil.

d)Todos os países acima.

4)Na história “Uma Viagem com Escalas”, qual foi a solução dada pelos técnicos para o problema do avião:

a)Eles fizeram a emissão de raios infravermelhos de alta intensidade de uma só vez e assim eliminaram o mofo no transistor, não se importando em danificar a frágil película que o envolvia.

b)Eles fizeram a emissão de raios infravermelhos de baixa intensidade, uns após os outros, em série, a intervalos de tempo que permitiam a absorção e o acúmulo de calor no transistor, eliminando assim o mofo de modo gradual e continuo, sem que a película fosse danificada.

c)Eles fizeram a emissão de raios infravermelhos, mas como isso não deu certo, acabaram utilizando outro tipo de solução. A nova solução foi a encomenda de um novo transistor para a substituição daquele que estava com mofo.

d) Eles não utilizaram nenhum tipo de raio para a eliminação do mofo no transistor.

\section{História III}

\section{VIAGEM DE NAVIO (modo de solução convergente)}

Em um navio de passageiros os encarregados do setor de cargas foram convocados pelo capitão para resolverem um problema que estava ocorrendo em um contêiner que carregava alimentos.

Era um grande navio de transporte de passageiros, mas que também possuía compartimentos no porão, onde eram transportados vários contêineres que armazenavam diferentes tipos de mercadorias, inclusive alimentos perecíveis e bebidas.

Após uma avaliação inicial do que estava acontecendo, os técnicos do setor de conservação e manutenção de cargas constataram, através de uma janela de vidro, que a temperatura de um dos contêineres de alimentos estava subindo, pois um filamento que estava dentro do contêiner e que fazia parte do seu sistema de refrigeração estava coberto de fungo, o que ocasionava o mau funcionamento deste sistema. Havia assim a necessidade de um rápido conserto para que não houvesse a deterioração desses alimentos. 
Após pensar muito, eles chegaram à melhor solução para este problema. A solução proposta foi o uso de raios ultravioletas (UV) para a esterilização do filamento com fungo. Os técnicos sabiam que não poderiam abrir o contêiner para manusear diretamente o filamento, pois os alimentos não poderiam ter contato com o ar. Também sabiam que havia a exigência de uma alta intensidade de raios para que esta esterilização fosse eficaz. Entretanto, sabiam também que não poderiam emitir toda e radiação necessária através de uma única emissão de raios da alta intensidade, pois a alta intensidade emitida de uma só vez poderia danificar as paredes internas do contêiner que eram feitas de um gel protetor.

A solução encontrada foi a de lançar feixes de raios ultravioletas, de baixa intensidade, emitidos uns após os outros, em série, que foram focalizados e incididos sobre o fungo do filamento, a intervalos de tempo que permitiam a absorção e o acúmulo de radiação no transistor, esterilizando assim o filamento de modo gradual e continuo, sem que o gel protetor fosse danificado. Os alimentos foram assim preservados, pois o sistema de refrigeração do contêiner voltou a funcionar normalmente após este conserto.

A partir da leitura da história “Viagem de Navio", marque uma única resposta em cada questão.

1)Na sua opinião, a história "Viagem de Navio" pode ser considerada:

a)Uma história que relata um episódio alegre e agradável.

b)Uma história que relata um episódio triste e desagradável.

c)Uma história que relata um episódio neutro: nem agradável/alegre, nem desagradável/triste.

2)Na história "Viagem de Navio", como poderia ser caracterizado o navio relatado na história::

a)Era um grande navio de passageiros que também transportava diferentes tipos de carga.

b)Era um grande navio de passageiros que fazia um cruzeiro pelo litoral do Brasil.

c)Era um navio petroleiro que transportava uma carga de petróleo para exportação.

d)Nenhuma das respostas acima. 
3)Na história "Viagem de Navio", selecione abaixo as mercadorias que foram citadas como estando no compartimento de cargas:

a)Carros, tratores e veículos de vários tipos.

b)Alimentos perecíveis e bebidas.

c)Computadores e todo tipo de peças de informática.

d)Todas as mercadorias acima.

4)Na história "Viagem de Navio", qual foi a solução dada pelos encarregados do setor de carga do navio para a conservação dos alimentos:

a)Eles fizeram a emissão de raios ultravioletas (UV) de baixa intensidade, emitidos de diferentes fontes de emissão, cada uma delas posicionada em um ponto diferente, e que foram focalizadas para convergir, todas ao mesmo tempo, para o filamento com fungo, de modo que pelo somatório de sua radiação pudessem chegar a uma forte radiação e assim pudessem esterilizar o filamento sem que fossem danificadas as paredes do contêiner.

b)Eles fizeram a emissão de raios ultravioletas (UV) de alta intensidade em uma única emissão sobre o filamento com fungo, sem se preocupar com eventuais danos nas paredes do contêiner.

c)Eles fizeram a emissão de raios ultravioletas (UV) sobre o filamento com fungo, mas como isso não deu certo, eles acabaram utilizando outro tipo de solução, que foi a de chamar técnicos de um outro navio para resolverem o problema.

d)Eles não utilizaram nenhum tipo de raio para esterilizar o filamento com fungo.

\section{História IV:}

\section{TESTANDO O MATERIAL}

Quatro alpinistas profissionais viajavam de jipe por uma área montanhosa, onde pretendiam escalar a maior pedra que se destacava na região. Pretendiam ir de jipe até uma localidade que se situava na base da cadeia de montanhas e começar a partir daí sua escalada.

O grupo levava os equipamentos necessários para e empreitada, bem como portavam mochilas com alimentos não perecíveis, medicamentos, sacos de dormir e roupas apropriadas.

Estes alpinistas tinham sido contratados por uma firma de equipamentos de montanhismo para testar um novo tipo de material a base de fibra de nylon que recobria 
as mochilas, com o intuito de verificar se este material era bastante resistente à chuva e ao peso da carga das mochilas.

Como era uma firma bem conhecida e respeitada no ramo, ela não queria colocar à venda um produto que não tivesse sido bem testado nas condições de uso para as quais foi desenvolvido. Para isso resolveu contratar profissionais experientes que pudessem avaliar a resistência do material para compará-lo com outros materiais existentes no mercado.

Na sua viagem de regresso, após alguns dias escalando, ao pegarem o jipe no local onde o deixaram, os alpinistas verificaram que, ao ligarem o carro, o ponteiro do marcador de gasolina começou a baixar rapidamente. Eles abriram a tampa do capô e verificaram que havia um furo no tubo que levava a gasolina para o motor. Porém não havia um tubo sobressalente. Mas um dos alpinistas se lembrou que havia um rolo de fita isolante no porta-luvas do jipe, pegou então a fita e enrolou-a bem apertada no tubo, na região do furo.

A viagem então pode prosseguir sem mais problemas e os alpinistas quando retornaram, apresentaram um relatório detalhado da viagem, onde foi avaliado o grau de resistência do material da nova mochila a ser colocada à venda no mercado.

A partir da leitura da história “Testando o Material”, marque uma única resposta em cada questão.

1)Na sua opinião a história “Testando o Material” pode ser considerada:

a)Uma história que relata um episódio alegre e agradável

b)Uma história que relata um episódio triste e desagradável

c)Uma história que relata um episódio neutro, nem agradável/alegre, nem desagradável/triste.

2)Na história “Testando o Material”, qual foi o principal objetivo dos alpinistas:

a)Testar um novo material à base de fibra de nylon, utilizado em mochilas, para avaliar sua resistência às chuvas e ao peso da carga das mochilas.

b)Testar um novo tipo de corda de nylon desenvolvida para a escalada em superfícies escorregadias, como a de determinadas pedras.

c)Testar o sabor de um novo tipo de alimento em pó não perecível que possuía alto teor nutritivo e seria adequado para consumo em longas escaladas.

d)Nenhuma das respostas acima. 
3)Na história “Testando o Material”, qual foi a solução dada ao problema que surgiu com o jipe dos alpinistas:

a)Um pedaço de algodão foi utilizado para secar a gasolina que vazou do tanque.

b)Uma fita isolante foi enrolada bem apertada no furo do tubo que levava a gasolina do tanque até o motor do jipe.

c)Um lenço foi utilizado para apertar o tubo na região do furo.

d)Foi chamado um mecânico de carros para consertar o jipe. 
Leia com atenção a história abaixo e após a leitura da mesma, responda a pergunta que será apresentada no final da folha.

\section{LEMBRANCAS DO LABORATÓRIO}

Lembro-me bem daquele ano de 1995, quando trabalhava no laboratório de pesquisa de Biologia Médica da Faculdade de Biologia. Nosso laboratório era bem equipado para testar procedimentos no tratamento de diferentes doenças e, em particular, vínhamos desenvolvendo uma série de abordagens experimentais com culturas de microorganismos.

Neste ano, nos foi trazido por um professor do Centro de Agropecuária, que conhecia nosso laboratório, uma cobaia com um tumor de difícil acesso cirúrgico. Esta cobaia despertou nosso interesse científico de imediato. De fato, acabou incentivando o início de uma nova linha de pesquisa.

Como, neste caso, havia a impossibilidade de uma intervenção cirúrgica, resolvemos optar por um procedimento de aplicação de radiação.

Porém havia um problema com o qual nós cientistas nos deparamos: o tumor precisava ser destruído por uma alta intensidade de radiação, pois uma baixa intensidade não conseguiria destruí-lo. Mas, por outro lado, a emissão de raios de alta intensidade poderia afetar os tecidos corporais sadios que estavam ao redor do tumor, o que não poderia acontecer.

Como você acha que foi resolvido este problema da emissão de raios para destruir o tumor, sem que fossem danificados os tecidos corporais sadios que o envolviam?

Lembre-se das histórias que você leu anteriormente, elas podem dar uma dica para a solução desse problema. Mas, lembre-se também que você deve escolher uma única solução para este problema, ou seja, aquela solução que vier primeiro à sua cabeça. Mas, somente após a escolha da solução por escrito, leia a pergunta da página seguinte.

Agora responda à seguinte questão:

Como você acha que os cientistas resolveram esse problema da emissão de raios para extinguir o tumor, sem danificar os tecidos corporais sadios que o envolviam? 
Lembre-se das histórias que você leu anteriormente, elas podem dar uma dica para a solução desse problema. Mas, lembre-se também que você deve escolher uma única solução para este problema, ou seja, aquela solução que vier primeiro à sua cabeça. Mas, só após a escolha da solução por escrito, leia a pergunta da página seguinte.

OBS: Na página seguinte foi feito o pedido de justificativa da escolha com a seguinte instrução: “Justifique, com suas palavras, porque escolheu esta solução”. 


\section{ANEXO 4: CONTROLE DA EQUIVALENNCIA DE PALAVRAS}

Este controle tem por finalidade manter certa equivalência das palavras que aparecem nas histórias dos problemas “fonte”, dos problemas distrativos e dos problemas “alvo”. Em outros termos, o controle dessa equivalência será feito em termos da manutenção de um número equivalente de palavras que se repetem, especialmente quando comparamos as histórias "fonte” a “alvo". Em relação às histórias alvo, estas também foram equiparadas entre si, mas com a preocupação de estabelecer uma contraposição de idéias e ações (de tonalidades opostas), com a manutenção dos personagens e do tipo de acontecimento que é narrado.

1) Equivalência entre os problemas “fonte” e “alvo"

\section{A)Entre o problema fonte triste serial e o alvo triste:}

Palavras comuns entre os dois:

Difícil; dinheiro; perder/perdido; morar; episódio; lembro; grande; muito; aqueles/aquele; velho/velha; todo; dia/dias; vários; fazer; chegamos/chegava; tivemos.

Palavras comuns em todos os problemas e aqui também:

Problema; solução; emissão e emitidos; alta; baixa; raios e radiação; intensidade; danificar e dano.

TOTAL: $16+8=24$

\section{B)Entre o problema fonte triste convergente e o alvo triste:}

Palavras comuns entre os dois:

Difícil; dinheiro; perder/perdido; morar; episódio; lembro; grande; aqueles/aquele; muito; velho/velha; todo; dia/dias; vários; fazer; chegamos/ chegava; tivemos.

Palavras comuns em todos os problemas e aqui também:

Problema; solução; emissão e emitidos; alta; baixa; raios e radiação; intensidade; danificar e dano.

TOTAL: $16+8=24$ 


\section{Palavras comuns entre os dois:}

Lembrar/lembrado; tudo; comprar/compras; feliz; atividades; grande; filho/ filhos; muito; emprego; bom/ boa; novo; risos/ rimos; presente; paredes; gostavam/ gostam; inclusive.

Palavras comuns em todos os problemas e aqui também:

Problema; solução; emissão e emitidos; alta; baixa; raios e radiação; intensidade; danificar e dano.

TOTAL: $16+8=24$

\section{D)Entre o problema fonte alegre convergente e o alvo alegre:}

\section{Palavras comuns entre os dois:}

Lembrar/lembrado; tudo; comprar/compras; feliz; atividades; grande; filho/filhos; muito; emprego; bom/boa; novo; risos/rimos; presente; paredes; gostavam/gostam; inclusive.

Palavras comuns em todos os problemas e aqui também:

Problema; solução; emissão e emitidos; alta; baixa; raios e radiação; intensidade; danificar e dano.

TOTAL: $16+8=24$

\section{E)Entre o problema fonte triste serial e o alvo alegre:}

Palavras comuns entre os dois:

Muito; grande; lembro; episódio; hoje; semanas; descansar; emprego;

dinheiro; dificuldade; disposição; morar; condições, físicas; fazer; pareciam.

Palavras comuns em todos os problemas e aqui também:

Problema; solução; emissão e emitidos; alta; baixa; raios e radiação; intensidade; danificar e dano.

TOTAL: $16+8=24$

F)Entre o problema fonte triste convergente e o alvo alegre:

Palavras comuns entre os dois:

Muito; grande; lembro; episódio; hoje; semanas; descansar; emprego; dinheiro; dificuldade; disposição; morar; condições; físicas; fazer; pareciam. Palavras comuns em todos os problemas e aqui também: 
Problema; solução; emissão e emitidos; alta; baixa; raios e radiação; intensidade; danificar e dano.

TOTAL: $16+8=24$

\section{G)Entre o problema fonte alegre serial e o alvo triste:}

Palavras comuns entre os dois:

Lembro/lembrando; todo/todos; inclusive; muito; novos; grande; vários;

alimento; diferentes; bastante; difícil; dia/dias; urgência; ano; fazer; gente.

Palavras comuns em todos os problemas e aqui também:

Problema; solução; emissão e emitidos; alta; baixa; raios e radiação; intensidade; danificar e dano.

TOTAL: $16+8=24$

H)Entre o problema fonte alegre convergente e o alvo triste:

Palavras comuns entre os dois:

Lembro/lembrado; todo/todos; inclusive; muito; novos; grande; vários;

alimento; diferentes; bastante; difícil, dia/dias, urgência; ano; fazer; gente.

Palavras comuns em todos os problemas e aqui também:

Problema; solução; emissão e emitidos; alta; baixa; raios e radiação; intensidade; danificar e dano.

TOTAL: $16+8=24$

I)Entre o problema fonte neutro serial (avião) e o alvo neutro:

Palavras comuns entre os dois:

Utilizar; aumentar/aumentasse; novos/novo; poderia; única; resolver.

Palavras comuns em todos os problemas e aqui também:

Problema; solução; emissão e emitidos; alta; baixa; raios e radiação; intensidade; danificar e dano.

TOTAL: $6+8=14$

J)Entre o problema fonte neutro convergente (avião) e o alvo neutro:

Palavras comuns entre os dois:

Utilizar; aumentar/aumentasse; novos/novo; poderia; todas; resolver.

$\underline{\text { Palavras comuns entre todos os problemas e aqui também: }}$ 
Problema; solução; emissão e emitidos; alta; baixa; raios e radiação; intensidade; danificar e dano.

TOTAL: $6+8=14$

K)Entre o problema fonte neutro serial (navio) e o alvo neutro:

Palavras comuns entre os dois:

Armazenada/armazenava; poderia; grande; resolver; única.

Palavras comuns entre todos os problemas e aqui também:

Problema; solução; emissão e emitidos; alta; baixa; raios e radiação;

intensidade; danificar e dano.

TOTAL: $5+8=13$

L)Entre o problema fonte neutro convergente (navio) e o alvo neutro:

Palavras comuns entre os dois:

Armazenada/armazenava; poderia; grande; resolver; todas.

Palavras comuns entre os problemas e aqui também:

Problema; solução; emissão e emitidos; alta; baixa; raios e radiação; intensidade; danificar e dano.

TOTAL: $5+8=13$

2)Equivalência entre os problemas distrativos triste e alegre:

A)Entre os dois problemas distrativos:

Palavras comuns entre os dois:

muito; tampa; parece/parecem; é/são; abriu; apertar/apertado; há; coberta/ coberto.

Palavras comuns com os outros problemas:

problema; consertar.

TOTAL: $8+2=10$

B)Entre o distrativo triste e o alvo triste:

Palavras comuns entre os dois:

lembro/lembrou; difícil; grande; período; dificuldade; muito/muitas; gente; velho/velha.

Palavras comuns com os outros problemas:

problema; consertar

TOTAL: $8+2=10$ 


\section{C)Entre o distrativo alegre e o alvo alegre:}

Palavras comuns entre os dois:

grande; muito; linda/lindas/lindo; acontecimentos; sentir; parece/parecia, qualquer; eventualidade.

Palavras comuns com os outros problemas:

problema; consertar.

TOTAL: $8+2=10$

\section{3) Equivalência entre os problemas "alvo" triste e alegre:}

Nesse caso, essa equivalência se refere mais a uma oposição de termos e idéias (e também de palavras), pois se pretende aqui estabelecer uma contraposição entre os acontecimentos que, no caso, são revestidos por uma tonalidade emocional oposta.

\section{Palavras comuns entre os dois:}

Ano; muito; lembro; fosse; hoje; logo; tudo; mulher; grande; estado; acabado; muito/ muitos; dia; precisou; bebê; morar; casa; meados; julho; exame; médico; dor/ dores; inclusive; saúde; atendimento; sala; paredes; enfermeira; encaminhada/ encaminhamento; recebida; rim; esquerdo; próxima; consulta; tratamento; atingido/ atingir; deparou; conseguiria; poderia; tecidos; corporais; sadios; acha; resolveu; envolviam, histórias; leu; dica; lembre-se; escolher; única; considerar; melhor; todas.

TOTAL: 56 palavras

Palavras (e idéias) com conotações opostas:

Ano difícil/ ano bom; perda do emprego / novo emprego; desemprego continua/ emprego continua; gastou todo o dinheiro/ guardou dinheiro; prevenido/ desprevenido; mulher perdeu um filho/ mulher ganhou um filho; casal deprimido/ casal feliz; mudança de casa involuntária/ mudança de casa voluntária; queda do padrão de vida/ melhora no padrão de vida; quarto pequeno e velho/ casa nova e ampla; paredes imundas /paredes limpas e decoradas; cama velha, feia e quebrada/ berço novo e bonito; mau cheiro/ bom cheiro; mau estado de saúde /bom estado de saúde; sem apetite (emagrecimento, etc.))/ com apetite; desânimo/ ânimo; hospital/ consultório médico; atendimento ruim/ bom atendimento; adiamento da consulta e espera de dois meses/ consulta imediata; depois a 
necessidade de um atendimento de urgência/ exame de rotina; atendimento coletivo (sala cheia)/ atendimento individualizado (sala individual); sala com paredes descascadas cheias de infiltração/ sala limpa e agradável (não parecia um consultório médico); médico antipático / médico simpático; enfermeira agressiva/ enfermeira carinhosa; grande tumor cancerígeno/ tumor benigno; rim não funcionava direito/ rim funcionava perfeitamente; dores e estado debilitado/ nenhum incômodo ou dor; episódio preocupante/ episódio engraçado; tomar medicamentos/ tomar líquidos; grave intoxicação/ um pouco de tonteira; todos preocupados com o episódio/ todos rindo do episódio; situação com gravidade/ situação sem gravidade; extinguir o tumor maligno com a radiação/ extinguir o tumor benigno com radiação; ameaça de um piora no estado de saúde/ sem ameaça de uma piora.

TOTAL: 34 idéias que se contrapõem.

Palavras comuns em todos os problemas e aqui também:

Problema; solução; emissão; intensidade; baixa; alta; raios; danificar.

TOTAL: 8 palavras 


\section{ANEXO 5: QUESTIONÁRIOS}

\section{1-Questionários apresentados após os problemas “fonte”:}

A partir da leitura da história “Aterrissagem Forçada”, marque uma única resposta em cada questão.

1)Na sua opinião, a história “Aterrissagem Forçada” pode ser considerada:

a)Uma história que relata um episódio alegre e agradável.

b) Uma história que relata um episódio triste e desagradável.

c)Uma história que relata um episódio neutro: nem agradável/alegre, nem desagradável/triste.

2)Quais foram os principais acontecimentos que levaram ao narrador desta história a viajar em um avião de carga:

a)A falta de dinheiro, a perda dos pais e a ida para a casa dos tios em outra cidade.

b)A falta de dinheiro, a visita aos pais em outra cidade e a vontade de viajar.

c)A perda dos pais, a vontade de deixar a faculdade e a visita aos tios em outra cidade.

d) Nenhuma das respostas acima.

3)Quais das situações abaixo foram vivenciadas pelo narrador desta história:

a)Uma grande tempestade que sacudiu o velho avião onde viajava.

b)Armas apontadas para a sua cabeça por soldados agressivos.

c)Passou fome, frio e sofreu maus tratos como prisioneiro.

d)Todas as respostas acima.

4)a sua opinião, nesta história, as experiências vividas pelo jovem no campo de prisioneiros deixaram:

a)Poucas cicatrizes físicas e nenhuma cicatriz psicológica.

b)Poucas cicatrizes psicológicas e nenhuma cicatriz física.

c)Muitas cicatrizes físicas e psicológicas que se tornaram lembranças tristes com o passar do tempo.

d) Não deixaram nenhuma marca, pois foram logo esquecidas. 
5)Após você ter lido a história “Aterrissagem Forçada”, você se sentiu:

a)Senti-me afetado(a) negativamente pela história, pois ela relata um episódio desagradável e angustiante.

b)Senti-me afetado(a) positivamente pela história, pois ela relata um episódio alegre e agradável.

c)Não me senti afetado(a) negativamente pela história, embora a tenha achado triste.

d)Não me senti afetado(a) nem positivamente, nem negativamente, pela história e não achei a história nem triste, nem alegre.

6)Na história “Aterrissagem Forçada”, qual foi a solução dada pelos técnicos que consertaram o avião na oficina?:

(questão a ser dada apenas para quem viu o modo de solução serial no problema fonte triste)

a)Eles fizeram a emissão de raios infravermelhos de alta intensidade de uma só vez e assim eliminaram o mofo no transistor, não se importando em danificar a frágil película que o envolvia.

b)Eles fizeram a emissão de raios infravermelhos de baixa intensidade, uns após os outros, em série, a intervalos de tempo que permitiam a absorção e o acúmulo de calor no transistor, eliminando assim o mofo de modo gradual e contínuo, sem que a película fosse danificada.

c)Eles fizeram a emissão de raios infravermelhos, mas como isso não deu certo, acabaram utilizando outro tipo de solução. A nova solução foi a encomenda de um novo transistor para a substituição daquele que estava mofado.

d) Eles não utilizaram nenhum tipo de raio para a eliminação do mofo no transistor.

OU

6)a história “Aterrissagem forçada”, qual foi a solução dada pelos técnicos que consertaram o avião na oficina:

(questão a ser dada apenas para quem viu o modo de solução convergente no problema fonte triste) 
a)Eles fizeram a emissão de raios infravermelhos de alta intensidade de uma só vez e assim eliminaram o mofo do transistor, não se importando em danificar a frágil película que o envolvia.

b) Eles fizeram a emissão de raios infravermelhos de baixa intensidade que foram emitidos de diferentes fontes de emissão, cada uma delas posicionada em um ponto diferente e que foram focalizadas para convergir todas ao mesmo tempo sobre o transistor mofado de modo que, pelo somatório de sua radiação, pudessem eliminar o mofo, sem que a película fosse danificada.

c) Eles fizeram a emissão de raios infravermelhos, mas como isso não deu certo, acabaram utilizando outro tipo de solução. A nova solução foi a encomenda de um novo transistor para a substituição daquele que estava mofado.

d)Eles não utilizaram nenhum tipo de raio para a eliminação do mofo no transistor.

A partir da leitura da história “Cruzeiro de Sonho”, marque uma única resposta em cada questão.

1)Na sua opinião, a história “Cruzeiro de Sonho” pode ser considerada:

a)Uma história que relata um episódio alegre e agradável.

b)Uma história que relata um episódio triste e desagradável.

c)Uma história que relata um episódio neutro, nem agradável/alegre, nem desagradável/triste.

2)Quais foram os principais acontecimentos que levaram o narrador desta história a fazer um cruzeiro de navio:

a)Não passou no vestibular e ganhou e viagem dos pais para se distrair.

b)Passou no vestibular e viajou junto com os pais e o irmão.

c)Passou bem colocado no vestibular e ganhou a viagem dos pais, viajando com amigos.

d)Nenhuma das respostas anteriores.

3)Quais foram as principais atividades do narrador desta história no navio:

a)Assistiu a filmes, fez compras no shopping e participou de jantares saborosos.

b) Participou de jogos e ganhou um torneio de frescobol.

c)Fez novos amigos e ficou amigo do cozinheiro do restaurante.

d)Todas as respostas acima. 
4) Na sua opinião, nesta história, a viagem do jovem no navio foi:

a) Divertida, com muitas experiências alegres e positivas.

b) Penosa, com muitas experiências tristes e negativas.

c) Em alguns momentos foi alegre em outros foi triste.

c) Nem divertida, nem penosa, foi apenas uma viagem comum.

5)Após ter lido a história “Cruzeiro de Sonho”, você se sentiu:

a)Senti-me afetado(a) negativamente pela história, pois ela relata um episódio desagradável e angustiante.

b)Senti-me afetado(a) positivamente pela história, pois ela relata um episódio alegre e agradável.

c)Não me senti afetado(a) positivamente pela história, embora a tenha achado alegre.

d)Não me senti afetado(a) nem positivamente, nem negativamente, pela história e não achei a história nem alegre, nem triste.

6)Na história “Cruzeiro de Sonho”, qual foi a solução dada pelos encarregados do setor de carga do navio para a conservação dos alimentos:

(questão a ser dada para quem viu o modo de solução serial no problema fonte alegre).

a)Eles fizeram a emissão de feixes de raios ultravioletas (UV) com baixa intensidade, que foram emitidos uns após os outros, em série, e que foram focalizados e incididos sobre o fungo do filamento, a intervalos de tempo que permitiam a absorção e o acúmulo gradativo de radiação neste filamento, esterilizando-o, sem que o gel protetor fosse danificado.

b)Eles fizeram a emissão de raios ultravioletas (UV) com alta intensidade em uma única emissão sobre o fungo do filamento, sem se preocupar com eventuais danos no gel protetor das paredes internas do contêiner.

c)Eles fizeram a emissão de raios ultravioletas (UV) sobre o fungo do filamento, mas como isso não deu certo, eles acabaram utilizando outro tipo de solução, que foi a de chamar técnicos de um outro navio para resolverem o problema.

d)Eles não utilizaram nenhum tipo de raio para esterilizar o filamento com fungo. 
6)Na história "Cruzeiro de Sonho", qual foi a solução dada pelos encarregados do setor de carga para a conservação dos alimentos no container:

(questão a ser dada para quem viu o modo de solução divergente no problema fonte alegre)

a)Eles fizeram a emissão de raios ultravioletas (UV) de baixa intensidade, emitidos de diferentes fontes de emissão, cada uma delas posicionada em um ponto diferente, e que foram focalizadas para convergir, todas ao mesmo tempo, para o filamento com fungo, de modo que pelo somatório de sua radiação pudessem chegar a uma forte radiação e assim pudessem esterilizar o filamento sem que fossem danificadas as paredes do contêiner.

b)Eles fizeram a emissão de raios ultravioletas (UV) de alta intensidade em uma única emissão sobre o fungo do filamento, sem se preocupar com eventuais danos nas paredes do contêiner.

c)Eles fizeram a emissão de raios ultravioletas (UV) sobre o filamento com fungo, mas como isso não deu certo, eles acabaram utilizando outro tipo de solução, que foi a de chamar técnicos de um outro navio para resolverem o problema.

d)Eles não utilizaram nenhum tipo de raio para esterilizar o fungo do filamento.

\section{2-Questionários apresentados após os problemas "fonte” neutros:}

A partir da leitura da história “Uma Viagem com Escalas”, marque uma única resposta em cada questão.

1)Na sua opinião, a história “Uma Viagem com Escalas” pode ser considerada:

a)Uma história que relata um episódio alegre e agradável.

b)Uma história que relata um episódio triste e desagradável.

c)Uma história que relata um episódio neutro: nem agradável/alegre, nem desagradável/triste.

2)Na história “Uma Viagem com Escalas”, como poderia ser caracterizado o avião relatado na história:

a)Era um avião de carga que fazia escalas em vários paises da América do Sul para se abastecer de carregamentos em cada país que aterrissava.

b)Era um avião de passageiros que fazia escalas em várias cidades do Brasil. 
c)Era um hidroavião que fazia escalas em diferentes rios da Amazônia.

d)Nenhuma das respostas acima.

3)Na história “Uma Viagem com Escalas”, quais foram os países que faziam parte da rota do avião, citados pelo narrador:

a)França, Bolívia e Venezuela.

b)México, Chile e Brasil.

c)Argentina, Turquia e Brasil.

d)Todos os países acima.

4)Na história “Uma Viagem com Escalas”, qual foi a solução dada pelos técnicos para o problema do avião:

(questão a ser dada apenas para quem viu o modo de solução serial )

a)Eles fizeram a emissão de raios infravermelhos de alta intensidade de uma só vez e assim eliminaram o mofo no transistor, não se importando em danificar a frágil película que o envolvia.

b)Eles fizeram a emissão de raios infravermelhos de baixa intensidade, uns após os outros, em série, a intervalos de tempo que permitiam a absorção e o acúmulo de calor no transistor, eliminando assim o mofo de modo gradual e continuo, sem que a película fosse danificada.

c)Eles fizeram a emissão de raios infravermelhos, mas como isso não deu certo, acabaram utilizando outro tipo de solução. A nova solução foi a encomenda de um novo transistor para a substituição daquele que estava com mofo.

d) Eles não utilizaram nenhum tipo de raio para a eliminação do mofo no transistor.

OU

4) Na história “Uma Viagem com Escalas”, qual foi a solução dada pelos técnicos para o problema do avião:

(questão a ser dada apenas para quem viu o modo de solução convergente)

a)Eles fizeram a emissão de raios infravermelhos de alta intensidade de uma só vez e assim eliminaram o mofo no transistor, não se importando em danificar a frágil película que o envolvia.

b)Eles fizeram a emissão de raios infravermelhos de baixa intensidade que foram emitidos de diferentes fontes de emissão, cada uma delas posicionada em um ponto 
diferente e que foram focalizadas para convergir todas ao mesmo tempo sobre o transistor mofado de modo que, pelo somatório de sua radiação pudessem eliminar o mofo sem que a película fosse danificada.

c) Eles fizeram a emissão de raios infravermelhos, mas como não deu certo, acabaram utilizando outro tipo de solução. A nova solução foi a encomenda de um novo transistor para a substituição do transistor com mofo.

d)Eles não utilizaram nenhum tipo de raio para a eliminação do mofo no transistor.

A partir da leitura da história "Viagem de Navio", marque uma única resposta em cada questão.

1)Na sua opinião, a história "Viagem de Navio" pode ser considerada:

a)Uma história que relata um episódio alegre e agradável.

b)Uma história que relata um episódio triste e desagradável.

c)Uma história que relata um episódio neutro: nem agradável/alegre, nem desagradável/triste.

2)Na história "Viagem de Navio", como poderia ser caracterizado o navio relatado na história::

a)Era um grande navio de passageiros que também transportava diferentes tipos de carga.

b)Era um grande navio de passageiros que fazia um cruzeiro pelo litoral do Brasil.

c)Era um navio petroleiro que transportava uma carga de petróleo para exportação.

d)Nenhuma das respostas acima.

3)Na história "Viagem de Navio", selecione abaixo as mercadorias que foram citadas como estando no compartimento de cargas:

a)Carros, tratores e veículos de vários tipos.

b)Alimentos perecíveis e bebidas.

c)Computadores e todo tipo de peças de informática.

d)Todas as mercadorias acima. 
4)Na história "Viagem de Navio", qual foi a solução dada pelos encarregados do setor de carga do navio para a conservação dos alimentos:

(questão a ser dada para quem viu o modo de solução serial no problema fonte alegre).

a)Eles fizeram a emissão de raios ultravioletas (UV) com baixa intensidade, que foram emitidos uns após os outros, em série, a intervalos de tempo que permitiam a absorção e o acúmulo gradativo de radiação neste filamento, esterilizando-o, sem que o gel protetor fosse danificado.

b)Eles fizeram a emissão de raios ultravioletas (UV) com alta intensidade em uma única emissão sobre o fungo do filamento, sem se preocupar com eventuais danos nas paredes internas do contêiner.

c)Eles fizeram a emissão de raios ultravioletas (UV) sobre o filamento com fungo, mas como isso não deu certo, eles acabaram utilizando outro tipo de solução, que foi a de chamar técnicos de um outro navio para resolverem o problema.

d)Eles não utilizaram nenhum tipo de raio para esterilizar o filamento com fungo.

$\mathrm{OU}$

4)Na história "Viagem de Navio", qual foi a solução dada pelos encarregados do setor de carga para a conservação dos alimentos no container:

(questão a ser dada para quem viu o modo de solução convergente no problema fonte alegre)

a)Eles fizeram a emissão de raios ultravioletas (UV) de baixa intensidade, emitidos de diferentes fontes de emissão, cada uma delas posicionada em um ponto diferente, e que foram focalizadas para convergir, todas ao mesmo tempo, para o filamento com fungo, de modo que pelo somatório de sua radiação pudessem chegar a uma forte radiação e assim pudessem esterilizar o filamento sem que fossem danificadas as paredes do contêiner.

b)Eles fizeram a emissão de raios ultravioletas (UV) de alta intensidade em uma única emissão sobre o filamento com fungo, sem se preocupar com eventuais danos nas paredes do contêiner.

c)Eles fizeram a emissão de raios ultravioletas (UV) sobre o filamento com fungo, mas como isso não deu certo, eles acabaram utilizando outro tipo de solução, que foi a de chamar técnicos de um outro navio para resolverem o problema.

d)Eles não utilizaram nenhum tipo de raio para esterilizar o filamento com fungo. 


\section{3- Questionários apresentados após os problemas “distrativos”:}

A partir da leitura da história "No Sertão", marque uma única resposta em cada questão.

1)Na sua opinião, a história “No Sertão" pode ser considerada:

a)Uma história que relata um episódio alegre e agradável.

b)Uma história que relata um episódio triste e desagradável.

c)Uma história que relata um episódio neutro: nem agradável/alegre, nem desagradável/triste.

2)Como poderia ser caracterizada e região onde se passa a história "No Sertão":

a)Uma região árida, com pouca água, quase sem vegetação, com longos períodos de seca e muito quente.

b)Uma região de floresta de vasta vegetação, com muitos riachos e onde a natureza é preservada pelos visitantes.

c)Uma região fria e montanhosa, onde a neve predomina na maior parte do tempo.

d)Nenhuma das respostas acima.

3)Qual foi a solução dada ao problema que surgiu na história "No Sertão":

a)O motorista do ônibus trocou um pneu que furou na estrada.

b)O motorista do ônibus enrolou uma fita isolante no furo do tubo que levava a gasolina do tanque para o motor para estancar um vazamento.

c)O motorista de ônibus pediu ajuda a um mecânico para consertar o motor que parou de funcionar.

d)Nenhuma das respostas acima.

A partir da leitura da história “No Parque Florestal”, marque uma única história em cada questão.

1)Na sua opinião, a história “No Parque Florestal” pode ser considerada:

a)Uma história que relata um episódio alegre e agradável. 
b)Uma história que relata um episódio triste e desagradável.

c)Uma história que relata um episódio neutro: nem agradável/alegre, nem desagradável/triste.

2)Como poderia ser caracterizada a região onde se passa a história "No Parque

\section{Florestal":}

a)Uma região árida, com pouca água, quase sem vegetação, com longos períodos de seca e muito quente.

b)Uma região de floresta de vasta vegetação, com muitos riachos e onde a natureza é preservada pelos visitantes.

c)Uma região fria e montanhosa, onde a neve predomina a maior parte do tempo.

d)Nenhuma das respostas acima.

3)Qual foi a solução dada ao problema que surgiu na história "No Parque Florestal":

a)Como o rádio transmissor não estava funcionando, o guarda florestal utilizou um telefone celular como meio de comunicação.

b)O guarda florestal usou um alicate para cortar um fio que se soltou dentro do rádio transmissor e assim o rádio voltou a funcionar normalmente.

c)O guarda florestal usou uma faca de ponta arredondada e com movimentos rotativos apertou o parafuso frouxo dentro do rádio transmissor e assim o rádio voltou a funcionar normalmente.

d)Nenhuma das respostas acima.

\section{4- Questionários apresentados após os problemas “distrativos” neutros:}

A partir da leitura da história “Estudo do Solo” , marque uma única resposta em cada questão.

1)Na sua opinião, a história “Estudo do Solo" pode ser considerada:

a)Uma história que relata um episódio alegre e agradável.

b)Uma história que relata um episódio triste e desagradável.

c)Uma história que relata um episódio neutro, nem agradável/alegre, nem desagradável/triste. 
2)Na história “Estudo do solo", qual foi o principal objetivo dos geógrafos:

a)Coletar amostras do solo para a construção de uma barragem na região.

b)Mapear os terrenos da região para a construção de um condomínio de casas.

c)Implementar um projeto do governo que visava analisar as condições do solo para o plantio de frutas e de legumes na região.

e)Nenhuma das respostas acima.

3)Na história "Estudo do solo", qual foi a solução dada ao problema que surgiu no radio transmissor:

a)Um dos geógrafos abriu a sua tampa e apertou um parafuso frouxo em seu interior com uma faca de ponta arredondada.

b)Um dos geógrafos abriu a sua tampa e retirou uma placa enferrujada de seu interior.

c)Os quatro geógrafos juntos amarraram a tampa do rádio com um barbante e apertaram bastante o nó que fizeram.

d)Os geógrafos preferiram se comunicar com um telefone celular ao invés de consertar o radio transmissor.

A partir da leitura da história “Testando o Material”, marque uma única resposta em cada questão.

1)Na sua opinião a história “Testando o Material” pode ser considerada:

a)Uma história que relata um episódio alegre e agradável

b)Uma história que relata um episódio triste e desagradável

c)Uma história que relata um episódio neutro, nem agradável/alegre, nem desagradável/triste.

2)Na história “Testando o Material”, qual foi o principal objetivo dos alpinistas:

a)Testar um novo material à base de fibra de nylon, utilizado em mochilas, para avaliar sua resistência às chuvas e ao peso da carga das mochilas.

b)Testar um novo tipo de corda de nylon desenvolvida para a escalada em superfícies escorregadias, como a de determinadas pedras.

c)Testar o sabor de um novo tipo de alimento em pó não perecível que possuía alto teor nutritivo e seria adequado para consumo em longas escaladas. 
d)Nenhuma das respostas acima.

3)Na história “Testando o Material”, qual foi a solução dada ao problema que surgiu com o jipe dos alpinistas:

a)Um pedaço de algodão foi utilizado para secar a gasolina que vazou do tanque.

b)Uma fita isolante foi enrolada bem apertada no furo do tubo que levava a gasolina do tanque até o motor do jipe.

c)Um lenço foi utilizado para apertar o tubo na região do furo.

d)Foi chamado um mecânico de carros para consertar o jipe.

\section{Considerações sobre as respostas dos sujeitos aos questionários}

As respostas dadas pelos sujeitos nos questionários podem ser consideradas satisfatórias. Nas sessões consecutivas e nas sessões com intervalo de uma semana houve um bom número de acerto nas soluções dadas aos 4 problemas apresentados nas 4 histórias, pois cerca de 95\% dos sujeitos acertaram as 4 soluções. Nesse sentido, o aprendizado das soluções serial e convergente parece ter sido reforçado.

A história fonte “Aterrissagem Forçada” foi avaliada, pelos sujeitos, como triste por 96,19\% dos sujeitos nas sessões consecutivas e por 95\% dos sujeitos, nas sessões com intervalo de uma semana. De modo complementar, a história fonte "Cruzeiro de Sonho” foi avaliada como alegre por 94\% dos sujeitos, nas sessões consecutivas e por 93,3\% dos sujeitos, nas sessões com intervalo de uma semana. Sendo assim, quase a totalidade dos sujeitos percebeu uma das histórias "fonte” como triste e a outra como alegre. Esse achado é importante, a nosso ver, pois parece reforçar os achados do estudo piloto 1 (anexo 2) sobre a tonalidade afetiva das histórias. Observa-se também que os sujeitos, em sua maioria, nos dois intervalos de tempo (cerca de 75\%) também não se sentiram afetados pela leitura das histórias “fonte” triste e alegre, apesar de terem considerado essas histórias, respectivamente, triste e alegre.

No que refere às histórias distrativas, a história "No Sertão” foi considerada, por cerca de 70\% dos sujeitos, de ambos os intervalos de tempo, como triste e a história "No Parque Florestal” foi considerada, por cerca de 60\% dos sujeitos como alegre. 


\section{ANEXO 6: AVALIAÇÃO DOS CONTROLES UTILIZADOS: ORDEM DE

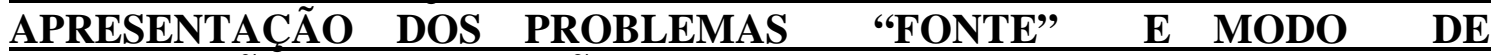 VINCULACÃO DAS SOLUCÕES AOS PROBLEMAS “FONTE”}

Nesse anexo encontram-se as principais tabelas e testes de significância utilizados para avaliação da eficácia dos controles utilizados na nossa pesquisa, no que se refere às variáveis intervenientes ordem de apresentação dos problemas fonte e modo de vinculação das solução aos problemas “fonte”.

\section{1-Sessões Consecutivas}

1.1-Freqüência de Transferências e a Ordem de Apresentação

TABELA 18 - FREQUÊNCIA DE SUJEITOS QUE EXIBIRAM TRANSFERÊNCIA E A ORDEM DE APRESENTAÇÃO DOS PROBLEMAS FONTE

\begin{tabular}{|c|c|c|c|c|c|}
\hline \multirow{2}{*}{ TRANSFERÊNCIA } & \multicolumn{5}{|c|}{ ORDEM DE APRESENTAÇÃO DOS PROBLEMAS FONTE } \\
\hline & $\begin{array}{l}\text { TRISTE SERIAL E } \\
\text { ALEGRE } \\
\text { CONVERGENTE }\end{array}$ & $\begin{array}{c}\text { TRISTE } \\
\text { CONVERGENTE E } \\
\text { ALEGRE SERIAL }\end{array}$ & $\begin{array}{l}\text { ALEGRE SERIAL } \\
\text { E TRISTE } \\
\text { CONVERGENTE }\end{array}$ & $\begin{array}{c}\text { ALEGRE } \\
\text { CONVERGENTE E } \\
\text { TRISTE SERIAL }\end{array}$ & TOTAL \\
\hline TRANSFERÊNCIA & 53 & 52 & 50 & 55 & 210 \\
\hline $\begin{array}{l}\text { TRANSFERÊNCIA } \\
\text { PARCIAL }\end{array}$ & 5 & 6 & 7 & 5 & 23 \\
\hline $\begin{array}{l}\text { SEM } \\
\text { TRANSFERÊNCIA }\end{array}$ & 7 & 8 & 8 & 7 & 30 \\
\hline TOTAL & 65 & 66 & 65 & 67 & 263 \\
\hline
\end{tabular}

$$
X^{2}(6)=0,819, p>0,05
$$

1.2- Freqüência de Escolha dos Problemas Fonte e a Ordem em que Foram Apresentados 
TABELA 19 - FREQUÊNCIA DE ESCOLHA DOS PROBLEMAS FONTE E A ORDEM EM QUE FORAM APRESENTADOS

\begin{tabular}{|c|c|c|c|c|c|}
\hline \multirow{2}{*}{$\begin{array}{l}\text { PROBLEMA } \\
\text { FONTE } \\
\text { ESCOLHIDO }\end{array}$} & \multicolumn{5}{|c|}{ ORDEM DE APRESENTAÇÃO DOS PROBLEMAS FONTE } \\
\hline & $\begin{array}{l}\text { TRISTE SERIAL E } \\
\text { ALEGRE } \\
\text { CONVERGENTE } \\
\end{array}$ & $\begin{array}{c}\text { TRISTE } \\
\text { CONVERGENTE E } \\
\text { ALEGRE SERIAL } \\
\end{array}$ & $\begin{array}{l}\text { ALEGRE SERIAL } \\
\text { E TRISTE } \\
\text { CONVERGENTE }\end{array}$ & $\begin{array}{c}\text { ALEGRE } \\
\text { CONVERGENTE E } \\
\text { TRISTE SERIAL } \\
\end{array}$ & TOTAL \\
\hline FONTE TRISTE & 35 & 31 & 27 & 35 & 128 \\
\hline FONTE ALEGRE & 18 & 21 & 23 & 20 & 82 \\
\hline $\begin{array}{l}\text { OUTRA } \\
\text { ESCOLHA }\end{array}$ & 12 & 14 & 15 & 12 & 53 \\
\hline TOTAL & 65 & 66 & 65 & 67 & 263 \\
\hline
\end{tabular}

$X^{2}(6)=2,492, p>0,05$

1.3-Variações do Humor e Ordem de Apresentação dos Problemas Fonte

\begin{tabular}{|c|c|c|c|c|c|}
\hline \multirow{2}{*}{$\begin{array}{l}\text { VARIAÇÃO DO } \\
\text { HUMOR }\end{array}$} & \multicolumn{5}{|c|}{ ORDEM DE APRESENTAÇÃO DOS PROBLEMAS FONTE } \\
\hline & $\begin{array}{l}\text { TRISTE SERIAL E } \\
\text { ALEGRE } \\
\text { CONVERGENTE } \\
\end{array}$ & $\begin{array}{c}\text { TRISTE } \\
\text { CONVERGENTE E } \\
\text { ALEGRE SERIAL } \\
\end{array}$ & $\begin{array}{l}\text { ALEGRE SERIAL } \\
\text { E TRISTE } \\
\text { CONVERGENTE } \\
\end{array}$ & $\begin{array}{c}\text { ALEGRE } \\
\text { CONVERGENTE E } \\
\text { TRISTE SERIAL } \\
\end{array}$ & TOTAL \\
\hline POSITIVA & 2 & 2 & 3 & 4 & 14 \\
\hline NEGATIVA & 7 & 13 & 4 & 10 & 34 \\
\hline SEM VARIAÇÃO & 55 & 51 & 58 & 53 & 217 \\
\hline TOTAL & 64 & 66 & 65 & 67 & 262 \\
\hline
\end{tabular}

$X^{2}(6)=6,702, p>0,05$

\section{2- Sessões com Intervalo de Uma Semana}

2.1- Freqüências de Transferências e a Ordem de Apresentação dos Problemas Fonte 
TABELA 21 - FREQUÊNCIA DE SUJEITOS QUE EXIBIRAM TRANSFERÊNCIA E A ORDEM DE APRESENTAÇÃO DOS PROBLEMAS FONTE

\begin{tabular}{|c|c|c|c|c|c|}
\hline \multirow{2}{*}{ TRANSFERENCIA } & \multicolumn{5}{|c|}{ ORDEM DE APRESENTAÇÃO DOS PROBLEMAS FONTE } \\
\hline & $\begin{array}{c}\text { TRISTE SERIAL E } \\
\text { ALEGRE } \\
\text { CONVERGENTE }\end{array}$ & $\begin{array}{c}\text { TRISTE } \\
\text { CONVERGENTE E } \\
\text { ALEGRE SERIAL } \\
\end{array}$ & $\begin{array}{l}\text { ALEGRE SERIAL } \\
\text { E TRISTE } \\
\text { CONVERGENTE } \\
\end{array}$ & $\begin{array}{c}\text { ALEGRE } \\
\text { CONVERGENTE E } \\
\text { TRISTE SERIAL } \\
\end{array}$ & TOTAL \\
\hline TRANSFERÊNCIA & 33 & 32 & 29 & 34 & 128 \\
\hline $\begin{array}{l}\text { TRANSFERÊNCIA } \\
\text { PARCIAL }\end{array}$ & 7 & 6 & 4 & 4 & 21 \\
\hline $\begin{array}{l}\text { SEM } \\
\text { TRANSFERÊNCIA }\end{array}$ & 5 & 6 & 11 & 9 & 31 \\
\hline TOTAL & 45 & 44 & 44 & 47 & 180 \\
\hline
\end{tabular}

$X^{2}(6)=4,557, p>0,05$

2.2- Freqüência de Escolha dos Problemas Fonte e a Ordem em que Foram Apresentados

TABELA 22 - FREQUÊNCIA DE ESCOLHA DOS PROBLEMAS FONTE E A ORDEM EM QUE FORAM APRESENTADOS

\begin{tabular}{l|c|c|c|c|c}
\hline \multirow{2}{*}{$\begin{array}{l}\text { PROBLEMA } \\
\text { FONTE } \\
\text { ESCOLHIDO }\end{array}$} & \begin{tabular}{c}
\multicolumn{5}{c}{ ORDEM DE APRESENTAÇÃO DOS PROBLEMAS FONTE } \\
TRISTE SERIAL E \\
ALEGRE \\
CONVERGENTE
\end{tabular} & $\begin{array}{c}\text { TRISTE } \\
\text { CONVERENTE E } \\
\text { ALEGRE SERIAL }\end{array}$ & $\begin{array}{c}\text { ALEGRE SERIAL } \\
\text { E TRISTE } \\
\text { CONVERGENTE }\end{array}$ & $\begin{array}{c}\text { ALEGRE } \\
\text { CONVERGENTE E } \\
\text { TRISTE SERIAL }\end{array}$ & TOTAL \\
\hline FONTE TRISTE & 19 & 17 & 13 & 20 & 69 \\
FONTE ALEGRE & 14 & 15 & 16 & 14 & 59 \\
OUTRA ESCOLHA & 12 & 12 & 15 & 13 & 52 \\
TOTAL & 45 & 44 & 44 & 47 & 180 \\
\hline
\end{tabular}

$X^{2}(6)=2,199, p>0,05$ 
2.3- Variação do Humor e a Ordem de Apresentação dos Problemas Fonte

TABELA 23-VARIAÇÃO DO HUMOR E ORDEM DE APRESENTAÇÃO DOS PROBLEMAS FONTE

\begin{tabular}{l|c|c|c|c|c}
\hline \multirow{2}{*}{$\begin{array}{l}\text { VARIAÇÃO DO } \\
\text { HUMOR }\end{array}$} & $\begin{array}{c}\text { ORDEM DE APRESENTAÇÃO DOS PROBLEMAS FONTE } \\
\text { TRISTE SERIAL E } \\
\text { ALEGRE } \\
\text { CONVERGENTE }\end{array}$ & $\begin{array}{c}\text { TRISTE } \\
\text { CONVERGENTE E } \\
\text { ALEGRE SERIAL }\end{array}$ & $\begin{array}{c}\text { ALERE SERIAL } \\
\text { E TRISTE } \\
\text { CONVERGENTE }\end{array}$ & $\begin{array}{c}\text { ALEGRE } \\
\text { CONVERGENTE E } \\
\text { TRISTE SERIAL }\end{array}$ & TOTAL \\
\hline POSITIVA & 3 & 3 & 5 & 3 & 14 \\
NEGATIVA & 9 & 9 & 3 & 4 & 25 \\
SEM VARIAÇÃO & 31 & 32 & 31 & 39 & 133 \\
TOTAL & 43 & 44 & 39 & 46 & 172 \\
\hline
\end{tabular}

$$
X^{2}(6)=6,597, p>0,05
$$

Como se pode observar, podemos considerar os controles utilizados eficazes, tendo em vista que as diferenças entre os grupos foram todas não significativas.

Por último, cabe ainda observar que, nas sessões consecutivas, um sujeito não deu nota ao seu estado de humor, após a leitura das histórias “alvo”, e oito sujeitos não deram nota ao seu estado de humor nas sessões com intervalo de uma semana. 


\section{ANEXO 7: FOLHAS DE INSTRUCÃO/ RESPOSTAS}

Abaixo as folhas de instrução/ respostas serão apresentadas em uma das quatro versões propostas aos quatro subgrupos das sessões consecutivas.

Nas páginas seguintes serão apresentadas quatro histórias que contém uma situaçãoproblema e sua respectiva solução. Leia as histórias com atenção, na ordem em que serão apresentadas e, logo após a leitura de cada história, responda a um pequeno questionário de múltipla escolha. Em outras palavras, mantenha a ordem na execução da tarefa: comece primeiro lendo a primeira história e responda ao questionário relativo à mesma, depois leia a segunda história e responda ao questionário relativo à segunda história e, assim por diante, até a última história. O tempo disponível será de cerca de 40 minutos.

Cabe destacar que a sua colaboração será muito importante. Agradeço a sua disponibilidade em participar dessa pesquisa.

Mas, antes de começar a leitura das histórias, por favor, forneça as seguintes informações a seu respeito:

IDADE:

SEXO: ( ) masculino ( ) feminino

CURSO:

PERÍODO:

DÊ UMA NOTA DE 0 A 100 AO SEU ESTADO ATUAL DE HUMOR.

NOTA: 


\section{HISTÓRIA I:}

NO SERTÃO

Atravessar, de ônibus, aquela região do interior é muito penoso. A paisagem é desoladora, semi-árida, quase não há vegetação e, quando há alguma, ela é espinhosa e retorcida. E tudo parece coberto por uma poeira vermelha, sufocante. De vez em quando se avista um casebre, feito de estuque e com cobertura de sapê, muito pequeno e pobre. Quando existe alguma plantação à volta dos casebres, ela é em pequena escala e as plantas, quase sempre pés de mandioca, parecem não se ter desenvolvido bem.

A água é precária na região e chove muito pouco. Grandes períodos de seca parecem predominar e tornar a vida ainda mais difícil. Não existe nenhum açude na região e há uma grande dificuldade para se encontrar um poço que tenha água suficiente. Muitas vezes o percurso para se chegar a um desses poços é extenso e as pessoas têm que carregar as latas de água na cabeça.

A estrada de terra batida é estreita e cheia de buracos. O calor durante o dia é intenso. Além disso, os ônibus são apinhados de gente. São velhos e mal conservados e dão muito defeito, levando a paradas que podem durar horas, sob o sol a pino neste calor opressor. Mas é a única condução coletiva disponível para transporte a distâncias maiores.

Nesta mesma semana, o ponteiro do marcador de gasolina de um ônibus começou a baixar rapidamente e um forte cheiro de gasolina se espalhou. O motorista abriu a tampa do capô e verificou que havia um furo no tubo que levava a gasolina para o motor. E não existia um tubo sobressalente. Após bastante tempo sob o sol escaldante, lembrou que tinha um rolo de fita isolante no porta-luvas, então pegou a fita e enrolou-a bem apertada no tubo, na região do furo.

A viagem prosseguiu tensa, pois não havia certeza de que a gasolina seria suficiente para a chegada ao destino. Aliás, a tensão e a incerteza parecem dominar o panorama dessa região tão árida.

A partir da leitura da história "No Sertão", marque uma única resposta em cada questão.

1)Na sua opinião, a história “No Sertão" pode ser considerada:

a)Uma história que relata um episódio alegre e agradável.

b)Uma história que relata um episódio triste e desagradável. 
c)Uma história que relata um episódio neutro: nem agradável/alegre, nem desagradável/triste.

2)Como poderia ser caracterizada e região onde se passa a história "No Sertão":

a)Uma região árida, com pouca água, quase sem vegetação, com longos períodos de seca e muito quente.

b)Uma região de floresta de vasta vegetação, com muitos riachos e onde a natureza é preservada pelos visitantes.

c)Uma região fria e montanhosa, onde a neve predomina na maior parte do tempo.

d)Nenhuma das respostas acima.

3)Qual foi a solução dada ao problema que surgiu na história "No Sertão":

a)O motorista do ônibus trocou um pneu que furou na estrada.

b)O motorista do ônibus enrolou uma fita isolante no furo do tubo que levava a gasolina do tanque para o motor para estancar um vazamento.

c)O motorista de ônibus pediu ajuda a um mecânico para consertar o motor que parou de funcionar.

d)Nenhuma das respostas acima.

\section{HISTÓRIA II: $\quad$ ATERRISSAGEM FORÇADA}

Há pouco tempo aconteceu um episódio que deixou marcas profundas em mim e nunca mais fui o mesmo depois do que me aconteceu.

Eu estava em um momento de vida particularmente difícil, pois tinha perdido recentemente meus pais em um desastre de carro e ia morar com meus tios em uma cidade muito distante de onde tinha passado toda a minha vida. Ia deixar para trás meus amigos e a faculdade em que acabara de entrar e isso me deixava ainda mais triste.

Como estava sem dinheiro e sem emprego e meus tios eram muito pobres para me ajudar na viagem, consegui uma carona em um avião de carga em troca de trabalhar durante um mês para o dono do avião.

Quando a viagem de avião começou, eu estava exausto e sem disposição após semanas trabalhando, sem descansar, em péssimas condições. Em um determinado momento da viagem, quando estávamos sobrevoando muito alto, o avião começou a 
tremer todo e a fazer um barulho ensurdecedor o que deixou em pânico todas as pessoas que nele viajavam. Pensei que íamos todos morrer e uma súbita angustia se apoderou de mim e comecei a chorar compulsivamente. Estávamos em um inverno rigoroso e lá fora tudo era cinza e desolado. Uma grande tempestade estava em curso e os raios e trovões só faziam aumentar o meu pavor e sacudiam ainda mais o velho avião.

O piloto resolveu aterrissar para pedir ajuda e, após muita dificuldade, conseguiu faze-lo em um local que parecia uma base militar e, confirmando minhas suspeitas, logo que chegou ao solo, o avião foi cercado por soldados que nos encararam com pesadas armas apontadas em nossa direção. Pensei: Meu Deus! Acho que agora não vou conseguir sair dessa situação, estou em um beco sem saída. Aqueles homens, com o rosto parcialmente coberto, pareciam terroristas e não tinham nada a perder se nos matassem. Tive muito medo do que poderia nos acontecer e fiquei paralisado, sem me mexer na minha poltrona.

O piloto, após uns minutos de hesitação, desceu do avião e foi pedir ajuda àqueles soldados. Após ter sido revistado e humilhado pelo chefe daquele exército, o piloto nos disse que eles até poderiam nos ajudar a consertar o avião, mas que só fariam isso se o avião levasse, em troca, um carregamento de metralhadoras para um grupo de soldados que estava em uma base militar de um país vizinho. Como não tinha outra escolha, o piloto concordou com isso.

Enquanto nós esperávamos o avião ser levado para um local que parecia uma grande oficina, vários soldados continuaram a apontar seus fuzis para as nossas cabeças. O piloto nos contou que, enfim, descobriram qual o problema do avião: tratava-se de um problema no sistema de controle da altitude do avião.

Após procurar bastante a causa do problema, os técnicos da oficina verificaram, através de um visor, que um dos transistores do sistema de controle da altitude estava recoberto de mofo. Como este transistor estava situado no centro de um compartimento lacrado, não poderia haver uma manipulação direta do mesmo, ou seja, o compartimento não poderia ser aberto para a limpeza do mofo.

Os técnicos resolveram, então, utilizar o calor emitido por raios infravermelhos para a eliminação do mofo no transistor, porém para que o mofo fosse totalmente eliminado, havia a necessidade de uma alta intensidade de radiação. Mas havia um problema com o qual os técnicos se depararam: como paredes do compartimento, onde se situava este transistor, eram recobertas internamente por uma frágil película, uma alta intensidade de radiação incidida sobre ela poderia danificá-la, o que deveria ser evitado. 
Após se perguntar como conseguiriam aumentar a intensidade da radiação infravermelha sobre o transistor, sem danificar a película, os técnicos chegaram a uma solução.

A solução encontrada foi a de lançar feixes de raios infravermelhos, de baixa intensidade, emitidos uns após os outros, em série, que foram focalizados e incididos na parte mofada do transistor, a intervalos de tempo que permitiam a absorção e o acúmulo de calor no transistor, eliminando assim o mofo de modo gradual e continuo, sem que a película fosse danificada.

Essa solução mostrou-se eficaz e logo que o conserto ficou pronto, os soldados nos empurraram para dentro do avião e três deles entraram conosco para nos vigiar e, com as armas apontadas para as nossas cabeças, pretendo matar-nos, caso não cumpríssemos o acordo, forçaram a levá-los, junto com o armamento.

Quando chegamos na base militar para onde nos forçaram a ir, fomos presos e ficamos semanas em um campo de prisioneiros, onde passamos todo o tipo de privação. Sentimos frio, fome e fomos maltratados. Sofremos horrores que gostaríamos de esquecer.

Quando me lembro de tudo que passei não sei como consegui sobreviver. Com freqüência acordo durante a noite suando frio e com terríveis pesadelos. Até hoje ainda guardo as cicatrizes físicas e psicológicas desta experiência tão angustiante.

A partir da leitura da história “Aterrissagem Forçada”, marque uma única resposta em cada questão.

1)Na sua opinião, a história “Aterrissagem Forçada” pode ser considerada:

a)Uma história que relata um episódio alegre e agradável.

b) Uma história que relata um episódio triste e desagradável.

c)Uma história que relata um episódio neutro: nem agradável/alegre, nem desagradável/triste.

2)Quais foram os principais acontecimentos que levaram ao narrador desta história a viajar em um avião de carga:

a)A falta de dinheiro, a perda dos pais e a ida para a casa dos tios em outra cidade.

b)A falta de dinheiro, a visita aos pais em outra cidade e a vontade de viajar.

c)A perda dos pais, a vontade de deixar a faculdade e a visita aos tios em outra cidade. 
d) Nenhuma das respostas acima.

3)Quais das situações abaixo foram vivenciadas pelo narrador desta história:

a)Uma grande tempestade que sacudiu o velho avião onde viajava.

b)Armas apontadas para a sua cabeça por soldados agressivos.

c)Passou fome, frio e sofreu maus tratos como prisioneiro.

d)Todas as respostas acima.

4)Na sua opinião, nesta história, as experiências vividas pelo jovem no campo de prisioneiros deixaram:

a)Poucas cicatrizes físicas e nenhuma cicatriz psicológica.

b)Poucas cicatrizes psicológicas e nenhuma cicatriz física.

c)Muitas cicatrizes físicas e psicológicas que se tornaram lembranças tristes com o passar do tempo.

d) Não deixaram nenhuma marca, pois foram logo esquecidas.

5)Após você ter lido a história “Aterrissagem Forçada”, você se sentiu:

a)Senti-me afetado(a) negativamente pela história, pois ela relata um episódio desagradável e angustiante.

b)Senti-me afetado(a) positivamente pela história, pois ela relata um episódio alegre e agradável.

c)Não me senti afetado(a) negativamente pela história, embora a tenha achado triste.

d)Não me senti afetado(a) nem positivamente, nem negativamente, pela história e não achei a história nem triste, nem alegre.

6)Na história “Aterrissagem Forçada”, qual foi a solução dada pelos técnicos que consertaram o avião na oficina?:

a)Eles fizeram a emissão de raios infravermelhos de alta intensidade de uma só vez e assim eliminaram o mofo no transistor, não se importando em danificar a frágil película que o envolvia.

b)Eles fizeram a emissão de raios infravermelhos de baixa intensidade, uns após os outros, em série, a intervalos de tempo que permitiam a absorção e o acúmulo de calor no transistor, eliminando assim o mofo de modo gradual e contínuo, sem que a película fosse danificada. 
c)Eles fizeram a emissão de raios infravermelhos, mas como isso não deu certo, acabaram utilizando outro tipo de solução. A nova solução foi a encomenda de um novo transistor para a substituição daquele que estava mofado.

d) Eles não utilizaram nenhum tipo de raio para a eliminação do mofo no transistor.

\section{HISTÓRIA III}

\section{CRUZEIRO DE SONHO}

Ontem eu estava conversando com uns amigos numa festa e lembrávamos de coisas alegres e engraçadas que nos acontecem na vida. Rimos muito de tudo e recordamos de tudo de bom que nos tinha acontecido nos últimos tempos.

Estava contando a todo mundo uma magnífica viagem de navio que eu tinha feito no ano passado. Era um navio muito luxuoso, com todo tipo de lazer que alguém possa imaginar. Os dias estavam lindos e ensolarados e pudemos tomar muitos banhos de piscina e praticar várias modalidades de esporte. Fomos a boates, a cinemas, a restaurantes com comidas deliciosas e tivemos muita animação dia e noite.

Eu fiz esse cruzeiro marítimo com uma turma de amigos. Como eu havia passado no vestibular muito bem colocado, meus pais, que têm uma boa situação financeira, me deram essa viagem de presente. Aliás, meus pais me apóiam sempre em tudo que faço e formam um casal muito feliz e dinâmico. Eu estava também satisfeito porque tinha um estágio em vista em uma empresa conceituada e isso significava uma chance real de um bom emprego quando terminasse meu curso.

Fomos todos, meus amigos e eu, comemorar juntos o fato de termos passado no vestibular nesse cruzeiro de sonho. Foi tudo tão perfeito que até nas fotos da viagem fica bem visível nossa alegria.

Durante o dia, a diversão maior era na piscina, onde participávamos de torneios e jogos dentro e fora da água. Inclusive, ganhei uma linda taça em um difícil torneio de frescobol e fui muito aplaudido pelo meu desempenho. No fim da tarde, costumávamos assistir a um filme e depois circulávamos pelo grande shopping do navio, onde costumávamos fazer compras e conversávamos com pessoas diferentes que por ali passeavam. Fizemos assim um monte de novos amigos, que se juntaram ao nosso grupo e nos acompanharam em muitas atividades.

Toda noite a gente ia jantar em um restaurante sofisticado e eu conheci vários tipos de comidas saborosas que nem imaginava existirem. Fiquei muito amigo do famoso 
cozinheiro do restaurante e ele acabou me dando várias receitas e me contando como preparava os alimentos e como os mesmos eram conservados no navio. Inclusive me contou que tinha havido recentemente um problema em um dos setores de conservação de alimentos, mas que, felizmente, os técnicos do setor tinham conseguido resolver.

Fiquei curioso e perguntei o que havia acontecido. Ele me disse que um contêiner que guardava alimentos muito caros tinha tido um problema em sua refrigeração e que requisitava um conserto rápido para que não houvesse um grande prejuízo com a perda da carga. Após uma avaliação inicial do que estava acontecendo, os técnicos do setor constataram, através de uma janela de vidro, que a temperatura de um dos contêineres de alimentos estava subindo, pois um filamento que estava dentro do contêiner e que fazia parte do seu sistema de refrigeração estava coberto de fungo, o que ocasionava o mau funcionamento deste sistema. Havia assim a necessidade de um rápido conserto para que não houvesse a deterioração desses alimentos.

Enfim, após pensar muito, chegaram à melhor solução para este problema. A solução proposta foi o uso de raios ultravioletas (UV) para a esterilização do filamento com fungo. Os técnicos sabiam que não poderiam abrir o contêiner para manusear diretamente o filamento, pois os alimentos não poderiam ter contato com o ar. Também sabiam que havia a exigência de uma alta intensidade de raios para que essa esterilização fosse eficaz. Entretanto, sabiam que não poderiam emitir toda a radiação necessária através de uma única emissão de raios de alta intensidade, pois a alta intensidade, emitida de uma só vez, poderia danificar as paredes internas do contêiner que eram feitas de um gel protetor.

A solução encontrada foi a de emitir raios ultravioletas, de baixa intensidade, emitidos de diferentes fontes de emissão, cada uma delas situada em um ponto diferente, e que foram focalizadas para convergir todas ao mesmo tempo, para o filamento com fungo, de modo que, pelo somatório de sua radiação, pudessem chegar a uma forte radiação e assim pudessem esterilizar o filamento, sem que fossem danificadas as paredes do contêiner.

Os alimentos foram assim preservados, pois o sistema de refrigeração do contêiner voltou a funcionar normalmente após este conserto.

Fiquei feliz em saber que havia tanto cuidado na conservação e no preparo dos alimentos e até me motivei em estudar um pouco esse assunto. Adoro comer comidas diferentes, especialmente com meus amigos e namorada. É claro que com ela prefiro uns 
jantares mais românticos e com meus amigos prefiro fazer uma farra, como essa que a gente fez no navio.

Foi uma viagem inesquecível e quero voltar a viajar sempre para ter muitas histórias para contar para meus filhos e netos. É tão bom quando a gente tem experiências alegres que nos enriquecem de imagens e de vivências tão positivas. Já marquei uma nova viagem com meus amigos de sempre. Gosto de viajar, de preferência com pessoas que compartilham dos meus interesses e que gostem muito de uma boa diversão e de rir bastante.

A partir da leitura da história “Cruzeiro de Sonho”, marque uma única resposta em cada questão.

1)Na sua opinião, a história “Cruzeiro de Sonho” pode ser considerada:

a)Uma história que relata um episódio alegre e agradável.

b)Uma história que relata um episódio triste e desagradável.

c)Uma história que relata um episódio neutro, nem agradável/alegre, nem desagradável/triste.

2)Quais foram os principais acontecimentos que levaram o narrador desta história a fazer um cruzeiro de navio:

a)Não passou no vestibular e ganhou e viagem dos pais para se distrair.

b)Passou no vestibular e viajou junto com os pais e o irmão.

c)Passou bem colocado no vestibular e ganhou a viagem dos pais, viajando com amigos.

d)Nenhuma das respostas anteriores.

3)Quais foram as principais atividades do narrador desta história no navio:

a)Assistiu a filmes, fez compras no shopping e participou de jantares saborosos.

b) Participou de jogos e ganhou um torneio de frescobol.

c)Fez novos amigos e ficou amigo do cozinheiro do restaurante.

d)Todas as respostas acima.

4) Na sua opinião, nesta história, a viagem do jovem no navio foi:

a) Divertida, com muitas experiências alegres e positivas.

b) Penosa, com muitas experiências tristes e negativas. 
c) Em alguns momentos foi alegre em outros foi triste.

c) Nem divertida, nem penosa, foi apenas uma viagem comum.

5)Após ter lido a história “Cruzeiro de Sonho”, você se sentiu:

a)Senti-me afetado(a) negativamente pela história, pois ela relata um episódio desagradável e angustiante.

b)Senti-me afetado(a) positivamente pela história, pois ela relata um episódio alegre e agradável.

c)Não me senti afetado(a) positivamente pela história, embora a tenha achado alegre.

d)Não me senti afetado(a) nem positivamente, nem negativamente, pela história e não achei a história nem alegre, nem triste.

6)Na história "Cruzeiro de Sonho", qual foi a solução dada pelos encarregados do setor de carga do navio para a conservação dos alimentos:

a)Eles fizeram a emissão de raios ultravioletas (UV) de baixa intensidade, emitidos de diferentes fontes de emissão, cada uma delas posicionada em um ponto diferente, e que foram focalizadas para convergir, todas ao mesmo tempo, para o filamento com fungo, de modo que, pelo somatório de sua radiação, pudessem chegar a uma forte radiação e assim pudessem esterilizar o filamento sem que fossem danificadas as paredes do contêiner.

b)Eles fizeram a emissão de raios ultravioletas (UV) de alta intensidade em uma única emissão sobre o fungo do filamento, sem se preocupar com eventuais danos nas paredes do contêiner.

c)Eles fizeram a emissão de raios ultravioletas (UV) sobre o filamento com fungo, mas como isso não deu certo, eles acabaram utilizando outro tipo de solução, que foi a de chamar técnicos de um outro navio para resolverem o problema.

d)Eles não utilizaram nenhum tipo de raio para esterilizar o fungo do filamento.

\section{HISTÓRIA IV NO PARQUE FLORESTAL}

Cada vez tem sido mais freqüente a presença de pessoas que exploram os caminhos mais sinuosos do enorme parque florestal. Ao andar por estes caminhos, pode-se ver uma vegetação exuberante. Muitas árvores nativas, como o pau-brasil, estão lá 
representadas. Há também muitos córregos e riachos cortando o parque e, não raro, se vê cachoeiras inesperadas. No verão, freqüentemente, há pessoas refrescando-se nelas. A paz é intensa e pode-se se sentir uma grande comunicação com a natureza.

Há também muitos animais no parque. Lindos pássaros e vários mamíferos, inclusive alguns exemplares raros, como o mico-leão dourado. Eles parecem não ter medo e se aproximam bastante.

O parque é muito bem cuidado. Há placas orientando os visitantes, solicitando que não se acenda fogueiras ou se deixe lixo no chão. Parece que os freqüentadores do parque têm prazer em contribuir na preservação, pois não há vestígios de lixo ou de destruição.

A área destinada ao acampamento fica em um platô de onde se tem uma vista de tirar o fôlego de tão bela. Há também uma área coberta com banheiros e um centro de apoio ao eco-turismo local.

Os celulares não funcionam no parque e deste modo o rádio transmissor é um recurso importante para qualquer eventualidade. No último fim de semana houve um pequeno problema com o rádio transmissor e o guarda florestal de plantão procurou consertá-lo. Abriu sua tampa e logo localizou o defeito que era apenas um parafuso frouxo. Ele procurou a chave de fenda para apertá-lo, mas, como não a encontrou, usou uma faca de ponta arredondada. Com movimentos rotativos cuidadosos conseguiu apertar o parafuso.

Porém neste parque acontecimentos que perturbam sua rotina são raros. Parece que seus freqüentadores o tratam como um santuário, um local privilegiado de paz e harmonia.

A partir da leitura da história “No Parque Florestal”, marque uma única história em cada questão.

1)Na sua opinião, a história “No Parque Florestal” pode ser considerada:

a)Uma história que relata um episódio alegre e agradável.

b)Uma história que relata um episódio triste e desagradável.

c)Uma história que relata um episódio neutro: nem agradável/alegre, nem desagradável/triste. 
2)Como poderia ser caracterizada a região onde se passa a história "No Parque

\section{Florestal":}

a)Uma região árida, com pouca água, quase sem vegetação, com longos períodos de seca e muito quente.

b)Uma região de floresta de vasta vegetação, com muitos riachos e onde a natureza é preservada pelos visitantes.

c)Uma região fria e montanhosa, onde a neve predomina a maior parte do tempo.

d)Nenhuma das respostas acima.

3)Qual foi a solução dada ao problema que surgiu na história “No Parque Florestal”:

a)Como o rádio transmissor não estava funcionando, o guarda florestal utilizou um telefone celular como meio de comunicação.

b)O guarda florestal usou um alicate para cortar um fio que se soltou dentro do rádio transmissor e assim o rádio voltou a funcionar normalmente.

c)O guarda florestal usou uma faca de ponta arredondada e, com movimentos rotativos, apertou o parafuso frouxo dentro do rádio transmissor e assim o rádio voltou a funcionar normalmente.

d)Nenhuma das respostas acima. 
Leia com atenção a história abaixo e, após a leitura da mesma, responda a pergunta que será apresentada no final da folha.

\section{TRISTES LEMBRANCCAS}

Aquele ano de 1995 foi um ano muito difícil. Lembro-me como se fosse hoje. Logo no início do ano eu perdi meu emprego e fiquei desempregado quase o ano todo. Nossas economias foram todas gastas e os acontecimentos que vieram a seguir nos pegaram desprevenidos.

Minha mulher tinha acabado de perder nosso primeiro filho e precisou fazer um tratamento com medicamentos muito caros. Eu comecei a fazer biscates entregando jornais de bicicleta. Andava muitos quilômetros por dia e chegava em casa todo doído e bastante cansado. Eu e minha mulher estávamos muito deprimidos com a perda do nosso bebê e com a falta de dinheiro. Além disso, tivemos que abandonar nossa casa, pois não podíamos mais pagar o aluguel. Tivemos que vender nossos móveis e objetos e fomos morar em um quarto alugado em uma pensão bem velha e suja, mas era o que podíamos pagar. O quarto tinha as paredes imundas, uma velha e feia cama quebrada e tudo tinha um cheiro muito desagradável. Mas o pior ainda estava por vir.

Em meados de julho, minha mulher começou a sentir muitas dores nas costas e dificuldade para urinar. Vinha emagrecendo muito rapidamente, pois rejeitava a ingestão de alimentos e não tinha ânimo para nada. Levei-a então a um hospital onde tivemos que enfrentar uma enorme fila de espera e, só depois de quase um dia inteiro, fomos atendidos e conseguimos marcar uma consulta para daí a dois meses.

Neste período ela foi piorando e foi preciso um atendimento de urgência. No pronto socorro onde foi atendida, havia muita gente sendo atendida ao mesmo tempo em uma sala de paredes descascadas e cheias de infiltração, onde estavam diversas mulheres. Quando chegou a vez da minha mulher, o antipático médico que a examinou mostrou-se muito preocupado e fez um encaminhamento para internação imediata em uma enfermaria onde havia vários leitos e onde ela foi recebida por uma enfermeira agressiva.

Os exames constataram um tumor cancerígeno, de alta malignidade com uma real possibilidade de metástase, no rim esquerdo. Este rim já não estava funcionando direito, por isso minha mulher sentia tantas dores e estava tão debilitada. Um episódio muito preocupante ocorreu depois disso. O médico receitou alguns medicamentos para dor e 
disse à minha mulher para tomá-los com precaução e que tomasse apenas um, antes da próxima consulta. Porém, minha mulher não entendeu bem a sua recomendação e tomou vários medicamentos diferentes de uma só vez antes da consulta, o que a levou a uma grave intoxicação com conseqüente piora do seu estado de saúde. Vê-la desmaiada e passando tão mal deixou todos no hospital preocupados e eu fiquei tão aflito que não sabia o que fazer.

O médico resolveu então atacar o tumor diretamente e recomendou um tratamento a base de radiação, pois a cirurgia não era indicada neste caso.

Havia, porém, um problema com o qual o médico se deparou: o tumor necessitava ser atingido por uma alta intensidade de raios, pois uma baixa intensidade não conseguiria extingui-lo. Mas, por outro lado, a emissão de raios de alta intensidade poderia atingir os tecidos corporais sadios ao redor do tumor e isso poderia danificar estes tecidos e piorar o estado de saúde da paciente.

Antes de você responder à questão apresentada abaixo, por favor, dê uma nota de 0 a 100 a seu estado atual de humor. Nota:

Agora responda à seguinte questão:

Como você acha que o médico resolveu este problema da emissão de raios para extinguir o tumor, sem danificar os tecidos corporais sadios que o envolviam?

Lembre-se das histórias que você leu anteriormente, elas podem dar uma dica para a solução desse problema. Mas, lembre-se também que você deve escolher uma única solução para este problema, ou seja, aquela solução que vier primeiro à sua cabeça. Mas, só após a escolha da solução por escrito, leia a pergunta da página seguinte.

Na página seguinte houve o pedido para a justificativa da escolha através da seguinte instrução: “Justifique, com suas palavras, porque escolheu esta solução”. 


\section{ANEXO 8: TERMO DE CONSENTIMENTO LIVRE E ESCLARECIDO}

Pesquisadora: Simone Cagnin.

Natureza da pesquisa: Você está sendo convidado para participar dessa pesquisa que tem como finalidade investigar se a leitura de algumas histórias pode vir a influenciar a escolha de um modo de solução de um problema que será apresentado em um momento posterior. O presente estudo faz parte da tese requerida para a obtenção do título de doutora em Psicologia Escolar e do Desenvolvimento Humano da Universidade de São Paulo, sob a orientação da Dra. Maria Isabel da Silva Leme.

Participantes da pesquisa: Estudantes universitários de diferentes cursos das Ciências Humanas.

Envolvimento na pesquisa: A participação na pesquisa é voluntária, ou seja, você tem a liberdade de participar ou não da mesma. Sempre que quiser, você poderá pedir informações sobre a pesquisa. Para isto, entre em contato com a pesquisadora por meio do telefone (21) 34152203 ou (21) 99990782 ou pelo e-mail: scagnin@oi.com.br.

Sobre a pesquisa propriamente dita: Os participantes serão divididos em grupos de modo aleatório. O tempo previsto de duração é de cerca de 40/50 minutos, mas os participantes podem terminar a tarefa antes desse tempo.

Riscos, desconforto e Confidencialidade: A participação nessa pesquisa não traz nenhum risco ou complicação para o participante. Todas as informações coletadas nesse estudo são estritamente confidenciais. As folhas serão identificadas com uma etiqueta e/ou um número arbitrário e não com seu nome. Apenas a pesquisadora e a orientadora da pesquisa terão acesso aos resultados. Se você der a sua autorização, os dados poderão ser utilizados para fins de ensino, de publicação em periódicos especializados e para apresentação em encontros e debates científicos.

Pagamento e Benefícios: Você não terá nenhum tipo de despesa por participar dessa pesquisa. Também nada lhe será pago por sua participação. Participando da pesquisa, 
você não terá nenhum benefício financeiro direto. Entretanto, a sua participação será de fundamental importância, pois irá contribuir com informações que nos permitirão um melhor entendimento do funcionamento da memória e do pensamento analógico. Agradecemos a sua disponibilidade em participar da mesma.

A pesquisadora assume também o compromisso de dar um “feedback" dos resultados obtidos a todos os participantes, através de uma palestra destinada e este fim, logo após a defesa de tese. No entanto, caso queira, você pode receber cópias dos resultados da pesquisa, contendo os resultados do estudo.

Tendo em vista os itens acima apresentados, eu, de forma livre e esclarecida, manifesto meu interesse em participar da pesquisa.

Assinatura do participante ou rubrica

Simone Cagnin 